\title{
Risk, Conflict and Challenges in the Context of Emerging Economies
}

\author{
Dissertation \\ Zur Erlangung des wirtschaftswissenschaftlichen Doktorgrades der \\ Wirtschaftswissenschaftlichen Fakultät der Georg-August-Universität Göttingen
}

vorgelegt von

Nils-Hendrik Klann, M.A.

aus Haan

Göttingen, 2012 
Erstgutachter:

Zweitgutachter:

Drittprüfer:

Tag der mündlichen Prüfung:
Prof. Stephan Klasen, Ph.D.

Prof. Dr. Axel Dreher

Jun.-Prof. Dr. Jann Lay

16. August 2012 


\section{Acknowledgements}

This thesis is the result of four years filled with hard work, countless intense experiences and too many nights in front of the computer. It would not have been possible to complete this task without the help, assistance and moral support of many people I had on my side, met and collaborated with throughout this time.

I'm grateful to Stephan Klasen for giving me the opportunity to write my Ph.D. thesis at his chair and providing me with excellent advice and support. Furthermore, I would like to thank Axel Dreher for his unconditional support and advice as well as the opportunity to gain worthwhile experiences in several fascinating projects at this chair. Also, I'm thankful to Jann Lay for his comments and agreeing to participate in my examination committee.

I have had the privilege to collaborate with amazing colleagues and friends on a wide range of projects and tasks during the last four years. Many thanks to my friend, coauthor and project partner Andreas Fuchs for the excellent and fruitful collaboration during all of our projects. Further thanks to Nicolás, Johannes and Dominik for great teamwork, moral support and a wonderful time together.

In addition, I would like to thank my parents for their exceptional and unconditional support throughout my life. I'm grateful to Anna for love, infinite support and understanding on this long and winding road. Also, many thanks to Axel, Carsten, Eva, Hannes, Laura, Lore, Manuel, Marlene, Martin and Thomas for their friendship and support throughout these years. 


\section{Table of Contents}

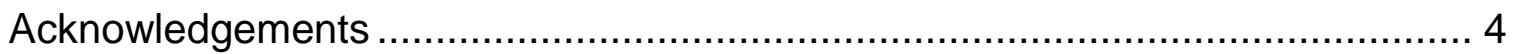

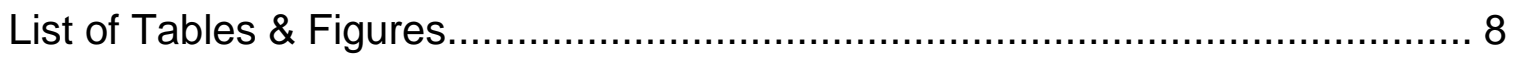

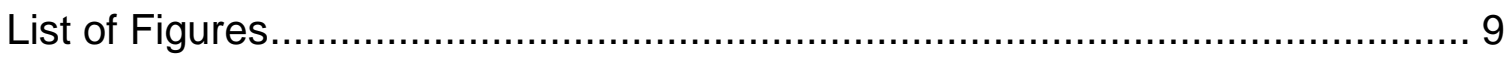

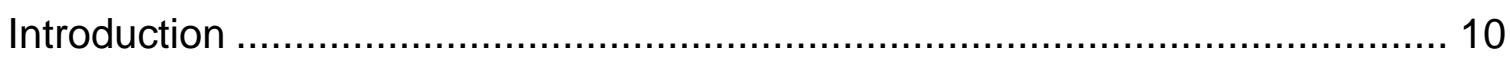

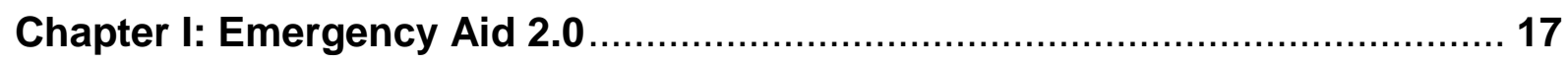

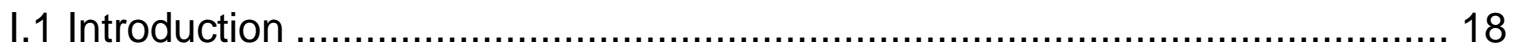

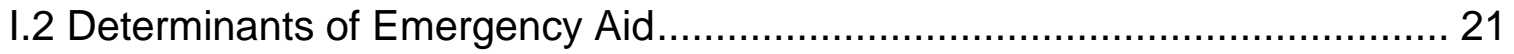

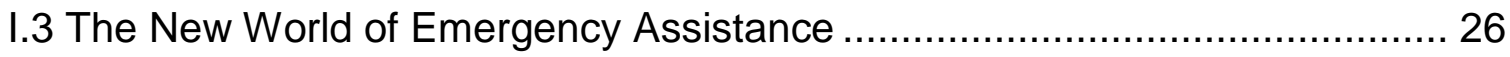

I.4. Empirical Analysis of Aid Selection ....................................................... 32

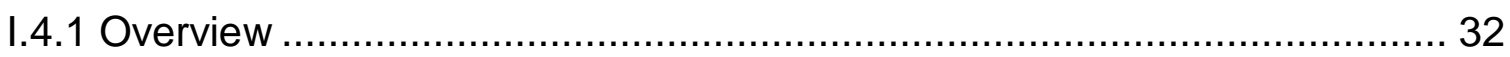

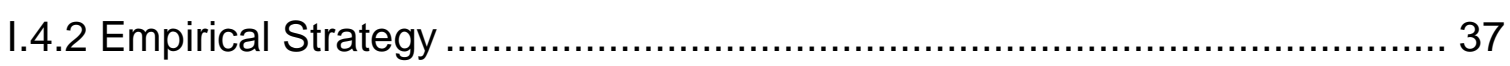

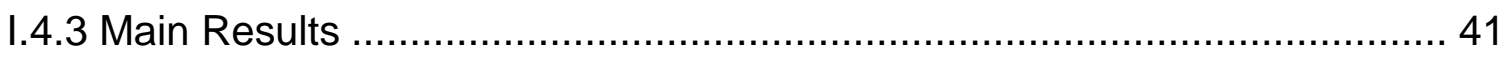

I.4.4 Testing for Differences between "New" and "Old" Donors......................... 45

I.5. Empirical Analysis of Aid Promptness ..................................................... 49

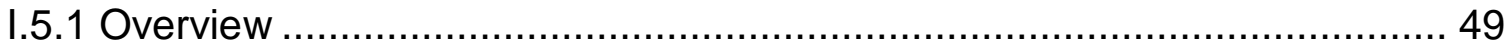

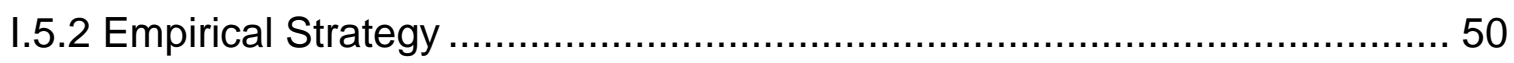

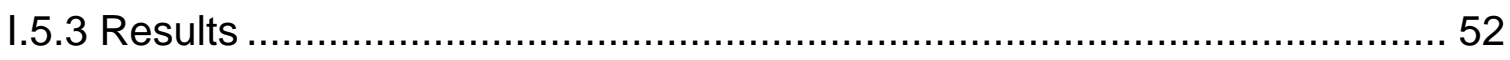

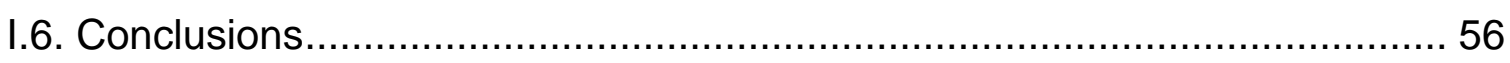

Chapter II: Incapacitation or Proliferation? A District-level Assessment of

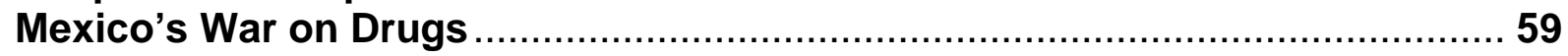

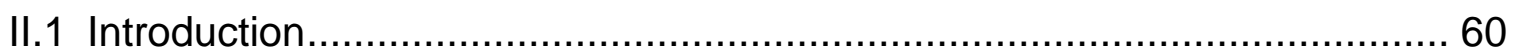

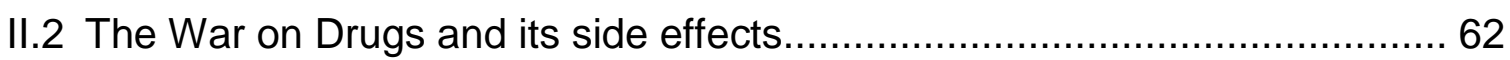

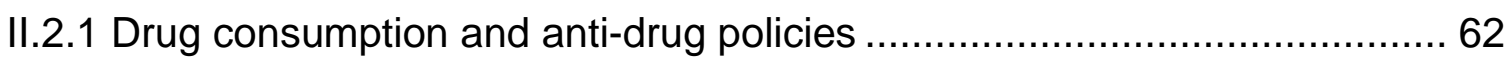

II.2.2 The 'War on Drugs' in the United States............................................. 64

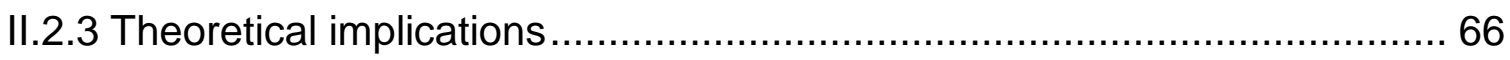

II.2.4 Mexico's growing involvement in the 'War on Drugs' ........................... 70

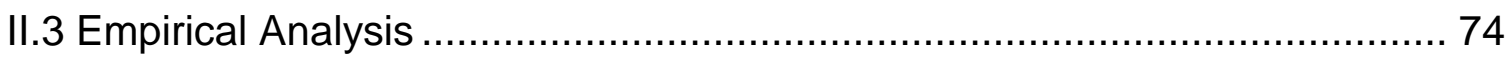

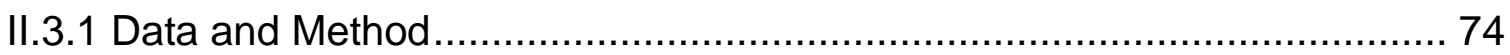

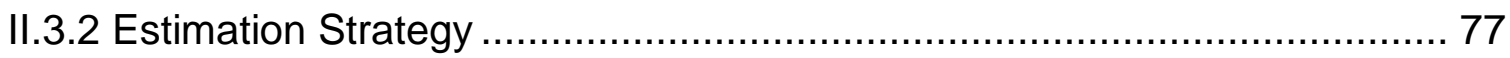

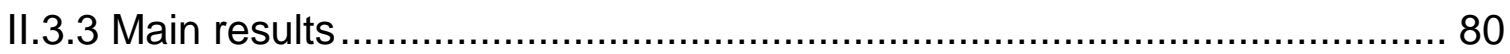

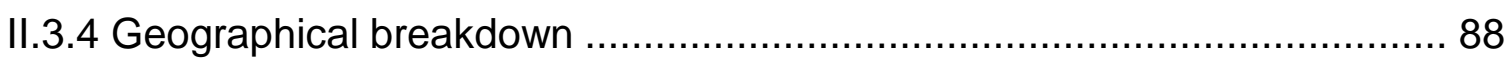

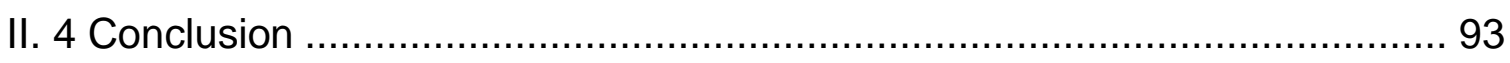

Chapter III: Paying a Visit: The Dalai Lama Effect on International Trade......... 95

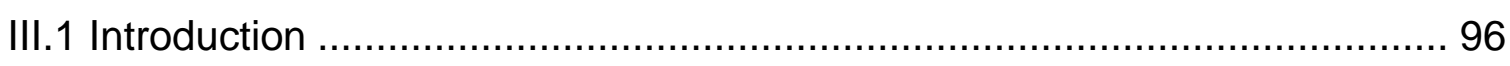

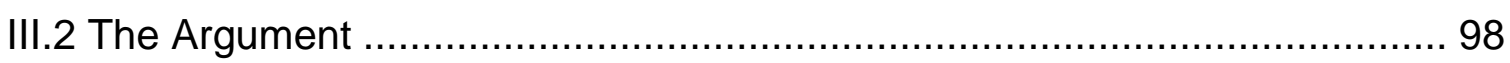

III.2.1 Political Determinants of Trade and the 'Dalai Lama Effect'.................... 98 


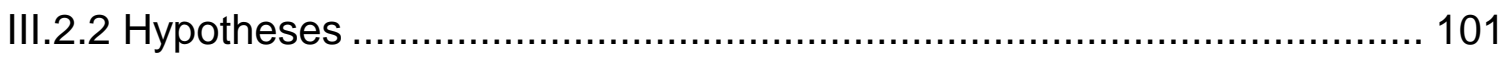

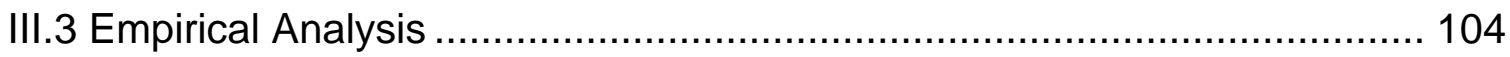

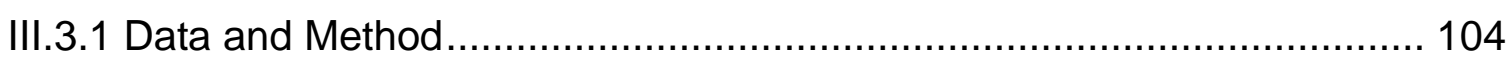

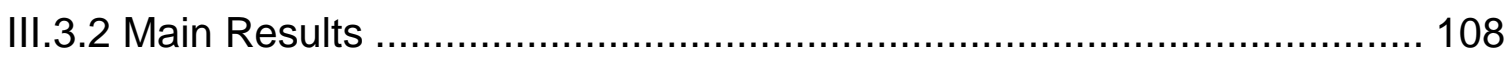

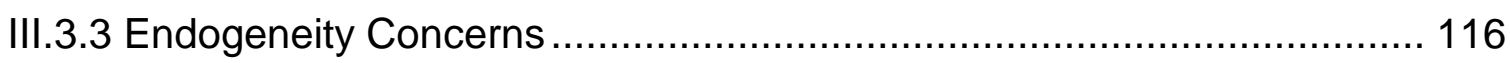

III.3.4 Results by Product Group .......................................................... 123

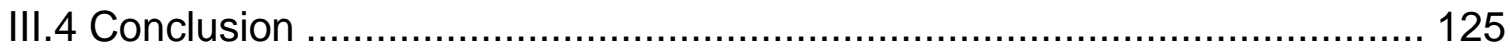

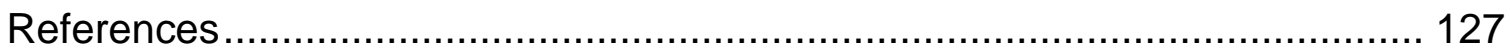

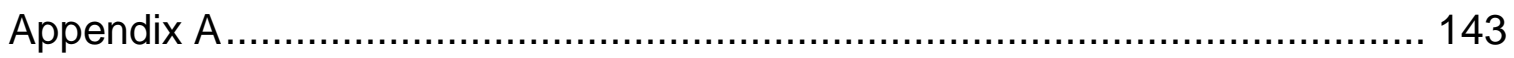

Appendix B.1: Testing for ratio bias in the crime deterrence measure ............ 155

Appendix B.2: Review of Mexican anti-drug legislation ................................ 158

Appendix B.3: Additional Regression Results ........................................... 160

Appendix B.4 Chronological split \& Additional robustness checks .................. 161

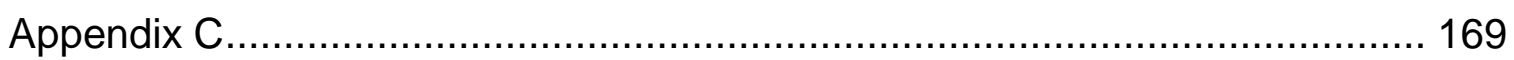

Appendix C.7: Anecdotal Evidence ..................................................... 175

Eidesstattliche Versicherung ................................................................... 183 


\section{List of Tables \& Figures}

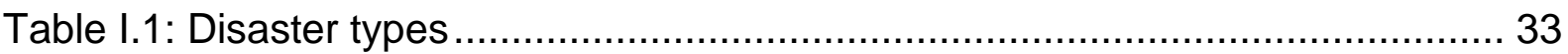

Table I.2: Determinants of aid selection (Logit, 2000-09) ................................... 43

Table I.3: Determinants of aid selection by donor group (Logit, SUR, 2000-09)....... 47

Table I.4: Determinants of aid promptness (Heckman, 2000-09) .......................... 54

Table II.1:Summary Statistics ........................................................................ 75

Table II.2: Effect of drug enforcement on the prevalence of robbery ...................... 81

Table II.3: Effect of drug enforcement on the prevalence of Assault ....................... 82

Table II.4: Effect of drug enforcement on the prevalence of Murder......................... 83

Table II.5: Effect of drug enforcement on the prevalence of Rape.......................... 84

Table III.1: Exports to China and Dalai Lama meetings of gov. members .............. 108

Table III.2: Exports to China and Dalai Lama meetings of gov. members (alternative model specifications, 2002-2008) .................................................................. 111

Table III.3: Exports to China and Dalai Lama meetings at various political levels (Hypothesis 2, all countries, 2002-2008) ...................................................... 114

Table III.4: Exports to China and Dalai Lama meetings of political leaders ............ 116

Table III.5: Exports to China and Dalai Lama meetings of political leaders (endogeneity, 2002-2008) ........................................................................ 120

Table III.6: Exports to China and Dalai Lama meetings of political leaders ............ 124

Table III.7: Exports to China and Dalai Lama meetings of political leaders ............ 125

\section{List of Tables Appendix A}

Table A.1: Humanitarian aid and disaster relief of "new" donors .......................... 143

Table A.2: List of donor countries by definition of "new" donors ........................... 150

Table A.3: Sources and definitions .................................................................... 152

Table A.4: Descriptive statistics .................................................................. 153

Table A.5: Determinants of aid selection (Logit, marginal effects, 2000-09).......... 154

\section{List of Tables Appendix B}

Table B.1: Difference Estimators and Measurement Error in Arrest Rates............. 156

Table B.2: Effect of Drug Enforcement on non-drug offences at the state level ..... 160

Table B.3: Robbery, chronological break-down ................................................ 161

Table B.4: Assault, chronological break-down.................................................. 162

Table B.5: Murder, chronological break-down .................................................. 163

Table B.6: Rape, chronological break-down ................................................... 164

Table B.7: Robbery, additional robustness checks ........................................ 165

Table B.8: Assault, additional robustness checks.............................................. 166

Table B.9: Murder, additional robustness checks ........................................... 167

Table B.10: Rape, additional robustness checks ............................................ 168

\section{List of Tables Appendix C}

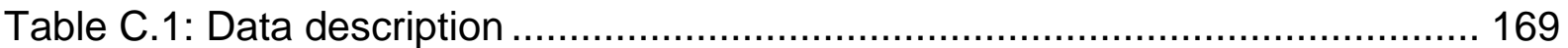

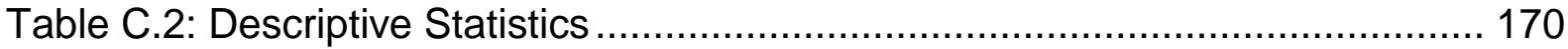


Table C.3: List of countries

Table C.4: Exports to China and Dalai Lama meetings of government members .. 172

Table C.5: Exports to China and DL meetings at various political levels (Hypothesis 2, European countries, 2002-2008)

Table C.6: Exports to China and Dalai Lama meetings of political leaders

\section{List of Figures}

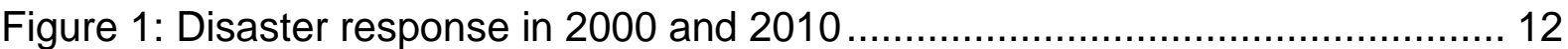

Figure 2: Drug-related arrests in the United States and Mexico ............................ 14

Figure 3: Dalai Lama receptions and China's global trade share ........................... 16

Figure I.1: Emergency aid over time and by donor group (2000-09) ...................... 36

Figure I.2: Aid promptness by disaster type and donor group (2000-09) ................ 51

Figure II.1: Effect of drug enforcement on the prevalence of robbery ....................... 89

Figure II.2: Effect of drug enforcement on the prevalence of assault...................... 90

Figure II.3: Effect of drug enforcement on the prevalence of murder....................... 91

Figure II.4: Effect of drug enforcement on the prevalence of rape.......................... 92

Figure III.1: Travel pattern of the Dalai Lama (1991-2008) .................................. 107 


\section{Introduction}

"Increased income and growth in the developing world means increasing influence. The old world of fireside chats among G-7 leaders is gone."

Robert B. Zoellick ${ }^{1}$

"China is ready, together with other countries in the world, to make joint efforts to facilitate the establishment of a new international political and economic order that is fair and rational and the creation of a new world of lasting peace and universal prosperity."

Ministry of Foreign Affairs of the People's Republic of China ${ }^{2}$

It is safe to assume that at no point in history have global affairs been interlinked to such a degree and shaped by as many states as is the case today. This shift away from a structure in which a few affluent countries shaped global events is often attributed to a new reality of globalization or the prominently quoted "death of distance" (Cairncross 2001). ${ }^{3}$ This degree of political and economic interaction between countries is evidently unprecedented and aided by the disappearance of political and structural boundaries.

However, this transition would not have been feasible without the massive growth in the economic capacity of the so-called emerging economies and their growing disposition to use this newly acquired economic clout to extend their influence and assume new responsibilities. This development has been fortified by the sustained weakness of many industrialized economies in the wake of the global financial crisis over the last six years. Given their high level of integration in global trade, the new economic powers are obviously not immune to the on-going crisis in

\footnotetext{
1 "The End of the Third World? Modernizing Multilateralism for a Multipolar World," available at http://go.worldbank.org/MI7PLIP8U0 (accessed: July 2012).

${ }_{2}$ "China's Position on Establishing a New International Political and Economic Order" (http://www.fmprc.gov.cn/eng/wjdt/wjzc/t24882.htm accessed: July 2012).

3 In his book "The Death of Distance: How the Communication Revolution is Changing our Lives," Cairncross (2001) describes the "elimination of distance as a perceptible concept from our lives" as a major economic shift as significant as the invention of electricity and the internal combustion engine. (http://hbr.org/product/the-death-of-distance-how-the-communications-revol/an/438X-PBK-ENG, accessed: July 2012).
} 
traditional economies. Notwithstanding, economic growth in the emerging and developing economies is forecasted at six percent compared to two percent in industrialized countries (IMF 2012).

Motivated by this growing relevance of emerging economies, this doctoral thesis conducts an empirical analysis grounded in three sub-disciplines of economic research. In three essays, this work links the topics of the empowerment of emerging economies' with the domains of the economics of foreign aid, economics of crime and international trade. The leitmotif of all essays is based on the question as to which ways emerging economies rely on their newly attained economic capabilities to exert influence to such an extent that repercussions will become visible around the globe.

\section{Part 1: The Provision of Emergency Aid}

Emerging economies are increasingly assuming the role of donors of foreign aid and thus slowly catching up to established member countries of the Development Assistance Committee (DAC). The first chapter - written together with Andreas Fuchs - primarily illustrates the new reality in the world of foreign assistance. Existing contributions extensively discuss the influence of humanitarian motives and donor self-interest as drivers of foreign aid by traditional donor nations (see, e.g., Alesina and Dollar 2000; Höffler and Outram 2011). With few exceptions (Neumayer 2003a; Dreher et al. 2011), the empirical aid literature largely ignores the proliferation of aid donors which has occurred in recent years. Figure 1 illustrates this development against the background of two comparable disasters which occurred within a ten-year period. As can be observed, the number of donors responding to a typical disaster has grown significantly. At the same time, the heterogeneity of donors is more pronounced. Notwithstanding, aid provided by low- and middle-income countries, autocratic regimes and donors operating outside the Development Assistance Committee of the OECD is gaining in importance.

Considering the specific characteristics of the so-called "new" donors, we develop and test several hypothesis using a dataset on emergency aid. First, with regards to aid institutions, we test the independent-donor hypothesis, which assumes that donors operating outside the DAC are less constrained by international 


\section{Figure 1: Disaster response in 2000 and 2010}

Panel A: Donors of Emergency Aid responding to the August 2000 floods in India (total affected: 20.4 million)

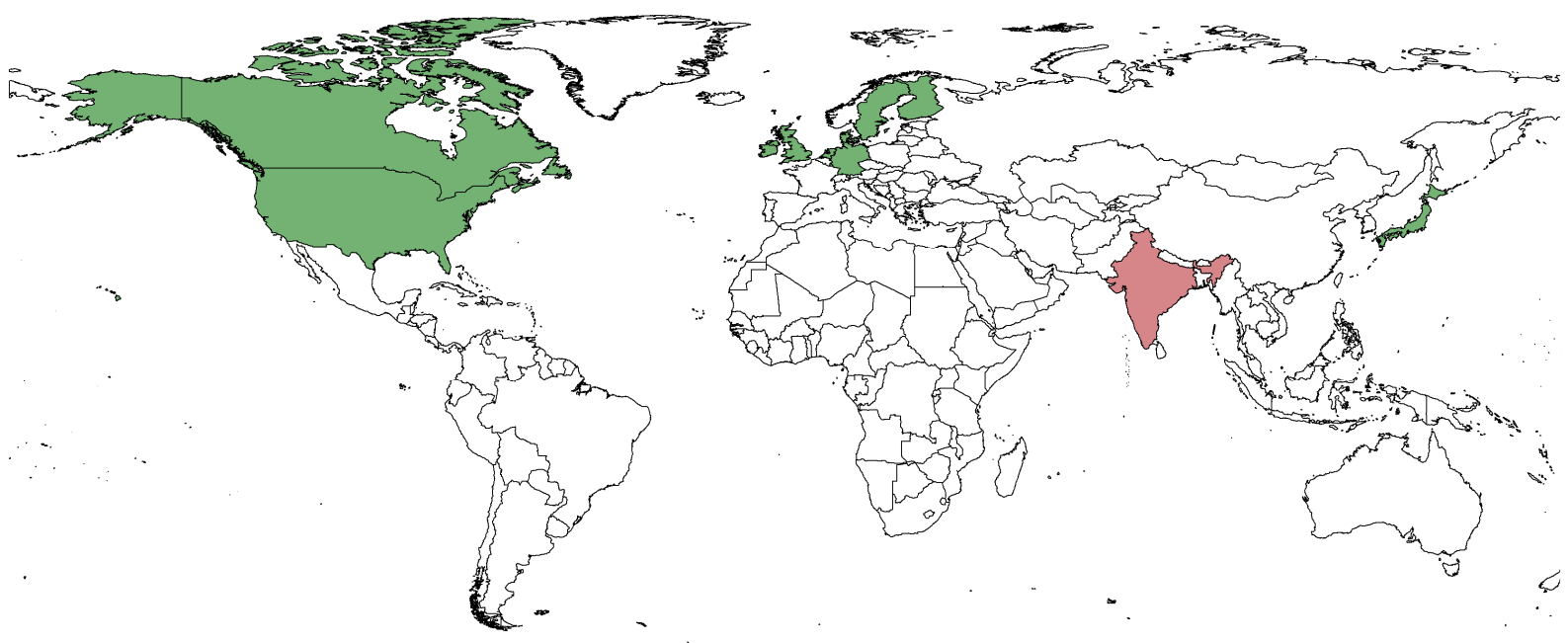

Panel B: Donors of Emergency Aid responding to the July 2010 floods in Pakistan (total affected: 22 million)

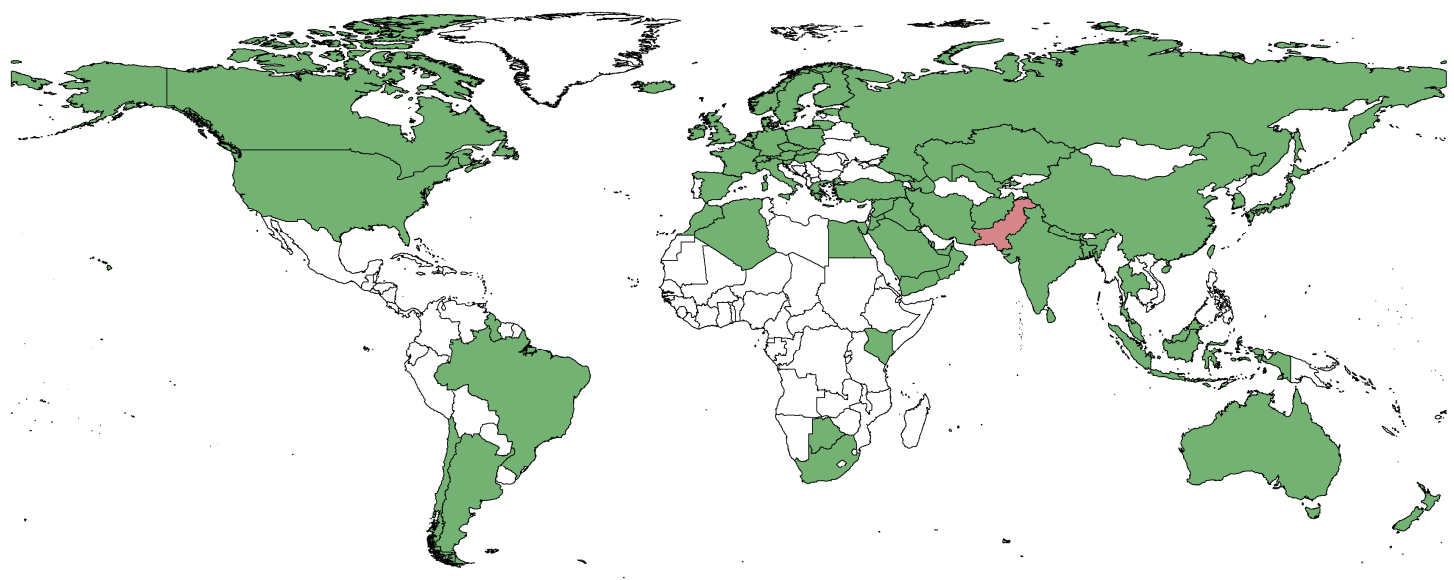

Sources: Author's calculations based on the following data sources: Information on emergency aid donors was retrieved from the Financial Tracking Service (http://fts.unocha.org/, accessed: July 2012). Data on the size of the affected population stems from EM-DAT (www.emdat.be, accessed: July 2012). Map data was provided by the Natural Earth Project (www.naturalearth.com, accessed: July 2012).

agreements and thus provide relatively more aid out of self-interest than DAC donors. Furthermore, to account for the lower economic status of many emerging donors, we investigate the needy-donor hypothesis in a second step. The hypothesis postulates that poor donors are driven by self-interest insofar as these countries minimize the economic costs of their commitments while maximizing their political and economic gains. 
A further assumption defined as the rogue-donor hypothesis states that autocratic donors favor countries with bad governance and base their aid decisions predominantly on political and commercial interests rather than recipient need. The empirical analysis of aid allocation in this article makes use of data on emergency aid supplied by 105 donor countries to explore differences in aid allocation patterns between "new" and traditional donors.

To be effective, emergency aid has to be provided in a timely manner. The second part of the chapter extends the comparison of "old" and "new" donors to their respective timeliness in providing emergency aid. As the timeliness of the aid delivery is crucial for its effectiveness, we continue by empirically analyzing which factors influence the number of days which pass after a natural disaster before a donor commits herself to provide emergency relief. Empirical results indicate that "new" and "old" donors alike provide aid based on humanitarian need and their self-interests, with considerable differences in the importance which is attached to different factors. With regard to aid promptness, DAC, developed, and democratic countries turn out to be significantly faster than non-DAC, developing, and autocratic countries.

\section{Part 2: The fight against organized crime}

As discussed above, the growing economic potential of emerging economies allows these countries to assume new responsibilities which might have been unthinkable a few decades ago. While the first chapter illustrates the implication of these nations' transition from aid recipients to donors, the second chapter singles out the role of Mexico in the fight against organized crime and, more specifically, in the trafficking of narcotics.

Many developing and transitional economies have the misfortune of being notorious sources of narcotics as well as safe havens for drug trafficking organizations. As noted in the 2012 World Drug Report, the largest retail markets for drugs are located in North America and Europe, which respectively create 44 and 33 percent of global demand calculated on the basis of retail prices. At the same time, the production of drugs is largely concentrated in less affluent regions of the world such as Afghanistan, Myanmar, the Andean region and Mexico (UNODC 2010, 2012). Although the so-called 'War on Drugs' is a global campaign against drug 


\section{Figure 2: Drug-related arrests in the United States and Mexico}

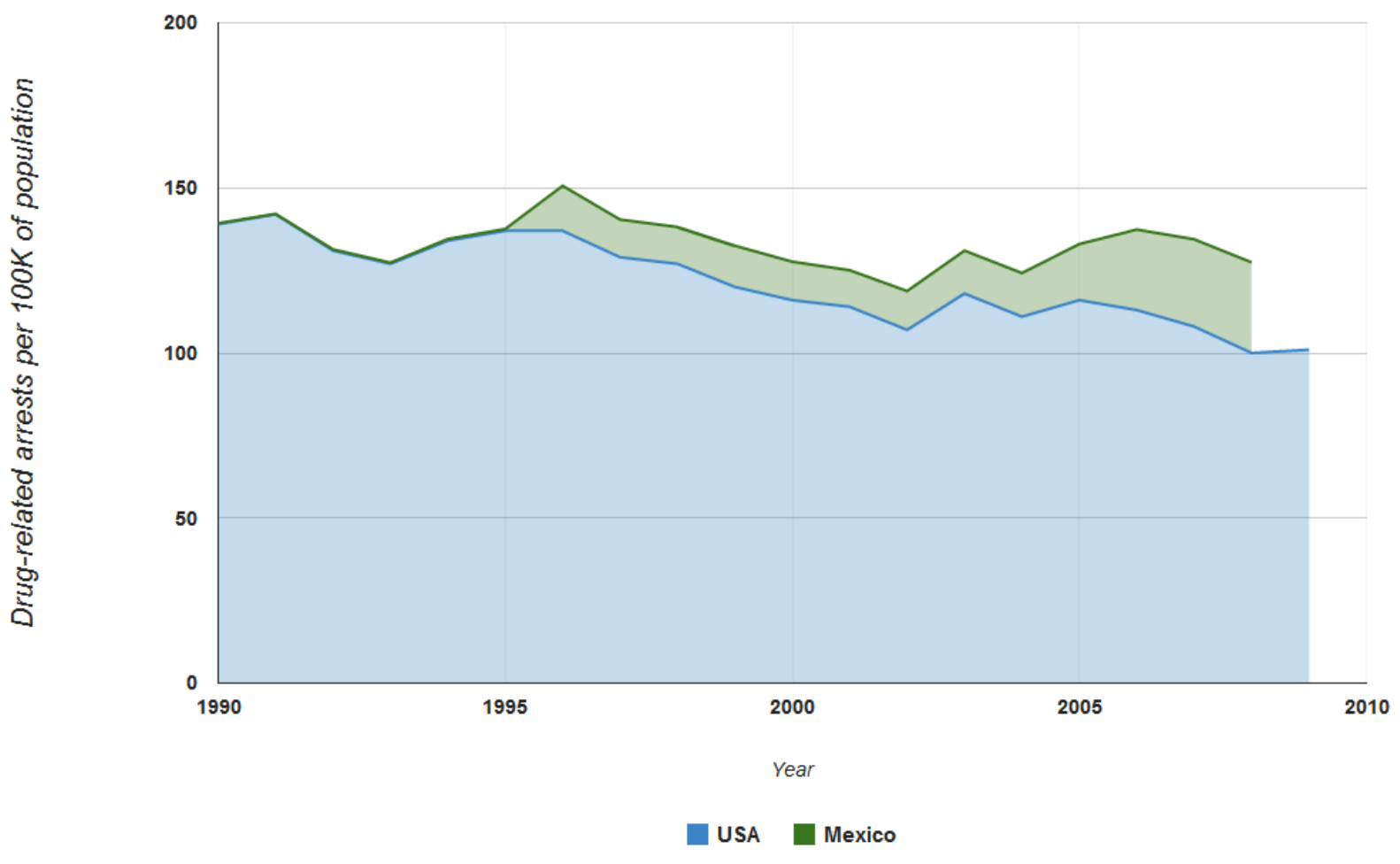

Sources: US drug arrest statistics were retrieved from the series "Arrests in the United States, 1980-2009" by the US Bureau of Justice Statistics (www.bjs.gov, accessed: July 2012). US population data stems from the US Census Bureau (www.census.gov, accessed: July 2012). Data on drug arrests and population in Mexico were retrieved from the Annual Yearbook of the United Mexican States (www.inegi.mx, accessed: July 2012) Note: most recent data for Mexico not published to this date.

traffickers, it largely focuses on the containment of South-North drug trafficking to the United States. Today, this campaign is a multilateral effort which assigns a significant share of the responsibility to fight drug traffickers to Mexico after several decades of passiveness.

Mexico's contribution to the 'War on Drugs' is significant in several regards. First, the country's location between the largest market for drugs and important narcotics production areas in the Andean mountains turns Mexico into a buffer zone with strategic importance in the on-going fight against drug traffickers.

Second, the country dedicates a significant amount of public funds to finance its on-going initiative against narcotraffickers in the face of additional challenges such as considerable poverty. As Figure 2 indicates, the country significantly stepped up its efforts to pursue drug offenders. While the success of this initiative is often questioned in terms of an actual reduction in drug trafficking, an empirical analysis of the impact of this massive campaign on public security is lacking to date. The question as to whether or not a massive intervention against drug traffickers will translate into lower overall crime rates or actually proliferates offences has only been 
extensively discussed and investigated empirically for the United States (see, e.g., Sollars et al. 1994; Benson et al. 1994, 1998, 2001).

By constructing a comprehensive dataset covering criminal and economic statistics at the municipal level, I quantify the effect of drug enforcement on non-drug related crime at the district level between 1998 and 2008 in Mexico. For the overall sample, results indicate that the incarceration of drug offenders significantly reduces the prevalence of property crime, assault, rape and to a smaller extent also murder. Taking these results at face value, Mexico's 'War on Drugs' thus appears to be beneficial to public security. However, splitting the sample by municipal states suggests that the transmission mechanism from drug enforcement to a universal reduction of crime hinges on the prevalence of gang murder and thus the concentration of drug cartels across federal states. This outcome helps to put the prior results into perspective and emphasizes that states ridden by elevated levels of cartel violence must first contain the most extreme forms of drug offences before they can expect to improve their public security situation through intensified drug enforcement.

\section{Part 3: International trade as foreign policy tool}

The first two chapters of this thesis discuss how the growing potential of emerging economies translates into the pursuit of objectives such as the provision of humanitarian aid and the fight against organized crime. The third and last chapter consists of joint work with Andreas Fuchs and illustrates how the growing economic clout of China is exploited to enforce the regime's national interests internationally. We shed light on this process by investigating whether political compliance is a precondition for healthy trade relations with China. To empirically test this hypothesis, we rely on official receptions of the 14th Dalai Lama by foreign dignitaries.

The Chinese government frequently threatens that meetings between its trading partners' officials and the Dalai Lama will be met with animosity and ultimately harm trade ties with China. At the same time, China has dramatically increased its share in global trade as is illustrated in Figure 3. 
Figure 3: Dalai Lama receptions and China's global trade share

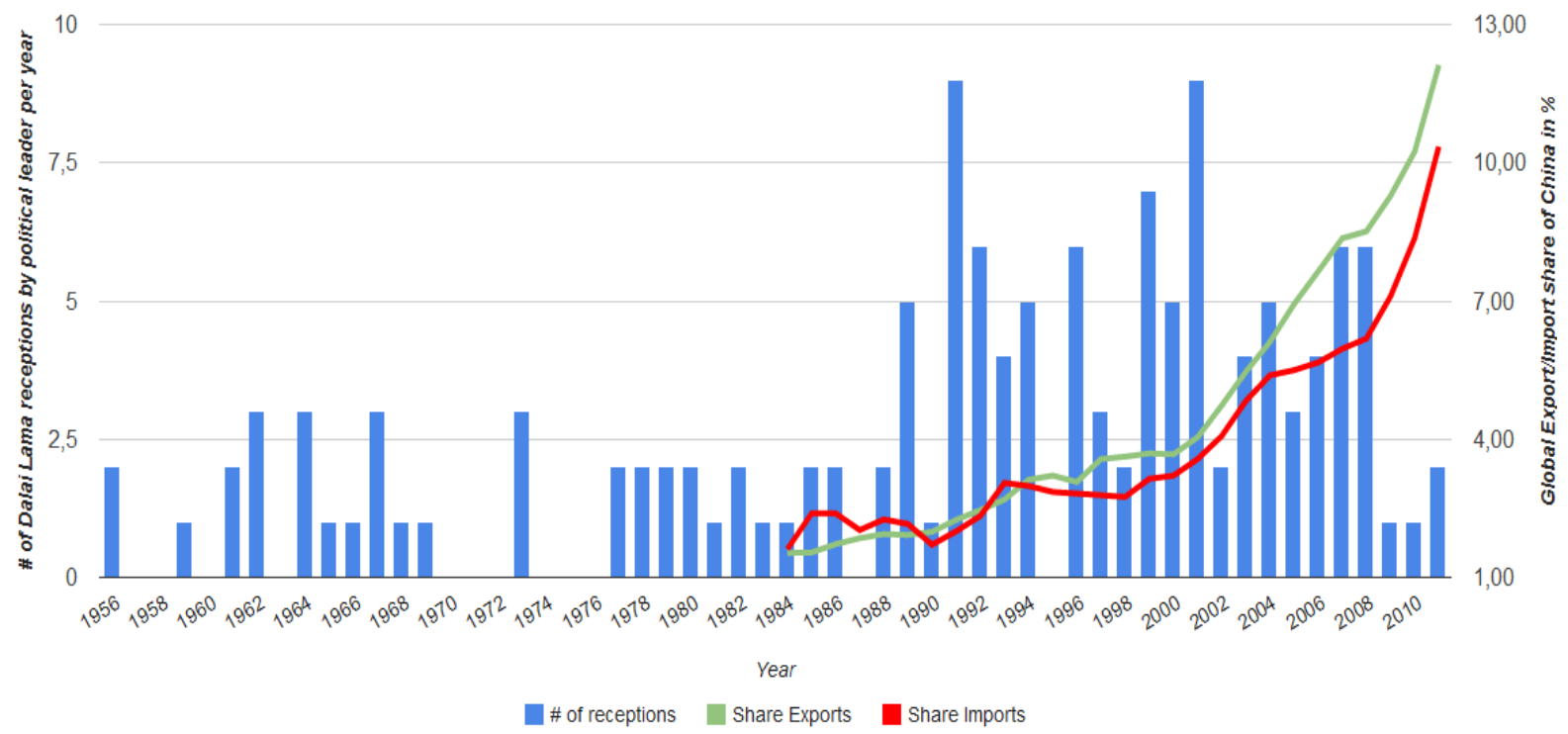

Sources: Authors' calculation. Data on Dalai Lama receptions is provided by the Office of the 14th Dalai Lama (www.dalailama.com, accessed: April 2012). Trade data was retrieved from the United Nations COMTRADE database (wits.worldbank.org, accessed: July 2012). Trade is measures in current USD and based on the SITC 2 classification.

We run a gravity model of exports to China from 159 partner countries between 1991 and 2008 to test the extent to which bilateral tensions affect trade with autocratic China. In particular, we empirically investigate whether countries that receive the Dalai Lama despite China's opposition experience a significant reduction in their exports to China. In order to account for the potential endogeneity of meetings with the Dalai Lama, the number of Tibet Support Groups and the travel pattern of the Tibetan leader are used as instruments.

Our empirical results support the idea that countries officially receiving the Dalai Lama at the highest political level are punished through a reduction in their exports to China. However, this 'Dalai Lama Effect' is only observed for the Hu Jintao era and not earlier periods. Furthermore, we find that this effect is mainly driven by reduced exports of machinery and transport equipment and that it disappears two years after a meeting took place. 


\section{Chapter I}

\section{Emergency Aid 2.0}

Joint work with Andreas Fuchs ${ }^{a}$

Abstract: Does the proliferation of aid donors lead to visible changes in the world of foreign assistance? Aid provided by low- and middle-income countries, autocratic regimes and donors operating outside the Development Assistance Committee (DAC) of the OECD is gaining in importance. This article uses data on emergency aid supplied by 105 donor countries to explore the determinants of aid and the differences in allocation patterns between donor groups. Our results show that both the so-called "new" and "traditional" donors provide emergency aid based on humanitarian need and their self-interests, but we find evidence that non-DAC donors attach relatively more importance to political motives. Additionally, autocratic donors seem to favor countries rich in natural resources and to disfavor democracies. Since the timeliness of the aid delivery is crucial for aid effectiveness, we furthermore analyze which factors influence the number of days that pass after a natural disaster before a donor commits herself to provide emergency relief. With regard to aid promptness, we find DAC, developed and democratic countries to be significantly faster than non-DAC, developing and autocratic countries.

Acknowledgements: This research is part of the project "Foreign Aid of Emerging Donors and International Politics" supported by the Deutsche Forschungsgemeinschaft (DR 640/4-1). We are grateful for the generous financial support. Excellent research assistance was provided by Clara Brune, Scott Jobson, Katrin Mauch, Jamie Parsons and Jan Paulick. We thank Axel Dreher, Stephan Klasen and Hannes Öhler for helpful comments on earlier drafts of this paper. Furthermore, we thank Paul A. Rashky for sharing data on humanitarian aid flows and disaster severity.

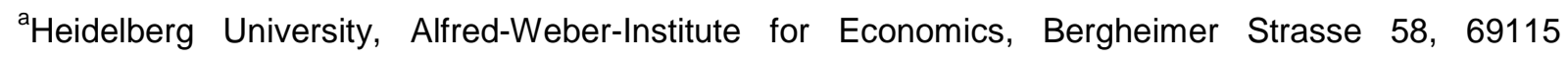
Heidelberg, Germany 
"The old binary division of the world-between rich countries which give aid and poor ones which get it-is gone."

The Economist, Official development assistance: Aid 2.0, August 13th 2011

\section{I.1 Introduction}

It is commonly anticipated that within donor-recipient relations rich countries, mainly those organized in the OECD Development Assistance Committee (DAC), will assume the role of providers of foreign aid to countries in need. However, this simple breakdown of countries into pure donors and recipients has lost its accuracy, as an increasing number of countries, not just the richest, have taken up responsibilities as donors (see ECOSOC 2008; Dreher et al. 2011). ${ }^{4}$ This new world of foreign assistance is most visible in the provision of humanitarian assistance. Since humanitarian aid requires considerably lower organizational capacities and planning skills than long-term development aid strategies, this type of aid offers a relatively easy way for less affluent nations to graduate from being pure aid recipients to becoming donors of foreign assistance. The Financial Tracking System (FTS) of the United Nations Office for the Coordination of Humanitarian Affairs (OCHA 2011) already lists more than 180 donors as providers of humanitarian aid. Consequently, almost every country in the world provides at least some form of foreign assistance.

The response of the international aid community to the earthquake that hit Haiti in January 2010 is a prime example of this proliferation of donors. In the aftermath of the catastrophe, which is believed to have killed at least 222,570 people (EM-DAT 2012), emergency relief was provided from a total of 175 countries (OCHA 2011). This included all DAC donors, more than 60 autocratic donors, 31 least developed countries and 11 countries that were poorer than Haiti itself. Within one day of the earthquake's occurrence, aid commitments from 30 countries had been registered. 19 non-DAC donors were among these fast-responding donors, including low-income countries like Nicaragua and autocratic countries like China.

\footnotetext{
${ }^{4}$ According to data provided by AidData (Tierney et al. 2011), a project-level database, the share in total aid allocations of non-DAC donors increased from $2.5 \%$ in 2005 to $6.4 \%$ in 2009 . Since many aid agencies and whole countries (e.g., China) are not captured in the dataset, these values provide a lower bound.
} 
Activities of countries, whose participation in aid efforts does not fit into the traditional image of an aid donor, are notable for a multitude of emergencies. For example, when a severe flood affected 200,000 people in Australia, India contributed over 90 percent of the total aid amount provided after the disaster. After the 2008 Yemen floods, DAC donors including Canada and Germany provided a negligible share of the aid delivery, while autocratic donors such as Kuwait, Saudi Arabia and Singapore contributed over 90 percent of the delivered aid amount. Furthermore, non-DAC donors are not only catching up with traditional DAC donors in terms of contribution scale, but are also often among the first to respond to disasters. For example, in terms of the time period after which a donor commits herself to help, China, together with Canada, was the fastest donor to respond to the devastating 2010 Chile earthquake. Similarly, Russia, together with Germany, was the first donor to provide emergency relief to Iran after the 2006 earthquake.

These examples illustrate that the proliferation of aid donors has led and continues to lead to visible changes in the world of foreign aid, with potential repercussions on aid allocation and aid effectiveness. This paper divides "new" donors from "old" donors in order to analyze these changes. In general, "new" donors are considered to be those donors that operate outside of the institutions of the DAC. ${ }^{5}$ It is important to note, however, that the non-DAC donors constitute a rather heterogeneous set of countries (Manning 2006; Kragelund 2008). Accordingly, we analyze different types of "new" donors. Being aware of the increasing activities of many poor donors, we analyze differences in aid decisions between donors based on their income level. Moreover, to reflect the increased importance of aid from authoritarian countries, we compare aid allocation between democracies and autocracies.

Although emerging economies such as China and India hold a growing stake in the global economy and an increased weight in global decision-making processes, hardly any consensus exists with regards to the motives of these countries as providers of humanitarian aid. This paper builds on the aid allocation literature (e.g., Alesina and Dollar 2000), and in particular, on the strands of the literature that cover aid from "new" donors on the one hand (e.g., Dreher et al. 2011; Neumayer 2003a,

\footnotetext{
${ }^{5}$ Note that we use "new" in quotation marks to take account of the fact that many of the so-called new donors have a long tradition of aid provision to other developing countries.
} 
2004) and humanitarian aid on the other (e.g., Eisensee and Strömberg 2007; Fink and Redaelli 2011; Raschky and Schwindt 2012). We combine data on humanitarian aid provided by the Financial Tracking Service covering the 2000-2009 period with a detailed dataset on disaster characteristics from the International Disaster Database (EM-DAT 2012), made available by the Centre for Research on the Epidemiology of Disasters (CRED).

In a first step, we analyze the differences in the determinants of the donor decision to provide emergency aid between "old" and "new" donors as well as between different types of "new" donors. More precisely, we explore how these allocation patterns differ according to disaster type and severity, recipient characteristics and the state and intensity of bilateral relations between donor and recipient. While the limited availability of data constrains our analysis to one single type of foreign aid, i.e., humanitarian assistance, we take advantage of FTS data to analyze a huge set of donor countries that are situated at all levels of income, have different political regimes and operate inside and outside the DAC.

In a second step, we analyze the determinants of the number of days following a disaster before a donor commits herself to provide emergency aid. A short response time is crucial for aid to be effective and reflects the donor's commitment to a particular country and disaster episode. Within the DAC, all donor countries endorse the Principles and Practices of Good Humanitarian Donorship (GHD), which emphasize the rapid response of donors after a disaster. Similarly, "new" donors outside the DAC pride themselves with the timeliness of their response to emergencies (Harmer and Martin 2010). An analysis of the determinants of the time a donor takes to commit aid will thus improve our understanding of whether the increased diversity of donors has impacted the promptness of aid provision.

To the best of our knowledge, this is not only the first paper that econometrically analyzes aid allocation by different types of "new" donors, but it is also the first that explicitly looks at the speed of the decision to provide aid in an empirical analysis. ${ }^{6}$ Our results indicate that "new" and "old" donors alike provide aid based on humanitarian need and donor self-interests. Considerable differences emerge with regard to the importance attached to different factors. We find that non-

\footnotetext{
${ }^{6}$ In a different context, Kilby (2011) analyzes the speed of aid disbursements after the initial aid decision was made.
} 
DAC donors attach greater importance to political allies than DAC donors. At the same time, aid from autocratic countries is to a stronger extent motivated by natural resource endowments than disaster relief from democracies. Furthermore, we find autocracies to disfavor democracies. With respect to the timeliness of the decision to help, we find DAC, "rich" and democratic donors to react significantly faster to emergencies than non-DAC, "poor" and autocratic donors.

The remaining paper is structured as follows: Section 2 introduces the literature on the determinants of emergency aid. Section 3 elaborates our hypotheses with respect to differences in aid decisions between "old" and "new" donors as well as between the different types of "new" donors. The following sections present empirical evidence on aid selection (Section 4) and the timeliness of the decision to provide emergency relief (Section 5). Finally, Section 6 summarizes our paper and concludes.

\section{I.2 Determinants of Emergency Aid}

Natural disasters pose a serious threat to the stability of countries and the well-being and life of many individuals worldwide. ${ }^{7}$ Therefore, disaster-affected countries frequently rely on disaster assistance provided by other countries to tackle the challenges faced in the aftermath of a catastrophe. Although poorer countries do not suffer from more natural disasters than richer ones, poorer countries experience more casualties after catastrophes on average (Kahn 2005; Strömberg 2007). ${ }^{8}$ Thus, the availability of foreign sources of funding is crucial for developing countries, in particular since governments in less affluent countries are more likely to possess insufficient capacities to provide domestic emergency relief. Previous research has analyzed the determinants of the allocation of emergency aid. While one strand of the emergency aid literature focuses on the allocation of disaster relief within

\footnotetext{
${ }^{7}$ See, for example, Nel and Righarts (2008) for an analysis of the link between natural disasters and the occurance of civil war and Neumayer and Plümper (2007) for a study of the effect of natural disasters on life expectancy and gender-specific differences in vulnerability. Luechinger and Raschky (2009) find a sizable reduction of life satisfaction after disasters.

${ }^{8}$ Similarly, disasters lead to fewer victims in countries with better institutions (Raschky 2008).
} 
countries, ${ }^{9}$ this article is part of the literature that analyzes aid allocation across countries and emergencies (e.g., Drury et al. 2005; Fink and Redaelli 2011).

Emergency aid intends to provide fast relief from humanitarian hardship after a (natural) disaster. Obviously, the more severe a disaster, the more aid is expected to flow to counter its effects. Previous research has shown that both the likelihood that a donor provides aid after a disaster as well as the aid amount provided increase with disaster severity, usually measured by the total number of people affected and the number of casualties (Drury et al. 2005; Strömberg 2007; Fink and Redaelli 2011; Raschky and Schwindt 2012). For humanitarian need to play its role, public awareness of a disaster is required to trigger assistance. In this context, Eisensee and Strömberg (2007) analyze the role of the media on US disaster relief between 1968 and 2002. They find that the likelihood to receive US aid increases with the coverage of the disaster in the television news. ${ }^{10}$

However, media attention and pure humanitarian needs are not the only deciding factors which affect the provision and timeliness of emergency aid. Within the general aid allocation literature, empirical research has been conducted to reveal whether donor motives that are not directly related to humanitarian concerns determine the allocation of aid. For example, Alesina and Dollar (2000) find in their much-quoted paper that aid flows are driven by past colonial relations between donor and recipient as well as by voting patterns in the United Nations General Assembly (UNGA). ${ }^{11}$ Similarly, empirical research has shown that non-permanent members of the United Nations Security Council (UNSC) receive a significantly larger amount of aid from the United States (Kuziemko and Werker 2006) and from international organizations (Dreher et al. 2009a, 2009b). With respect to emergency aid, aid giving based on economic, political and strategic considerations - which reflect the donor countries' self-interests rather than humanitarian need - would contradict the guiding principles stated in UN resolution $A / R E S / 46 / 182$. According to this resolution, "[h]umanitarian assistance must be provided in accordance with the principles of

\footnotetext{
${ }^{9}$ Benini et al. (2009) and Wiesenfarth and Kneib (2010) study relief supply to earthquake-affected communities in Pakistan after the 2005 earthquake. See also Francken et al. (2012) for a study of the political economy of aid allocation inside Madagascar after cyclone Gafilo in 2004.

${ }_{11}^{10}$ Potter and Van Belle (2008) find similar results for Japanese disaster aid.

11 Empirical results of Höffler and Outram (2011) and Younas (2008) confirm the importance of commercial and political motives. Note that these studies limit their analysis to OECD donors.
} 
humanity, neutrality and impartiality." ${ }^{12}$ Despite official claims that the provision of disaster assistance was less prone to political bias or strategic considerations than general development assistance, Drury et al. (2005) find in their study covering the 1964-1995 period that US disaster assistance is influenced by political considerations at the initial "gate-keeping phase," and, to a smaller extent, with regards to the subsequent decision on the amount of aid to be allocated. In particular during the Cold War period, allies of the United States "were almost assured of at least some assistance" (Drury et al. 2005: 466).

However, the motivations for providing humanitarian aid based on political considerations appear ambiguous. On the one hand, donors may rely on disaster aid to express their support of befriended countries or even to ensure the survival of politically-aligned governments in cases where a severe disaster threatens the political stability of an entire country (Drury and Olson 1998; Drury et al. 2005). On the other hand, donors may give aid to persuade adversaries or politically unaligned recipients to make concessions to the donor in the future. This second effect seems to be more likely to influence emergency aid contributions rather than general development assistance. In contrast to emergency aid, the provision of assistance aimed at long-term economic and structural development requires a fair amount of collaboration between donor and recipient and hence at least some goodwill to facilitate negotiations (Fink and Redaelli 2011). Many aid initiatives have long-term goals, such as the alleviation of poverty, which require certain stability in bilateral relations. In contrast to general development aid, emergency aid requires hardly any negotiations and less coordination with a recipient. This type of aid thus provides donors with an opportunity to approach nations in distress, while bypassing potential bilateral conflicts.

The case of the 2010 Haiti earthquake provides a prime example of these two opposing mechanisms. In the aftermath of the disaster, Taiwan - which currently entertains diplomatic relations with 23 countries including Haiti - engaged in a largescale humanitarian mission. Moreover, Taiwan restructured Haiti's debt to ease financial pressure on the government. (The People's Republic of) China, which considers Taiwan as being a renegade province and attempts to isolate Taiwan

\footnotetext{
${ }^{12}$ The UN Resolution on "Strengthening of the coordination of humanitarian emergency assistance of the United Nations", adopted on December 19, 1991, available at http://www.un.org/documents/ga/res/46/a46r182.htm (accessed: June 1, 2012). 
diplomatically, showed similar generosity towards Haiti, despite refusing diplomatic relations with the government in Port-au-Prince as a consequence of Haiti's diplomatic recognition of Taiwan. ${ }^{13}$ Tubilewicz (2012: 6) describes these activities of the two Chinese donors as "aid competition."

In line with the behavior of China in the case of the Haiti earthquake, Fink and Redaelli (2011) find politically less affine countries to be more likely to receive emergency aid from a particular donor. ${ }^{14}$ Political affinity between countries is proxied by their voting alignment in the United Nations General Assembly. Fink and Redaelli also find that donors favor former colonies in their aid allocation decisions. Their study analyzes the disaster response of OECD countries after the occurrence of 270 emergencies worldwide. The authors conclude that donors provide aid out of political and strategic considerations in addition to humanitarian concerns.

Commercial motives could also play a role in the decision to provide emergency relief. ${ }^{15}$ For example, disaster aid can be used as a tool to prevent trade reductions with disaster-struck economies. In line with this idea, Gassebner et al. (2010) find that natural disasters harm trade with countries suffering from a catastrophe. Raschky and Schwindt (2012) confirm that the likelihood that a country receives aid in the aftermath of a disaster increases with its imports from the donor economy. Moreover, the empirical finding of Fink and Redaelli (2011) that oilexporting countries are, on average, more likely to receive help after a catastrophe can also be explained with donor countries' commercial interests. Many donors have larger strategic interests in oil-rich countries and will therefore seek to secure their access to these markets through aid provision. ${ }^{16}$ According to the findings in Raschky and Schwindt (2012), donors favor only oil exporters with bad institutions, i.e., a low rule of law and a high level of corruption.

While most articles analyze the decision to provide aid and the aid amounts attached, Raschky and Schwindt (2012) contribute to a better understanding of the decision-making process underlying the provision of aid. In particular, they

\footnotetext{
${ }^{13}$ Taiwan's initial aid support amounted to US\$ 5 million, while China has pledged US\$4.1 million and provided additional US\$ 2 million worth of medical supplies six days after the earthquake (see http://in.reuters.com/article/2010/01/18/idINIndia-45477020100118, accessed: July 2012).

${ }_{14}$ See also Neumayer (2005) for similar findings with respect to emergency food aid provided by the United States and the European Union.

${ }^{15}$ On the role of development aid for export promotion, see Nowak-Lehmann D. et al. (2009).

${ }^{16}$ Alternatively, larger oil extraction may also be an indicator of need. As argued by Fink and Redaelli (2011), countries rich in natural resources usually show a higher inequality and higher poverty rates.
} 
investigate the determinants that influence the donors' choice between bilateral and multilateral aid provision (aid channel) and between cash and in-kind contributions (type of aid). They find that politically-aligned countries and important trading partners are more likely to receive bilateral aid rather than assistance channeled via multilateral institutions. At the same time, countries with lower corruption and better institutions have a higher probability to receive cash instead of in-kind disaster aid, while humanitarian need has only a weak impact on the type of aid committed. ${ }^{17}$

The international aid community places growing emphasis on the rapid response of donors after a disaster strikes. The immediate delivery of emergency relief is essential for aid to be effective. Consequently, aid promptness is part of the 23 principles of GHD, according to which donors should "strive to ensure flexible and timely funding, on the basis of the collective obligation of striving to meet humanitarian needs" (principle 5) and "maintain readiness to support the implementation of humanitarian action" (principle 17). ${ }^{18}$ In line with these principles, the commitment to provide quick disaster relief is communicated as a key priority by many donors. For example, Canada claims to assess the need for humanitarian aid within "hours of a natural disaster of significant scale."19 Similarly, Ireland emphasizes its goal to "respond effectively, efficiently and in a timely manner to the humanitarian needs of crisis affected peoples." 20 Given the importance assigned to a timely response after a disaster, it is necessary to evaluate the effort of donor countries not only based on their monetary dedication, but also by the promptness with which they react to a natural disaster. To date, however, no research exists to our knowledge that empirically investigates which factors lead to a rapid reaction from donor countries after a disaster.

\footnotetext{
${ }^{17}$ Raschky and Schwindt (2012) also split their sample into OECD and non-OECD donors. In contrast to non-OECD countries, OECD countries favor to channel aid to autocracies multilaterally rather than bilaterally. Empirical evidence for commercial motives guiding the channel decision is found for OECD countries only.

${ }^{18}$ The 23 Principles and Good Practice of Humanitarian Donorship are the result of an attempt to "reform and strengthen systems for humanitarian needs, and prioritize and allocate funds more efficiently to meet the needs" (OECD 2005). The DAC endorsed the GHD principles in March 2004 and introduced a regular peer review of the aid activities of DAC members to derive recommendations for improvement. As such, the harmonization of aid practices is at the core of the GHD agenda. See the webpage of the GHD initiative available at http://www.goodhumanitariandonorship.org/gns/principles-good-practice-ghd/overview.aspx (accessed: June 3, 2012).

19 See website of the Department of Foreign Affairs and International Trade, available at http://www.international.gc.ca/humanitarian-humanitaire/faq.aspx?view=d\#q3 (accessed: July 2012).

20 See policy report by Ireland's Department of Foreign Affairs, available at: http://www.irishaid.gov.ie/Uploads/Humanitarian\%20Relief\%20Policy1.pdf (accessed: July 2012).
} 


\section{I.3 The New World of Emergency Assistance}

Today, in the area of humanitarian assistance, almost every country in the world acts as a provider of foreign aid. This runs counter to the common belief that being a donor is synonymous with being one of the rich democracies organized in the DAC. In this context, Harmer and Martin (2010:1) note that "[h]umanitarian action is not the preserve of the rich, industrialised West, but a common pursuit among nations, rich and poor." While the term "new donor" is frequently used in the literature and policy debates to describe donor countries operating outside of the DAC, its usage is misleading (see Manning 2006). Many so-called "new" donors have acted as providers of foreign assistance for decades. China and India, for example, started providing aid to other countries already in the 1950s. In order to take account of this, Kragelund (2010) proposes the use of the term "non-traditional donor" instead. This raises similar concerns, however, since the term implies that long-standing donors like China, India, Saudi Arabia or the United Arab Emirates have no aid traditions. Therefore, we prefer the term "non-DAC donor" for those donor countries operating outside of the aid institutions of the OECD and use the term "new donors" with "new" in quotation marks when referring to them.

The group of non-DAC donors constitutes a heterogeneous set of countries. It includes high-income countries like Poland or Trinidad and Tobago on the one hand as well as low-income countries like Bangladesh or Tajikistan on the other. It contains democracies like Brazil or Slovenia as well as autocracies like China or Singapore. Appendix A.1 provides a list of the 21 most important donors of emergency aid according to their number of aid interventions following a disaster. It contains information on their aid agencies, official missions and objectives as well as sectoral and geographic priorities. As can be seen from this list, there are considerable differences in the way humanitarian aid is managed in different nonDAC donor countries as well as in the principles that officially guide donor decisions. For example, the fact that Brazil - like DAC donor countries - adheres to the GHD initiative makes it plausible that the country's behavior as donor of humanitarian aid is to a significant degree comparable to the practices of DAC donors. The aid architecture of Morocco, for example, stands in complete contrast to Brazil's 
approach as the country's donations are centrally directed by Morocco's ruling monarch. $^{21}$

Although "new" donors deprive the "old" donors of their quasi-monopoly on aid provision, the empirical aid literature, including the strand of the literature that studies emergency aid, is largely centered on aid from DAC donors. By analyzing the determinants of Arab aid allocation, Neumayer (2003a) goes beyond the traditional group of donors scrutinized in prior contributions and reveals that Arab aid allocation is not primarily driven by recipient need but rather based on ethnic and religious similarity as well as donor countries' voting alignment in the UNGA. In an investigation of the aid allocation pattern of 16 non-DAC donors, Dreher et al. (2011) find striking similarities in the aid allocation decisions of "old" and "new" donors. The average non-DAC donor, however, shows a weaker poverty orientation, which contradicts the idea that poorer donors should empathize with the problems of the countries which they support.

Rather than grouping all "new" donors together, we refine the approach taken in Dreher et al. (2011) and classify donors according to the following criteria. First, based on aid institutions, we divide donors into DAC members and non-DAC donors. The DAC serves as the major institution to set aid agendas and influence the direction and principles of the majority of global aid flows. Therefore, a "new" donor is a country acting independently from this comprehensive and supranational framework on aid provision. Second, donors may show differences in their aid allocation behavior as a consequence of differences in income level (see also Fuchs and Vadlamannati 2012). More precisely, we distinguish between high-income countries on the one hand and low- and middle-income countries on the other. Third, based on regime type, we expect to find differences in donor behavior between democratic and authoritarian donors in line with Bermeo (2011).

A consensus has emerged in the literature that aid follows humanitarian need, rewards recipient countries with good institutions but also follows donor countries' political and commercial self-interests (e.g., Alesina and Dollar 2000; Neumayer 2003b; Höffler and Outram 2011). First, with regard to aid institutions, we expect to

\footnotetext{
${ }^{21}$ Several reports issued by the Government of Morocco, which are available on the ReliefWeb homepage, emphasize that the delivery of humanitarian aid was carried out by "high instructions" of King Mohammed VI, see http://reliefweb.int/node/492950 and http://reliefweb.int/node/488837 (accessed: July 2012).
} 
find systematic differences in aid allocation behavior between DAC and non-DAC donors. Donors within the DAC have committed themselves to align their aid efforts with principles of impartiality, neutrality and international humanitarian law and accept a regular peer review of their actions by the DAC (OECD 2005). Non-DAC donors on the other hand are less "constrained" by such arrangements. It is therefore more feasible for these countries to align aid flows with their political and economic selfinterests and strategic considerations rather than the humanitarian needs of the recipient.

Hypothesis 1a: (independent-donor hypothesis) Non-DAC donors, less constrained by international agreements, provide more aid out of self-interests than DAC donors.

Second, a donor's income level might have important repercussions on donor motives. Fuchs and Vadlamannati (2012) expect that a "needy" donor puts more emphasis on its own interests rather than on recipient needs. ${ }^{22}$ Given these donors' lower wealth and significant development challenges faced at home, the decision to commit aid based purely on altruism would be a luxury these countries could illafford. Therefore, in order to obtain support for the aid program from her own populace, a "needy" donor needs to emphasize the "mutual benefits" of her aid operations. For example, the idea of a mutually beneficial aid relationship has been one of the key characteristics of China's aid efforts since the early days of its aid program (see Bräutigam 2010 for a discussion). Similarly, India considers its aid program to be "about cooperation and partnership for mutual benefit." 23 Moreover, we expect less affluent donors to minimize costs by predominantly helping recipients located within a closer proximity to their own borders. In line with this idea, the Slovakian Ministry of Foreign Affairs states that its "flexibility in providing in-kind humanitarian aid is limited by the lack of financial resources to cover transport costs in cases of a humanitarian crisis in remote countries." ${ }^{24}$ In summary, we formulate

${ }^{22}$ This is largely confirmed by their empirical analysis on India's aid efforts with respect to political
interests.
${ }_{23}$ See website of the Indian Technical and Economic Cooperation (ITEC) Programme, available at:
http://itec.mea.gov.in/about\%20itec.html (accessed: June 2012).
24 See website of the Ministry of Foreign Affairs: http://www.foreign.gov.sk/en/foreign policy/slovak aid (accessed: June 2012). 
Hypothesis 16 (needy-donor hypothesis): Poor donors are driven by selfinterest insofar as they minimize the economic costs of their commitments while maximizing their political and economic gains.

Third, we expect that a donor's behavior depends on the country's regime type. If emergency aid is provided according to merit, then we would expect that democratic donors support democracies (see Bermeo 2011). Conversely, to the extent that democratic donors want to destabilize an autocratic regime, they may be less likely to support an autocratic country after an emergency. In line with this idea, Bueno de Mesquita and Smith (2010) find that a windfall in free resources - such as aid - provides autocratic recipient governments with additional means to entrench themselves in office. Autocratic donors in turn may be more likely to provide aid to autocracies (see Bermeo 2011). Autocratic recipients, potentially shunned by democratic donors due to bad governance or humanitarian rights abuses, may favor donors with a policy of non-interference in internal affairs. ${ }^{25}$ Furthermore, autocratic aid is said to be more focused on donors' self-interests than aid from democratic donor countries. For example, Naím (2007) characterizes development aid from autocratic donors such as China, Venezuela, Iran and Saudi Arabia as "rogue aid" whose allocation is solely guided by international alliances and the extraction of natural resources. By providing some counterexamples, Woods (2008) criticizes Naím's characterization of emerging aid as "rogue aid" as unfounded and points out that evidence for harmful effects of aid from these donors is so far lacking. In line with this, empirical analyses do not find empirical support of the rogue-aid hypothesis. Dreher et al. (2011) find that "new" donors do not systematically favor more autocratic and more corrupt recipients. In a similar vein, Dreher and Fuchs (2011) analyze China's allocation of project aid and show that China provides aid regardless of the recipient's regime type and institutional characteristics, which is empirical support of the country's principle of non-interference.

With respect to emergency aid, empirical support of the rogue-aid hypothesis is still lacking. We test the following hypothesis:

\footnotetext{
${ }^{25}$ According to Pehnelt (2007: 8), autocratic China faces "higher opportunity costs of morality and governance and human rights oriented policies then the traditional powers" and concludes that China has a "comparative advantage" in providing assistance to "unstable and problematic regions and rogue states."
} 
Hypothesis 1c (rogue-donor hypothesis): Autocratic donors favor countries with bad governance and their aid decisions are predominantly driven by political and commercial interests rather than recipient need.

With respect to the promptness with which DAC and non-DAC donors respond to a natural disaster, donors from both groups emphasize the importance of fast reaction times and claim to be quick providers of relief. ${ }^{26}$ While all DAC donors endorse the GHD framework and thus the associated timely response requirements, non-DAC donors also highlight the rapidity of their response and emphasize their reaction time as being a key point of distinction with their DAC counterparts (Harmer and Martin 2010). Non-DAC donor Israel, for example, claims that "[n]o other country can dispatch search and rescue teams and field hospitals as fast and effectively." ${ }^{27}$ Similarly, India's government highlights its speedy assistance, which is explained by Meier and Murphy (2011) with the country's striving for international visibility.

While the comparative advantage of DAC donors may lie in their significant experience with aid delivery, non-DAC donors might be able to decide on aid provisions in a more flexible manner given their independence from a regulatory aid framework or the need for coordination with other donors (see ECOSOC 2008 for a discussion). India, for example, lacks a common humanitarian aid policy. Meier and Murphy (2011: 11) describe the country's humanitarian aid bureaucracy as "organically grown" with decisions made "in an ad hoc manner" and "on a case-bycase basis." They conclude that "such a flexible set up enables India to [...] provide aid quickly" (p. 11-12). Since less affluent countries have generally a smaller aid budget, they cannot boast of vast aid contributions, but they can (try to) set themselves apart with a speedy response to emergencies. At the same time, however, most "new" donors do not have dedicated facilities or capacities to quickly disburse funds after a shock. It is thus conceivable that poorer donor countries

\footnotetext{
${ }^{26}$ In this regard, also refer to the mission statements by South Korea, Turkey, United Arab Emirates, Brazil, and Hungary provided in Appendix A, which emphasize the importance of a quick donor reply.

${ }^{27}$ Israel also claims that its "200-strong relief team was the first on the scene in January 2010 after the earthquake hit Haiti" and that it "was one of the first countries to send aid according to the needs and request of the Japanese government" after the 2011 earthquake. See website of Israel's Ministry of Foreign Affairs, available at: http://www.mfa.gov.il/mfa/humanitarianaid/overview/ (accessed: June 2012).
} 
exhibit a slower response to other countries' needs as both financial means and administrative capacities in poor countries are less abundant on average. ${ }^{28}$

With respect to the regime type of donors, decision-making processes in autocratic donor countries are less constrained by veto players than in democracies where checks and balances may slow down decisions. In Saudi Arabia and Morocco, for example, the king decides whether to provide emergency aid (see Appendix $A$; also refer to Al-Yahya and Fustier 2011 for an overview on Saudi Arabia's humanitarian aid). At the same time, the need to satisfy veto players and different opinions represented in legislature and government could lead to quicker decisionmaking processes as different groups lobby for their interests. ${ }^{29}$ Which of these two effects dominates the other is an empirical question. Summarizing these arguments, we formulate two competing hypotheses:

Hypothesis 2: "New" donors, lacking routine and usually working in a less efficient institutional environment, are slower than DAC donors in providing emergency relief.

Hypothesis 2 (alternative): Non-DAC donors, less constrained by bureaucracy, are faster to provide emergency relief.

These hypotheses are tested below. While the existing literature is confined to analyze a maximum of only 16 "new" donors (Dreher et al. 2011) with notable omissions (e.g., China and India), we empirically analyze the behavior of 105 donor countries. This is what we turn to next.

\footnotetext{
${ }^{28}$ As can be seen from Appendix A, many "new" donor countries lack a clear assignment of competencies to agencies as well as clear objectives guiding their provision of humanitarian assistance.

${ }^{29}$ See Round and Odedokum (2004) for a discussion of the role of checks and balances on aid effort.
} 


\section{I.4. Empirical Analysis of Aid Selection}

\section{I.4.1 Overview}

Our analysis exploits humanitarian aid data obtained from the FTS database (OCHA 2011). ${ }^{30}$ In contrast to the commonly used OECD database maintained by the DAC and the project-level database AidData, FTS has the advantage that the dataset is not limited to a relatively small set of donors, but covers virtually every country in the world. Even countries with a low aid transparency like China and Russia are covered by FTS.

While FTS reports humanitarian aid flows pledged, committed and contributed, we exclude pledged funds as these entries represent only a "non-binding announcement of an intended contribution or allocation by the donor" (OCHA 2011). Committed and contributed funds on the other hand constitute either a de factopayment guaranteed by a signed contract or the actual transfer of funds and in-kind goods from the donor to the recipient. Aid contributions in kind are very heterogeneous and include, for example, medical aid, search and rescue teams, shelter and clothing. Donors send humanitarian assistance either directly to the affected country or channel relief through multilateral institutions or via nongovernmental organizations like the Red Cross.

FTS data is based on self-reported information, which is provided by either donor governments, recipient agencies, collected from donor websites or quoted in pledging conferences. ${ }^{31}$ In addition, FTS invests significant efforts into the crossvalidation and reconciliation in cases where donation data stems from various sources. By comparing FTS data with DAC data, Fink and Redaelli (2011) find only minor differences between both databases, which show that FTS has relatively good data coverage. Although data coverage may be worse for non-DAC donors, FTS is the best database available for analyses of all kinds of donors. The database is widely used in policy analysis and academic research (e.g., Fink and Redaelli 2011), including empirical research on non-DAC donors (Raschky and Schwindt 2012).

\footnotetext{
${ }^{30}$ The database is publicly available at: http://fts.unocha.org (accessed: August 2011).

${ }^{31}$ For a more detailed description of the data collection and subsequent cross-checking process refer to http://fts.unocha.org/pageloader.aspx?page=showpage\&PagelD=61-Data (accessed: July 2012). See Harmer and Cotterrell (2005) for a discussion of strengths and weaknesses of FTS data.
} 
Table I.1: Disaster types

\begin{tabular}{|l|lllll|}
\hline Disaster type & $\begin{array}{l}\text { \# of } \\
\text { events }\end{array}$ & $\begin{array}{l}\text { Disaster start } \\
\text { reported (in \%) }\end{array}$ & $\begin{array}{l}\text { Average \# of } \\
\text { people killed }\end{array}$ & $\begin{array}{l}\text { Average \# of } \\
\text { people affected }\end{array}$ & $\begin{array}{l}\text { Average \# of } \\
\text { donors }\end{array}$ \\
\hline Drought & 27 & 0.0 & 27 & $15,836,072$ & 6.4 \\
Earthquake & 65 & 100.0 & 7,484 & $1,119,623$ & 13.9 \\
Epidemic & 4 & 25.0 & 92 & 5,153 & 5.0 \\
Extreme Temperature & 7 & 71.4 & 342 & $1,446,904$ & 3.9 \\
Floods & 220 & 91.4 & 124 & $2,620,126$ & 6.0 \\
Insect Infestation & 11 & 9.1 & 0 & 500,000 & 1.7 \\
Mass Movement Wet & 4 & 100.0 & 77 & 77,899 & 1.0 \\
Slides & 7 & 100.0 & 306 & 72,153 & 7.3 \\
Storm & 108 & 87.0 & 1,524 & 843,096 & 6.9 \\
Volcanic eruption & 15 & 100.0 & 8 & 76,649 & 3.9 \\
Wild fires & 4 & 75.0 & 14 & 150,000 & 2.5 \\
\hline
\end{tabular}

Source: Own calculations based on data from OCHA (2011) and EM-DAT (2012)

The UNOCHA defines humanitarian aid as "[a]n intervention to help people who are victims of a natural disaster or conflict meet their basic needs and rights" (OCHA 2011). Definitions of what constitutes humanitarian aid, however, differ across donor countries. To circumvent this caveat, we follow the previous literature and restrict our analysis to official UN appeals issued after emergencies. Consequently, all UN appeals need to be linked to a particular catastrophe. We have therefore updated and cross-validated the dataset used in Raschky and Schwindt (2012). ${ }^{32}$ Data on disaster characteristics are obtained from the emergency database EM-DAT (2012).

Fink and Redaelli (2011) note that measures of humanitarian need, e.g., the number of people killed after a catastrophe, are endogenous to the probability to provide aid. This holds if aid is effective in reducing the number of victims. To mitigate endogeneity issues, we follow their approach and restrict our analysis to cover fast-onset disasters only. These disasters usually take less than one day.

\footnotetext{
${ }^{32}$ We thank Paul A. Raschky for generously providing us with the dataset.
} 
Since it is difficult to identify what constitutes a fast-onset disaster, we first exclude all disaster types from our sample that lack information on the respective disaster start dates in the majority of emergencies. These are emergencies caused by drought, extreme temperature and insect infestation. Of the remaining disaster types, we keep only those emergencies that have a clearly defined start date. Table I.1 provides an overview on the share of reported disaster start dates by disaster type. We also report disaster-type-specific information on the frequency and severity of disasters as well as on the average number of donor interventions per catastrophe.

The resulting dataset covers 396 fast-onset emergencies over the 2000-2010 period. The non-availability of some of the (lagged) explanatory variables for 2010 , however, constrains us to an analysis of 347 emergencies between 2000 and 2009. Since 19 disasters affect more than one country at the same time, as for example the 2004 Indian Ocean Tsunami, we end up with 394 emergency-recipient pairs. We consider every country as a (potential) donor of emergency aid if it has repeatedly (i.e., at least twice) provided emergency assistance after a natural disaster in our sample. By doing so, we investigate the behavior of 105 donor countries. In summary, we obtain $394 \cdot 105=41,370$ observations. Data availability of control variables reduces the final sample size to about 30,000 observations.

Appendix A.2 lists all donor countries under investigation. The table is sorted by the number of aid interventions, i.e., the number of emergencies for which a donor provided aid to a particular recipient. As can be seen, the most active non-DAC donors are Turkey and South Korea with 54 involvements each. ${ }^{33}$ Thus, Turkey is also the most active donor among the group of low- and middle-income countries. Saudi Arabia tops the list of autocratic donors with 51 involvements.

Figure I.1 compares the share of "new" donors in disaster relief of the first half of the 2000s (2000-04) with the second half (2005-09). As can be seen, emergency aid provided by "new" donors has gained in importance. Of all aid responses by donors in 2005-09, more than one third came from non-DAC donor countries, compared to only about one fourth in 2000-04. The respective share of poor and autocratic donors, however, was rather stable.

\footnotetext{
${ }^{33}$ In our paper, Korea is still considered as a non-DAC donor since it joined the OECD's aid organization in 2010 only.
} 
If one compares the share of aid amounts that each country provided, the increasing role of non-DAC donors becomes even more evident. The share of emergency aid funds that non-DAC donors contributed more than tripled from 9.1 to 28.9 percent, the share provided by less developed donors increased from 4.0 to 7.4 percent and the share of autocratic donors almost quadrupled from 5.4 to 23.3 percent over the same time period. This overall increase of aid from autocracies is mainly due to a surge in aid from Saudi Arabia (additional US\$ 415 million), but also caused by substantial increases in aid from Russia and Kazakhstan (additional US\$ 27 million each). 
Figure I.1: Emergency aid over time and by donor group (2000-09)

Aid interventions

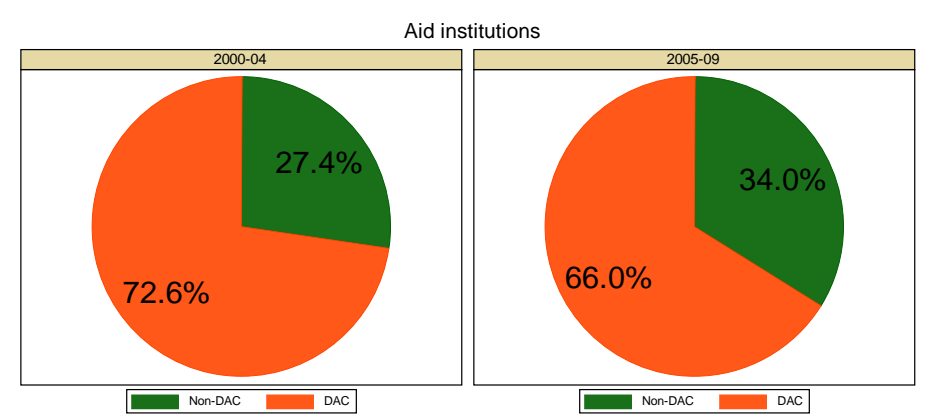

Income level
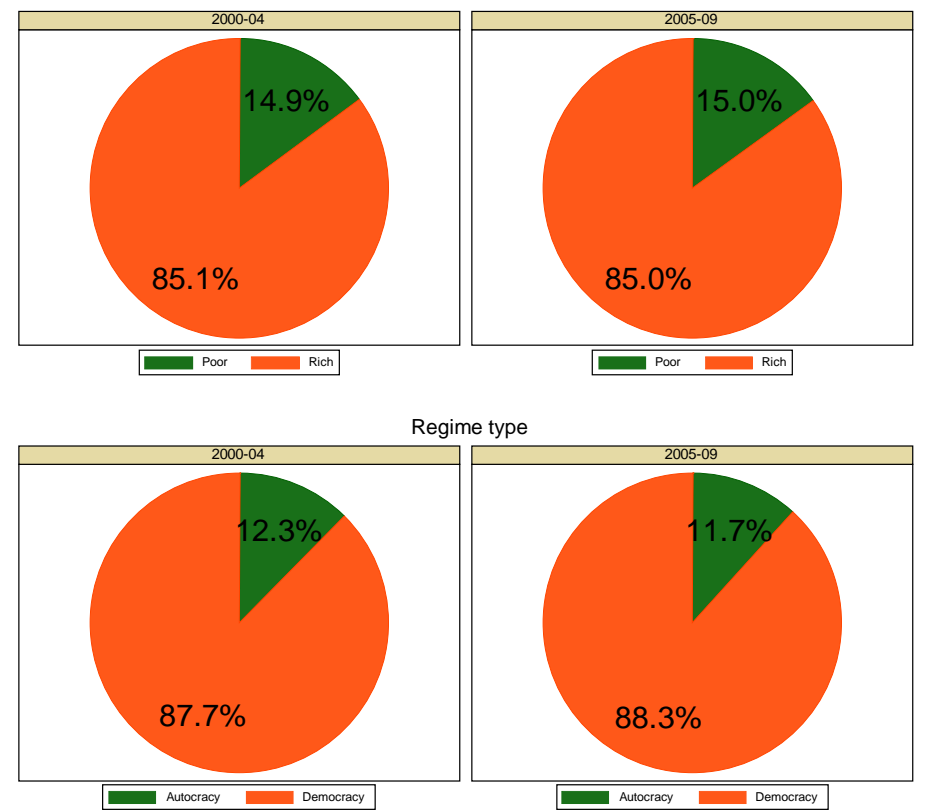

Aid amounts

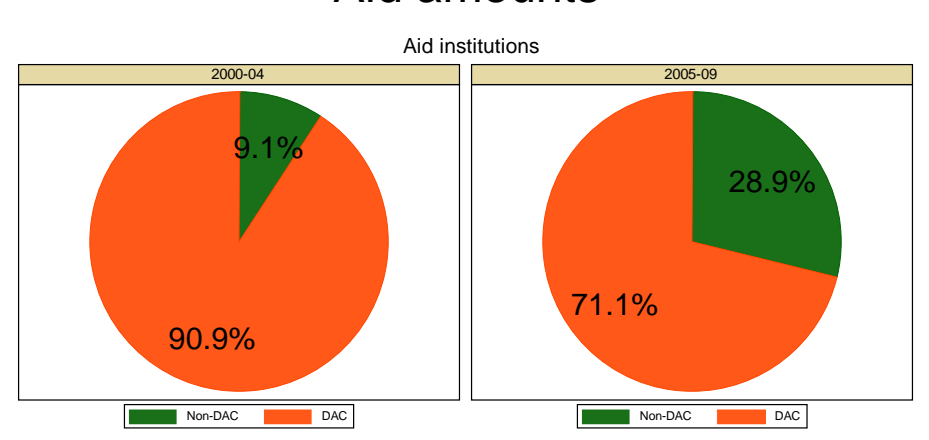

Income level
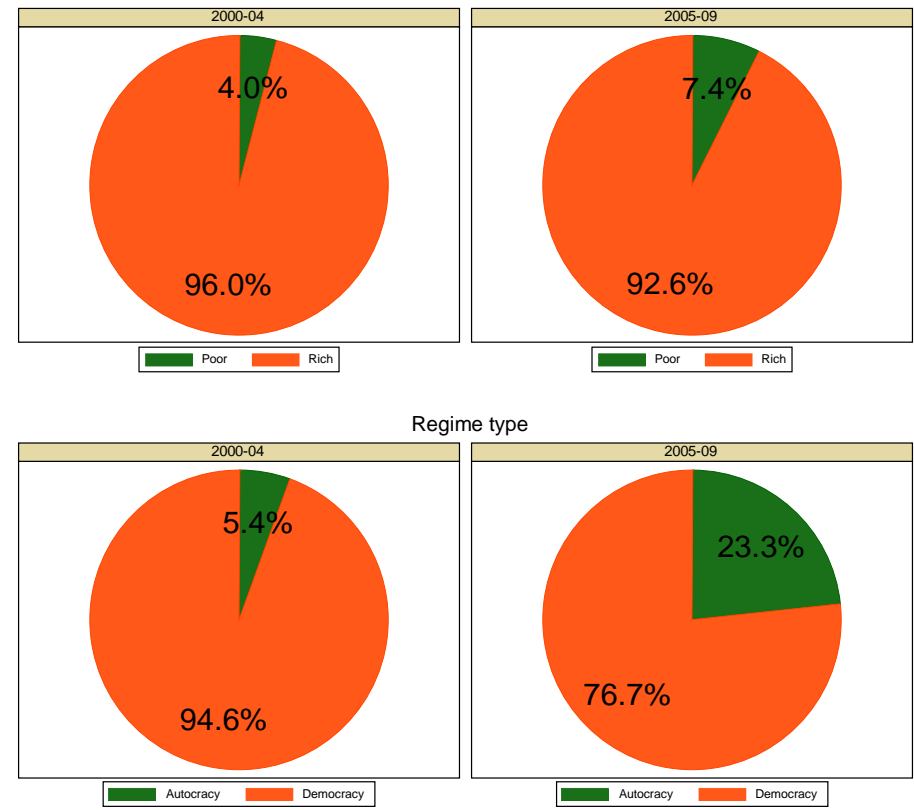


\section{I.4.2 Empirical Strategy}

We start with estimating the probability that a country provides emergency aid to another country after a natural disaster. Our dependent variable aid is a dummy that takes a value of one if a country $i$ provides emergency assistance to another country $j$ after a natural disaster $k$. The probability to provide emergency assistance can be written as

(1) $P\left(\operatorname{aid}_{i j k}=1 \mid x_{i j k}\right)=P\left(x_{i j k} \beta+\varepsilon_{i j k} \mid x_{i j k}\right)$,

where $x$ is a set of explanatory variables and $\varepsilon$ is a white noise term. For the selection of appropriate explanatory variables, we use the variables employed in the aid allocation literature as guidance, in particular the literature on humanitarian aid (Fink and Redaelli 2011; Raschky and Schwindt 2012) and on "new" donors (Dreher et al. 2011). In line with the previous literature, we include four sets of variables that are said to impact the likelihood that a donor provides emergency relief after a natural disaster, namely disaster severity, donor characteristics, recipient characteristics and variables capturing donor-recipient relations.

First, to control for disaster severity, we employ two indicators that measure humanitarian need after the occurrence of a disaster. The first indicator is the (logged) number of total people affected by the disaster, i.e., the sum of all people injured, left homeless or affected in another way. Our second measure is the number of people killed, which includes all individuals confirmed as dead as well as those missing and presumed dead. Both variables are obtained from EM-DAT (2012) ${ }^{34}$ Moreover, we include disaster-type dummies to account for unobserved characteristics of the different disaster types. With the inclusion of these variables, we control for differences in the measurement of impact through our two measures of disaster severity (see Fink and Redaelli 2011). It is also imaginable that different types of disasters per se trigger different responses from the aid community. In line

34 Data were cross-validated with information from situation reports provided by the Reliefweb, available at http://reliefweb.int/disasters (accessed: July 2012). 
with this, Eisensee and Strömberg (2007) report that the newsworthiness of emergencies depends on disaster type.

Second, we expect that donor characteristics impact on the likelihood of aid provision. We construct one dummy variable to account for country membership in the DAC and a second one that takes a value of one if a donor country is classified as a democracy (Cheibub et al. 2010). To control for the income of a donor country, we include the (logged) real GDP per capita of a donor country, which is retrieved from the Penn World Tables (Heston et al. 2011), as well as a dummy variable that takes a value of one if a donor is classified as a high-income country by the World Bank. ${ }^{35}$ Finally, we rely on the total population size in logs from the World Development Indicators (WDI) to measure capacity aid of donor countries.

With regards to recipient characteristics, we control for a country's self-aid capacity by using the (logged) per-capita GDP in constant 2005 international US dollar from the Penn World Tables (Heston et al. 2011) and once again (logged) population size from the WDI. Moreover, we follow Raschky and Schwindt (2012) and use population density as a further control for the socioeconomic environment. Different predictions prevail with regards to the effect of greater population density (see Fink and Redaelli 2011). On the one hand, densely populated areas may be in larger need of assistance as a greater density complicates evacuation of survivors, while fostering the spread of infectious diseases. On the other hand, areas with high population density may possess better networks that facilitate rescue efforts after a disaster.

Moreover, we include a measure of control of corruption from the Governance Matters database (Kaufmann et al. 2009). ${ }^{36}$ There are several reasons to believe that the probability to receive aid depends on a country's institutional characteristics. First, (democratic) donors may reward recipient merit (see Öhler et al. 2012). If this is the case, countries with a low level of corruption should be more likely to receive support after a catastrophe. Second, donor decisions may take account of a lower institutional capacity and thus provide more emergency aid to counteract the

\footnotetext{
35 The income classification is based on $2010 \mathrm{GNI}$ per capita data and available at http://data.worldbank.org/about/country-classifications (last accessed: July 2012).

${ }^{36}$ The control of corruption index "[r]eflects perceptions of the extent to which public power is exercised for private gain, including both petty and grand forms of corruption, as well as "capture" of the state by elites and private interests" (Kaufmann et al. 2009).
} 
recipient's reduced self-aid capacity. More specifically, donors may anticipate that a certain share of their humanitarian aid is embezzled in countries with high levels of corruption and thus donate larger amounts to ensure that a certain amount of aid reaches the needy.

Next, we add a dummy variable indicating whether a disaster-affected country is categorized as democracy (Cheibub et al. 2010). On the hand, democratic donors may be more likely to provide aid to democracies to support the country's institutions. On the other hand, donors could also favor autocracies if they believe that countries with such a regime are less capable to handle disasters (see Sen 1990). Moreover, aid effectiveness could differ in democracies and autocracies. In line with this, Plümper and Neumayer (2009) find in the context of famines that autocracies need much more aid to reduce mortality. Finally, donors guided by commercial interests could provide more support to autocracies to buffer trade reductions. According to empirical results in Gassebner et al. (2010), trade with autocracies suffers more from disasters than commercial relationships of democracies.

To control for commercial interests of donors, we furthermore control for a recipient country's natural resource endowment, which is proxied by the (logged) product of unit resource rents and physical quantities of minerals and energy extracted, which is obtained from the WDI. To capture donor's political interests, we add a dummy variable that takes a value of one if a recipient is a temporary member of the UNSC. In line with Dreher et al. (2009a, 2009b), we expect donors to engage in vote-trading activities and thus to increase aid to UNSC members. Note, however, that a positive coefficient could be simply driven by the fact that disaster-struck UNSC members can communicate their humanitarian needs after a disaster to a greater audience of potential donors and thus mobilize more disaster aid (see also Dreher et al. 2009a, 2009b).

Our fourth set of variables accounts for bilateral relations between donor and recipient. Geographic distance between donor and recipient (in logs) is used as a proxy for transportation costs of aid provided in kind as well as for cultural similarities between countries. ${ }^{37}$ In addition, the contiguity dummy controls for additional support offered to neighboring countries. As past research has shown that having a common

\footnotetext{
${ }^{37}$ The distance variable employed is the distance between major cities of the two countries, weighted by their population size, as defined in Mayer and Zignago (2006).
} 
colonial history increases the likelihood to receive emergency aid (e.g., Strömberg 2007), we include a dummy variable which takes a value of one if donor and recipient ever had a common colonizer or have been in a colonial relationship before. These variables have been extracted from the CEPII database (Mayer and Zignago 2006).

By including a dummy variable that takes a value of one if donor and recipient country share the same major religion, we control for the fact that some donors might feel more affinity to countries with similar religious orientation (see for example Neumayer 2003a, 2004 on the role of Islamic solidarity) ${ }^{38}$ The propensity of a donor to assist a disaster-struck country might further be influenced by migratory flows between the two countries. On the one hand, donors might be more inclined to assist those countries that host their expatriates. On the other hand, migrants originating from a disaster-affected country could raise the awareness of a disaster in the donor country, thus triggering the donor government to assist the migrants' country of origin. ${ }^{39}$ To test these predictions, we include the (logged) stock of migrants from the donor country in the recipient country and vice versa. The data are retrieved from the Global Migrant Origin Database (Parsons et al. 2007).

Out of self-interest, donors might be more inclined to assist countries with which they maintain close political ties. ${ }^{40}$ As a proxy for bilateral affinity, we include the voting alignment of recipient and donor country in the UNGA (Voeten and Merdzanovic 2009), which is a widely used indicator in the empirical aid literature (e.g., Thacker 1999; Neumayer 2005; Kilby 2009, 2011). The indicator is the share of total votes in which donor and recipient showed the same voting behavior. ${ }^{41}$ Regarding the measurement of potential economic interest of a donor, we use the (logged) exports of the donor country to the recipient economy as a share of total

\footnotetext{
${ }^{38}$ With respect to India, Meier and Murphy (2011) points out that solidarity with individuals in need are core values within religions such as Hinduism, Buddhism and Islam. Information on countries' major religions is obtained from the World Christian Database (available at http://www.worldchristiandatabase.org/wcd/, accessed: November 2009).

${ }^{39}$ With respect to the 2010 Haiti earthquake, for example, some policymakers consider the Haitian diaspora to play a vital role and to help coordinating the work of foreign non-governmental organizations (available at http://www.trust.org/alertnet/news/qa-haitian-diaspora-on-haitisreconstruction-and-foreign-aid-agencies/, accessed: July 2012).

${ }^{40}$ For example with respect to India, Meier and Murphy (2011) expect humanitarian aid to reflect the quality and importance of bilateral relations as India strives for an improvement of the relationship with the affected country.

${ }^{41}$ Two countries are considered to be voting in line with each other if they jointly vote yes or no, if both abstain, or if both are absent.
} 
donor exports. The data are retrieved from the United Nations COMTRADE database. $^{42}$

We follow Fink and Redaelli (2011) and use one-year lags of all time-varying recipient-specific and bilateral variables (except UNSC membership) to mitigate concerns regarding potential feedback effects from aid to the explanatory variables. Appendix C summarizes all variables and their definitions and sources. Appendix D provides descriptive statistics.

\section{I.4.3 Main Results}

We start with an analysis of the determinants that influence the decision to allocate aid to disaster-affected countries for our full sample. This setup allows us to evaluate the decision of 94 donors to commit aid to 394 emergency-recipient pairs in our dataset. Relying on Logit regressions, we estimate four model specifications to which we add alternating sets of dummy variables to observe whether our results hinge on the control of unobserved factors. ${ }^{43}$ While Table 1.2 presents our coefficient estimates, Appendix A.5 adds information on the corresponding average marginal effects. Column 1 of each table shows results based on the inclusion of disaster-type and year dummies. A dummy variable for each emergency-recipient pair is included in the specification shown in column 2. Columns 3 and 4 replicate the specifications in columns 1 and 2 with donor dummies added.

As discussed above, we expect the selection decision of donors to be driven by disaster severity, donor and recipient characteristics as well as bilateral relations between donor and recipient. Our results are largely in line with the previous literature (Fink and Redaelli 2011; Raschky and Schwindt 2012). Regarding humanitarian need as captured by disaster severity, our results reveal a marked need-orientation of donors. In column 1, the coefficients on the number of total individuals affected and people killed are both positive and statistically significant at

\footnotetext{
${ }^{42}$ As the reporting of trade flows is fragmentary for some countries, we use mirror data to fill missing entries. This implies that export information from a donor is completed with import values as reported by the recipient. We take the mean in those cases, in which a trade flow is reported by both donor and recipient.

${ }^{43}$ Katz (2001) suggests that the bias in unconditional fixed-effects Logit decreases with the number of time periods. Since our "time" dimension reflects 394 emergency episodes, we run unconditional Logit estimations.
} 
the one-percent level. The probability that a country receives aid from a particular donor increases by 0.6 percentage points if the number of people affected doubles. ${ }^{44}$ Analogously, a doubling of the number of mortalities causes this likelihood to increase by 1.9 percentage points. Given that the average donor propensity to contribute after a particular disaster is 8.7 percent, these effects are sizable. This finding is virtually unaffected by the inclusion of donor dummies in column 3 .

Turning to donor characteristics, our results show that DAC members are on average more likely to provide emergency aid. The respective coefficient remains significant at the one-percent level when controlling for either the type of disaster (column 1) or the actual emergency-recipient pair (column 2). The propensity to provide relief is on average 3.8 percentage points higher for DAC members than for non-members. Since DAC membership is captured by the donor dummies, this variable is omitted from columns 3 and 4 . The coefficients on donor GDP per capita and population size are both positive and significant at the one-percent level in the specifications without donor dummies, implying that richer and larger countries are more likely to help. In contrast, conditional on all other factors, donor regime type has no statistically significant influence on the likelihood to provide disaster relief, at conventional levels of significance. Note, however, that these results should not be overemphasized as they might simply reflect the more complete reporting of these donor groups.

With respect to recipient characteristics, the coefficients on GDP per capita, population size and density are all negative and statistically significant at conventional levels. In line with our expectations, recipients' self-aid capacity thus seems to influence the likelihood that a donor provides emergency aid. In a similar manner, the coefficient on control of corruption has a significantly negative impact on the probability to receive aid. Rather than rewarding countries with a low level of corruption, donors support countries with higher levels of corruption, which should conceivably suffer from a reduced self-aid capacity.

${ }^{44}=0.008 \cdot \log (2)$ 
Table I.2: Determinants of aid selection (Logit, 2000-09)

\begin{tabular}{|c|c|c|c|c|}
\hline & $(1)$ & (2) & (3) & (4) \\
\hline \multicolumn{5}{|l|}{ Disaster severity } \\
\hline $\begin{array}{l}\text { (log) Total affected } \\
\text { (log) Killed }\end{array}$ & $\begin{array}{l}0.149^{* * \star} \\
(0.000) \\
0.499^{* * \star} \\
(0.000)\end{array}$ & & $\begin{array}{l}0.158^{\star * \star} \\
(0.000) \\
0.537^{\star * \star} \\
(0.000)\end{array}$ & \\
\hline \multicolumn{5}{|l|}{ Donor characteristics } \\
\hline $\mathrm{DAC}$ & $\begin{array}{l}0.720^{\star \star \star} \\
(0.003)\end{array}$ & $\begin{array}{l}0.862^{\star \star \star} \\
(0.005)\end{array}$ & & \\
\hline (log) GDP per capita & $\begin{array}{l}1.425^{* * *} \\
(0.000)\end{array}$ & $\begin{array}{l}1.654^{* * *} \\
(0.000)\end{array}$ & $\begin{array}{r}1.175 \\
(0.201)\end{array}$ & $\begin{array}{r}1.439 \\
(0.199)\end{array}$ \\
\hline $\begin{array}{l}\text { Democracy } \\
\text { (log) Population }\end{array}$ & $\begin{array}{l}0.352 \\
(0.138) \\
0.403^{\star \star \star} \\
(0.000)\end{array}$ & $\begin{array}{l}0.245 \\
(0.357) \\
0.415^{\star * *} \\
(0.000) \\
\end{array}$ & $\begin{array}{r}0.114 \\
(0.869) \\
1.868 \\
(0.163) \\
\end{array}$ & $\begin{array}{r}0.546 \\
(0.429) \\
2.226 \\
(0.173) \\
\end{array}$ \\
\hline \multicolumn{5}{|l|}{ Recipient characteristics } \\
\hline (log) GDP per capita & $\begin{array}{l}-0.263^{\star * *} \\
(0.000)\end{array}$ & & $\begin{array}{l}-0.283^{\star * *} \\
(0.000)\end{array}$ & \\
\hline (log) Population & $\begin{array}{l}-0.518^{* * *} \\
(0.000)\end{array}$ & & $\begin{array}{l}-0.539^{* * *} \\
(0.000)\end{array}$ & \\
\hline Population density & $\begin{array}{l}-0.046^{* *} \\
(0.012)\end{array}$ & & $\begin{array}{l}-0.050^{\star * *} \\
(0.008)\end{array}$ & \\
\hline Democracy & $\begin{array}{r}0.013 \\
(0.851)\end{array}$ & & $\begin{array}{l}-0.013 \\
(0.846)\end{array}$ & \\
\hline Control of corruption & $\begin{array}{l}-0.250^{* * *} \\
(0.000)\end{array}$ & & $\begin{array}{l}-0.294^{* \star *} \\
(0.000)\end{array}$ & \\
\hline $\begin{array}{l}\text { UNSC member } \\
\text { (log) Minerals and energy depletion }\end{array}$ & $\begin{array}{l}0.275^{\star \star \star} \\
(0.002) \\
0.009^{\star \star \star} \\
(0.000)\end{array}$ & & $\begin{array}{l}0.278^{\star * \star} \\
(0.003) \\
0.008^{\star * \star} \\
(0.003)\end{array}$ & \\
\hline \multicolumn{5}{|l|}{ Bilateral variables } \\
\hline (log) Distance & $\begin{array}{l}-0.658^{\star * \star} \\
(0.000)\end{array}$ & $\begin{array}{l}-0.550^{\star \star \star} \\
(0.000)\end{array}$ & $\begin{array}{l}-0.718^{\star \star \star} \\
(0.000)\end{array}$ & $\begin{array}{l}-0.562^{\star * \star} \\
(0.000)\end{array}$ \\
\hline Neighbor & $\begin{array}{l}0.621^{* * *} \\
(0.004)\end{array}$ & $\begin{array}{l}0.757^{* * *} \\
(0.006)\end{array}$ & $\begin{array}{l}0.478^{\star *} \\
(0.039)\end{array}$ & $\begin{array}{l}0.564^{* *} \\
(0.045)\end{array}$ \\
\hline Common colonial history & $\begin{array}{r}0.215 \\
(0.120)\end{array}$ & $\begin{array}{r}0.106 \\
(0.568)\end{array}$ & $\begin{array}{l}0.388^{* * *} \\
(0.006)\end{array}$ & $\begin{array}{l}0.296^{*} \\
(0.099)\end{array}$ \\
\hline Common official language & $\begin{array}{r}0.045 \\
(0.732)\end{array}$ & $\begin{array}{r}0.256 \\
(0.119)\end{array}$ & $\begin{array}{l}0.282^{* \star} \\
(0.013)\end{array}$ & $\begin{array}{l}0.579^{* * *} \\
(0.000)\end{array}$ \\
\hline Common major religion & $\begin{array}{l}0.543^{* * *} \\
(0.000)\end{array}$ & $\begin{array}{c}0.301 \\
(0.145)\end{array}$ & $\begin{array}{l}0.548^{* * *} \\
(0.000)\end{array}$ & $\begin{array}{r}0.250 \\
(0.171)\end{array}$ \\
\hline (log) Migration in & $\begin{array}{l}0.059^{* *} \\
(0.039)\end{array}$ & $\begin{array}{l}0.081^{* *} \\
(0.026)\end{array}$ & $\begin{array}{l}0.045^{\star *} \\
(0.029)\end{array}$ & $\begin{array}{l}0.072^{* * *} \\
(0.010)\end{array}$ \\
\hline (log) Migration out & $\begin{array}{r}0.016 \\
(0.454)\end{array}$ & $\begin{array}{r}0.062 \\
(0.145)\end{array}$ & $\begin{array}{r}0.029^{*} \\
(0.095)\end{array}$ & $\begin{array}{l}0.115^{* * *} \\
(0.000)\end{array}$ \\
\hline UNGA voting & $\begin{array}{l}-0.969^{*} \\
(0.068)\end{array}$ & $\begin{array}{l}-1.556^{\star *} \\
(0.019)\end{array}$ & $\begin{array}{r}0.667 \\
(0.364)\end{array}$ & $\begin{array}{l}-0.527 \\
(0.434)\end{array}$ \\
\hline (log) Exports & $\begin{array}{l}0.099^{\star * \star} \\
(0.005)\end{array}$ & $\begin{array}{l}0.159^{* * *} \\
(0.001)\end{array}$ & $\begin{array}{l}0.109^{\star * *} \\
(0.000)\end{array}$ & $\begin{array}{l}0.197^{* * *} \\
(0.000)\end{array}$ \\
\hline $\begin{array}{l}\text { Disaster-type dummies } \\
\text { Donor dummies } \\
\text { Emergency-recipient dummies } \\
\text { Year dummies }\end{array}$ & Yes & Yes & $\begin{array}{l}\text { Yes } \\
\text { Yes } \\
\text { Yes } \\
\end{array}$ & $\begin{array}{l}\text { Yes } \\
\text { Yes }\end{array}$ \\
\hline $\begin{array}{l}\text { Number of observations } \\
\text { Number of donor countries }\end{array}$ & $\begin{array}{c}29412 \\
94\end{array}$ & $\begin{array}{c}30622 \\
94\end{array}$ & $\begin{array}{c}29412 \\
94\end{array}$ & $\begin{array}{c}30622 \\
94\end{array}$ \\
\hline Pseudo R squared & 0.38 & 0.50 & 0.42 & 0.54 \\
\hline
\end{tabular}

Notes:

- All models are Logit models with standard errors clustered at the donor level

- $p$-values in parentheses $\left({ }^{\star \star *} p<0.01,{ }^{* \star} p<0.05,{ }^{*} p<0.1\right)$ 
Next, we turn to recipient characteristics that proxy donor countries' selfinterests. When a disaster-affected country is a member of the UNSC, it increases the likelihood to receive disaster aid by 1.5 percentage points. The coefficient is significant at the one-percent level in both specifications. This finding could indicate that donors exchange votes at the UNSC for the provision of disaster aid. A greater abundance of natural resources in disaster-affected countries furthermore increases the propensity of donors to help after a natural disaster. The coefficient on recipients' mineral and energy extraction is positive and statistically significant at the onepercent level. Taken together, it seems that donors provide aid with their own political and commercial interests in mind; the results suggest that donors favor potential allies in the UNSC as well as recipients rich in natural resources.

Turning to bilateral variables, the coefficients capturing geographic proximity of donor-recipient pairs, i.e., distance and contiguity, are both statistically significant at conventional levels and show that donors favor geographically close countries. When controlling for unobserved donor characteristics, we find that a common colonial history and linguistic ties increase the likelihood that a donor will provide aid (columns 3 and 4). Aid flows are more likely if donor and recipient share the same major religion (columns 1 and 3), but the respective coefficient does not reach statistical significance at conventional levels when we control for emergency-recipient dummies (columns 2 and 4). Results also indicate that a greater stock of migrants originating from a disaster-affected country makes it more likely that the host country provides help after a disaster. The corresponding coefficient on outward migration is statistically significant at conventional levels in all four specifications. Once we control for donor dummies, we also find that donors are more likely to provide aid to countries which are home to their expatriates (columns 3 and 4).

The extent to which donor and recipient countries vote in line at the UNGA is a proxy for bilateral affinity. According to columns 1 and 2, donors are more likely to help countries less aligned to their agenda at the UNGA. While this appears counterintuitive at first, it seems that donors use humanitarian aid as a measure to improve relations with countries with diverging interests, in line with Fink and Redaelli (2011). Note, however, that this does not hold if we control for unobserved donor characteristics (columns 3 and 4). Finally, the coefficient on exports is positive and statistically significant at the one-percent level in all specifications. The average 
marginal effect of a doubling of the export volume is 0.35 percentage points. On the one hand, this could be an indicator that donors attach importance to the stability of their export destinations and export flows. On the other hand, more intense trade relations could increase the mutual awareness between countries and thus the likelihood of providing humanitarian aid to trading partners. Furthermore, close commercial ties to a disaster-affected country facilitate the provision of aid as donors can use existing logistical networks with the recipient country to disburse humanitarian aid.

In summary, our results indicate that the donors' decision to provide disaster relief is driven by humanitarian need, recipients' self-aid capacity and donor selfinterests. Moreover, donors are more inclined to help countries which are geographically or culturally proximate. The results do not only confirm previous findings for an extended time period (2000-09), but confirm the role of factors that have not been tested in the previous literature on emergency aid (e.g., UNSC membership, migratory flows). Since these results only provide evidence for the average donor, it remains unclear whether aid motives of "new" and "old" donors differ. This is what we turn to next.

\section{I.4.4 Testing for Differences between "New" and "Old" Donors}

In Table I.3, we investigate whether the determinants of aid selection differ across donor groups. This requires us to apply our estimation strategy to subsamples of our main dataset. Specifically, we run seemingly unrelated regressions (SUR) and reestimate column 3 of Table 1.2 for each subsample. By weighting the estimates by the covariance of the residuals from the individual subsample regressions, SUR deliver asymptotically more efficient estimates than those obtained in separate estimations (Zellner 1962). We are then able to test for statistically significant differences in the coefficients across subsamples with a Wald test (in italics). Accordingly, we divide our sample according to the donor groups introduced above. Column 1 splits our sample into DAC and non-DAC donor countries. The two subsequent models are based on a division of our sample into "rich" and "poor" donors (column 2) as well as democratic and autocratic donors (column 3). 
Furthermore, we subdivide the group of non-DAC donors into "rich" and "poor" (column 4 ) as well as democratic and non-democratic donors (column 5). ${ }^{45}$

Turning to our results and starting with the two measures of disaster severity, we find aid decisions of all donor groups to be driven by humanitarian need. According to the p-values of the Wald test reported in italics, no statistically significant difference emerges between most donor groups. We only find that nonDAC donors have a higher propensity to align their aid efforts to the number of casualties, the difference being significant at the five-percent level. Recipient characteristics show greater differences in their impact on aid decisions of donor groups. Comparing DAC and non-DAC donors as well as rich and poor donors in columns 1 and 2, statistically significant differences appear in the donor reactions towards recipients' self-aid capacity. While DAC donors as well as "rich" donors account for the income level of disaster-struck countries, this factor is unaccounted for in the considerations of non-DAC and "poor" donors. The Wald test confirms the observed differences in the coefficients to be statistically significant at conventional levels. Interestingly, population size, another measure of recipient self-aid capacity, has a significant influence on the aid allocation decision of all donors, but the coefficient size shows significant differences across donor groups. According to columns 1-3, non-DAC, "poor" and autocratic donors have a significantly lower likelihood to commit aid to more populous recipient countries, at conventional levels of significance.

With regard to democracy, most donor groups provide relief independently from the recipients' regime type. Autocratic donors, however, seem to disfavor democratic recipients (columns $3 b$ and $5 b$ ). When taking into account the level of corruption in the recipient country, all donor groups except the autocratic donors provide less aid to recipients with stronger control of corruption. As argued above, control of corruption can be interpreted as an indicator for self-help capacity. Although autocracies deviate from this general pattern with an insignificant coefficient, we cannot reject the hypothesis that the coefficient is equal to the one for democracies. Democratic non-DAC donors show the strongest bias towards countries with high levels of corruption. With regard to UNSC membership, no

${ }^{45}$ Since we split our sample by donor characteristics, we drop the donor variables from the regressions. 
Table I.3: Determinants of aid selection by donor group (Logit, SUR, 2000-09)

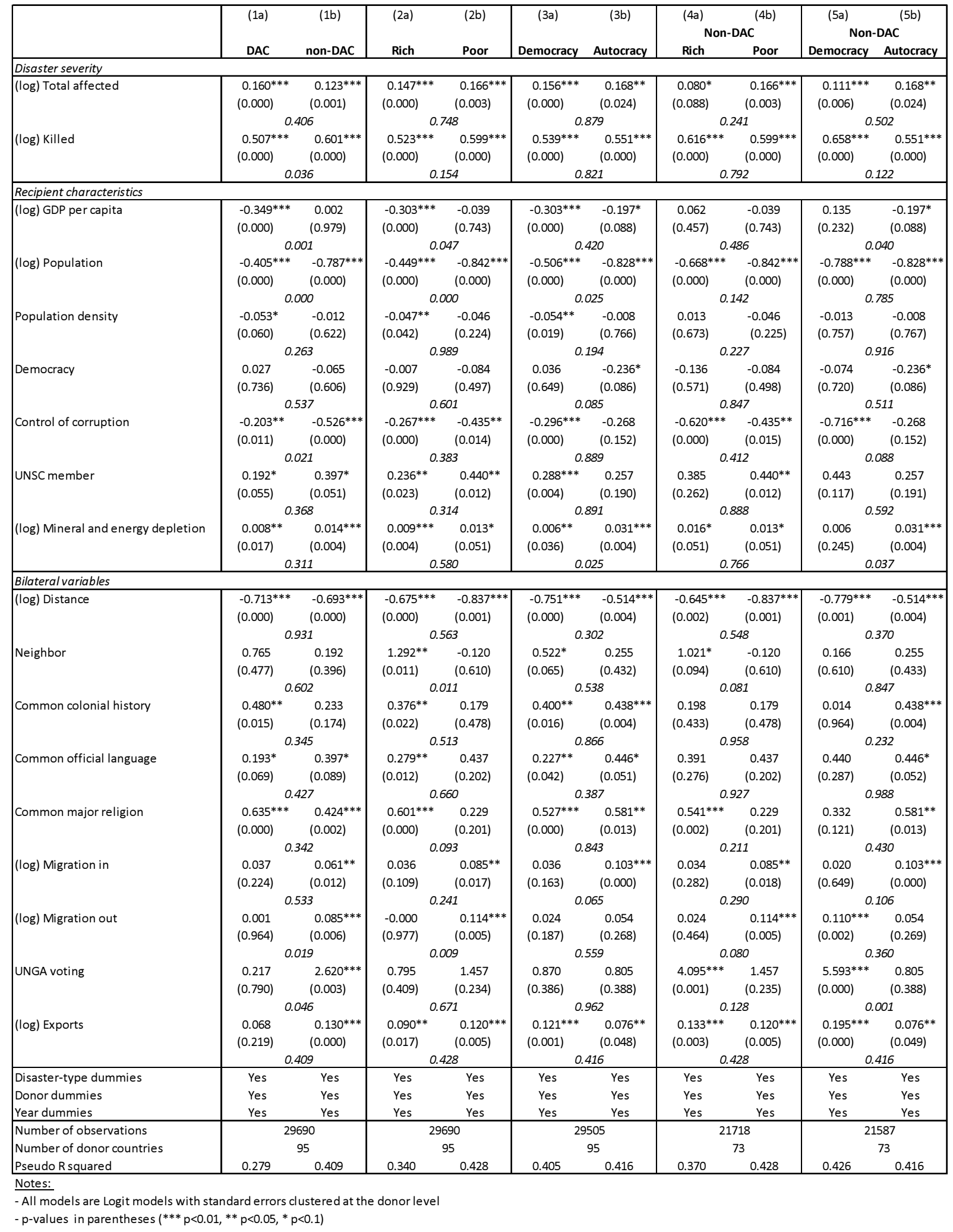


statistically significant differences emerge between donor groups. While resourceabundant recipients are favored by DAC and non-DAC as well as "rich" and "poor" donors, no statistically significant differences emerge between these groups according to the Wald test. Splitting our sample between democracies and autocracies (columns 3 and 5), however, reveals that recipients' extraction of natural resources has a larger influence on donor decisions taken by autocracies. Turning to our bilateral measures, a larger geographic distance between donor and recipient significantly reduces the likelihood of aid provision for each donor group under investigation, at the one-percent level of significance. In contrast to our expectations and previous findings for general development aid, distance is neither more important for non-DAC donors (Dreher et al. 2011) nor poorer donors (Fuchs and Vadlamannati 2012). The Wald test in italics shows no statistically significant differences between donor groups. While contiguity encourages "rich" and democratic donors to provide disaster aid, "poor" and autocratic donors do not seem to favor neighbors. Cultural ties, as proxied by common colonial history, common language and common major religion, provide incentives to commit disaster aid for "rich" donors but not for "poor" donors. With regard to any systematic differences between the estimated coefficients, results from the Wald test show little support for systematic differences across the donor groups. Inward and outward migration has a statistically significant impact on non-DAC donors and "poor" donors, at conventional levels of significance. Contrasting non-DAC donors by regime type shows that inward migration has a statistically significant effect on aid from autocracies, while the democratic donors' decision to provide aid is influenced by outward migration.

With respect to political and economic self-interests of donor countries, nonDAC countries (column $1 b$ ), and within this group the rich and democratic donors (colums $4 \mathrm{a}$ and $5 \mathrm{a}$ ), favor politically-aligned recipients. The coefficient on the UNGA voting alignment between donor and recipient is statistically significant at the onepercent level in these three donor groups. Lastly, with the exception of the DAC donors, all donor groups have a statistically significant greater probability to provide emergency aid to more important trading partners, at conventional levels. Note, however, that there is no indication of statistically significant differences between DAC and non-DAC donors with respect to the role of exports. 
In conclusion, some interesting differences emerge from our analysis of differences in aid motives between donor groups. While DAC and non-DAC donors both seem to attach importance to humanitarian need, aid flows from non-DAC donors is guided to a larger extent by deadly disasters. Whereas non-DAC donors attach more importance to the support of small countries, they do not favor poorer countries as DAC donors do. This is evidence that "old" donors are more needoriented than "new" donors. Finally, non-DAC donors attach a greater importance to political allies, as proxied by their UNGA voting alignment with disaster-affected countries, and autocracies show stronger commercial motives with respect to increased help provided to autocratic recipients and countries rich in natural resources.

\section{I.5. Empirical Analysis of Aid Promptness}

\section{I.5.1 Overview}

We now turn our attention to the determinants of the amount of time that passes between the occurrence of a natural disaster and a donor's decision to commit aid. Analyzing the determinants of this duration in days introduces a novel way of assessing donor behavior in terms of the promptness with which they react to the needs of a recipient in distress. Therefore, we construct a unique measure of the speed of aid responses by combining the information on the date of the onset of a natural disaster, obtained from EM-DAT (2012), with the decision date reported in the FTS aid database. Note that the day on which a disaster started is taken to be Day $1{ }^{46}$ The decision date is defined as the "[d]ate on which the donor is reported to have made the funding commitment for that item." ${ }^{, 47}$ From the resulting measure, we exclude observations with a decision time greater than or equal to 180 days as aid delivered with such a delay hardly aims at urgent needs that require speedy

\footnotetext{
${ }^{46}$ To account for the time difference between donor and recipient as well as for a certain imprecision of the exact day of onset for certain disaster types, we consider all aid decisions taken on the day before the reported disaster-start day as taken on Day 1. In the case of storms, all aid decisions taken in the week before the onset are taken to be taken on Day 1 to account for donors' efforts for disaster preparedness.

See data provided on the website of the Financial Tracking System (FTS) available at http://fts.unocha.org/pageloader.aspx?page=showpage\&PagelD=62-Definitions (accessed June 28, 2012). Ideally, one would use information on the exact day when an aid package reaches the disaster area or when funds are transferred rather than the decision day. Unfortunately, this information is not available. However, committing aid is an important precondition for timely help.
} 
assistance. ${ }^{48}$ Appendix A provides information on the average decision time for all donor countries.

Figure 1.2 plots the average number of days after which a particular donor commits herself to provide emergency relief to a disaster-affected country as a function of disaster type and donor type. Starting with all disasters, we find that the average decision time is one day shorter for DAC donors (Day 27) than for non-DAC donors (Day 28). Surprisingly, low- and middle-income countries (Day 22) react on average six days earlier to emergencies than high-income countries (Day 28). While democracies respond on average on Day 27 to a catastrophe, autocracies have a slightly longer response time (Day 28). We obtain a more nuanced picture when we split the sample by disaster type. DAC members respond on average more quickly to six of eight disaster types under investigation. Non-DAC donors show a shorter reaction time only with respect to extreme temperature and wild fires. Poorer donors react faster than richer donors to five disaster types. ${ }^{49}$ Taken together, no clear pattern emerges whether "new" or "old" donors provide faster relief. Next, we apply econometric techniques that allow us to control for confounding factors.

\section{I.5.2 Empirical Strategy}

We estimate the following equation:

(2) $\operatorname{speed}_{i j k}=\alpha+\beta x_{i j k}+\varepsilon_{i j k}$,

where speed is the (logged) number of days after a natural disaster by which a donor commits herself to provide emergency aid, $x$ is a set of explanatory variables, and $\varepsilon$ is a white noise term. By definition, our estimation sample only includes information on the decision time if the respective donor has committed aid after a specific disaster.

\footnotetext{
${ }^{48}$ The selection of 180 days as cut-off level is in line with the UN's definition of a Flash Appeal, which structures a coordinated humanitarian response for up to six months after the start of an emergency (see http://unocha.org/cap/about-the-cap/faqs, accessed: July 2012).

${ }^{49}$ Note that our dataset does not contain any case in which a low- and middle-income country provided emergency aid to help victims suffering from extreme temperature. High-income countries react on average on Day 44 to this disaster type.
} 
Therefore, we face the problem of incidental truncation of our data. If omitted variables affect both the selection of donors to provide relief (gate-keeping decision) as well as the timing, the use of standard linear regression techniques leads to biased estimates. For example, the (unobservable) intrinsic motivation of a country's government to provide humanitarian aid should determine donor behavior with respect to aid selection and aid promptness.

\section{Figure I.2: Aid promptness by disaster type and donor group (2000-09)}
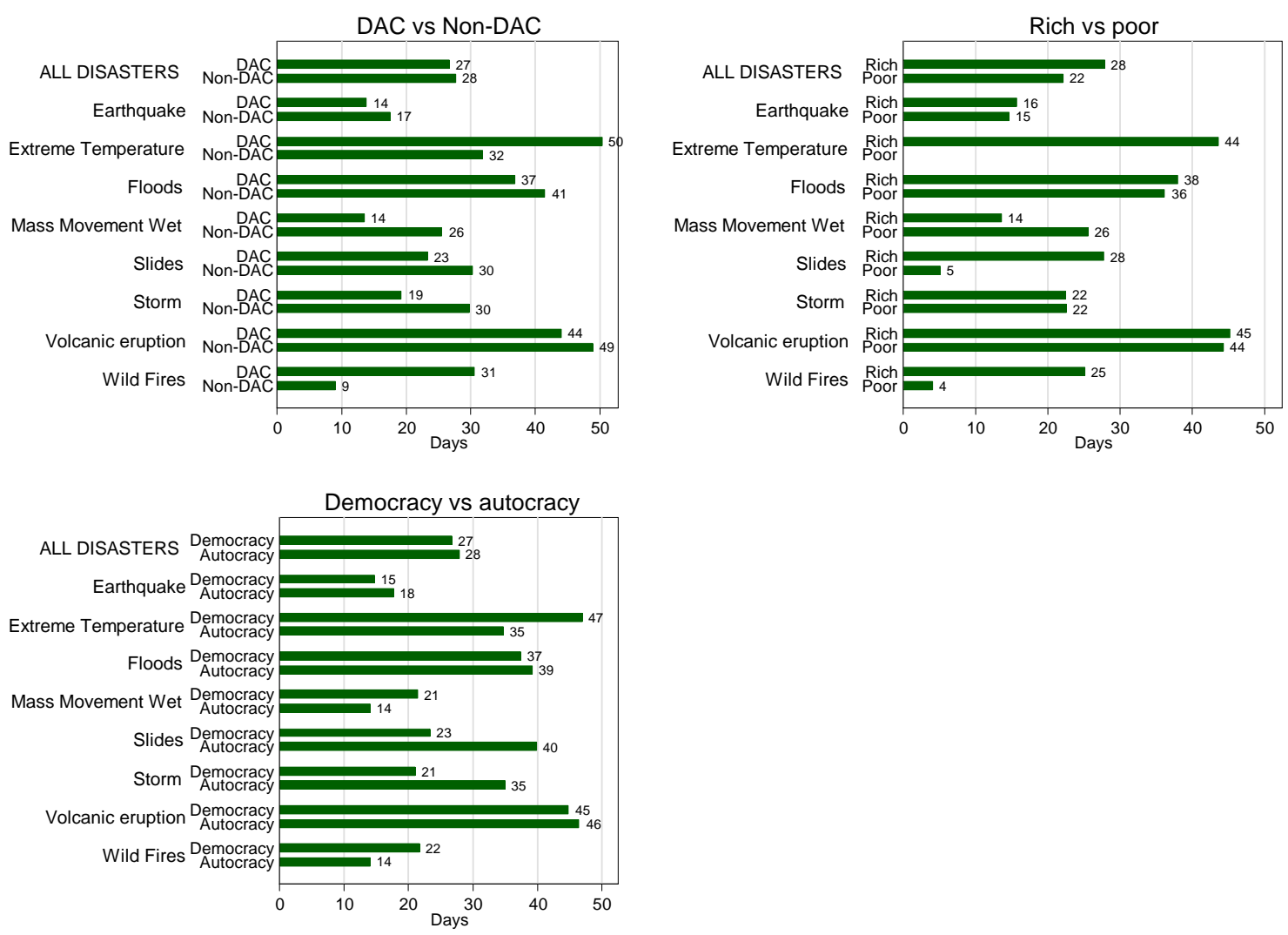

Therefore, we follow the approach presented in Heckman (1979) and convert our estimation to a two-step procedure. More precisely, we employ a Probit estimation to estimate the decision to provide aid in a first step (see equation 1). In a second step, we include the inverse Mills ratio in an OLS estimation of aid promptness (see equation 2). It is preferable to add an exclusion variable to the firststep regression, i.e., an explanatory variable that impacts on the likelihood to provide emergency relief after a certain disaster episode but not on the timeliness of the decision to provide aid. Since we lack a suitable exclusion variable, we instead make 
use of the non-linearity inherent in the underlying Probit estimation of the first step and estimate our Heckman model without an exclusion variable. ${ }^{50}$

We use the same explanatory variables as for aid selection (see again Section I.4.2). In most cases, we expect to find the opposite sign in the aid promptness regression compared to aid selection. More precisely, we expect donors to react faster with increasing disaster severity. With respect to donor characteristics, we include the DAC dummy, our income measure and the democracy dummy to test the hypotheses raised in Section I.3. Donor population size proxies donor countries' aid capacities and we thus expect to find a negative effect on the decision time. Moreover, we anticipate a donor to respond quicker if she has stronger political and commercial interests in the disaster-struck country, as measured by the United Nations variables, export shares and recipients' extraction of natural resources. Conversely, we expect that recipients with a larger self-aid capacity, proxied by GDP per capita, population, population density and control of corruption, receive aid at a later point in time. The stronger the links between donor and recipient, as measured by distance, colonial links, common language, common major religion and migratory flows, the earlier the disaster-affected country should receive the aid commitment.

All time-varying covariates, with the exception of UNSC membership, are again lagged by one year (see Appendix C for full details). Standard errors are clustered by donor countries to control for group-wise heterogeneity.

\section{I.5.3 Results}

Table I.4 provides the results of the second-stage estimation of aid promptness. ${ }^{51}$ As for aid selection in Section 1.4, we estimate four model specifications. While we include only year and disaster-type dummies in column 1, column 2 presents results

\footnotetext{
${ }^{50}$ See Bushway et al. (2007) for a comprehensive discussion of the usage of a Heckman estimation without exclusion variable and its caveats. Note that we included a donor country's debt ratio, fiscal deficit and GDP growth rate as potential exclusion variables. It can be argued that donors are less likely to provide emergency relief in times of tight budgets and economic recession. Given that a donor makes aid funds available, there seems is no reason to believe that these factors impact on the speed of aid. However, none of these variable showed a robust significant effect on aid selection.

${ }^{51}$ Results for the first stage deviate from the results described in Section 4, but the general picture stays the same. This is because we lose observations due to missing information on the decision time for some emergency-recipient-donor pairs. Most notably, the negative coefficient on democracy and the positive coefficient on UNGA voting become statistically significant at conventional levels in column 3. The detailed regression table is available upon request.
} 
of a regression with one dummy variable for each emergency-recipient pair. In column 3 and 4, we add donor dummies to column 1 and 2, respectively. We find that the number of people killed after a disaster has a significantly negative impact on the decision time, at the one-percent level of significance. If the number of mortalities increases by one percent, the decision time is roughly 0.2 percent lower. The total number of people affected, however, does not show a significant impact on aid promptness. A potential explanation could be the role of television news as disasters that involve a high number of casualties are more likely to be covered in the news (Eisensee and Strömberg 2007).

The results on the variables capturing donor characteristics will allow us to draw conclusions with respect to the hypotheses outlined in Section I.3. While nonDAC donors pride themselves with speedy assistance, we do not find empirical support for this claim. Analyzing differences between donor groups, we find that DAC donors and richer donors, as measured by donor GDP per capita, show a shorter reaction time, at conventional levels of significance. All else being equal, the decision time of DAC members is 33.5 percent shorter than the reaction time of non-DAC donors (column 1). This finding is empirical support of hypothesis 2 . Moreover, a tenpercent increase in donor GDP per capita reduces the duration by about three percent, which again supports hypothesis 2 . With regard to regime type, the coefficient on donor democracy is negative in all four specifications, but gains statistical significance at conventional levels only in column 2 (p-value: 0.092). According to this specification, which controls for emergency-recipient characteristics, a democracy's response time is 16.8 percent shorter than that of an autocracy. This is further evidence in favor of hypothesis 2 and against the alternative hypothesis that autocracies take speedier decisions. 
Table I.4: Determinants of aid promptness (Heckman, 2000-09)

\begin{tabular}{|c|c|c|c|c|}
\hline & (1) & (2) & (3) & (4) \\
\hline \multicolumn{5}{|l|}{ Disaster severity } \\
\hline (log) Total affected & $\begin{array}{r}0.012 \\
(0.234)\end{array}$ & & $\begin{array}{r}0.006 \\
(0.564)\end{array}$ & \\
\hline$(\log )$ Killed & $\begin{array}{l}-0.182^{\star \star \star} \\
(0.000)\end{array}$ & & $\begin{array}{l}-0.202^{* * *} \\
(0.000)\end{array}$ & \\
\hline \multicolumn{5}{|l|}{ Donor characteristics } \\
\hline DAC & $\begin{array}{l}-0.409^{\star * \star} \\
(0.006)\end{array}$ & $\begin{array}{l}-0.410^{\star \star \star} \\
(0.002)\end{array}$ & & \\
\hline \multirow[t]{2}{*}{ (log) GDP per capita } & $-0.313^{* * *}$ & $-0.302^{\star \star \star}$ & $-1.849^{* * *}$ & $-1.310^{*}$ \\
\hline & $(0.000)$ & $(0.001)$ & $(0.008)$ & $(0.074)$ \\
\hline \multirow[t]{2}{*}{ Democracy } & -0.104 & $-0.184^{*}$ & -0.500 & 0.140 \\
\hline & $(0.407)$ & $(0.092)$ & $(0.116)$ & $(0.853)$ \\
\hline \multirow[t]{2}{*}{ (log) Population } & $-0.139^{\star * *}$ & $-0.146^{\star * *}$ & -0.607 & -0.698 \\
\hline & $(0.000)$ & $(0.000)$ & $(0.590)$ & $(0.533)$ \\
\hline \multicolumn{5}{|l|}{ Recipient characteristics } \\
\hline (log) GDP per capita & $\begin{array}{l}-0.206^{\star * *} \\
(0.000)\end{array}$ & & $\begin{array}{l}-0.169^{* \star *} \\
(0.000)\end{array}$ & \\
\hline \multirow[t]{2}{*}{ (log) Population } & $0.206^{\star * *}$ & & $0.267^{\star * *}$ & \\
\hline & $(0.000)$ & & $(0.000)$ & \\
\hline \multirow[t]{2}{*}{ Population density } & -0.005 & & -0.006 & \\
\hline & $(0.624)$ & & $(0.578)$ & \\
\hline \multirow[t]{2}{*}{ Democracy } & $-0.102^{*}$ & & -0.061 & \\
\hline & $(0.088)$ & & $(0.367)$ & \\
\hline \multirow[t]{2}{*}{ Control of corruption } & $0.248^{* * *}$ & & $0.260^{* * *}$ & \\
\hline & $(0.000)$ & & $(0.000)$ & \\
\hline \multirow[t]{2}{*}{ UNSC member } & 0.037 & & 0.035 & \\
\hline & $(0.661)$ & & $(0.679)$ & \\
\hline \multirow[t]{2}{*}{ (log) Minerals and energy depletion } & $-0.005^{* *}$ & & $-0.005^{* *}$ & \\
\hline & $(0.028)$ & & $(0.041)$ & \\
\hline \multicolumn{5}{|l|}{ Bilateral variables } \\
\hline \multirow[t]{2}{*}{ (log) Distance } & $0.202^{\star \star \star}$ & $0.228^{* \star \star}$ & $0.190^{* \star *}$ & $0.195^{\star}$ \\
\hline & $(0.000)$ & $(0.001)$ & $(0.001)$ & $(0.057)$ \\
\hline \multirow[t]{2}{*}{ Neighbor } & -0.126 & -0.151 & 0.033 & -0.001 \\
\hline & $(0.343)$ & $(0.166)$ & $(0.817)$ & $(0.992)$ \\
\hline Common colonial history & -0.048 & -0.022 & -0.049 & -0.073 \\
\hline & $(0.555)$ & $(0.742)$ & $(0.492)$ & $(0.373)$ \\
\hline Common official language & -0.063 & $-0.190^{\star * *}$ & -0.012 & $-0.151^{* *}$ \\
\hline & $(0.450)$ & $(0.002)$ & $(0.880)$ & $(0.019)$ \\
\hline Common major religion & 0.142 & 0.081 & 0.127 & 0.045 \\
\hline & $(0.106)$ & $(0.469)$ & $(0.197)$ & $(0.744)$ \\
\hline (log) Migration in & -0.008 & -0.019 & -0.014 & $-0.030^{*}$ \\
\hline & $(0.658)$ & $(0.244)$ & $(0.481)$ & $(0.091)$ \\
\hline (log) Migration out & $-0.036^{\star * *}$ & -0.014 & $-0.042^{* * *}$ & -0.034 \\
\hline & $(0.002)$ & $(0.437)$ & $(0.000)$ & $(0.115)$ \\
\hline UNGA voting & -0.008 & 0.133 & -0.480 & 0.045 \\
\hline & $(0.968)$ & $(0.436)$ & $(0.104)$ & $(0.896)$ \\
\hline (log) Exports & $-0.063^{* * *}$ & $-0.038^{* *}$ & $-0.101^{* * *}$ & $-0.057^{* *}$ \\
\hline & $(0.002)$ & $(0.044)$ & $(0.000)$ & $(0.023)$ \\
\hline Disaster-type dummies & Yes & & Yes & \\
\hline Donor dummies & & & Yes & Yes \\
\hline Emergency-recipient dummies & & Yes & & Yes \\
\hline Year dummies & Yes & & Yes & \\
\hline athrho & $\begin{array}{l}-0.312^{\star * \star} \\
(0.000)\end{array}$ & $\begin{array}{l}-0.394^{\star \star} \\
(0.020)\end{array}$ & $\begin{array}{l}-0.406^{\star \star \star} \\
(0.001)\end{array}$ & $\begin{array}{c}-0.497 \\
(0.259)\end{array}$ \\
\hline Insigma & -0.007 & $-0.224^{* * *}$ & -0.041 & $-0.258^{\star *}$ \\
\hline & $(0.806)$ & $(0.001)$ & $(0.318)$ & $(0.042)$ \\
\hline Number of observations & 29049 & 30414 & 29049 & 30414 \\
\hline Number of donor countries & 94 & 94 & 94 & 94 \\
\hline Prob > chi2 & 0.000 & 0.020 & 0.001 & 0.259 \\
\hline
\end{tabular}

Notes:

- All models are Heckman models with standard errors clustered at the donor level

- $p$-values in parentheses $\left({ }^{* * *} p<0.01,{ }^{\star *} p<0.05,{ }^{*} p<0.1\right)$

- Results of first-stage regressions available upon request 
It is not surprising that the democracy variable loses statistical significance once we control for donor dummies (columns 3 and 4) since regime type hardly varies for many countries over a short period of time. Finally, we find that larger countries make faster decisions after emergencies, at the one-percent level of significance (columns 1 and 2). This effect also disappears once we include donor characteristics (columns 3 and 4).

Turning to recipient characteristics, we find that poorer countries receive slower disaster relief, at the one-percent level of significance. From a humanitarian point of view, this is undesirable since less affluent countries possess on average a smaller capacity for self-aid, which puts disaster-affected individuals at greater peril and in larger need of fast assistance. However, we find donor decisions to reflect self-aid capacity as smaller recipients are favored through earlier aid commitments, at the one-percent level of significance. A recipient's population density does not turn out to be a statistically significant predictor of aid promptness, at conventional levels of significance. While column 1 suggests that democracies receive faster relief, once we introduce donor dummies, recipient democracy loses its statistical significance at conventional levels (column 3). Countries with a higher level of corruption receive on average more timely disaster assistance, at the one-percent level of significance. Donors seem to adjust their timeliness of aid provision to counteract the inefficiencies caused by corruption in the recipient country. With regard to the timeliness of the aid decision, members of the UNSC do not receive favorable treatment, which is in contrast to our findings on aid selection in Section 4. The coefficient on the UNSC dummy fails to gain statistical significance at conventional levels in column 1 and 3 . Disaster-affected countries that are rich in natural resources, however, receive faster aid. The reaction time of donors decreases with increased levels of mineral and energy extraction, at the five-percent level of significance.

Next, we turn to the bilateral variables. Countries that are geographically closer receive timelier aid commitments than more distant disaster-struck countries, at the one-percent level of significance. There is no additional effect stemming from adjacency of donor and recipient. While the results do not show a statistically significant impact of common colonial history and common major religion on aid promptness, donors react on average faster if they share a common official language with a country suffering from a catastrophe. The coefficient is statistically significant 
at conventional levels in columns 2 and 4 . Reduced communication costs may explain this finding. There is also evidence that migrant networks speed up the aid process. While the coefficients on donor countries' inward and outward migration show the expected negative sign in all four specifications, the coefficient on inward migration in column 4 and the coefficients on outward migration in column 1 and 3 gain statistical significance at conventional levels.

Political affinity of donor and recipient, as proxied by their voting alignment in the UNGA, does not to affect the timeliness of the aid commitment. Note, however, that once we control for donor dummies, the $p$-value of the negative coefficient in column 3 is close to the ten-percent level of significance. Finally, we find robust evidence that countries with strong commercial ties to the donor country receive faster aid commitments following a disaster. The respective coefficients are statistically significant at conventional levels in all four specifications.

In sum, we find that the timeliness of the aid decision depends on similar determinants as does the allocation of aid. The speed with which a country responds to a catastrophe follows a mixture of need-related motives and donor countries' selfinterests. All else being equal, we did not find any support for claims that "new" donors respond faster than "old" donors to natural disasters. Identifying "new" donors by their membership in the DAC, income level and regime type, we found "new" donors to be significantly slower than "old" donor countries.

\section{I.6. Conclusions}

The new world of foreign assistance is most visible in the provision of humanitarian assistance, where virtually every country acts as an aid donor. This proliferation of donors, with increasing aid activities outside the DAC and more aid flows from lowand-middle income countries and authoritarian regimes, is likely to change the international aid architecture. We started by analyzing aid decisions of 105 donor countries and examined differences in allocation behavior between "old" and "new" donors and different types of "new" donors. Next, we analyzed whether "new" donors differ from "old" donors with respect to the timeliness of the decision to provide aid. 
Our empirical results show that both DAC and non-DAC donors attach great importance to humanitarian need, recipients' self-aid capacity and their political and commercial self-interests. This confirms previous findings on general development aid (e.g., Dreher et al. 2011). Within these broad categories of donor motives, some interesting differences emerged between donor groups. Although non-DAC donors put greater emphasis on the support of small countries, they do not favor poorer countries, a behavior which is in contrast with the decisions of DAC donors. This is can be interpreted as evidence that "old" donors are more need-oriented than "new" donors. While self-interests guide aid selection of both "old" and "new" donors alike, non-DAC donors attach greater importance to political allies, as proxied by their UNGA voting alignment, than DAC donors. Autocratic donors put more emphasis on commercial motives than democracies with respect to increased help provided to countries rich in natural resources. This can be seen as evidence that aid allocation of "new" donors is inferior to that of "old" donors from a humanitarian point of view.

To be effective, emergency aid has to be provided in a timely manner. We extended our comparison of "old" and "new" donors to their respective timeliness in providing emergency aid. Our results show that, all else being equal, non-DAC donors, developing countries and autocracies are slower than DAC donors, highincome countries and democracies in their decision to commit to providing emergency aid. This is striking empirical evidence against the claim of many "new" donors that they are faster in their aid responses than the allegedly "bureaucratic" club of DAC donors. We also find that aid promptness - albeit influenced by humanitarian need - suffers, like aid selection, from the strategic motivations of donors.

Finally, it has to be emphasized that our analysis faces some limitations. First, we lack information on the actual delivery date and are confined to an analysis of the timing of aid commitments. Although aid commitments are legally binding, information on the day the aid flow crosses the border would be preferable. Second, donor decisions could be heavily influenced by actual aid requests from disaster-affected countries. The recipient behavior is an important part of the donor decision to provide aid. This is an important topic for future research. Third, although a speedy decisionmaking process is an important prerequisite for (most types of) disaster aid to be effective, a fast response following a disaster is not the sole objective of emergency 
assistance. Disaster preparedness, for example, should be an important part of humanitarian aid activities. To the extent to which a long decision time stems from aid coordination between donors that provide fast relief and those who focus on reconstruction and disaster preparedness, donors should not solely be judged on their aid promptness. Beyond the timeliness of the aid decision, future research should evaluate the effectiveness of disaster aid efforts of "new" and "old" donors in greater detail. Domestic and international evaluations of many "new" donors remain widely non-existent (see Harmer and Martin 2010). Although aid efforts by "new" donors are to be welcomed, based on our results, it seems that the "old" providers of aid will remain the important pillars of the emergency aid architecture for the next years to come. 


\title{
Chapter II
}

\section{Incapacitation or Proliferation? A District-level Assessment of Mexico's War on Drugs}

\begin{abstract}
Mexico has become a key strategic element in the 'War on Drugs' and has taken up the responsibility to provide an important contribution to the overall fight against South-North narcotrafficking on the American continent. With the passing of time, the financial and operational burden incurred by Mexico has grown to considerable dimensions. Mexico's 'War on Drugs' as such constitutes an unprecedented commitment by an emerging economy to contain organized crime. While the success of this initiative is often put into question in terms of containing drug trafficking, the effect of the ongoing campaign on overall public safety has yet to be investigated. Relying on panel data at the Mexican administrative district level covering the 19982008 period, this paper empirically tests whether the 'War on Drugs' affects the prevalence of non-drug related offences (e.g., property crime, assault, rape and murder). Estimation results, consistent across multiple estimation techniques, suggest that the targeting of drug traffickers generally causes a reduction of non-drug crime through the 'incapacitation effect.' This effect is however severely hampered in states with a high concentration of narcotrafficking organizations.
\end{abstract}

Acknowledgements: The author is grateful for helpful comments by Stephan Klasen as well as Nicolás Corona-Juárez, Axel Dreher, Andreas Fuchs, Ingo Geishecker and participants at the "New Directions in Welfare" Conference (OECD, Paris 2011) and the Ph.D. Seminar at the University of Göttingen. Excellent Research assistance was provided by Katharina Richert, Karla Henning, Scott Jobson and Jamie Parsons. 


\section{II.1 Introduction}

Within the last two decades, the United Mexican States have become one of the most heavily besieged frontlines in the War on Drugs. While Mexico has been a mostly undisputed transit route for the South-North smuggling of narcotics in the 1970s and 1980s, the country has to a growing extent taken on the challenge of fighting the activities of several highly organized drug smuggling organizations. At the same time, Mexico has attempted to contain increasing violence and corruption.

Mexico's engagement in the War on Drugs provides a key contribution to the overall goal to reduce drug consumption in the United States. Its importance stems directly from the country's location between the United States - one of the largest market for narcotics - and the Andean region - one of the most important producers of narcotics. As such, the containment of drug trafficking in Mexico has become a necessary - but not sufficient - precondition to fight drug consumption in the United States.

While the efforts of the Mexican government to contain drug traffickers as well as its degree of cooperation with neighboring countries are lauded as "unprecedented" and "courageous" by the United States, the costs Mexico incurs have become sizeable. From a fiscal point of view, the security budget for 2012 has reached 12 billion US dollars or roughly 1.2 percent of annual GDP, which represents an increase of over ten percent from the amount spent the year before. ${ }^{52}$ This amount constitutes more than twice the amount assigned to Mexico's internationally recognized conditional cash transfer program Oportunidades ${ }^{53}$ Moreover, the country bears additional costs as the on-going clashes between security forces and heavily armed (drug) cartels produce high levels of almost daily violence, a severe erosion of

\footnotetext{
${ }^{52}$ The budget estimates are retrieved from the 2012 International Narcotics Control Strategy Report by the US Department of State. (http://www.state.gov/j/inl/rls/nrcrpt/2012/vol1/184100.htm\#Mexico, accessed: July 2012).

53 The program provides poor households with welfare benefits if families fulfill certain obligations such, e.g., ensuring their children to attend school and medical exams on a regular basis. 46.2 percent of all Mexicans are classified as poor. The most recent budgetary information for Oportunidades covers the year 2010. http://www.oportunidades.gob.mx/Portal/work/sites/Web/resources/ArchivoContent/622/Oportunidades un programa de resultados 2010.pdf (accessed: July 2012). Poverty statistics are based on a report by the Consejo Nacional de Evaluación de la Politica de Desarrollo Social (CONEVAL). http://web.coneval.gob.mx/Informes/Interactivo/Medicion pobreza 2010.pdf (accessed July 2012).
} 
administrative integrity through corruption, as well as a deterioration in the quality of life in communities all across the country.

As the fiscal and social costs of Mexico's engagement in the 'War on Drugs' have become sizeable, the reported successes of the initiative are mostly limited to the arrest of prominent cartel leaders while considerable amounts of drugs continue to cross the border to the United States. Given this outcome, the merit of extensively fighting drug crime in Mexico is a matter of intense discussions. Advocates of the campaign frame the increased amount of drug arrests as preliminary victories, while human rights groups point to rampant violations of basic rights in the wake of drug enforcement (e.g., Human Rights Watch 2011).${ }^{54}$ In this regard, Mexico's 'War on Drugs' faces criticisms similar to those directed at the United States' own attempt to fight drug use and trafficking.

In the economic literature, the fight against drugs is often presented not only as means to contain drug trafficking but also as a universal remedy against overall crime and other social ills (Sollars et al. 1994). In the United States, the 'War on Drugs' is thus often associated with the provision of a "silver bullet" against a multitude of related challenging social problems including, for example, overall crime and the degradation of public health. The scrutiny of this assumption has lead to a significant amount of theoretical and empirical research, focusing on the analysis of several anti-drug campaigns conducted in the US over the course of time. Kuziemko and Levitt (2004), Resignato (2000), Shepard et al. (2005) and Sollars et al. (1994) point out the priority which policymakers have assigned to the fight against drug offenders in the United States. Furthermore, they also provide empirical evidence, which suggests that the intensification of drug enforcement is not by all means a straightforward strategy to contain drug offences and increase public safety. Instead, they conclude that the efforts to curtail a rampant drug market may in fact backfire and deteriorate public security instead of furthering it.

Although the new multilateral approach to the "War on Drugs" has required Mexico to place a similar - if not even greater - emphasis on the containment of drug traffickers, the side-effects of its 'War on Drugs' is not covered in the empirical

\footnotetext{
${ }^{54}$ See also media reports, e.g., http://elpais.com/elpais/2012/04/16/opinion/1334572319 078909.html and http://edition.cnn.com/2012/02/16/world/americas/mexico-drug-war-strategy/index.html (accessed: July 2012).
} 
literature. While there is evidence to suggest that the on-going campaign has so far provided little relief in the containment of drug trafficking to the US, and has had a proliferating effect on violence, no assessment exists to date, which analyses the effect of drug enforcement on overall crime levels in Mexico.

To fill this gap in the literature, I collect highly disaggregated data on drugrelated crimes, several types of committed criminal offences unrelated to narcotics, as well as incarceration statistics and further regional characteristics to construct a panel dataset at the municipal district level. The resulting dataset covers the 19982008 period. I use this dataset to empirically address the question whether an intensification of drug enforcement provides additional public security or whether it worsens the already frail security situation in the country. I proxy public security by measuring non-drug related crime such as robbery, assault, murder and rape. The question is addressed through the use of multiple panel estimation strategies. For the overall sample, my results indicate that intensified drug enforcement appears to reduce a district's overall level of crime. The outcome is robust to the use of different estimation techniques as well as offence types. Differentiating the regressions across federal states reveals however that the beneficial transmission mechanism from drug enforcement to gains in public safety is severely hampered by the prevalence of gang activities.

The rest of the paper is structured as follows: Section II.2 provides an introductory overview into the dimensions of the drug trafficking challenge faced by Mexico and the United States, the countries' anti-drug policies as well as literature discussing the implications of drug enforcement. Section II.3 discusses the data used, provides an outline of the estimation strategy and discusses the empirical results. Section II.4 summarizes the findings and concludes.

\section{II.2 The War on Drugs and its side effects}

\section{II.2.1 Drug consumption and anti-drug policies}

Reducing the consumption of drugs and its numerous side-effects remains a key priority of many governments worldwide. In terms of the negative health impacts, the United Nations Office for Drug and Crime estimates that the total cost attributable to 
drug treatment amounts to 250 billion USD (UNODC 2012). The trafficking and consumption of narcotics remains an especially significant challenge on the entire American continent as its most affluent country, the United States, which is home to five percent of the global population, accounts for 25 percent of global drug consumption.

Given the illicit nature of the phenomenon, exact data on production and consumption of narcotics are either imprecise or unavailable. As a result, decisionmakers are forced to shape anti-drug policies with the rather fractional information at their disposal. ${ }^{55}$ Consider the case of cocaine for example. For the time period of 2003-2007, the US Department of Justice estimates that cultivation areas ranging from 166,300 hectares to 232,500 hectares in Bolivia, Columbia and Peru have generated a supply of 760 to 930 metric tons of pure cocaine. ${ }^{56}$ Drug use surveys reveal that in 2009, roughly 2.4 percent of the US population allegedly consumed cocaine on a regular basis. ${ }^{57}$ The overall consumption of users in the United States amounts to 165 metric tons annually which implies that the US remains the largest market for cocaine. In comparison, Mexico remains a far less significant market with an annual consumption of 16 metric tons.

Another popular narcotic amongst Americans is cannabis. Acting as the most important supplier to the US, it is estimated that the potential production of marijuana in Mexico increased from 13,500 to 21,500 metric tons within the period of 2003 until 2008. While the exact amount of consumption is obviously hard to assess, best estimates assume that in 2009 at least 13.7 percent of the US population aged 15-64 had consumed cannabis within the preceding year. Consumption levels remain lower in Mexico, where a mere one percent of the total population in the ages of 12 to 65 was estimated to have consumed the drug in $2007 . .^{58}$ In addition, the trafficking and abuse of amphetamines - also known as synthetic drugs - is a spreading

\footnotetext{
55 See http://www.unodc.org/documents/data-and-analysis/statistics/Drugs/lisbon consensus.pdf (accessed: July 2012) for a discussion of the challenges faced when measuring narcotics consumption.

${ }_{56}$ http://www.usdoj.gov/ndic/pubs25/25921/index.htm (accessed: July 2012)

57 Refer to the detailed report provided at http://www.unodc.org/unodc/en/data-and-analysis/WDR2011.html (accessed: July 2012) for a country-by-country summary of consumption of different types of drugs.

${ }^{58}$ The most recent statistic on cannabis consumption in Mexico dates back to 2008 and was reported in the statistical annex of the 2011 World Drug Report by the United Nations Office on Drugs and Crime (UNODC). Data are available at http://www.unodc.org/documents/data-andanalysis/WDR2011/StatAnnex-consumption.pdf (accessed: July 2012).
} 
phenomenon. Transnational Mexican criminal organizations have become the single most important distributor of these drugs and the chemicals needed for their production (UNODC 2010, 2012). ${ }^{59}$

\section{II.2.2 The 'War on Drugs' in the United States}

With regards to the significant challenges posed by narcotrafficking and the wide repercussions associated with drug consumption, the United States has maintained a firm stance throughout the last decades with the aim to reduce both narcotics demand and supply. Under the Nixon administration there was a marked intensification of the government's fight against drug use. Most notably, in 1971, the government responded to the rise in public concern over widespread drug abuse by proclaiming its firm stance of the drug issue, summed up under the term 'War on Drugs'. The 1970s and 80s in particular saw large increases in the consumption of cocaine, as Columbian drug trafficking cartels utilized smuggling routes across the Gulf of Mexico and the Caribbean to transport the drug to the United States. Under this setup, trafficking cartels became complex multinational organizations with sophisticated supply chains stretching from remote production sites in the Andean mountains to consumers in the United States. With the passing of time and the disintegration of most Colombian drug cartels in the 1980s and 90s, narcotics began to be supplied, to an increasing extent, by Mexican organizations. By 1991, these criminal organizations were responsible for the trafficking of several hundred tons of cocaine and a third of all heroin and marijuana imported into the United States (Astorga and Shirk 2010).

To counter this development and to enforce its anti-drug agenda, the United States has largely, and to a growing extent, relied on the threat of arrest and incarceration. Up until the 1980s, incarceration rates were characterized by relative stability, with approximately 100 per 100,000 citizens serving a prison sentence at a given moment. The subsequent decades of zero-tolerance with regards to the consumption and sale of drugs, however, have drastically augmented the country's

\footnotetext{
${ }^{59}$ The increasing involvement of Mexican narcotraffickers is indicated by the amounts of drugs seized at the US-Mexican border. While seizures in 1998 amounted to 96 kilograms, the total amount confiscated reached 638 kilograms just two years later (International Narcotics Control Strategy Report 2001, available at: http://www.state.gov/j/inl/rls/nrcrpt/2000/888.htm, accessed: July 2012).
} 
prison population. Consequently, the following 35 year period has seen a steep rise in the incarceration rate, reaching the level of 491 incarcerations per 100,000 citizens in $2005 .{ }^{60}$

Naturally, the emphasis that is put on incarcerating drug offenders has led to a significant increase in the share of drug-related arrests among overall arrests within the US. While 7.4 percent of all arrests were on the grounds of drug charges in 1987, this share has risen to 12.2 percent in 2010. Maurer and King (2007) point out that the total number of drug arrests has more than tripled in the period between 1980 and 2005. Among these arrests, only 18.3 percent were carried out for drug sales while the large remaining share was based on drug possession charges. This ratio has been fairly stable in the following years. ${ }^{61}$ The significant share of drug users among all arrestees is an obvious indicator of the drug enforcement's approach to tackle the market for narcotics simultaneously from both the demand and supply sides. The US anti-drug initiative has led to the incarceration of over 1.8 million felons on the basis of drug crimes, turning this type of offence into the prime reason for incarceration in the United States (see, e.g., Caulkins and Chandler 2006; Bushway and Reuter 2011; Kuziemko and Levitt 2004). However human rights groups as well as scholars criticize the over-proportional share of felons incarcerated on the basis of small-scale drug use and possession among all drug convicts and point out that the costs of incarnating these individuals often outweigh the damages caused by smallscale dealing and drug consumption. (see, e.g., Nadelmann 1989 and King et al. 2002). Advocates of the zero-tolerance approach to narcotics, however, point to the variety of side-effects that wide-spread drug use has on society, which they see as only being contained through the simultaneous targeting of drug users and vendors.

In this context it is thus of crucial importance whether or not drug enforcement simultaneously reduces the prevalence of overall crime. Pro-enforcement policy makers seek to draw a logical link between the overall crime rate and drug use. Firstly, they make the case for the so-called psychopharmacological effect, in which it is argued that drug use can trigger criminal behavior amongst users. Secondly, there

\footnotetext{
${ }^{60}$ Data from the US Department of Justice and Bureau of Justice Statistics (available at http://bjs.ojp.usdoj.gov/content/pub/pdf/fjs05.pdf, accessed: July 2012).

${ }^{61}$ In 2010, the share of arrests on the grounds of drug possession remained at levels above 80 percent. During the 1990s, $79 \%$ of the total growth in drug arrests was attributable to marijuana possession. While overall arrests were decreasing by $3 \%$ in the 1990 s, marijuana arrests increased by 113\%. (http://www.fbi.gov/about-us/cjis/ucr/crime-in-the-u.s/2010/crime-in-the-u.s.-2010/personsarrested, accessed: July 2012).
} 
is the case for economic compulsion, i.e., users' potential addiction for drugs combined with the need to finance their addiction leads to criminal behavior. Thirdly, systemic violence, inherent to underground drug markets, can be held responsible for increased non-drug related crime rates. With these potential interlinkages between drug consumption and general societal problems in mind, winning the War on Drugs' has been presented as a panacea or "silver bullet" in the fight against an array of challenges ranging from gang violence to a wide array of social problems such as HIV/Aids and community disruption.

Isolated from human rights' implications of locking up large groups of drug users, a comprehensive selection of empirical literature tests whether or not a 'War on Drugs' that maximizes the amount of individuals incarcerated on the basis of drug charges delivers the promised increase in public security. The following section provides an overview of this discussion.

\section{II.2.3 Theoretical implications}

This subsection elaborates on the potential mechanisms at work in the context of drug enforcement and general crime and derives the hypotheses to be tested in the proceeding section. Past contributions analyzing the link between incarcerating drug offenders and non-drug related offences and public security differ substantially in their theoretical predictions. While authors rely on several interaction channels to support their arguments, contributions to this topic can generally be broken down into two competing predictions stating that drug enforcement either furthers public security or proliferates crime.

\section{Hypothesis 1: Intensified drug enforcement increases public security}

A first strand of literature argues in line with advocates of a strict prosecution of all drug offences that the drug enforcement offers complementarities to the extent that both drug- and non-drug crimes are contained. Therefore, the strict punishment of drug offenders will not only reduce drug crimes, but yield additional gains in the form of a simultaneous reduction in non-drug related offences like robbery, assault and kidnapping. According to this argument, drug enforcement thus improves public 
security. The process of eliminating multiple types of crime at the same time is often described as the incapacitation effect. The term makes reference to the fact that offenders will not limit themselves to one single type of crime, but engage in a wider range of illicit activities. This implies that locking up a burglar might reduce the prevalence of both break-ins and assault if the perpetrator has a tendency for violent behavior (see e.g., Levitt 1998).

Analyzing US crime and incarceration data for the 1983-1996 period, Kuziemko and Levitt (2004) find evidence that stricter punishment of drug offences yields a twofold effect. On the one hand, longer incarceration of drug offenders impacts negatively on the duration served by non-drug crime felons. More precisely, the less severe the non-drug offence for which an inmate serves time is, the more profoundly the arrest duration will be reduced by the arrival of a newly incarcerated drug offender. ${ }^{62}$ No significant reduction in arrest time occurs for the severest offences, e.g., murder. Although, at first sight, these results confirm the theory that drug enforcement crowds out the punishment of all remaining crimes, to the author's surprise, the effective reduction of non-drug crime punishment has little or no proliferating effect on the non-drug crime rate. Despite a sizeable reduction of prison time served for non-drug crimes, the prevalence of these offences increases by no more than three percent. Instead, the authors find a significantly negative relationship between the incarceration of drug offenders and non-drug related crime, pointing to a particularly strong incapacitation effect regarding the locking up of drug offenders. Sending more drug offenders to prison therefore reduces overall crime to such extends that even the early release of some "ordinary" criminals has little impact on public safety.

These results stem from the fact that significant shares of non-drug related offences are in fact committed by drug offenders. The author's findings are in line with a paper by Beck et al. (1989), wherein a detailed study on the recidivism tendencies of formerly incarcerated drug offenders indicates a strong trend of drug felons towards recommitting non-drug crimes after their release from prison. In line with these findings, in their analysis of the daily activities and finances of a Chicago

\footnotetext{
${ }^{62}$ The authors estimate that the increased share of inmates incarcerated on the grounds of drug related charges increased from 10 to $30 \%$ during the 1985-1996 period. Taken at face value, the results by Kuziemko and Levitt (2004) predict that felons convicted for murder benefited from a $4 \%$ reduction in their prison sentence. Reductions for property crimes were $10 \%-12 \%$, and $7 \%$ for robbery and aggravated assault, respectively.
} 
drug gang, Levitt and Venkatesh (2000) observe that violent conflict with competitors made up about 25 percent of gang activities during the study period. The targeting of drug offenders thus appears to concentrate law enforcement resources on the most notorious offenders who commit a variety of offences. ${ }^{63}$

It thus seems comprehensible that policy makers adhering to this theory will be tempted to place special emphasis on the incapacitation of drug offenders in order to achieve the reduction of both drug and non-drug related crime. Given the relatively easy targeting of offenders based on the possession of contraband, law enforcement may be able to exploit a shortcut to arrest individuals who are simultaneously responsible for crimes such as, e.g., robberies and assaults for which evidence and thus convictions might be harder to achieve.

Despite the theoretical allure of battling a multitude of social ills with a single policy and the vigorous arguments of zero tolerance advocates presented above, some evidence points to the fact that an emphasis on drug enforcement may backfire and produce undesired spillover effects such as an overall degradation of public safety. This process is explained in the following subsection.

\section{Hypothesis 2: Intensified drug enforcement deteriorates public security}

A contrary strand of literature expects a trade-off between achieving greater public security and drug-related crime enforcement. As a consequence, administrators will dedicate a certain share of finite law enforcement resources to each of these ends, while trying to find the optimal combination of non-drug crime and drug crime enforcement which maximizes society's utility, i.e., by minimizing overall crime levels.

Past research indicates that a strong concentration of law enforcement resources on one offence - in this case narcotrafficking - overstresses police resources required to deal with all remaining types of crime. The credibility of these assumptions grows in light of the penal statistics for drug-related arrests presented above as the significant amount of drug offenders would obviously consume large parts of a countries police and prison capacities. Consequently, an initiative such as

\footnotetext{
${ }^{63}$ Further theoretical discussion of this relationship can be found in Donohue and Levitt (1998).
} 
the 'War on Drugs' would be expected to have the undesirable side-effect of decreasing the penalization and thus increasing the attractiveness of non-drug offences, e.g., property crime, assault, rape and murder. Therefore, the targeting of one specific group of criminals could conceivably lead to a deterioration in public safety if certain groups within all criminals were systematically under-pursuit by law enforcement agencies.

The theoretical assumptions of this theory are based on classic contributions by Becker (1968) and Ehrlich (1973), who formulate an economic model of crime in which a felons' expected utility is based on the expected gains and costs (i.e., getting arrested) which are associated with a potential offence. Within this framework, a reduced likelihood of being arrested for an offence has a direct impact on the expected economic outcome of a committing a certain offence. Ceteris paribus, rational felons would therefore choose to engage in offences which, at a given time, are not a key priority for law enforcement agents and thus carry a lower risk of arrest and therefore a higher expected payoff.

Multiple studies have been carried out which test this hypothesis. Sollars et al. (1994) as well as Benson et al. (1994, 1998, 2001), investigate the effect law enforcement agencies' prioritization of drug offenders in 67 counties of Florida throughout the 1980s and 1990s. Their results show that under the credible assumption of a limited supply of police forces, a strong concentration of law enforcement on narcotrafficking increases property and violent offences. ${ }^{64}$ Likewise, Resignato (2000) analyses crime data from 24 US cities, covering the 1987-1995 period, and shows that a reallocation of police resources towards drug enforcement designed in the first place to reduce non-drug related crime committed by drug offenders - actually increases the level of violent and property crime. In a similar vein, Shepard and Blackley (2005) unveil a positive relationship between drug enforcement and the rates of assault and property crime in New York State during the 1996-2000 period. Running a cross-country regression of homicide rates on drug seizures and gun prohibition laws, Miron (2001) also finds increasing murder rates in the wake of intensified drug enforcement.

${ }^{64}$ The data from Sollars et al. (1994) covers 269 local jurisdictions of Florida in 1987. Benson et al. (2001) extend this analysis to data for 67 Florida counties during the 1994-1997 period. 
Additional theories exist to explain the idea of a negative relationship between drug crime enforcement and non-drug crime but rely on different channels of interaction. For example, Miron (1999) points out that the process of prohibiting a product - such as alcohol or heroin - and the ensuing enforcement of said prohibition can have an adverse effect on public safety. According to the author, violence is a systemic feature of black markets, predominantly stemming from the fact that as an established prohibition scheme renders a market illicit, its participants are no longer able to resort to legal institutions such as the police or courts to resolve disputes or enforce their property rights. Intensifying enforcement efforts against such a market might furthermore disturb any existing balance between its participants, thus leading to violent turf wars between gangs. A prominent potential example of this process is depicted in the spikes of violent gang crime witnessed in the ambit of alcohol prohibition in the United States in the 1920s (see, e.g., Asbridge and Weerasinghe 2009).

While this causal relationship has been extensively studied and evaluated for the United States (see, e.g., Benson et al. 1992; Sollars et al. 1994; Miron 1999), no attempt to conduct a comparable empirical investigation exists to date for Mexico. This is particularly striking given that the country is engaged to a comparable extent in the fight against narcotraffickers. The following section illustrates Mexico's efforts against drug offenders and contrasts the findings to the above discussed 'War on Drugs' in the United States.

\section{II.2.4 Mexico's growing involvement in the 'War on Drugs'}

Similar to the United States, Mexico looks also back on several decades of fighting narcotraffickers. Since 2007, the country has been a core element of the Mérida initiative, a US-led cross border initiative against drug trafficking. As such, the country has received substantial amounts of equipment, training and further assistance to use in the fight against drugs. In the period between 2008 and 2010, contributions reached a value of 1.4 billion USD. ${ }^{65}$ While the outside support that Mexico is

\footnotetext{
${ }^{65}$ Furthermore, the initiative laid the groundwork for profound cooperation between the US and Mexico in areas such as immigration, arms trafficking, bulk cash smuggling and transnational gangs. See (accessed: July 2012) for a brief fact summary for the Merida initiative.
} 
receiving in this regard is sizeable, it stands in no proportions to the Mexican government's budget spending on public safety. More precisely, the fiscal contributions of the Mexican state surpass funds provided by the Merida initiative by a factor of $13 .{ }^{66}$ In addition, while the deployment of up to 45,000 soldiers in 2006 signified a marked increase in Mexico's efforts to fight drug traffickers, the country has relied on military support in combating illegal drugs for decades. Whereas the army was traditionally used for crop eradication, its role has evolved over time from providing support and logistics to taking over police work and directly confronting drug cartels. As the problem was for a long time basically ignored by policymakers, this development marked a significant escalation of efforts put forward against the country's narcotrafficking cartels.

While drug trafficking was for the first time declared a "national security matter" in 1987, real efforts to contain the cartels did not emerge before 1996 when President Zedillo supported a law which assigned the Mexican army direct responsibilities in the provision of public security. As a result, military forces have taken on patrolling streets in high-crime areas under the presidencies of the Zedillo government (1994-2000) and the subsequent Fox administration (2000-2006). In 2002, President Fox additionally introduced a national drug control program with the aim to curtail the demand and supply of narcotics. Finally, President Calderón (20062012) has maintained and extended this strategy and has additionally launched large-scale military campaigns in narcotrafficking hotspots such as Acapulco, Michoacán, Nuevo Laredo as well as Ciudad Juarez. ${ }^{67}$ On the one hand, this development is seen as a positive step since Mexico's army is widely believed to be less prone to corruption and thus enjoys higher levels of public confidence than local police forces. On the other hand, however, the involvement of heavily armed soldiers has also been accompanied by an escalation of violence and an increase in human rights abuses (Olson et al. 2011).

Furthermore, the ensuing intra-cartel conflict has produced an exponential increase in the homicide rate, especially in areas where cartels hold significant

${ }_{66}$ A detailed report by the US Committee on Foreign Relations is available at http://www.foreign.senate.gov/publications/download/judicial-and-police-reforms-in-mexico-essentialbuilding-blocks-for-a-lawful-society" (accessed: July 2012).

${ }^{67}$ Additionally, the staff size of Mexico's Federal Police - which largely deals with drug offences - has more than tripled from 10,241 in 2001 to 34,646 in 2011. (Quinto Informe de Gobierno 2011, available at: http://www.informe.gob.mx/informe-de-gobierno/anexo-estadistico, accessed: July 2012). 
power. For example in some hotspots, mostly cities near the US-Mexican border, the murder rate has approached 50 cases per 100,000 persons. ${ }^{68}$ While these numbers are striking, what is even more discomforting is the fact that cartel violence does not limit itself to spontaneous shoot-outs between rival cartels, but also includes the strategic assassination of politicians, journalists and members of law enforcement agencies.

As opposed to the United States' anti-drug strategy, Mexico's approach is, to a certain degree, less transparent as official statistics do not to reveal to which subcategory of drug offences different drug offenders belong. One noticeable fact is the growing priority the Mexican administration has assigned to the arrest of drug offenders, which is reflected in the country-wide arrest statistics over the course of time. In this regard, the nationwide average share of drug-related arrests among total annual arrests rose from 0.28 to 6.32 percent under the Zedillo government (19942000). At the end of the Fox administration (2000-2006), this rate had increased further to 8.4 percent and stood at 8.1 percent in 2008 under the Calderón presidency ${ }^{69}$ Although these shares remain below the levels exhibited for the case of the United States, they reflect a significant increase in the country's efforts to pursue drug offenders. Notwithstanding, an assessment of how much of the Mexican drug enforcement respectively targets drug demand and supply is impossible to conduct with this information alone.

In the case of the United States, the orientation of law enforcement agencies towards tackling demand and supply of narcotics and thus targeting the full spectrum of drug offenders - i.e., users, vendors and traffickers - can be inferred from the arrest statistics discussed above. For Mexico, this assessment is significantly more complex as the country has and continues to publish only aggregate statistics on drug offences without splitting the group of perpetrators into users, vendors and traffickers. As such, it is challenging to evaluate the extent to which Mexico's drug enforcement is directly comparable to the US approach which tackles both narcotics demand and supply. While the interpretation of the data on this issue thus remains challenging, some anecdotal evidence provides certain guidance despite the fact that detailed data on the arrest of users and traffickers are lacking. Certain conclusions

\footnotetext{
${ }^{68}$ See, e.g., http://www.eluniversal.com.mx/nacion/192833.html (accessed: July 2012)

${ }^{69}$ All shares calculated with arrest statistics from the Annual Statistical Yearbooks for the United Mexican States. Available at: http://www.inegi.org.mx (last accessed: July 2012).
} 
can be drawn from Mexico's regulatory framework which governs the punishment for the possession of different amounts of narcotics and the alterations that were introduced to these regulations in the course of time.

In 2009, President Calderón signed the so-called narcomenudeo law which for the first time sought to distinguish between drug addicts and dealers based on the amount of drugs found on apprehended convicts. A core element of this legislation lies in the legalization of the possession of small amounts of drugs for personal use while increasing the penalties for drugs trading. Whereas the law itself offers no insight into past practices regarding small-scale drug possession, the discussion following the ratification of the law provides an insight into the prior focus of the otherwise opaque drug enforcement polices of the Mexican government. ${ }^{70}$ Commenting on these adjustments and the fear that the legalization would increase drug consumption, government officials pointed out that the reform does not constitute drug legalization but the regulation of a status-quo. ${ }^{71}$ Other comments to the newly introduced law point out that, "Mexico has emphasized the need to differentiate between addicts (...) and the violent drug traffickers (...)" while in the past "relatively few people were prosecuted and sentenced to jail for small-time possession."72

Although the sole possession of drugs was up to the year 2009 in theory punishable with significant jail sentences, Mexican drug users thus appear to have been less pursued than consumers in the US, while more emphasis has been put on the capturing of drug vendors and traffickers. How pronounced these differences in the arrest of drug users have been between the two countries can however not be assessed with the current information available. The next section elaborates on the empirical framework which is used to examine what effects Mexico's drug enforcement policies have had on overall crime levels and public safety.

\footnotetext{
${ }^{70}$ Appendix B.2 provides excerpts from the amendments to Mexico's Health regulations and Penal Code.

71“'In Mexico, Ambivalence on a Drug Law”, The New York Times, August 23 2009, available at: http://www.nytimes.com/2009/08/24/world/americas/24mexico.html (accessed: July 2012).

72 "Mexico decriminalizes small-scale drug possession" The Guardian, August 21 2009, available at: http://www.guardian.co.uk/world/feedarticle/8667553 (accessed: July 2012). 


\section{II.3 Empirical Analysis}

\section{II.3.1 Data and Method}

This paper empirically assesses the implications of the 'War on Drugs' for public security in Mexico by following up on the two strands of literature illustrated above. More specifically, the empirical investigation focuses on the link between drug enforcement and other non-drug related offences, namely property crime, assault, rape and murder. As indicated in the discussion above, a positive relationship between drug enforcement and non-drug crime prevalence lends credibility to the assumption that the emphasized prosecution of drug traffickers crowds out the prevention of other types of crime. In contrast to this, a negative relationship between the two variables supports the incapacitation theory (Levitt 1998), according to which the arrest of drug traffickers substantially lowers overall crime.

The dependent variable is the $(\mathrm{log})$ number of these reported non-drug related crime (NDC) incidents $N D C_{i t}$ in a municipal district $i$ in a given year $t^{73}$ Separate regressions are conducted for property offences, assault, rape and murder. The estimated relationship is represented by the following regression framework:

$$
\begin{gathered}
N D C_{i t}=\beta_{0}+\beta_{1} D E_{i t}+\beta_{2} C D E T_{i t}+\beta_{3} D C_{i t}+\beta_{4} P O P_{i t}+\beta_{5} U R A T E_{i t} \\
+\gamma_{t}+\delta_{i}+\varepsilon_{i t}
\end{gathered}
$$

The main variable of interest $D E_{i t}$ is a measure of the intensity of drug enforcement at the district level. The variable is constructed by calculating the share of drug crime arrests as a percentage of total arrests for each district and period (Benson et al. 1998; Resignato 2000; Shepard and Blackley 2005). ${ }^{74}$ As law enforcement resources are reassigned to prioritize the fight against narcotraffickers, the share of drug-related incarcerations in the total number of incarcerations is expected to increase within the associated period.

\footnotetext{
${ }^{73}$ As an alternative approach, all regressions were additionally estimated using the number of nondrug related offences per 1000 habitants in a district. The results are in line with the estimations found herein.

${ }^{74}$ Note that the prevalence of each crime type in question is subtracted from the total number of offences to counter any potential downward bias on the estimator.
} 
Table II.1:Summary Statistics

\begin{tabular}{|l|llllc|}
\hline Variable & Observations & Mean & Std. Dev. & Min & Max \\
\hline Robbery & & & & & \\
Assault & 7230 & 661.4775 & 2265.301 & 0 & 47575 \\
Murder & 7230 & 291.7835 & 801.7759 & 0 & 8591 \\
Rape & 7230 & 30.09129 & 82.91739 & 0 & 2006 \\
Drug enforcement & 7230 & 20.71134 & 83.72379 & 0 & 3312 \\
Deterrence (Robbery) & 7230 & .1526042 & .1924723 & .000351 & 1 \\
Deterrence (Assault) & 5097 & .1928999 & .1726164 & .0032362 & .9821429 \\
Deterrence (Murder) & 4976 & .2361267 & .2012308 & .000815 & .9821429 \\
Deterrence (Rape) & 3876 & .2738887 & .1923244 & .0074074 & .9876543 \\
Drug Crime & 2330 & .2867063 & .1994887 & .005 & .9852941 \\
Population & 7230 & 18.14816 & 61.98564 & 1 & 1133 \\
Unemployment Rate & 7230 & 112635.6 & 215990.7 & 123 & 1845410 \\
\hline
\end{tabular}

$C D E T_{i t}$ is a deterrence measure. In line with the Becker framework discussed above, I expect felons to account for the potential costs of their offences, i.e., the punishment they might receive. Therefore, deterrence is measured by the ratio of arrests for the given non-drug related crime in question, divided by the amount of all (reported) related offences in a given period in that district. Similar approaches to model crime deterrence have already been carried out by Gould et al. (2002), Sollars et al. (1994), Benson et al. (1994; 1998; 2001) and Resignato (2000), among others.

Furthermore, $D C_{i t}$ is the number of arrests in a district based on charges of drug-related crimes. The inclusion of this measure allows for an interpretation of other coefficients in the regression, while also controlling for the severity of drug crime in a municipal district. Since drug crime is usually not reported like other types of crime, its severity in a district has to be proxied by the number of arrests related to narcotics. The data for the calculation of the dependent non-drug crime variable $N D C_{i t}$, the variable of interest measuring the intensity of drug enforcement $D E_{i t}$, the deterrence measure $C D E T_{i t}$ as well as the number of drug-related arrests $D C_{i t}$ are extracted from 32 different statistical yearbook series provided by the Mexican 
Statistics Institute (INEGI) ${ }^{75}$, and are subsequently manually recoded and collected into one joint database. ${ }^{76}$

Additional variables are included to account for the different characteristics of the municipal districts. $P O P_{i t}$ is the log of the respective district's total population and $U_{R A T E} E_{i t}$ is the unemployment rate at district level. Both data series are retrieved from the Mexican Federal Office of Labor and Social Security. ${ }^{77}$ While unemployment data are usually not publicly available at the district level, the ministry has generously provided a disaggregated dataset which provides detailed unemployment data at the district level for the 1998-2008 period. Table 1 provides summary statistics of all variables employed in my empirical analysis.

The construction of the deterrence measure as a ratio of the number of arrests for a specific crime over the total number of reported cases of the crime is a subject of discussion in the previous literature. One key theoretical discussion centers on the question of whether or not it is adequate to model crime deterrence with a probability of arrest. In terms of empirical issues, it is necessary to address the issues of endogeneity and ratio bias. While these theoretical considerations are briefly presented in the following subsection, the issue of endogeneity is discussed in greater detail in the model discussion in Section II.3.3. Finally, Appendix B.1 replicates a calculation performed in Levitt (1998) to test the deterrence measure for ratio bias. To foreshadow results, replicating the approach found in Levitt (1998), the deterrence measure seems to be unaffected by ration bias.

In terms of the theoretical foundation of the deterrence measure, the abovementioned contributions by Becker (1968) and Ehrlich (1973) provide sound reasoning for the use of such an indicator and, as such, the measure is employed with slightly varying specifications - in a large amount of the existing empirical crime literature. The threat of potential arrest is therefore assumed to be a key element of

\footnotetext{
${ }_{75}^{7 n}$ Intituto Nacional de Estadística y Geografía (www.inegi.org.mx, accessed: July 2012).

${ }^{76}$ Although the data are publicly available online, the creation of one country-wide panel dataset involves a considerable amount of data coding as each federal state publishes its own statistical series on criminal offences in varying formats over the course of time. This seriously inhibits any attempts to introduce automation in the preparation of the dataset. First, each of the 32 federal states provides the data relevant for this paper in a separate dataset on an annual basis, which required retrieving 320 datasets from the INEGI website to cover the time period of 10 years. Second, datasets needed to be manually recoded across different time periods even within one statistical yearbook series as reporting styles were modified on several occasions. In addition, considerable work went into correcting obvious errors like misspelled district names.

${ }^{77}$ Secretaría del Trabajo y Previsión Social (http://www.stps.gob.mx, accessed: July 2012).
} 
the decision process on whether or not to engage in criminal behavior. The validity of this assumption has been debated to a considerable extent, e.g., by Nagin (1998); Durlauf and Nagin (2011) and Bushway and Reuter (2011). One argument against the implied rational view of criminals regarding their potential prison sentence relies on the conclusive assumption that future jail time will most likely be discounted by the criminal - especially given the fact that such individuals often act impulsively which implies a certain disregard for the potential of additional punishment in the future.

In summary, the analysis is on the one hand expected to benefit from the highly disaggregated nature of the data, which cover several hundred municipal districts over the time period of ten years. On the other hand, however, this level of disaggregation poses a challenge with regards to the inclusion of additional control variables from alternative sources. One consequential drawback in this analysis is the lack of data on income per capita at the district level. Additionally, to the author's knowledge, no reliable data exists at this level of disaggregation that provides information on the demographic composition of a district's population. This would be a beneficial addition to the set of explanatory variables since most offences are committed by individuals between the ages of 15 and 34 years. As far as possible, these shortcomings will be partially mitigated through the use of adequate estimation strategies which are discussed in the following section.

\section{II.3.2 Estimation Strategy}

Given the structure of the data, several estimation techniques are employed to test for the hypotheses illustrated above. In a first step, I estimate pooled OLS regressions for all offence types. This estimation strategy provides a baseline and allows for comparison with the results from the quoted sources, which generally rely on OLS estimations. In addition, all models are estimated using three more advanced estimation strategies in order to assess whether any significant effect prevail across different models.

More precisely, in a second step, I include time and district fixed effects to account for any unobserved district-specific characteristics, as well as effects varying over time but not across districts. Ignoring these unobserved information could result in inconsistent coefficient estimates. Fixed Effects estimations allow accounting for 
potentially important district characteristics, e.g., systematic underreporting or any other district-level heterogeneity potentially correlated with the district crime rate (see, e.g., Cornwell and Trumbull 1994 and Baltagi 2006). As Fajnzylber et al. (2002) remark, measurement error of crime rates is most likely the most relevant unobserved district-specific effect. Furthermore, standard errors are adjusted for clustering across districts to address groupwise heteroskedasticity.

In a third step, an additional set of regressions is estimated using Negative Binomial regressions. This estimation strategy reflects the fact that the dependent variable is discrete as well as non-negative, thus representing count data. As is generally valid for data used in the analysis of crime, the independent variable measures the prevalence of an event in a geographical area within a certain timeframe. It is usually found that over the sum of all districts under analysis, such events will not be distributed evenly over all observed entities, thus assuming that a symmetric distribution around the mean will not exist. Instead, events such as robberies are often much more prevalent in certain regional hotspots, while other regions remain unaffected, causing the variable in question to have a skewed distribution.

Negative Binomial regression is used in place of Poisson regression due to the nature of the data. When the data in question are over-dispersed, this estimation technique usually delivers results superior to those of a Poisson regression framework. This is due to the fact that over-dispersion implies that the variance of a distribution far exceeds its mean, a clear violation of a key property of the Poisson distribution, which requires unity of the mean and its variance. ${ }^{78}$ As a result of this, residual errors will be underestimated using a Poisson model, leading to overly optimistic assumptions regarding the significance of variables to be selected in the regression. Given the highly skewed nature of the data used in the estimations, the selection of the Negative Binomial regression model is obviously necessary.

In a fourth and final step, Two-step System General Method of Moments (GMM) estimations are carried out to tackle the potential simultaneity. This issue arises when at least one explanatory variable - in this case the deterrence measure

\footnotetext{
${ }^{78}$ Calculating mean and variance values for all dependent variables reveals the prevalence of overdispersion in all five cases. For the case of robbery, the variance dominates the variable mean by a factor of 7587.75 , while for assault this number is 2125.09 , murder 219.92 , and gang killings 330.96 .
} 
- is simultaneously determined alongside the dependent variable, i.e., the prevalence of crime. Consequently, the measure of deterrence will be correlated with the error term. Against the background of this analysis, it is conceivable that a district burdened with high levels of crime would expand its police force, thus raising the overall rate of arrests which again directly influences the deterrence measure. This constitutes an endogenous relationship between the two variables.

Endogenous relationships are rather common in the empirical analysis of crime and are therefore extensively discussed (see, for example, Cornwell and Trumbull 1994; Baltagi 2006; Levitt 1997, 2002; and McCrary 2002). Worrall and Kovandzic (2010) represent contributions that seek to tackle the endogeneity issue through an instrumental variable (IV) approach. While Levitt (1997) tests the number of firefighters as a potential instrument, Levitt (2002) relies on electoral cycles to instrument the amount of police forces available in a district. Other approaches include the use of fiscal budgets dedicated for law enforcement or the cost of police officers to predict the level of crime deterrence (see, for example, Bahl et al. 1978; Cornwell and Trumbull 1994; Swimmer 1974a, 1974b). Further attempts have been made using overall levels of crime, which are supposed to determine the amount of police forces employed (see, e.g., Howsen and Jarrell 1987).

As Worrall and Kovandzic (2010) point out, the large majority of these approaches did not manage to construct a model with over-identified endogenous regressors. This is mostly due to the difficulty of finding a sufficient group of adequate variables and renders tests of instrument validity unfeasible. As mentioned above, the availability of district-level data is limited, which rules out Two-Stage OLS (2SLS) estimations due to the lack of a potential instrument. Instead, the issue of simultaneity will be addressed through the use of the Two-step System GMM estimator, which relies on equations in first differences and levels. ${ }^{79}$ Roodman (2009) and Blundell and Bond (1998) show that the System GMM estimator is preferable to the first-differenced GMM estimator in the context of potential large finite sample bias. Although the two-step estimator is asymptotically more efficient, the reported two-step standard errors are prone to negative bias (Arellano and Bond 1991; Arellano and Bover 1995; and Blundell and Bond 1998). This fact is compensated for

\footnotetext{
79 I rely on the xtabond2 STATA command by Roodman (2009), which allows for the estimation of "small-T and large-N" panels.
} 
through the use of a finite-sample correction for the two-step covariance matrix based on Windmeijer (2005). The standard errors are adjusted for clustering at the level of municipal districts.

Instruments for the "GMM-style" instruments are not collapsed as, first, the number of instruments remains significantly below the number of observations in all estimations, and second, the use of a smaller set of conditions for the "GMM-style" instruments reduces the statistical efficiency of the estimator in large samples. Furthermore, no restrictions are imposed for the instrument matrix. Police deterrence, drug enforcement as well as registered drug crimes are treated as endogenous whereas all remaining additional covariates are expected to be exogenous. The regression furthermore includes time-fixed effects. Note that the lagged value of the dependent is included in the GMM estimations. It is imaginable that prevailing conditions and structures at the municipal level cause a certain persistence of crime levels over time. ${ }^{80}$

\section{II.3.3 Main results}

Based on empirical results from the estimation strategy discussed above, this section discusses the predicted effect of increasing drug enforcement on public safety for the case of Mexico. Overall safety is measured by the prevalence of robbery, assault, murder and rape in municipal districts. Tables II.1 to II.4 present the results for all estimation techniques and based on the complete sample for the time period of 1998 to 2008.

First, I start with an analysis of the amount of robberies in a district. The results displayed in Table II.1 indicate that increased drug enforcement impacts negatively on the number of robberies. The coefficient on the drug enforcement measure is significant at conventional level across all estimation techniques. More specifically, the impact of an increase in the share of arrests on the grounds of drug offences by one percentage point decreases the amount of reported robberies by 0.9 to 0.6

\footnotetext{
${ }^{80} \mathrm{I}$ exclude the lagged dependent variable in the prior estimates for several reasons: first, given the relatively short panel, it is possible that lagged crime rates are endogenous which, according to Nickel (1981), leads to biased results unless this problem is tackled by an instrumental variable approach such as GMM. Furthermore, the inclusion of the lagged dependant variable reduces the number of observations available for estimation. When including the lagged dependent variables despite these caveats, results remain in line with the findings described above. Results are available on request.
} 
percent, depending on the estimation technique used.$^{81}$ Relating these results to the two possible impacts of drug enforcement discussed in Section 2, the empirical

Table II.2: Effect of drug enforcement on the prevalence of robbery

\begin{tabular}{|c|c|c|c|c|}
\hline & $\begin{array}{l}\text { OLS } \\
(1)\end{array}$ & $\begin{array}{l}\mathrm{FE} \\
(2)\end{array}$ & $\begin{array}{l}\text { Neg. Binomial } \\
\text { (3) }\end{array}$ & $\begin{array}{c}\text { GMM } \\
(4)\end{array}$ \\
\hline Lagged dependent & & & & $\begin{array}{c}0.600 * * * \\
-12.23\end{array}$ \\
\hline Drug enforcement & $\begin{array}{c}-1.626 * * * \\
(-17.70)\end{array}$ & $\begin{array}{c}-0.617 * * * \\
(-10.01)\end{array}$ & $\begin{array}{c}-0.662 * * * \\
(-12.79)\end{array}$ & $\begin{array}{c}-0.456 * * \\
(-2.53)\end{array}$ \\
\hline Deterrence & $\begin{array}{c}-2.583 * * * \\
(-39.04)\end{array}$ & $\begin{array}{c}-1.775 * * * \\
(-25.49)\end{array}$ & $\begin{array}{c}-1.952 * * * \\
(-34.66)\end{array}$ & $\begin{array}{c}-1.836 * * * \\
(-8.48)\end{array}$ \\
\hline (log) Drug Crime & $\begin{array}{c}0.490 * * * \\
-27.97\end{array}$ & $\begin{array}{c}0.116^{* * *} \\
-8.68\end{array}$ & $\begin{array}{c}0.108 * * * \\
-10.95\end{array}$ & $\begin{array}{c}0.252 * * * \\
-6.14\end{array}$ \\
\hline (log) Population & $\begin{array}{c}0.823 * * * \\
-42.77\end{array}$ & $\begin{array}{c}0.074 * \\
-1.87\end{array}$ & $\begin{array}{c}0.112^{* * *} \\
-5.76\end{array}$ & $\begin{array}{c}0.283 * * * \\
-5.13\end{array}$ \\
\hline Unemployment Rate & $\begin{array}{c}0.091 * * * \\
-21.69\end{array}$ & $\begin{array}{l}0.005 \\
-0.82\end{array}$ & $\begin{array}{l}0.001 \\
-0.28\end{array}$ & $\begin{array}{c}0.021 * * * \\
-3.53\end{array}$ \\
\hline (2) & 0.872 & 0.367 & & \\
\hline $\mathrm{N}$ & 5097 & 5097 & 4878 & 3380 \\
\hline Hansen J & & & & 184.773 \\
\hline (p-value) & & & & 0.292 \\
\hline Arellano-Bond test for AR1 in 1st differences & & & & -6.633 \\
\hline ( $p$-value) & & & & 0.000 \\
\hline $\begin{array}{l}\text { Arellano-Bond test for AR2 in 1st differences } \\
\text { (p-value) }\end{array}$ & & & & $\begin{array}{l}-0.601 \\
0.548\end{array}$ \\
\hline Number of districts & 1007 & 1007 & 796 & 662 \\
\hline Number of instruments & & & & 316 \\
\hline
\end{tabular}

Notes:

- Robust t-values in parenthesis; ${ }^{*}$ significant at $10 \%$; ${ }^{* *}$ significant at $5 \%{ }^{* * *}$ significant at $1 \%$

- Fixed Effects regressions with time and district fixed effects

- Standard errors are clustered at the district level

- Two-step System GMM with time fixed effects and Windmeijer finite sample correction

results provide support to the concept of incapacitation, i.e., the arrest on the basis of drug charges targets individuals which are at the same time prone to committing additional non-drug offences.

With regards to the additional crime-related coefficients, the coefficient of crime deterrence, i.e., the ratio of arrests for robbery divided by the total number of reported robberies, behaves according to expectation for all estimations. Increasing

${ }^{81}$ For example, $\exp ((-2.413)-1=0.91$ which implies that a one-unit increase of drug enforcement indicator $(+0.01)$ causes a reduction of robberies by 0.9 percent. 
Table Il.3: Effect of drug enforcement on the prevalence of Assault

\begin{tabular}{|c|c|c|c|c|}
\hline & $\begin{array}{l}\text { OLS } \\
(1)\end{array}$ & $\begin{array}{l}\mathrm{FE} \\
(2)\end{array}$ & $\begin{array}{l}\text { Neg. Binomial } \\
\text { (3) }\end{array}$ & $\begin{array}{c}\text { GMM } \\
(4)\end{array}$ \\
\hline Lagged dependent & & & & $\begin{array}{c}0.375^{* * *} \\
(6.05)\end{array}$ \\
\hline Drug enforcement & $\begin{array}{c}-1.863 * * * \\
(-19.87)\end{array}$ & $\begin{array}{c}-0.620 * * * \\
(-9.28)\end{array}$ & $\begin{array}{c}-0.692^{* * *} \\
(-10.80)\end{array}$ & $\begin{array}{c}-0.952 * * * \\
(-2.95)\end{array}$ \\
\hline Deterrence & $\begin{array}{c}-2.011 * * * \\
(-36.02)\end{array}$ & $\begin{array}{c}-1.322^{* * *} \\
(-19.45)\end{array}$ & $\begin{array}{c}-1.405^{* * *} \\
(-28.53)\end{array}$ & $\begin{array}{c}-1.392 * * * \\
(-6.07)\end{array}$ \\
\hline Drug Crime & $\begin{array}{c}0.231 * * * \\
(16.00)\end{array}$ & $\begin{array}{c}0.083 * * * \\
(5.87)\end{array}$ & $\begin{array}{c}0.060 * * * \\
(5.57)\end{array}$ & $\begin{array}{c}0.170 * * * \\
(3.58)\end{array}$ \\
\hline Population & $\begin{array}{c}0.861 * * * \\
(48.76)\end{array}$ & $\begin{array}{c}0.158 * * * \\
(3.69)\end{array}$ & $\begin{array}{c}0.084 * * * \\
(4.34)\end{array}$ & $\begin{array}{c}0.519 * * * \\
(6.56)\end{array}$ \\
\hline Unemployment Rate & $\begin{array}{c}0.039 * * * \\
(9.79)\end{array}$ & $\begin{array}{c}-0.024 * * * \\
(-3.52)\end{array}$ & $\begin{array}{c}-0.029 * * * \\
(-6.20)\end{array}$ & $\begin{array}{l}0.007 \\
(1.10)\end{array}$ \\
\hline $\mathrm{R} 2$ & 0.850 & 0.230 & & \\
\hline N & 4903 & 4903 & 4643 & 3201 \\
\hline Hansen J & & & & 186.753 \\
\hline (p-value) & & & & 0.258 \\
\hline Arellano-Bond test for AR1 in 1st differences & & & & -6.003 \\
\hline (p-value) & & & & 0.000 \\
\hline Arellano-Bond test for AR2 in 1st differences & & & & -1.196 \\
\hline (p-value) & & & & 0.232 \\
\hline Number of districts & 1043 & 1043 & 794 & 678 \\
\hline Number of instruments & & & & 192 \\
\hline
\end{tabular}

Notes:

- Robust t-values in parenthesis; * significant at $10 \%$; ** significant at $5 \%$; *** significant at $1 \%$

- Fixed Effects regressions with time and district fixed effects

- Standard errors are clustered at the district level

- Two-step System GMM with time fixed effects and Windmeijer finite sample correction

the clearance rate for robbery by one percentage point decreases the prevalence of this offence between 0.8 to 0.9 percent. The existence of drug crime in a municipal district, proxied for by the reported number of drug offences, appears to drive up robberies as indicated by the positive coefficient in all estimation results. Regarding the coefficients for further district characteristics, the coefficient for the log of district population is, as expected, positive and significant, at conventional levels. This outcome appears consequential if one assumes that increasing populations result in greater opportunities to commit robberies. Furthermore, an increase in the district 
Table II.4: Effect of drug enforcement on the prevalence of Murder

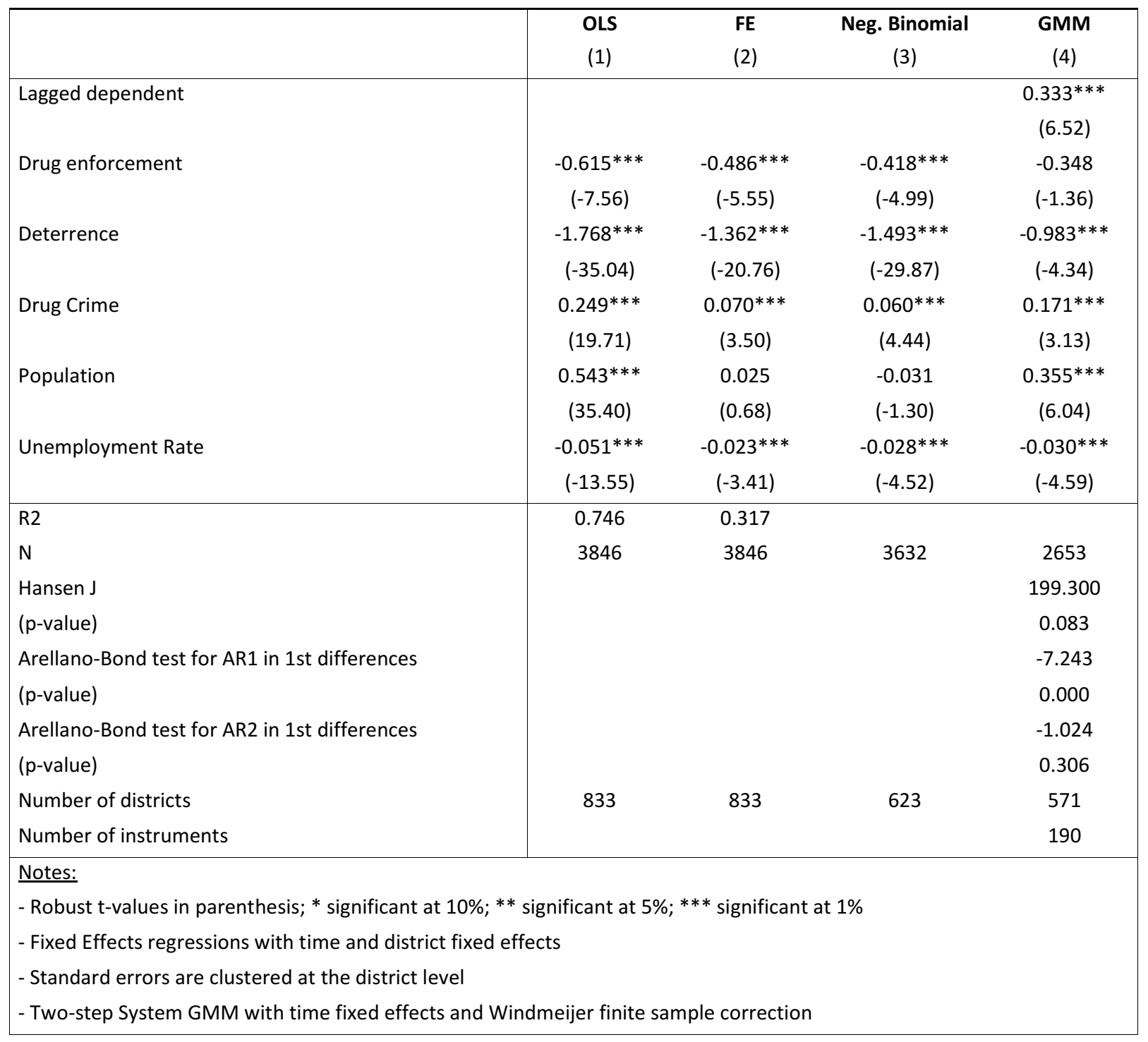

unemployment rate by one percentage point increases the prevalence of robberies by 2.9 to 3.8 percent. ${ }^{82}$ With respect to the GMM results, the coefficient on the lagged

\footnotetext{
${ }^{82}$ The theory generally states that unemployment implies the inability to maintain a particular standard of living for many individuals, causing a reaction in the form of a criminal act in some cases (predominantly offences with a property component). Cantor and Land (1985), however, provide some arguments in favor of a more differentiated view on the relationship between unemployment and (property) crime. As the authors point out, most studies find only weak evidence of a positive relationship between the two phenomena. Second, the authors identify two counterbalancing mechanisms - criminal motivation and criminal opportunity: A lack of labor-based income clearly increases the motivation among some individuals to commit offences. However the reduced number of worthwhile economic targets in the wake of widespread economic downturn also renders robbery less profitable. In addition, widespread unemployment lowers the chance of remaining undiscovered while committing a crime due to more individuals being at home instead of in the workplace (guardianship effect). The overall effect of unemployment on crime is thus not ambiguous. In this regard, also refer to Fougère et al. (2009) and Rosenfeld (2009).
} 
Table II.5: Effect of drug enforcement on the prevalence of Rape

\begin{tabular}{|c|c|c|c|c|}
\hline & $\begin{array}{l}\text { OLS } \\
(1)\end{array}$ & $\begin{array}{l}\text { FE } \\
(2)\end{array}$ & $\begin{array}{l}\text { Neg. Binomial } \\
\text { (3) }\end{array}$ & $\begin{array}{c}\text { GMM } \\
(4)\end{array}$ \\
\hline Lagged dependent & & & & $\begin{array}{c}0.313 * * * \\
(4.36)\end{array}$ \\
\hline Drug enforcement & $\begin{array}{c}-1.313^{* * *} \\
(-7.28)\end{array}$ & $\begin{array}{c}-0.601 * * * \\
(-3.20)\end{array}$ & $\begin{array}{c}-0.663 * * * \\
(-3.67)\end{array}$ & $\begin{array}{c}-1.442 * * * \\
(-3.75)\end{array}$ \\
\hline Deterrence & $\begin{array}{c}-1.939 * * * \\
(-32.15)\end{array}$ & $\begin{array}{c}-1.338 * * * \\
(-17.12)\end{array}$ & $\begin{array}{c}-1.515^{* * *} \\
(-20.42)\end{array}$ & $\begin{array}{c}-2.017 * * * \\
(-8.84)\end{array}$ \\
\hline Drug Crime & $\begin{array}{c}0.249 * * * \\
(12.13)\end{array}$ & $\begin{array}{c}0.062 * * * \\
(2.70)\end{array}$ & $\begin{array}{l}-0.017 \\
(-0.87)\end{array}$ & $\begin{array}{c}0.285^{* * *} \\
(3.65)\end{array}$ \\
\hline Population & $\begin{array}{c}0.593 * * * \\
(23.33)\end{array}$ & $\begin{array}{c}0.132 * * * \\
(3.05)\end{array}$ & $\begin{array}{l}0.020 \\
(0.69)\end{array}$ & $\begin{array}{c}0.293 * * * \\
(4.18)\end{array}$ \\
\hline Unemployment Rate & $\begin{array}{c}-0.014 * * * \\
(-3.12)\end{array}$ & $\begin{array}{l}-0.006 \\
(-0.59)\end{array}$ & $\begin{array}{l}0.006 \\
(0.83)\end{array}$ & $\begin{array}{l}-0.009 \\
(-1.32)\end{array}$ \\
\hline R2 & 0.802 & 0.391 & & \\
\hline $\mathrm{N}$ & 2324 & 2324 & 2083 & 1548 \\
\hline Hansen J & & & & 180.296 \\
\hline ( $p$-value) & & & & 0.317 \\
\hline Arellano-Bond test for AR1 in 1st differences & & & & -4.454 \\
\hline (p-value) & & & & 0.000 \\
\hline Arellano-Bond test for AR2 in 1st differences & & & & 0.950 \\
\hline (p-value) & & & & 0.342 \\
\hline Number of districts & 688 & 688 & 450 & 452 \\
\hline Number of instruments & & & & 189 \\
\hline $\begin{array}{l}\text { Notes: } \\
\text { - Robust t-values in parenthesis; * significant } \\
\text { - Fixed Effects regressions with time and distr } \\
\text { - Standard errors are clustered at the district } \\
\text { - Two-step System GMM with time fixed effe }\end{array}$ & $\begin{array}{l}\text { nificant at } 5 \\
\text { ts } \\
\text { neijer finite }\end{array}$ & $\begin{array}{l}\text { ** significan } \\
\text { ole correctio }\end{array}$ & & \\
\hline
\end{tabular}

number of robberies carries the expected positive sign and is statistically significant. The overidentifying restriction is tested relying on the commonly employed $\mathrm{J}$ statistic by Hansen (1982). As indicated in column 4 of Table II.2, the null hypothesis that the instruments are valid is not rejected for the case of robbery. Furthermore, the null hypothesis of no second-order autocorrelation is not rejected at conventional levels by the Arellano-Bond test. Second, the regressions described above are repeated for the incidence of assault. Results are presented in Table II.3. While a certain connection between robbery and assault is conceivable, assault still represents an escalation of violence in comparison to robbery. Just as robberies, assaults can also be interpreted as a proxy for overall levels of crime given their relative frequency in comparison to more grave offences. Predictions of the impact of drug enforcement 
Depending on the estimation method, the predicted impact of a unit increase in the drug enforcement coefficient lies between -0.9 and -0.6 percent. All coefficients are once more highly significant. As for robberies, the so-called incapacitation effect thus seems to prevail for assaults as well. The results for most control variables are in line with earlier results. While an increase of arrests on the basis of assault seems to discourage the crime - leading to a reduction of 0.7 to 0.9 percent for each unit increase of the deterrence measure -, an increase in drug crime, ceteris paribus, increases the number of registered assaults. With regards to district population, all estimation results are significant at conventional levels across all regression techniques, depicting a positive and statistically highly significant relationship between population size and the amount of assaults committed. A one-percent increase in the district population adds from 0.16 to 0.78 percent to the assault count. Leaving aside the baseline estimation, the predicted effect of rising unemployment is a reduction in the prevalence of assault crime for both the fixed effects and negative binomial regressions while no effect is found for the GMM results. Once more, the hypothesis of instrument validity and the absence of second-order autocorrelation are not rejected for the GMM estimates at conventional levels. Third, I turn to the impact of drug enforcement on cases of murder (see Table II.4). Given the experience of Mexico with drug trafficking cartels, increases in violence are associated with the activities of drug cartels and as such, more intense drug crime on the district level is expected to drive up the murder count. The dependent variable in these estimations could thus reflect the effect of more intense competition and clashes between drug smuggling cartels on the murder rate.

Despite these predictions, the coefficient on the variable of interest shows a consistent negative sign across estimation techniques, but the coefficient fails to gain statistical significance in the GMM estimation. In all four specifications, the predicted effect is considerably smaller than in previous regressions. Perpetrators, however, seem to be discouraged to commit homicides in districts that show a larger clearance rate for murder. As for the population size's effect on the murder rate, it is shown to have a positive and significant effect on the incidence of murder cases for the baseline and GMM estimations. Interestingly, districts with greater unemployment rates also seem to enjoy a lower number of murder cases. 
The empirical results in terms of the murder rate should be interpreted with caution. Recalling Miron (1999), a positive relationship between might prevail as intensified drug enforcement causes a higher degree of supersession between cartels, leading to turf wars and a rise in murder cases. Gould et al. (2002) provide a discussion on the specifics of murder in this regard, emphasizing the fact that murderers and victims tend to know each other, while the crime often provides the perpetrator with no material gain. Note, that given the data in its current state, hardly any differentiation can be made between murder cases related to either the activity of narcotrafficking cartels or the 'War on Drugs', and those not related to this activity.

Therefore, the data essentially treats a murder occurring for personal reasons as being equal to the execution of one cartel member by another. In the case of murder, however, the relationship between police presence and the probability of the crime is far from unequivocal. While a murder committed for personal reasons appears to hinge less on the likelihood of conviction, the decision to murder with the intent of personal gain (as many drug-related murders could be assumed as being) might be evaluated in the light of the probability of being caught to a greater degree. The results related to homicide rates should be handled with the above relationships in mind.

Fourth, I analyze the effect of drug enforcement on the prevalence of rape (see Table II.5). Similar to assault and robbery in terms of the size of the predicted effect, the prevalence of rape offences again seems to hinge on the intensity with which drug enforcement is carried out at the municipal level.$^{83}$ Across all estimation techniques, the variable of interest is highly significant with a negative sign, pointing to the fact that increasing the proportion of arrests on drug charges among all arrests has, on average, the side-effect of incapacitating potential rape offenders. Furthermore, the estimated effects of deterrence and drug crime mostly behave in line with expectations and prior results. In contrast to other offence types, the district unemployment rate, however, is unfit to predict the prevalence of rape offences. This type of crime seems to be unrelated to monetary considerations.

\footnotetext{
${ }^{83}$ With regards to issues of underreporting, rape is most likely to be prone to a high number of unreported cases. Two separate processes can be identified in this regard. First, this type of offence often goes unreported for a multitude of personal reasons, especially when the offence occurs within the boundaries of a family. In any case, rape is a crime which carries a large social stigma for the victim, which is an important driver of underreporting of this type of offence. As such, statistics on sexual assault might suffer from a negative bias.
} 
In summary, the first set of regressions provides statistically significant evidence that the intensified pursuit of drug offenders in Mexico is beneficial to public safety. Specifically, the empirical results show that as a greater share of drug-related arrests among all imprisonments impacts negatively on the prevalence of all four types of offences investigated above.

In suggesting that public security increases with intensified drug enforcement these results are in direct contradiction to those of all similar and previously cited studies. With regards to similar studies, these results distinguish themselves strongly in terms of the estimated direction of the effect as all previously cited studies predict that public security deteriorates with intensified drug enforcement. Greater similarities however exist in terms of the scale of impact. Benson et al. (2001) focuses on robbery for an assessment of overall public security. In their paper, the authors only conduct simple OLS regressions and predict a coefficient close to the one found for the OLS regressions presented in this paper (2.20 and 2.41) - yet with contrary results regarding the predicted direction of impact. Based on Fixed Effects regressions, Benson and Rasmussen (1998) predict an increase of 0.7 percent as a consequence of a unit increase in the measure on drug enforcement intensity. Once more, the size of the coefficient for the variable of interest generally coincides with the results found above while the direction of impact is reversed. Resignato (2000) focuses on the relationship between drug enforcement and murder cases. His results are hardly comparable to the results presented above as first, the direction of impact is positive - thus, drug enforcement promotes murder - and second, the predicted size of the impact is smaller than in the case of Mexico.

Finally, I investigate the robustness of the results by splitting the sample chronologically. More precisely, the data is split up into a pre-2006 and a post-2006 sample. As mentioned above Mexico's 'War on Drugs' experienced a significant militarization under President Felipe Calderón in 2006. To assess whether this strategy reflects in the estimation results, all estimations discussed above are repeated for the pre-2006 and post-2006 sample. Regression results are provided in Tables B.2 to B.6. Focusing on the main variable of interest, the coefficient for the intensity of drug enforcement remains negative and statistically significant at conventional levels for almost all subsample estimates. Only some of the GMM and Fixed Effects results for the pre-2006 sample in the case of robbery and rape lose 
statistical significance at conventional levels. Furthermore, in terms of predicted size, the impact of an increase in drug enforcement moves within the boundaries seen for the complete sample. Also, the remaining control variables exhibit results in line with the prior findings shown in Tables II.2 to II.5. While these results lend credibility to the estimates on the full sample, the estimations do not show significant changes after the militarization of Mexico's 'War on Drugs' took place in 2006.

\section{II.3.4 Geographical breakdown}

Next, I split the sample by federal states to investigate whether systematic differences arise in the effect of drug enforcement on public security between Mexican states. As especially northern federal states in proximity to the border with the United States face high levels of cartel violence, overall results based on the full sample might be driven by these outliers. This implies running one regression for each of the 32 states for all four non-drug offences over the time period of 1998 to 2008. As discussed in Section II.2, the data are available at the level of municipal districts which provides sufficient observations to carry out Fixed Effects regressions with time- and district-fixed effects for most states. ${ }^{84}$ While it is not feasible to reproduce the GMM estimates from above and thus tackle the issue of endogeneity, the previously presented results appear sufficiently robust to the use of different estimation techniques that an interpretation based on Fixed Effects results appears justifiable.

\footnotetext{
${ }^{84}$ The results for some states with very few districts and thus observations can be expected to be less robust. For example, Baja California Sur has only five municipal districts.
} 


\section{Figure II.1: Effect of drug enforcement on the prevalence of robbery}

(coefficients calculated at the state level)

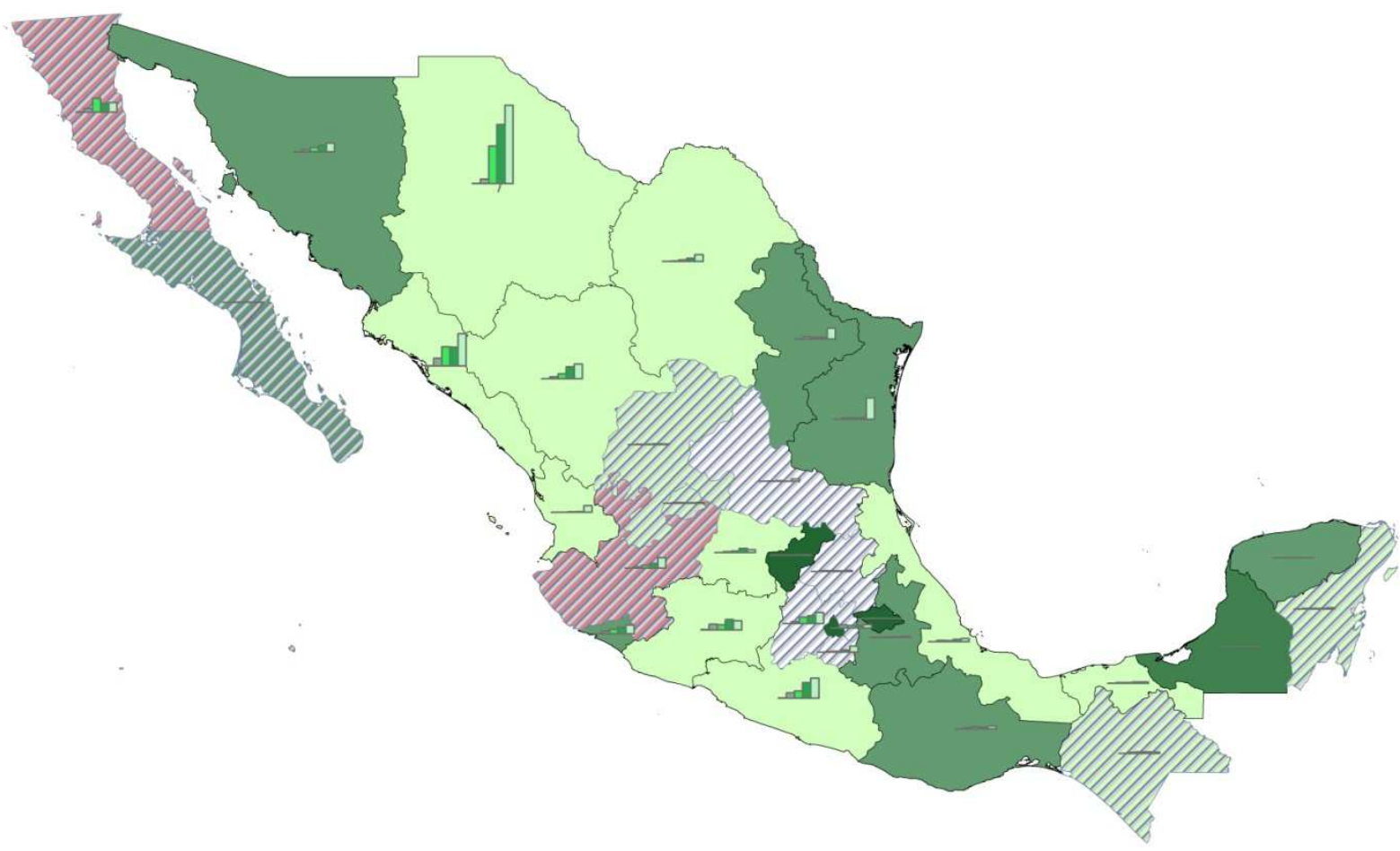

To gain a better understanding of any systematic differences in the effect of drug enforcement between states, I rely on a graphical representation of the regression results with an emphasis on the predicted impact of drug enforcement on the four different non-drug offences. ${ }^{85}$ Figures II. 1 to II.4 provide an insight into how the predicted effect of drug enforcement varies across different states. Furthermore, I add bar charts indicating the amount of gang-related murder cases in each state. The data on gang murder are provided by the Mexican government for the time period of 2006 to 2010. Each bar indicates the amount of gang-related murder cases recorded in a state during each of the four available years in the dataset. Although the data are not available for earlier years, it provides an insight into the concentration of gang violence and thus drug cartels across different federal states. ${ }^{86}$ As a significant share

\footnotetext{
${ }^{85}$ The data on administrative boundaries to construct the maps shown in Graphs II.1 to II.4 was retrieved from the Natural Earth Project (available at: http://www.naturalearthdata.com, accessed: July 2012).

${ }^{86}$ In the dataset, murder cases are categorized as gang violence if the victim was killed with big calibre weapons, the deceased shows indications of torture prior to death, the murderer struck at close range -hinting at an execution - and bodies were later disposed of in ways that intent to mask their identity. The Data is available at http://www.presidencia.gob.mx/base-de-datos-de-fallecimientos (accessed: July 2012). For a detailed description on the compilation of the data refer to http://200.23.123.5/Documentos.aspx (accessed: July 2012).
} 
Figure II.2: Effect of drug enforcement on the prevalence of assault (coefficients calculated at state level)

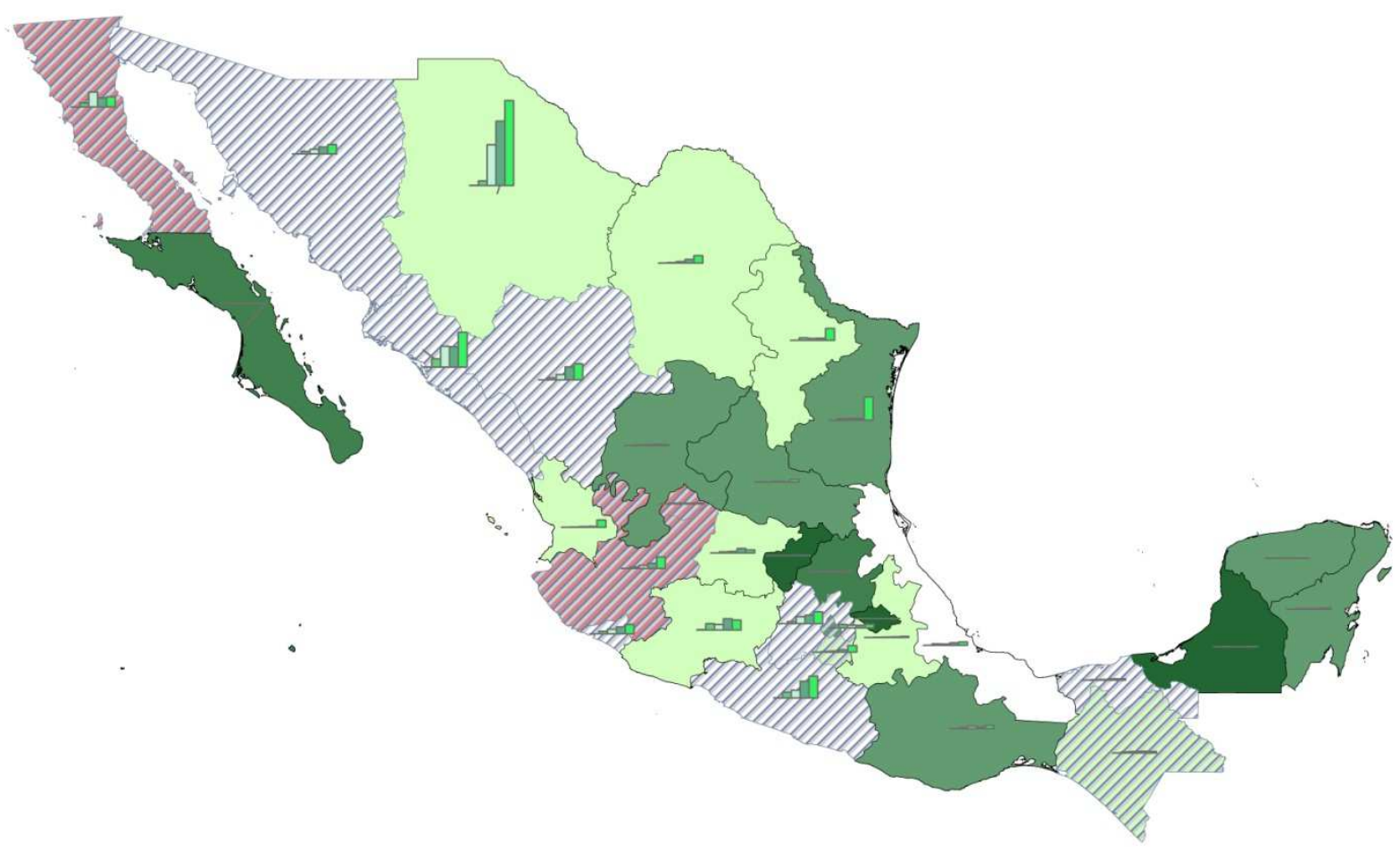

of gang murder is the result of competition between different organizations, the numbers furthermore indicate in which regions the clashes between narcotrafficking cartels are especially intense.

Foremost, it is observable that especially the northern states of Baja California, Sonora, Chihuahua, Coahuila, Nuevo Leon and Tamaulipas show increased levels of gang murder while states in the middle and South of Mexico also exhibit increases but at a lower rate. Detailed regression results at the state level, information on the statistical significance of the coefficient of interest, the average rate of drug enforcement in states during the time period of 1998 to 2008 as well as the data on gang murder for all states are provided in Table B. 3 in the appendix.

In the graphs, the estimation result for the coefficient of interest - the share of drug arrests among all arrests - is represented by color shades. Green (red) shades indicate a negative (positive) relationship between drug enforcement and the prevalence of the four different offence types. Therefore, public safety is furthered by intensified drug enforcement in all states colored in green, and deteriorates in states colored in red color. More intense coloration represents a quantitatively stronger 
Figure II.3: Effect of drug enforcement on the prevalence of murder

(coefficients calculated at state level)

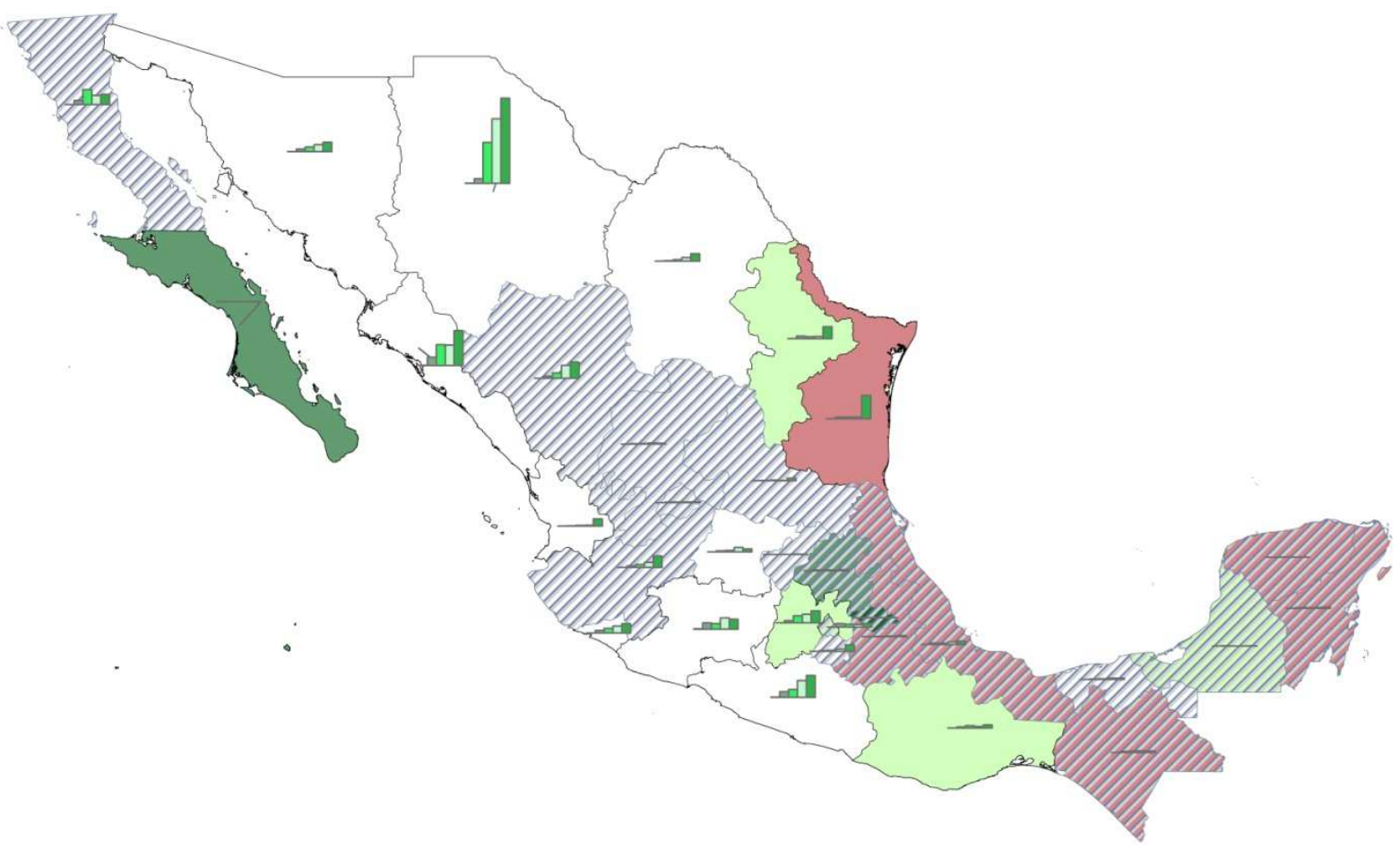

impact of drug enforcement on public safety. All states for which the predicted coefficient is estimated to be below the value of 0.5 are coded in white. Also note that the color shades are hatched for states for which the hypothesis of no relationship between drug enforcement and an offence could not be rejected at conventional levels of significance.

Turning to the graphical representation of results for the four offence types, the first noteworthy finding is the considerable variation in the predicted impact of drug enforcement across states and offence types. While a clear distributional pattern in terms of states with high and low impact cannot be explicitly inferred from the four graphs, the most sizeable impact of drug enforcement are predicted in states which are either at a certain distance from the country's Northern border or in remote parts of the country such as Baja California Sur. Interestingly, while the predicted impact of drug enforcement was always negative for the overall sample, thus indicating an improvement of public security, the outcome is now more diverse for the state-based regressions. As can be seen in Graphs II.3 and II.4, an increase in the share of drugbased arrests among all arrests, actually raises the number of murders and rapes in 
Figure II.4: Effect of drug enforcement on the prevalence of rape

(coefficients calculated at state level)

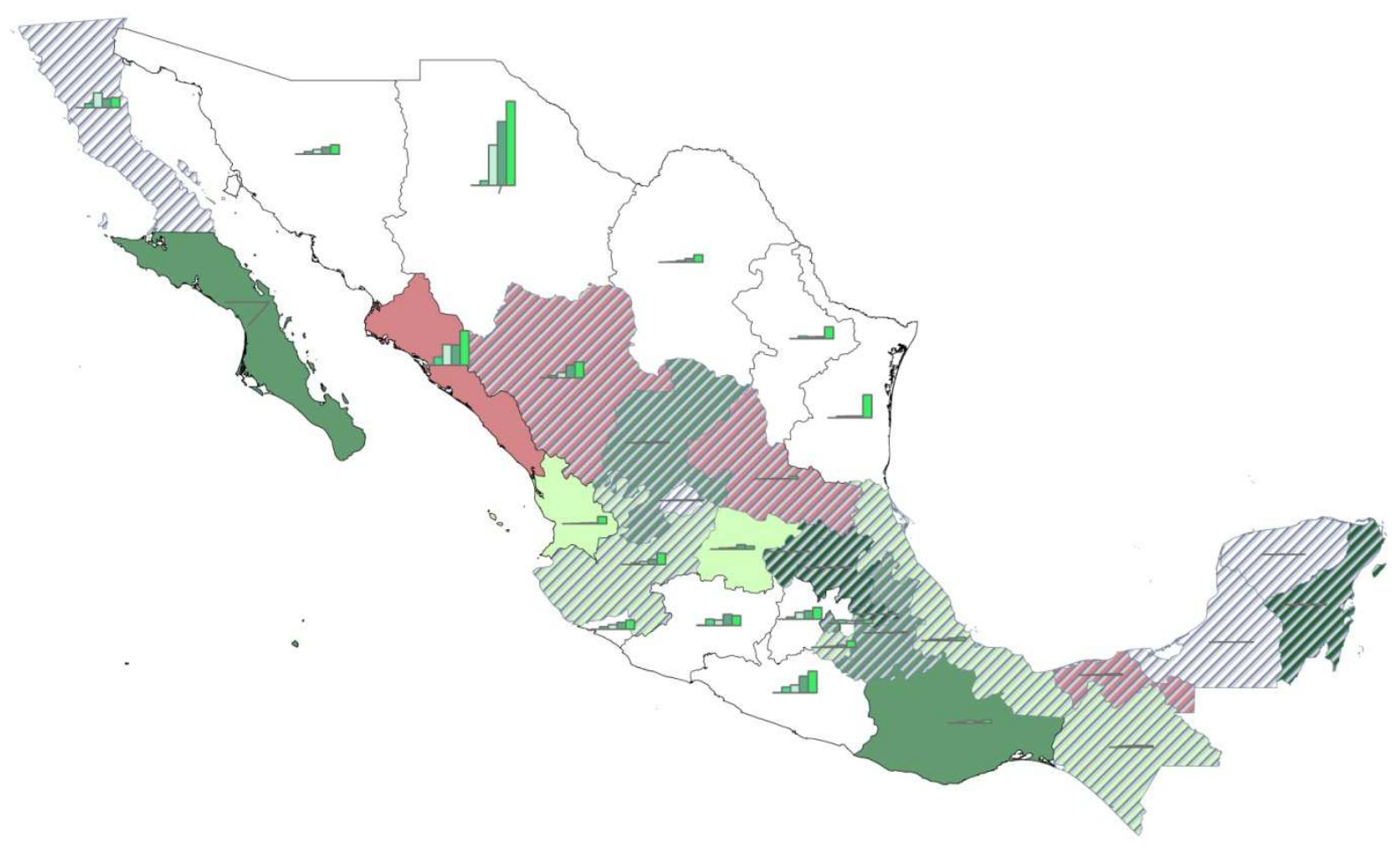

two states. Also, statistical significance of the coefficient of interest varies to a considerable extent across states and the four offence types.

This outcome is, however, considerably more informative when taking into account the distributional pattern of gang killings across states. As mentioned above, a high number of gang homicides is an indicator for strong presence and rivalries between the competing cartels. This is illustrated by the fact that especially the northern half of the country suffers from a great number of gang-related homicides. With regards to the variable of interest, it is noticeable that the above discussed incapacitation effect of drug enforcement is comparatively weaker in states with a high prevalence of gang murder. This outcome is visible, for example, for the number of robberies and assaults while in the case of the latter offence the coefficient of interest is not only systematically lower in cartel hotspots but often completely insignificant at conventional levels. This trend is accentuated for the more severe offences of murder and rape. As can be seen in Graphs II.3 and II.4, all states in which cartel violence is sufficiently pronounced to be visible in the homicide statistics is the predicted effect of drug enforcement either marginal in size or statistically insignificant at conventional levels. 
The consequences of the 'War on Drugs' displayed in the overall sample and those stated in the existing literature are quite salient. Whereas overall results based on the aggregate sample support the claim that Mexico's 'War on drugs' contributes to public safety, the effect is heterogeneous across Mexican states. Here, the statement that Mexico's War on Drugs - as ineffective as it might be at containing drug trafficking - at least furthers public safety cannot be affirmed for all states. Even more so, the beneficial process of incapacitation deteriorates in the wake of rampant gang violence. This outcome may indicate that states with numerous narcotrafficking gangs concentrate a lot of resources on the fight against these criminals, while small scale drug vendors and users face a smaller risk of being caught and convicted. This implies, however, that a lot of potential criminals are not locked up. The opposite occurs in states which are relatively less affected by a high concentration of trafficking organizations. Here, drug enforcement translates into an overall reduction of crime as the systematic arrest of drug offenders incapacitates a sizeable amount of potential repeat offenders.

\section{4 Conclusion}

This paper analyzes Mexico's experience in the 'War on Drugs' and empirically assesses whether, as well as to what extent, this significant intervention against drug trafficking organizations is creating spillover effects in terms of promoting or deteriorating public safety. An extensive body of literature has laid the groundwork for the analysis of the effects and efficiency of crime enforcement, discussing the deterrence effect of penalization, the incapacitating effect of locking up criminals, and the repercussions of focusing law enforcement on one predominant issue such as narcotrafficking. Despite the existence of this comprehensive literature, none of these concepts have - to the author's best knowledge - been applied in an empirical investigation to the 'War on Drugs' in Mexico. This is surprising given that the country now carries key responsibilities in the 'War on Drugs' and assigns a considerable share of its budget towards the fight against narcotrafficking organizations.

By constructing a comprehensive dataset on the development of criminal and economic statistics based on municipal data from different sources, this paper quantifies the effect of drug enforcement on non-drug related crime at the district 
level between 1998 and 2008. For the overall sample, results indicate that the incarceration of drug offenders significantly reduces the prevalence of property crime, assault, rape and murder and it thus appears to be beneficial to public security. Empirical results are found to be highly robust across different estimation techniques as well as the breakdown into sub-samples. However, the effect is especially sizeable for the two less severe offences - robbery and assault - under analysis, while murder and rape are to a smaller extent contained by drug enforcement. Most strikingly, my empirical results suggest that the transmission mechanism from drug enforcement to the universal fight of crime - i.e., the incapacitation effect significantly hinges on the prevalence of gang murder and thus the concentration of drug cartels across federal states.

Taken together, my findings are partially in line with the strand of the literature predicting positive spillover or incapacitation effects through focusing law enforcement resources on drug offenders and stand in contrast to what past studies of drug enforcement efforts have found for the case of the United States. However, the outcome also indicates that the observed beneficial effect of drug enforcement on public security is only achievable in a context in which drug cartels are contained. 


\title{
Chapter III
}

\section{Paying a Visit: The Dalai Lama Effect on International Trade}

\author{
Joint work with Andreas Fuchs ${ }^{a}$
}

\begin{abstract}
Is political compliance a precondition for healthy trade relations with China? The Chinese government frequently threatens that meetings between its trading partners' officials and the Dalai Lama will be met with animosity and ultimately harm trade ties with China. We run a gravity model of exports to China from 159 partner countries between 1991 and 2008 to test the extent to which bilateral tensions affect trade with autocratic China. In particular, we empirically investigate whether countries that receive the Dalai Lama despite China's opposition experience a significant reduction in their exports to China. In order to account for the potential endogeneity of meetings with the Dalai Lama, the number of Tibet Support Groups and the travel pattern of the Tibetan leader are used as instruments. Our empirical results support the idea that countries officially receiving the Dalai Lama at the highest political level are punished through a reduction of their exports to China. However, this 'Dalai Lama Effect' is only observed for the Hu Jintao era and not for earlier periods. Furthermore, we find that this effect is mainly driven by reduced exports of machinery and transport equipment and that it disappears two years after a meeting took place.
\end{abstract}

\begin{abstract}
Acknowledgements: The authors thank Axel Dreher and Stephan Klasen; Christian Bjørnskov, Ron Davies, Jana Friedrichsen, Samuel Kortum, Christoph Moser, Randall E. Newnham and Bernd Süßmuth; participants at presentations at University of Goettingen, Germany, RWTH Aachen University, Germany, and Princeton University, U.S.A.; and conference participants at the Beyond Basic Questions Workshop 2010 at the University of Aarhus, Denmark, the Silvaplana Workshop of Political Economy 2010 in Pontresina, Switzerland, the Annual Conference of the European Trade Study Group 2010 in Lausanne, Switzerland, the CESifo Workshop on Political Economy, Dresden, Germany, the ISA Annual Convention 2011 in Montreal, Canada, and the Meeting of the European Public Choice Society 2011 in Rennes, France, for valuable comments on earlier drafts. Excellent research assistance was provided by Hendrik van Broekhuizen, Juliane Kästner, Karla Henning and Katharina Richert.
\end{abstract}

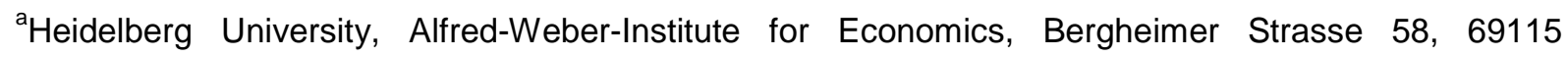
Heidelberg, Germany 
"We will take corresponding measures to make the relevant countries realise their mistakes."

Zhu Weiqun, executive deputy head of the Communist party's United Front Work Department in an official press statement given on February 2nd, 2010, in the forerun of a potential reception of the Dalai Lama by Barack Obama

"There is a Tibetan saying: some wounds in the mouth recover by themselves." Tendzin Gyatsho, $14^{\text {th }}$ Dalai Lama

\section{III.1 Introduction}

Political determinants of trade have received considerable attention in the literature (e.g, Aidt and Gassebner 2010; Méon and Sekkat 2008; Nitsch and Schumacher 2004). Previous research has shown that diplomatic exchanges between trading partners foster bilateral trade through diplomatic representations (Rose 2007) and state visits (Nitsch 2007). However, the importance of economic diplomacy for trade has been questioned recently (Head and Ries 2010). Furthermore, there is mixed evidence on whether the bilateral political climate plays an important role in trade relationships (e.g., Pollins 1989; Gowa and Mansfield 1993; Davis and Meunier 2011). In this context, political relations with state-controlled economies are more likely to impact trade than in the case of trade between free-market economies. In this regard, Aidt and Gassebner (2010) theoretically and empirically show that a country's involvement in international trade differs between democracies and autocracies. Since China is neither a democracy nor a free market economy, its administration has a greater capacity to influence trading decisions than a government in a democratic free-market economy. Such significant scope for government intervention opens up the opportunity to utilize trade flows as a foreign policy tool.

Since the leader of the Tibetan community, the $14^{\text {th }}$ Dalai Lama, travels frequently and over long periods of time, his travel pattern offers a valuable case to empirically test the extent to which political relations matter for trade with statecontrolled economies. China considers the status of Tibet as an internal affair, in 
which any outside interference is rejected. ${ }^{87}$ Therefore, official receptions of the Dalai Lama regularly lead to severe diplomatic tensions between China and countries hosting him. In addition to purely diplomatic threats, China warns potential host countries that it will respond to such meetings with a deterioration of their trade relationships. The government's decisiveness on this matter is reflected in instances such as the prominent case of France, where the country was crossed off the travel agenda of two Chinese trade delegations in retaliation to a meeting between French President Nicolas Sarkozy and the Dalai Lama in 2008. In an interview conducted in 2007, the Dalai Lama himself acknowledged the unwillingness of state officials to receive him, so as not to jeopardize the intense economic ties that their countries have established with China. ${ }^{88}$

To the best of our knowledge, to date no empirical analysis has been conducted unveiling whether China responds to meetings between its trading partners and the Dalai Lama with any systematic economic punishment. This paper aims to fill this gap. Moreover, results may offer valuable insights into the extent to which political relations matter for trade with state-controlled economies. We run a gravity model of exports to China from 159 partner countries between 1991 and 2008 to test whether countries that receive the Dalai Lama are economically punished by the Chinese through a reduction in their exports to China. We also test whether the size of the punishment increases with the rank of the highest official receiving the Tibetan leader and how the effect evolves over time. Furthermore, we provide results when controlling for the potential endogeneity of meetings with the Dalai Lama and exploit disaggregated trade data to deepen our understanding of what we call the 'Dalai Lama Effect'.

Does China carry out its threats to sanction non-compliant trading partners or does the emerging economy simply play on its targets' fears? Our empirical results confirm the existence of a negative effect of Dalai Lama receptions at the highest level on exports to China for the Hu Jintao era (2002-2008). Meetings between a head of state or head of government and the Dalai Lama lead to a reduction of exports to China by $8.1 \%$ or $16.9 \%$, on average, depending on the estimation

\footnotetext{
${ }^{87}$ See Goldstein (1997) for a historical overview on the so-called 'Tibet Question', i.e., the long-lasting conflict over the political status of Tibet.

88 "Dalai Lama Visit Jeopardizes German Business Interests," Spiegel Online, September 17' 2007, available at: http://www.spiegel.de/international/world/0,1518,506166,00.html (accessed: July 12, 2012).
} 
technique used. This effect is mainly driven by reduced exports of machinery and transport equipment and it disappears in the second year after a meeting took place.

The paper is structured as follows: Section 2 provides a literature overview to gain insights into how meetings with the Dalai Lama might adversely affect exports to China. Moreover, we illustrate how the bilateral climate between China and its trading partners deteriorates after meetings between foreign officials and the Tibetan leader, and develop our hypotheses. Section 3 presents the empirical approach, the data used and the empirical results. Finally, Section 4 summarizes our findings and concludes.

\section{III.2 The Argument}

\section{III.2.1 Political Determinants of Trade and the 'Dalai Lama Effect'}

Trade ties can be exploited as a foreign policy tool by governments to influence the political decisions of trading partners. Research has been devoted to the analysis of the effectiveness of economic sanctions to induce political compliance (e.g., Eaton and Engers 1992; Hufbauer Schott and Elliot 2007). Our study, however, investigates whether the threats frequently voiced by China's administration are actually carried out to sanction trading partners in response to an official reception of the Dalai Lama. With the rapidly expanding size of the Chinese economy, the asymmetry of trade dependencies between China and its trading partners is shifting in China's favor. This development enables China to enforce political compliance among its trading partners to an ever increasing extent. ${ }^{89}$ Despite the country's growing scope for economic retaliation, the Chinese administration does not communicate in a transparent manner whether, and to what extent, it actually retaliates after a Dalai Lama reception has taken place. ${ }^{90}$

There is a large literature discussing whether politics matter for bilateral trade relationships. While some studies focus on the link between military conflicts and trade (e.g., Glick and Taylor 2005; Martin et al. 2008), conflicts do not need to be

\footnotetext{
${ }^{89}$ The degree of political compliance that can be induced by the dominant country increases with the asymmetry of the trade interdependency between the two trading partners (Keohane and Nye 1977; Richardson and Kegley 1980).

${ }_{90}$ Eaton and Engers (1999) argue that such incomplete information about the threatening country's resolve, as well as about the target's cost of compliance, induces the former to carry out threats to sanction non-compliant countries.
} 
militarized in order to influence trade flows. An anticipated conflict alone might trigger reductions of bilateral trade due to "the threat of future government action to restrict trade" (Morrow et al. 1998: 650). Importantly, trade reductions are not necessarily the result of direct government action to sanction a state. While pure economic theory suggests that economic actors base their trading decisions entirely on intrinsic characteristics of goods and services such as price, quantity and quality, political relations exert additional influence on private actors' decisions. In a public choice model of bilateral trade, Pollins (1989) argues that importing decisions of economic agents are influenced by the place of origin of traded goods and services. Based on security concerns, risk-averse importers reward political friends and punish adversaries in order to minimize commercial risks related to potential trade disruptions. ${ }^{91}$ A recent study by Davis and Meunier (2011), however, raises doubts over the link between political tensions and international trade in the era of globalization. They argue that actors that face sunk costs "lack incentives to link political and economic relations" (p. 1). Analyzing trade patterns of the United States and Japan since the end of the Cold War, the authors do not find that political tensions have an impact on bilateral trade.

Economic diplomacy is one of the channels via which the state of political relations might impact on trade. There is mixed evidence whether diplomatic exchanges among trading partners foster bilateral trade. Analyzing export flows from 22 countries for 2002 and 2003, Rose (2007) finds that the size of a country's diplomatic service has a positive impact on its exports: each additional consulate leads to an increase of exports by about six to ten percent. Most relevant to our study, Nitsch (2007) finds empirical evidence that state and official visits have a trade-increasing effect. Estimating export flows from France, Germany and the United States for the 1948-2003 period, he finds that one additional visit is associated with an increase in exports of between eight and ten percent. While GilPareja et al. (2008) find that Spanish regional trade agencies abroad have a positive impact on exports, Head and Ries (2010) do not find empirical evidence that Canadian trade missions have a trade-promoting effect.

\footnotetext{
${ }^{91}$ Using bilateral event data on conflict and cooperation for the period 1955-1978, Pollins' (1989) empirical results support the hypothesis that greater amity between trading partners increases trade, while greater hostility has a trade-reducing effect. In a related contribution, Gowa and Mansfield (1993) show that alliances between trading partners foster bilateral trade.
} 
Arguably, the effect of politics on trade might depend on a country's regime type. Political relations clearly influence bilateral trade, with the extent of this influence varying between political regimes "since governments in free market economies still set the rules under which firms import and export, while governments in managed economies directly negotiate the terms of trade" (Morrow et al. 1998: 649). In line with this, Mansfield et al. (2000) discuss regime differences in trade policy that emerge as the chief executive does not rely on the approval of a legislative majority in an autocracy. In a related article, Aidt and Gassebner (2010) theoretically and empirically show that autocratic governments exert more influence on trade flows than democratic administrations, which they explain by a lack of political accountability faced by the executive of an autocratic regime.

Taken together, in the case of China, the significant scope of government influence in the Chinese economy provides the country's political leaders with all the means required to manage trade in such a way that it rewards countries that adhere to China's political preferences and punishes those that do not. Since meetings of foreign officials with the Dalai Lama cause a deterioration of the bilateral political climate and a decrease in bilateral diplomatic exchanges, a meeting may subsequently lead to a systematic reduction of exports to China through government influence. For example, countries receiving the Tibetan leader might be punished directly through a reduction of trade missions and, thus, exports of goods typically purchased in the ambit of such missions. Also, tariff and non-tariff barriers might be raised and negotiations regarding free trade agreements might be postponed as a response to receptions of the Dalai Lama by foreign officials.

China's political leadership may be willing to bear the economic and political costs that arise from diverting trade away from countries receiving the Dalai Lama if such 'punishment' increases the likelihood of its political survival. By exerting economic pressure on these countries, the Chinese administration seeks to suppress any notion potentially challenging the territorial integrity of China and intends to strengthen the stability of its Communist regime in the multiethnic country. A punishment is imposed if the benefits from maintaining a reputation for toughness outweigh the costs of punishing a certain nation (Eaton and Engers 1999). China might be interested in carrying out a threat to sanction countries receiving the Dalai Lama in order to signal resolve, with the intention being to deter foreign leaders from future receptions of the Tibetan leader. However, any economic punishment 
mechanism will only prevail as long as the expected political gains from stabilizing the regime outweigh the losses incurred through trade diversion.

Finally, it should also be mentioned that a trade-deteriorating effect of official Dalai Lama receptions may also operate through consumer behavior. Prior empirical research indicates that bilateral opinions (or the affinity between nations) impact on trade as they shift consumer preferences (Disdier and Mayer 2007; Guiso et al. 2009). ${ }^{92}$ Similarly, the state of bilateral political relations between China and its trading partners might have important repercussions for consumer behavior. Since media information on foreign officials meeting with the Dalai Lama may alter public opinions towards countries receiving the Tibetan leader, Dalai Lama receptions can be expected to affect the demand for consumption goods, in particular certain symbolic goods that are characteristic of the country hosting the Dalai Lama. ${ }^{93}$

\section{III.2.2 Hypotheses}

Although the Dalai Lama himself emphasizes the non-political nature of his visits, China perceives any meeting of foreign officials with the Buddhist monk as interference with internal affairs. Therefore, Beijing increasingly exerts economic pressure on foreign governments in order to discourage meetings with the Dalai Lama. As early as 1989, when the Dalai Lama was awarded the Nobel Peace Prize in Oslo, China threatened to cut economic ties with Norway if the Norwegian king or government attended the ceremony. ${ }^{94}$ Similarly, the plans of Italy's Prime Minister Silvio Berlusconi to receive the Dalai Lama in 1995 provoked warnings by his Chinese counterpart that "if this [the Italian] government will adopt a policy that could damage a matter of principle [for China], it may also damage trade relations. ${ }^{95}$ In regards to this, Berlusconi openly admitted that the international community was

\footnotetext{
${ }_{92}$ Using Eurobarometer opinion data on the accession of Central and East European countries to the European Union, Disdier and Mayer (2007) show that 'bilateral affinity' has a trade-increasing effect. In a related study, Guiso et al. (2009) find that trade increases significantly with their measure of bilateral trust obtained from Eurobarometer surveys. Beyond its effect on trade via trust, cultural similarities seem to positively impact on trade volumes via other channels.

${ }_{93}$ For example, the disruption of the Olympic torch relay of the 2008 Beijing Olympic Games through the French capital Paris by pro-Tibet activists caused irritation among the Chinese public and subsequently sparked calls for a consumer boycott against French products.

94 "China Threatens to Cut Ties with Norway over Nobel Award," The Associated Press, October 19, 1989.

95 "Li Peng "diffida" Berlusconi; II Cavaliere l'aveva promesso a Pannella. Ma Pechino avverte: "Sono in pericolo le relazioni commerciali," La Stampa, June 15, 1994, p. 4, own translation.
} 
"caught between the importance of maintaining trade relations and protecting human rights." 96

Similarly, the reception of the Dalai Lama by Germany's head of government Angela Merkel in the chancellery caused tensions between China and Germany in 2007. Before the meeting, China warned that an encounter would severely damage economic ties. After the reception of the Dalai Lama, China responded by cancelling several bilateral meetings with German officials at various political levels. The chancellor's foreign policy was said to come with a "Merkel cost" for business, according to a press article entitled "The Cost of Being Honest."" After the announcement of a meeting between French President Nicolas Sarkozy and the Dalai Lama in 2008, China cancelled the $11^{\text {th }}$ annual EU-China summit as well as talks regarding the finalization of a contract to purchase 150 passenger planes from the Franco-German aerospace company Airbus. ${ }^{98}$ After the meeting with the Dalai Lama, China crossed France off the travel agenda of two Chinese trade delegations. Our first hypothesis thus reads as follows:

Hypothesis 1: There is a trade-deteriorating effect caused by foreign officials receiving the Dalai Lama.

It seems unlikely that this 'Dalai Lama Effect' - if existent - is independent of the rank or the political importance of the dignitary met. Meetings with higher-ranking politicians pose a greater affront to the Chinese, who may then retaliate through a more pronounced reduction in bilateral trade. For example, during his 1995 visit to the United States, the Dalai Lama was formally received by a minister of the Clinton administration only, but President Bill Clinton dropped in during the talks. A related New York Times article suggested that a better treatment of the Dalai Lama "would [have] cost us [the United States] trade with the Chinese."99

\footnotetext{
96 "'Italia, grazie per il coraggio"; II leader tibetano a Palazzo Chigi, per la prima volta un governo italiano sfida il veto cinese", La Stampa, June 18, 1994, p. 7, own translation.

97 "Merkel Foreign Policy Is Bad for Business," Spiegel Online, October 23, 2007, available at: http://www.spiegel.de/international/germany/0,1518,513067,00.html (accessed: July 12, 2012).

98 "China tells France Dalai Lama meeting could hurt trade," AFP, December 4, 2008, available at: http://www.google.com/hostednews/afp/article/ALeqM5ifBAQ8quVlihgqVgOrfEUzkzrHWg (accessed: July 12, 2012).

99"On My Mind; If He Can, Can I?" The New York Times, September 15, 1995, available at: http://www.nytimes.com/1995/09/15/opinion/on-my-mind-if-he-can-can-i.html (accessed: July 12, 2012).
} 
This example illustrates that some leaders prefer to delegate a meeting with the Dalai Lama to lower-ranking government representatives in the hope of reducing the negative effect that such meetings may have on bilateral relations with China. By employing such a strategy, the government still manages to sedate pro-Tibet lobby groups, human rights organizations and other sympathizers of the Dalai Lama. For example, although Dutch Prime Minister Jan Peter Balkenende feared that a personal meeting with the Dalai Lama would bring "unwarranted risk" to Sino-Dutch relations, some members of parliament and the country's foreign minister met with the Tibetan leader during his visit in $2009 .{ }^{100}$ The Dalai Lama himself remarked that most politicians start avoiding meetings with him after they become minister or president. He concluded that "economic relations with China gain the upper hand."101 Therefore, we derive the following hypothesis:

Hypothesis 2: The detrimental effect of meetings with the Dalai Lama on exports increases with the rank of the dignitary met.

Facing a trade-off between the economic losses incurred from trade diversion and the political gains from stabilizing the regime, it is in China's best interest that trade ties are restored as quickly as possible to reduce the economic losses that arise from the political bias in its importing decisions. At the same time, China's trading partners are also interested in a restoration of trade ties and are likely to direct diplomatic efforts towards restoring these bilateral relations. For example, nine months after the meeting between French President Nicolas Sarkozy and the Dalai Lama, France declared that it recognized Tibet as an integral part of the Chinese territory and, consequently, went "back on China's shopping list" as reported by China Daily, which refers to the point when France received the first trade delegation after the tensions. ${ }^{102}$ Along these lines, we expect exports to China to recover after a

\footnotetext{
100 "Dalai lama meets foreign minister, but not prime minister," NRC Handelsblad, June 5, 2009, available http://www.nrc.nl/international/article2262841.ece/Dalai lama meets foreign minister, but not prime minister (accessed: July 12, 2012).

${ }^{101}$ „Ich will eine echte Autonomie," Cicero Magazin für Politische Kultur, January 1, 2008, own translation, available at: http://www.cicero.de/weltbühne/\%3Fich-will-eine-echte-autonomie\%3F/23497 (accessed: July 12, 2012).

102 "France goes back on China's shopping list," China Daily, October 29, 2009, available at: http://www.chinadaily.com.cn/china/2009-10/29/content 8865307.htm (accessed: July 12, 2012). 
certain period, i.e., the trade-deteriorating effect of Dalai Lama meetings is only of temporary nature:

Hypothesis 3: The trade-deteriorating 'Dalai Lama Effect' disappears as bilateral relations between China and partner countries recover.

If purchases were only postponed as a signal of temporary Chinese discontent after a Dalai Lama meeting, a positive 'Dalai Lama Effect' may even develop after a while as Chinese imports make up for past cutbacks. For the interested reader, Appendix C offers a more detailed analysis of available anecdotal evidence on how the bilateral climate between China and its trading partners is influenced by meetings of foreign officials with the Dalai Lama.

\section{III.3 Empirical Analysis}

\section{III.3.1 Data and Method}

We estimate econometrically whether and to what extent the diplomatic tensions caused by official receptions of the Dalai Lama impact negatively on the volume of exports to China. Our econometric model builds on the gravity equation of international trade, the workhorse for statistical analyses of trade flows, which translates Newton's 'Law of Universal Gravitation' to economics. The gravity model assumes that bilateral trade is proportional to the product of the trading partners' economic masses, proxied by GDP, and inversely proportional to the geographic distance between them. In order to control for country heterogeneity, we make use of partner country fixed effects. The effect of bilateral distance and other time-invariant factors, such as being landlocked or contiguous, is thus captured by the partner country fixed effects. ${ }^{103}$ In addition to partner country GDP, we add population size and the bilateral exchange rate to our specification, two frequently used variables in the gravity framework. Moreover, we control for time-specific factors by including dummy variables for each time period. We run the following econometric model:

\footnotetext{
${ }^{103}$ The inclusion of a full set of country-by-time effects is not feasible in our model as we estimate bilateral exports to a single country (China).
} 


$$
\text { exports }_{i t}=\beta_{1} \text { dalai }_{i t}+\beta_{2} g d p_{i t}+\beta_{3} \text { pop }_{i t}+\beta_{4} \text { exch }_{i t}+\gamma_{t}+\delta_{i}+\varepsilon_{i t}
$$

where exports ex $_{i t}$ is the $\log$ of exports of partner country $i$ to China at time $t$ in US dollars; $g d p_{i t}$ is the log of the partner country's gross domestic product in US dollars; pop $_{i t}$ is the log of the partner country's population size; $\operatorname{exch}_{i t}$ is a nominal exchange rate index of the partner country's local currency unit in Yuan; $\gamma_{t}$ and $\delta_{i}$ are time and country fixed effects; and $\varepsilon_{i t}$ is a stochastic error. Trade data are obtained from the United Nations COMTRADE database. ${ }^{104}$ Data on GDP, population size and exchange rates are drawn from the World Development Indicators (World Bank 2009).

Our variable of interest is the binary dummy variable dalai $i_{i t}$, which takes a value of 1 if the Dalai Lama was received by a dignitary in the partner country in year $t$ or $t-1 .^{105}$ Information on the travel pattern of the Buddhist leader is obtained from the Office of His Holiness the 14th Dalai Lama. ${ }^{106}$ The variable is coded in four different ways: In its narrowest definition, we only include Dalai Lama meetings with heads of state or government. Our second definition extends the first by including all meetings between the Dalai Lama and government members. By also adding encounters with speakers of parliament, the third definition produces a dummy variable that accounts for all meetings between the Dalai Lama and national officials. Finally, we construct a variable that incorporates all meetings of the Tibetan leader that are listed by the Office of the Dalai Lama. This definition also includes regional leaders, party leaders, ex-presidents, ambassadors and scientists, among others. Furthermore, we construct a binary dummy variable that takes a value of 1 if the Dalai Lama travelled to a Chinese trading partner country in a given year, irrespective of whether or not the Tibetan leader met with any dignitary there.

Our dataset covers the period 1991 to 2008. Hypothesizing that a potential 'Dalai Lama Effect' might only be observable in more recent years, in which China's

\footnotetext{
${ }^{104}$ Since Belgium and Luxembourg did not report trade data separately for the years prior to 1999, we use the GDP-weighted values of exports from Belgium-Luxembourg instead.

${ }^{105}$ The reason why we also include the lagged value is because it may take some time for the diplomatic tensions to translate into an actual decrease in trade values. Since trade flows are tied to contracts, the 'Dalai Lama Effect' may only become visible in trade statistics with a certain time delay. However, our results do not hinge on this assumption. At a later point, we also show results for different definitions of the variable of interest.

${ }^{106}$ Data are available at $\mathrm{http}: / / \mathrm{www}$.dalailama.com/ (accessed: April 2010). Information was completed with information provided on http://www.buddhismtoday.com (accessed: April 2010).
} 
economic and political power grew significantly, we further split our dataset into two periods: 1991-2001 and 2002-2008. Two main arguments motivate 2002 as an appropriate point at which to split our sample. First, the leadership change that occurred when Huo Jintao took power of the Communist Party in $\mathbf{2 0 0 2}$ may have reoriented China's foreign policy towards a more assertive advocacy of its global interests. Second, China became a WTO member in December 2001, which is likely to have significantly affected China's trading relations. Next, we extend the analysis by restricting our sample to European partner countries to compare the results from previous estimations with those for this more homogenous set of countries. ${ }^{107}$ Europe has been the most important travel destination of the Dalai Lama. Leaving aside his host country India, of the 266 trips that the he made between 1991 and 2008, 160 of them were to European countries.

All models are estimated using two estimation strategies: First, we run Fixed Effects regressions. Standard errors are adjusted for clustering across partner countries since a modified Wald test indicates groupwise heteroskedasticity. There is an emerging literature on biased estimates caused by the prevalence of zero trade flows in gravity models. In our sample, however, this issue seems to be negligible since the number of zero export flows is very small in our sample (57 of 2,269 observations, i.e., 2.5\%). Second, we rerun all models using Feasible Generalized Least Squares (FGLS) to account for cross-sectional heteroskedasticity across panels and autocorrelation. We employ a common $\mathrm{AR}(1)$ term since an estimation with a panel-specific AR(1) term would lead to biased results. As noted by Beck and Katz (1995), in contrast to a panel-specific $A R(1)$ term, the use of the FGLS correction for a common $\mathrm{AR}(1)$ is unlikely to lead to inaccurate estimations of the standard errors.

Panel A of Figure III.1 provides a geographical overview of the Dalai Lama's travel pattern in the 1991-2008 period, whereas Panel B and Panel B show a map indicating where and how many times the Dalai Lama was received by a government official or a political leader, respectively. In many cases, the Dalai Lama was not received by any government member during a visit to a country. Russia and Spain, both of which struggle with independence movements, are examples of this. Appendix A1 lists all the variables employed in the analysis along with their

\footnotetext{
107 Our definition of European countries excludes members of the Community of Independent States (CIS) to create a rather homogeneous group of countries. However, our results do not hinge on this definition.
} 
definitions and sources. Table C.2 provides descriptive statistics on all variables. Finally, Table C.3 lists all countries included in the analysis.

Figure III.1: Travel pattern of the Dalai Lama (1991-2008)

A. Dalai Lama visits

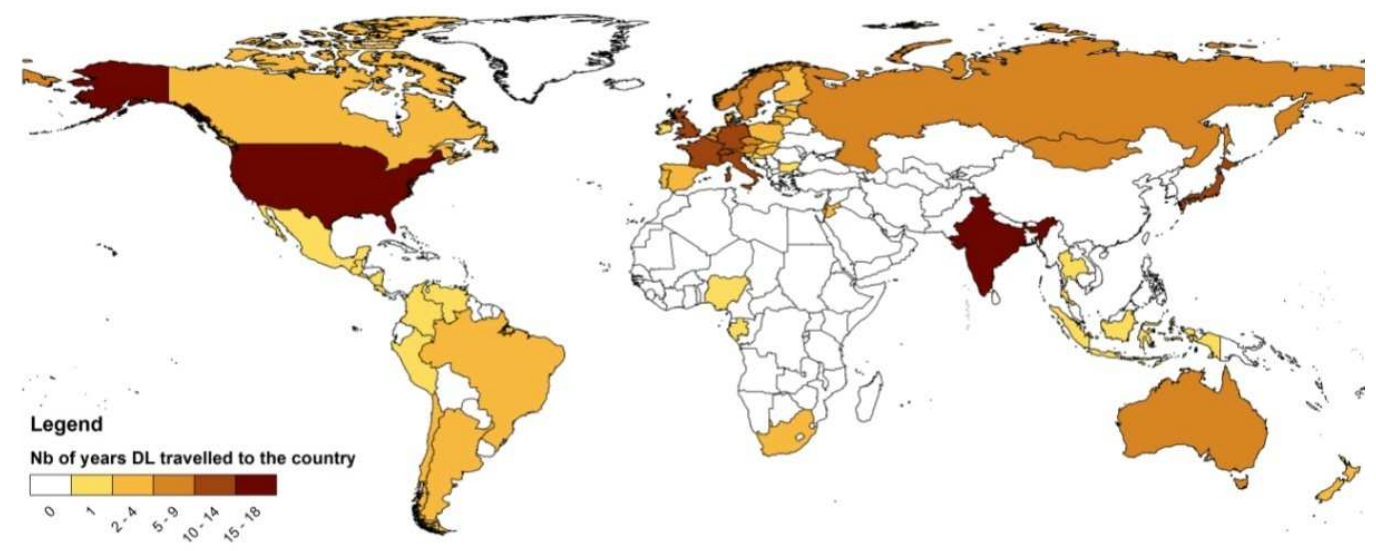

B. Dalai Lama meetings with government members

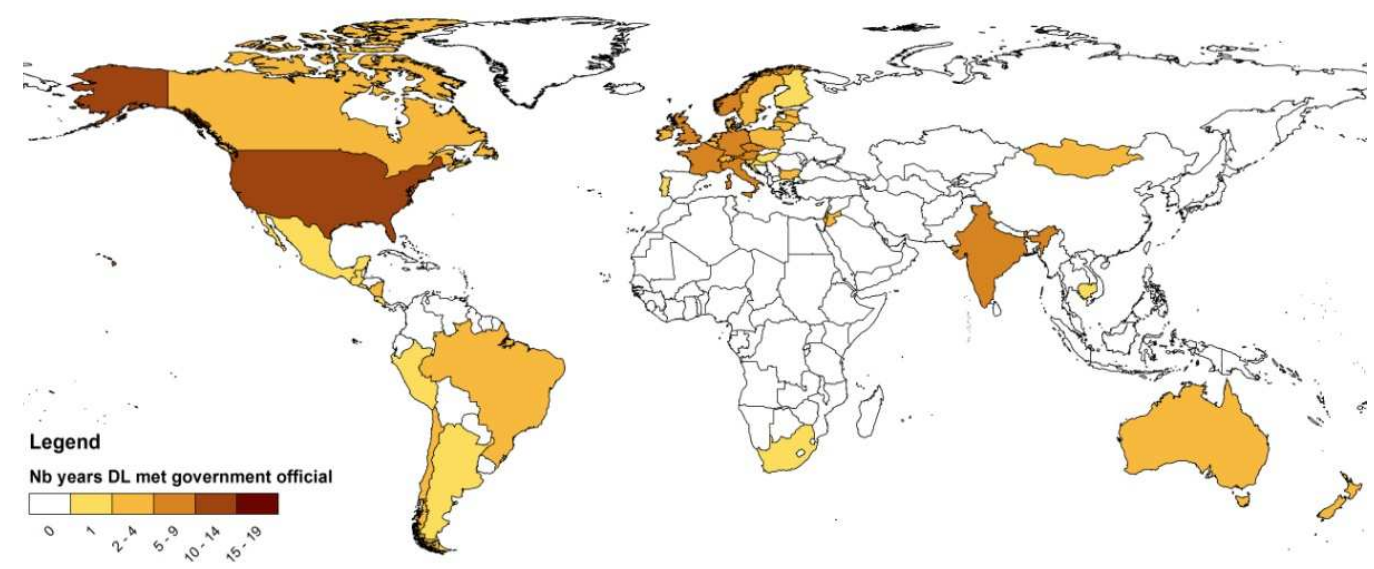

C. Dalai Lama meetings with political leaders

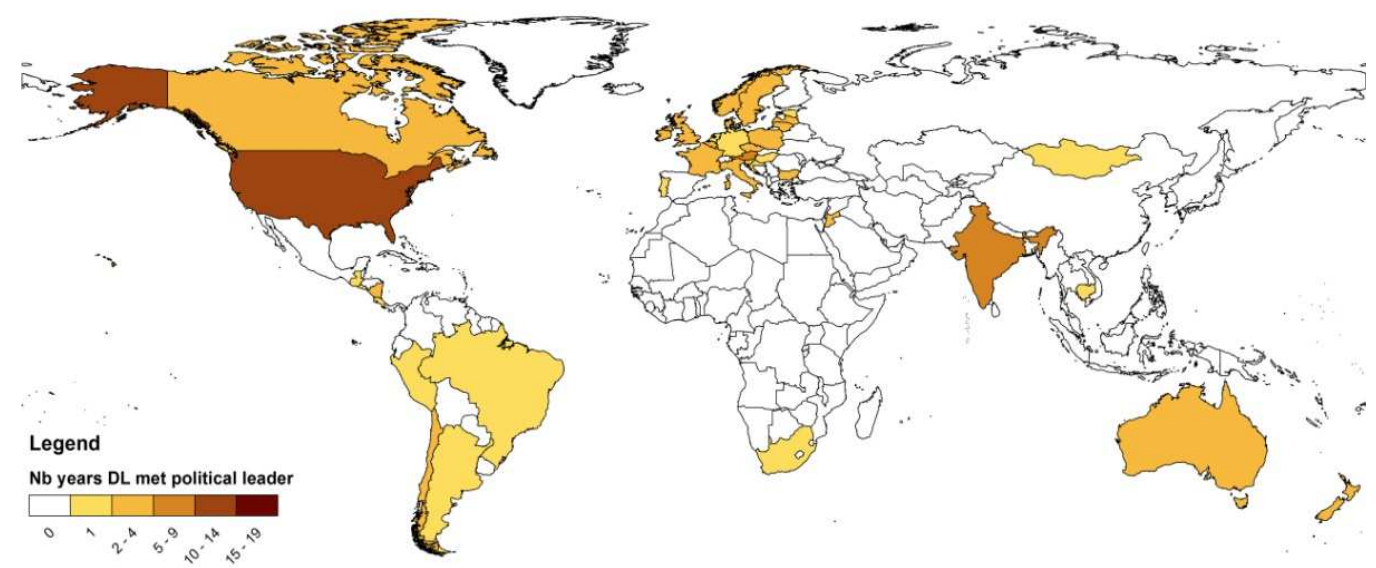

Source: Authors' calculations 
Table III.1: Exports to China and Dalai Lama meetings of gov. members (Hypothesis 1, all countries)

\begin{tabular}{|c|c|c|c|c|c|c|}
\hline & \multicolumn{3}{|c|}{ Fixed Effects } & \multicolumn{3}{|c|}{ FGLS AR(1) } \\
\hline & $\begin{array}{c}1991-2008 \\
\text { (1) }\end{array}$ & $\begin{array}{c}1991-2001 \\
(2)\end{array}$ & $\begin{array}{c}2002-2008 \\
\text { (3) }\end{array}$ & $\begin{array}{c}1991-2008 \\
(4)\end{array}$ & $\begin{array}{c}1991-2001 \\
\text { (5) }\end{array}$ & $\begin{array}{c}2002-2008 \\
(6)\end{array}$ \\
\hline DL meets government member & $\begin{array}{l}-0.102 \\
(0.296)\end{array}$ & $\begin{array}{l}-0.091 \\
(0.409)\end{array}$ & $\begin{array}{c}-0.133^{* \star} \\
(0.027)\end{array}$ & $\begin{array}{c}-0.080^{\star \star} \\
(0.019)\end{array}$ & $\begin{array}{c}-0.058^{\star} \\
(0.073)\end{array}$ & $\begin{array}{c}-0.059^{\star \star} \\
(0.011)\end{array}$ \\
\hline$(\log )$ GDP & $\begin{array}{c}0.597^{* *} \\
(0.019)\end{array}$ & $\begin{array}{l}0.816^{* *} \\
(0.040)\end{array}$ & $\begin{array}{l}-0.007 \\
(0.981)\end{array}$ & $\begin{array}{c}0.197^{\star *} \\
(0.011)\end{array}$ & $\begin{array}{c}0.311^{\star \star *} \\
(0.004)\end{array}$ & $\begin{array}{c}0.382^{\star \star *} \\
(0.000)\end{array}$ \\
\hline (log) Population & $\begin{array}{c}3.648^{\star \star \star} \\
(0.002)\end{array}$ & $\begin{array}{c}2.822 \\
(0.102)\end{array}$ & $\begin{array}{l}3.411^{\star *} \\
(0.035)\end{array}$ & $\begin{array}{c}0.501^{* \star *} \\
(0.001)\end{array}$ & $\begin{array}{c}0.272 \\
(0.176)\end{array}$ & $\begin{array}{c}2.689^{\star \star *} \\
(0.000)\end{array}$ \\
\hline (log) Exchange rate & $\begin{array}{l}-0.047 \\
(0.615)\end{array}$ & $\begin{array}{l}-0.059 \\
(0.594)\end{array}$ & $\begin{array}{c}0.158 \\
(0.357)\end{array}$ & $\begin{array}{l}0.042^{\star} \\
(0.084)\end{array}$ & $\begin{array}{l}-0.025 \\
(0.394)\end{array}$ & $\begin{array}{c}0.270^{\star \star \star} \\
(0.000)\end{array}$ \\
\hline R squared & 0.444 & 0.129 & 0.280 & & & \\
\hline Observations & 2,062 & 1,142 & 912 & 2,062 & 1,142 & 912 \\
\hline Number of countries & 159 & 148 & 151 & 159 & 148 & 151 \\
\hline
\end{tabular}

Notes:

- All regressions with country and time fixed effects.

- Robust p-values in brackets; ${ }^{*}$ significant at $10 \% ;{ }^{* *}$ significant at $5 \% ;{ }^{* * *}$ significant at $1 \%$

- Standard errors in Fixed Effects regressions are adjusted for clustering across partner countries.

- FGLS regressions are corrected for cross-sectional heteroskedasticity across panels and first order autocorrelation.

\section{III.3.2 Main Results}

Table III.1 reports empirical results for the entire sample testing our first hypothesis that meetings between the Dalai Lama and foreign officials have a trade-deteriorating effect. Results are reported for both Fixed Effects and FGLS. Starting with the results from the Fixed Effects regression, we find a negative coefficient on our dummy variable that takes a value of 1 if a government member has received the Tibetan leader in the current or previous year. However, the coefficient is only statistically significant in the second sub-period, which covers the Hu Jintao era (2002-2008). ${ }^{108}$ This result is in line with the increased political and economic power China has acquired in the world in recent years. We find that Dalai Lama meetings with a

\footnotetext{
${ }^{108}$ As a robustness check, we ran 159 regressions of the same model specification, each time excluding one of China's trading partners. In each case, the coefficient remained negative and statistically significant at conventional levels.
} 
government member decrease exports to China by $12.5 \%$ on average. ${ }^{109}$ The coefficient is statistically significant at the five-percent level. This effect is comparable in size to the effect of a state visit in Nitsch (2007) - of course in our case running in the opposite direction. FGLS results confirm the negative effect of Dalai Lama receptions on exports to China in the second sub-period. The expected impact on trade is significant at the five-percent level and, with $5.7 \%$, considerably smaller than the effect estimated under Fixed Effects. In addition, the FGLS results unveil a negative effect for the first sub-period as well as for the overall sample. Closer investigation, however, reveals that this finding is driven by product group 9 of the Standard International Trade Classification (SITC), a rather heterogeneous group of products. $^{110}$

In five of the six models in Table III.1, the coefficient on GDP is positive and thus in line with the gravity model of trade. It is only in the Fixed Effects model for the second sub-period that we do not find the expected positive coefficient on GDP. However, if we exclude the time dummies, the coefficient becomes positive and significant (results available upon request). Apparently, China's major trading partners were on the same business cycle during the second sub-period. Turning to the effect of the population size of China's trading partners, the corresponding coefficient is positive in all models, but not statistically significant at conventional levels in the first sub-period. This positive coefficient suggests the existence of export-promoting scale effects as a result of a larger population size. The coefficient on the nominal exchange rate is positive in the FGLS estimations for the overall sample and the second sub-period, which shows that a depreciation of the partner country's currency with respect to the Chinese Renminbi has a positive effect on their exports to China. Summing up to this point, empirical results consistently confirm that there is a trade-deteriorating effect caused by foreign officials receiving the Dalai Lama in the 2002- 2008 period (Hu Jintao era). ${ }^{111}$ In what follows, we thus restrict our analysis to this relevant time period.

\footnotetext{
${ }^{109} \exp (-0.133)-1=-12.5 \%$.

${ }^{110}$ We ran the same regression with product groups and found results in the first period (1991-2001) to be driven by exports from SITC section 9 ('Commodities and transactions not classified elsewhere in the SITC'). The negative significant effect of Dalai Lama meetings on exports vanishes when we exclude this group from the regression (see Appendix B2). SITC section 9 consists of 'Postal packages not classified according to kind', 'Special transactions and commodities not classified according to kind', 'Coin (other than gold coin), not being legal tender', and 'Gold, non-monetary (excluding gold ores and concentrates)'.

${ }_{111}$ Note that we do not claim that this finding is necessarily due to the personality of $\mathrm{Hu}$ Jintao. Alternatively, it may reflect the economic and political rise of China.
} 
Column 2 (Fixed Effects) and Column 7 (FGLS) of Table III.2 show results for a sample restricted to the more homogenous group of European countries that accounts for roughly half of all Dalai Lama receptions by government members. For the reader's convenience, we show the results of our baseline regressions from Table III.1 in column 1 (Fixed Effects) and column 6 (FGLS) of Table III.2. We also find evidence in favor of a trade-deteriorating effect in our European subsample. The estimated negative effect of Dalai Lama meetings at government level on European exports to China amounts to $11.5 \%$ in the Fixed Effects regression and $13.1 \%$ in the FGLS regression. 
Table III.2: Exports to China and Dalai Lama meetings of gov. members (alternative model specifications, 2002-2008)

\begin{tabular}{|c|c|c|c|c|c|c|c|c|c|c|}
\hline & \multicolumn{5}{|c|}{ Fixed Effects } & \multicolumn{5}{|c|}{ FGLS AR(1) } \\
\hline & $\begin{array}{l}\text { World } \\
\text { (1) }\end{array}$ & $\begin{array}{l}\text { Europe } \\
\text { (2) }\end{array}$ & $\begin{array}{l}\text { World } \\
\text { (3) }\end{array}$ & $\begin{array}{l}\text { World } \\
\text { (4) }\end{array}$ & $\begin{array}{l}\text { World } \\
\text { (5) }\end{array}$ & $\begin{array}{l}\text { World } \\
\text { (6) }\end{array}$ & $\begin{array}{l}\text { Europe } \\
\text { (7) }\end{array}$ & $\begin{array}{l}\text { World } \\
\text { (8) }\end{array}$ & $\begin{array}{l}\text { World } \\
\text { (9) }\end{array}$ & $\begin{array}{l}\text { World } \\
(10)\end{array}$ \\
\hline \multirow[t]{2}{*}{ DL meets government member } & $-0.133^{\star \star}$ & $-0.122^{*}$ & $-0.136^{\star \star}$ & $-0.132^{\star \star}$ & $-0.127^{\star \star}$ & $-0.059^{\star *}$ & $-0.140^{\star \star \star}$ & $-0.043^{*}$ & $-0.065^{\star \star}$ & $-0.064^{\star \star *}$ \\
\hline & $(0.027)$ & $(0.098)$ & $(0.023)$ & $(0.030)$ & $(0.035)$ & $(0.011)$ & $(0.003)$ & $(0.084)$ & $(0.011)$ & $(0.006)$ \\
\hline \multirow[t]{2}{*}{ (log) GDP } & -0.007 & 0.362 & -0.025 & -0.147 & -0.014 & $0.382^{* \star \star}$ & $0.691^{* * *}$ & $0.331^{* \star *}$ & $0.240^{\star \star \star}$ & $0.359^{\star \star *}$ \\
\hline & $(0.981)$ & $(0.587)$ & $(0.931)$ & $(0.640)$ & $(0.962)$ & $(0.000)$ & $(0.000)$ & $(0.000)$ & $(0.002)$ & $(0.000)$ \\
\hline \multirow[t]{2}{*}{ (log) Population } & $3.411^{\star *}$ & 2.208 & $3.250^{*}$ & $3.075^{\star}$ & $3.325^{\star \star}$ & $2.689^{* * *}$ & -0.123 & $3.487^{\star \star *}$ & $2.055^{\star \star \star}$ & $2.638^{* * *}$ \\
\hline & $(0.035)$ & $(0.495)$ & $(0.055)$ & $(0.055)$ & $(0.032)$ & $(0.000)$ & $(0.627)$ & $(0.000)$ & $(0.000)$ & $(0.000)$ \\
\hline \multirow[t]{2}{*}{ (log) Exchange rate } & 0.158 & -1.086 & 0.029 & 0.101 & 0.129 & $0.270^{\star \star \star}$ & -0.445 & $0.140^{\star \star}$ & $0.186^{\star \star}$ & $0.268^{\star \star *}$ \\
\hline & $(0.357)$ & $(0.320)$ & $(0.883)$ & $(0.566)$ & $(0.465)$ & $(0.000)$ & $(0.249)$ & $(0.026)$ & $(0.015)$ & $(0.000)$ \\
\hline \multirow[t]{2}{*}{ Other exports / GDP } & & & 2.757 & & & & & $2.098^{\star \star \star}$ & & \\
\hline & & & $(0.150)$ & & & & & $(0.000)$ & & \\
\hline \multirow[t]{2}{*}{ (log) Tariff rate } & & & & -0.030 & & & & & $-0.064^{\star * *}$ & \\
\hline & & & & $(0.761)$ & & & & & $(0.000)$ & \\
\hline \multirow[t]{2}{*}{ UNGA voting alignment } & & & & & 2.020 & & & & & $0.718^{\star \star}$ \\
\hline & & & & & $(0.208)$ & & & & & $(0.030)$ \\
\hline R squared & 0.280 & 0.502 & 0.294 & 0.296 & 0.283 & & & & & \\
\hline Observations & 912 & 247 & 906 & 887 & 912 & 912 & 247 & 906 & 887 & 912 \\
\hline Number of countries & 151 & 36 & 150 & 148 & 151 & 151 & 36 & 150 & 148 & 151 \\
\hline
\end{tabular}

- All regressions with country and time fixed effects.

- Robust p-values in brackets; ${ }^{*}$ significant at $10 \%$; ${ }^{* *}$ significant at $5 \%$; ${ }^{* * *}$ significant at $1 \%$

- Standard errors in Fixed Effects regressions are adjusted for clustering across partner countries.

- FGLS regressions are corrected for cross-sectional heteroskedasticity across panels and first order autocorrelation. 
Next, we include three additional control variables to our baseline regression to further test the robustness of our results. In a first step, we assess the effect of partner countries' export orientation on exports to China. While time-invariant country characteristics are captured by the country fixed effects, changes in export orientation across time are not accounted for in our baseline model. We hypothesize that exports to China grow over time when a partner country's export orientation increases. The export orientation of China's trading partners is measured as the total exports to all countries except China as a share of GDP. Trade data are again retrieved from UN COMTRADE and GDP data are obtained from the World Development Indicators (World Bank 2009). The effect of export orientation is not statistically significant at conventional levels in the Fixed Effects regression (column 3). However, in the FGLS estimation, the coefficient is significant at the one-percent level and correctly signed (column 8). Independent of the estimation strategy, the coefficient on our Dalai Lama variable is stable and remains significant at conventional levels.

As a second control variable, we add the log of the trade-weighted bilateral tariff rate to our baseline model in order to account for tariff barriers to trade between each country and China. ${ }^{112}$ Tariff data are taken from the UNCTAD-TRAINS database. In both regression frameworks, the coefficient on the dummy variable for the reception of the Dalai Lama by a government member is robust to the inclusion of tariff rates. While the tariff coefficient is negative, in line with theory, it is only statistically significant at conventional levels in the FGLS estimation. The addition of tariff rates slightly increases the absolute size of the coefficient on the Dalai Lama variable in the FGLS framework (column 9) and leaves the coefficient in the Fixed Effects setting virtually unchanged (column 4). In both cases, the coefficient remains significant at the five-percent level. This finding can be taken as an indication that the trade-reducing 'Dalai Lama Effect' does not operate via an increase of tariff barriers.

The third additional control variable aims to account for the effect of political friendship or hostility on trade with China. A frequently used measure for the extent of bilateral friendship is the degree to which countries vote in line with each other in the United Nations General Assembly (UNGA) (e.g., Richardson and Kegley 1980; Barro and Lee 2005; Dreher and Jensen 2007; Kastner 2007; Dreher and Gassebner

\footnotetext{
${ }^{112}$ Arguably, China's import tariffs themselves may be affected by diplomatic tensions caused by meetings of foreign officials with the Tibetan leader. Hence, the estimated coefficient on the Dalai Lama variable has to be attributed to channels other than the bilateral tariff rate.
} 
2008). Although this measure has its drawbacks, it also has the advantage that it is available for virtually every country in the world over a long time period. We construct a variable for capturing the voting coincidence at the assembly using the same method as Richardson and Kegley (1980) and Thacker (1999). ${ }^{113}$ Therefore, our indicator of friendship with China is the number of times that a trading partner had the same voting behavior as China as a fraction of all voting instances. Votes in agreement are coded as 1 , votes in disagreement as 0 and abstentions and absences as 0.5 . The regressions in columns 5 and 10 in Table III.2 show that greater amity with China seems to promote trade, but that the effect is only statistically significant at conventional levels in the FGLS regression and has a negligible impact on the size of the Dalai Lama dummy variable.

In order to test Hypothesis 2, we run a modified version of the basic regression for the relevant time period (2002-2008), accounting for the different ranks of dignitaries who met with the Dalai Lama. To this end, we include four dummy variables covering an increasingly broader group of people. Furthermore, we include a dummy variable, which takes a value of 1 if the Dalai Lama travelled to the country - regardless of whether he was received by any dignitary. All dummy variables take a value of 1 if an event was registered in the current or previous year.

The regressions in columns 1 to 5 (Fixed Effects) and 10 to 14 (FGLS) in Table III.3 confirm our hypothesis that the trade deteriorations caused by Dalai Lama meetings are associated with the rank of the dignitary that receives the Tibetan leader. We find that meetings between the Dalai Lama and political leaders, defined as head of state or government, have the greatest significant negative impact on exports to China. Dalai Lama meetings at the highest political level reduce exports to China by $16.9 \%$ according to the Fixed Effects results and by $8.1 \%$ in our FGLS regression framework. Smaller, but still significant, effects are found when the definition of our variable of interest is extended to include government members and national officials, respectively. The effect is again smaller for the group including all dignitaries listed by the Office of the Dalai Lama. The corresponding coefficient is only significant at the ten-percent level in the FGLS regression and even becomes statistically insignificant at conventional levels in the Fixed Effects regression.

${ }^{113}$ The UNGA roll-call voting data are made available by Voeten and Merdzanovic (2009). We thank Axel Dreher for providing us with a Stata do-file to process the data. 
Table III.3: Exports to China and Dalai Lama meetings at various political levels (Hypothesis 2, all countries, 2002-2008)

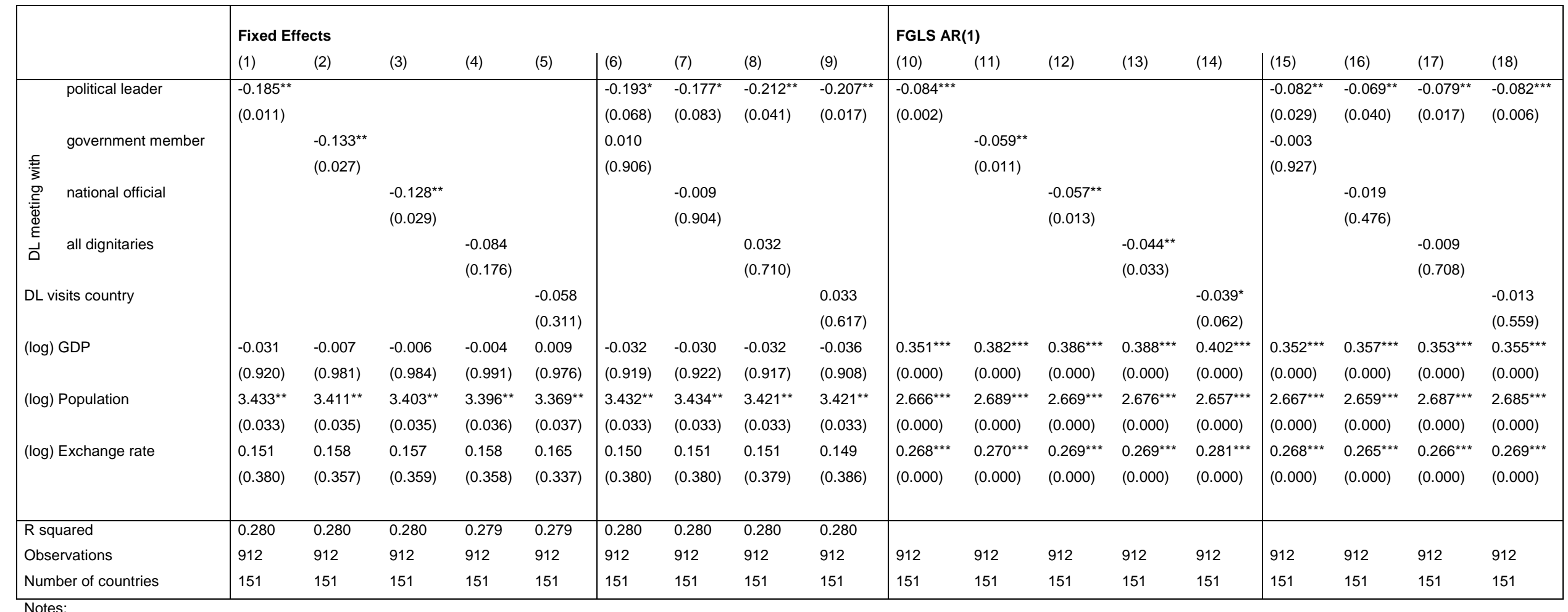

- All regressions with country and time fixed effects.

- Robust p-values in brackets; * significant at $10 \%$; ** significant at $5 \%$; *** significant at $1 \%$

- Standard errors in Fixed Effects regressions are adjusted for clustering across partner countries.

- FGLS regressions are corrected for cross-sectional heteroskedasticity across panels and first order autocorrelation. 
Since meetings with political leaders seem to have the highest impact, we test whether additional effects occur when the Dalai Lama is also received by lower ranked dignitaries. As shown in columns 6 to 8 (Fixed Effects) and columns 15 to 17 (FGLS), there is no additional effect for lower-ranked dignitaries meeting the Dalai Lama in addition to the effect found for political leaders. When controlling for receptions at the highest political level, each coefficient for meetings at a lower level is not statistically significant at conventional levels. ${ }^{114}$ The coefficient on the dummy indicating the presence of the Dalai Lama in the country - irrespective of whether he was received by a dignitary - is not statistically significant at conventional levels in the Fixed Effects (column 5) and loses its significance in the FGLS regression when controlling for whether an encounter with the Tibetan leader took place (column 18). This underlines that the effect is only caused by a meeting with a foreign leader, whereas the mere presence of the Dalai Lama in the respective country has no effect.

Having shown that the trade-deteriorating effect is driven by meetings with heads of state or government, we focus on these meetings in the following regression analyses. Table III.4 shows how the 'Dalai Lama Effect' evolves over time in a Fixed Effects and in an FGLS regression framework (Hypothesis 3). In order to compare the effect of Dalai Lama meetings over time, we include separate dummy variables that take a value of 1 if the Tibetan leader is received by a political leader in the next year, current year, previous year, two years ago and three years ago, respectively. Starting with the worldwide sample, we find statistically significant negative coefficients on the Dalai Lama dummies for the current and previous years. Both coefficients are similar in size and a t-test does not reject the null hypothesis that the two coefficients are equal in size at the ten-percent level. All other coefficients on the Dalai Lama variables are not statistically significant at conventional levels. We thus conclude that the trade-reducing impact of Dalai Lama meetings disappears after two years, which is in line with Hypothesis 3. Turning to our smaller European sample, we find a similar pattern. The coefficient for Dalai Lama meetings in the current year is statistically significant at the five-percent level, but the coefficient on the dummy for a

\footnotetext{
${ }^{114}$ When restricting our sample to European countries, a similar pattern emerges. Once more, we find the largest effect for Dalai Lama meetings with political leaders. Again, the coefficients for Dalai Lama meetings with lower-ranked dignitaries are substantially smaller. In the Fixed Effects regression, however, the size of the coefficient for a Dalai Lama meeting with any dignitary outperforms the size of the corresponding dummy restricted to government members or national officials. See Appendix B3.
} 
Dalai Lama reception in the previous year loses significance in the Fixed Effects regression, while retaining significance in the FGLS estimation.

Table III.4: Exports to China and Dalai Lama meetings of political leaders (Hypothesis 3, time-event specification, 2002-2008)

\begin{tabular}{|c|c|c|c|c|}
\hline & $\begin{array}{l}\text { Fixed Ef } \\
\text { World } \\
\text { (1) }\end{array}$ & $\begin{array}{l}\text { Europe } \\
\text { (2) }\end{array}$ & $\begin{array}{l}\text { FGLS AR } \\
\text { World } \\
\text { (3) }\end{array}$ & $\begin{array}{l}\text { Europe } \\
\text { (4) }\end{array}$ \\
\hline DL met political leader in $\mathrm{t}+1$ & $\begin{array}{l}-0.113 \\
(0.203)\end{array}$ & $\begin{array}{l}-0.092 \\
(0.276)\end{array}$ & $\begin{array}{l}-0.044 \\
(0.155)\end{array}$ & $\begin{array}{l}-0.037 \\
(0.629)\end{array}$ \\
\hline DL met political leader in $t$ & $\begin{array}{l}-0.189^{\star *} \\
(0.011)\end{array}$ & $\begin{array}{l}-0.183^{*} \\
(0.065)\end{array}$ & $\begin{array}{l}-0.105^{\star \star \star} \\
(0.001)\end{array}$ & $\begin{array}{l}-0.135^{\star} \\
(0.064)\end{array}$ \\
\hline DL met political leader in $\mathrm{t}-1$ & $\begin{array}{l}-0.192^{\star *} \\
(0.031)\end{array}$ & $\begin{array}{l}-0.150 \\
(0.300)\end{array}$ & $\begin{array}{l}-0.087^{\star *} \\
(0.023)\end{array}$ & $\begin{array}{l}-0.318^{\star \star \star} \\
(0.000)\end{array}$ \\
\hline DL met political leader in $\mathrm{t}-2$ & $\begin{array}{l}0.061 \\
(0.441)\end{array}$ & $\begin{array}{l}0.191 \\
(0.203)\end{array}$ & $\begin{array}{l}0.009 \\
(0.827)\end{array}$ & $\begin{array}{l}0.103 \\
(0.137)\end{array}$ \\
\hline DL met political leader in t-3 & $\begin{array}{l}-0.019 \\
(0.778)\end{array}$ & $\begin{array}{l}0.021 \\
(0.854)\end{array}$ & $\begin{array}{l}-0.016 \\
(0.611)\end{array}$ & $\begin{array}{l}-0.047 \\
(0.433)\end{array}$ \\
\hline$(\log )$ GDP & $\begin{array}{l}-0.033 \\
(0.914)\end{array}$ & $\begin{array}{l}0.303 \\
(0.667)\end{array}$ & $\begin{array}{l}0.341^{\star * *} \\
(0.000)\end{array}$ & $\begin{array}{l}0.559^{\star * *} \\
(0.001)\end{array}$ \\
\hline (log) Population & $\begin{array}{l}3.368^{\star *} \\
(0.042)\end{array}$ & $\begin{array}{l}1.864 \\
(0.547)\end{array}$ & $\begin{array}{l}2.577^{\star \star *} \\
(0.000)\end{array}$ & $\begin{array}{l}0.074 \\
(0.782)\end{array}$ \\
\hline (log) Exchange rate & $\begin{array}{l}0.145 \\
(0.399)\end{array}$ & $\begin{array}{l}-1.127 \\
(0.304)\end{array}$ & $\begin{array}{l}0.266^{\star \star \star} \\
(0.000)\end{array}$ & $\begin{array}{l}-0.435 \\
(0.259)\end{array}$ \\
\hline R squared & 0.281 & 0.507 & & \\
\hline Observations & 912 & 247 & 912 & 247 \\
\hline Number of countries & 151 & 36 & 151 & 36 \\
\hline
\end{tabular}

\section{Notes:}

- All regressions with country and time fixed effects.

- Robust p-values in brackets; * significant at 10\%; ${ }^{* *}$ significant at $5 \%$; ${ }^{* * *}$ significant at $1 \%$

- Standard errors in Fixed Effects regressions are adjusted for clustering across partner countries.

- FGLS regressions are corrected for cross-sectional heteroskedasticity across panels and first order autocorrelation.

\section{III.3.3 Endogeneity Concerns}

In analogy to the reverse causal relationship between trade and military conflicts (e.g., Glick and Taylor 2010), the precise nature of the causal link between diplomatic 
conflicts and trade is unclear. On the one hand, we hypothesize that receiving the Dalai Lama leads to reduced exports to China. On the other hand, stronger commercial ties might also make it less likely that a political leader invites the Dalai Lama in the first place. There are good reasons to believe that a country is more reluctant to receive the Buddhist leader if it has a well-established trade relationship with China, which it does not want to jeopardize.

We make use of a Two-Stage-Least-Squares (2SLS) model to account for the potential endogeneity of Dalai Lama meetings. The crucial point in a 2SLS regression framework is the choice of an appropriate instrument, which sufficiently explains Dalai Lama meetings with political leaders, but is uncorrelated with the error term in the second stage regression. According to the exclusion restriction, an appropriate instrument should not affect exports to China through channels other than the potentially endogenous variable, i.e., the dummy for Dalai Lama receptions. In other words, an appropriate instrument should have no direct influence on exports to China. In order to find suitable instruments, one needs to gain a better understanding of the Dalai Lama's travel behavior. According to the Dalai Lama himself, most visits abroad follow from invitations from Tibetan and Buddhist communities (Gyatso 1990). During his stays abroad, the Dalai Lama gives lectures and religious speeches and meets local Buddhist communities. While most meetings with lower-ranked dignitaries are scheduled long in advance, it is usually unclear some weeks or even days before the Dalai Lama embarks on a journey, whether he will be received by high-ranked officials. ${ }^{115}$ In some cases, the head of state or government just "drops in" while the Dalai Lama is meeting with a lower-ranked government member. The political leader's decision process of whether or not to meet with the Dalai Lama is usually accompanied by discussions in the media and demands from pro-Tibet lobby groups.

We employ the following three instruments in an attempt to control for endogeneity. The first instrument is the binary dummy variable discussed above, which takes a value of 1 if the Dalai Lama travelled to a partner country in a given

\footnotetext{
115 For example, shortly before the Dalai Lama's arrival in Italy in 2003, Prime Minister Silvio Berlusconi left it open whether he would accept the invitation of the Italian Parliamentary Group for Tibet to meet with the Tibetan leader. Finally, he refused the invitation. In the forerun of a trip to Mongolia in 2006, it remained unclear whether or not the Dalai Lama would be received by President Nambaryn Enkhbayar during his stay in the country. In the end, no meeting was scheduled. In a similar manner, the encounter of the Austrian chancellor Alfred Gusenbauer in 2007 was made public only one day before the actual meeting took place.
} 
year. The underlying idea here is that the Tibetan leader is more likely to meet with officials in those years in which he travels to their respective partner countries. Most meetings with foreign dignitaries take place in the dignitary's own country, although meetings have also occurred in third-party countries such as the 2008 meeting between French President Nicolas Sarkozy and the Dalai Lama in Poland. As outlined above, the Dalai Lama usually fixes his travel itinerary based on invitations from Buddhist or Tibetan communities to give teachings and public talks. Since his travel plans do generally not follow invitations from political leaders, we assume that our instrument is exogenous. Our second instrument is the number of days that the Dalai Lama spent in a partner country. We hypothesize that the longer the duration of the Dalai Lama's stay in a country, the greater will be the public awareness of his presence in the country, the more intense will be the public discussion regarding his potential official reception, and the greater will be the pressure on political leaders to receive him.

As a third instrument, we use the number of Tibet Support Groups (TSG) in a trading partner country. TSGs are non-governmental organizations (NGOs) formed voluntarily and maintained by private individuals with the aim of rallying regional, national, or international awareness of and support for the Tibet issue. TSGs work independently from the Central Tibetan Administration and act as non-profit organizations that are open to any individuals willing to join the pro-Tibet movement. The larger the pro-Tibetan network in a partner country, the more inclined the political leader might be to receive the Dalai Lama in order to satisfy the demands of these pressure groups. Moreover, the number of TSGs may serve as a proxy for the extent to which a country's population is interested in the Tibet issue.

The dataset on the number of TSGs was established based on a list of proTibet movements that was released by the Central Tibetan Administration in exile. ${ }^{116}$ To account for the evolution of the pro-Tibet movement over time, we construct a time series by collecting information on the year of foundation of each TSG. In order to get information for those TSGs that do not provide this information on their homepage, we contacted them via e-mail and fax. Using this approach, we obtained information on the founding year for about $53.8 \%$ of all listed 295 organizations. Unfortunately, insufficient information is available on the number of members of each group so that we cannot account for differences in size between Tibet NGOs. With 31

${ }^{116}$ The list is available at http://www.tibet.net (accessed: June 2009). 
recorded organizations, most TSGs in our sample are located in France, followed by the United States with 20 Tibet NGOs.

The first stage results of our 2SLS estimation approach (see Appendix B4) are in line with our expectations: the likelihood that a political leader meets the Dalai Lama increases when the Tibetan head of government in exile travels to the leader's country, increases with the duration of the visit and also increases with the number of Tibet Support Groups in the partner country. The Angrist-Pischke test of excluded instruments displayed in Table III.5 underlines the relevance of the instruments selected in the first stage. The null hypothesis of the test is rejected in all specifications. Only in the smaller European sample does the F statistic fall below the critical rule of thumb value of 10 (Staiger and Stock 1997). 
Table III.5: Exports to China and Dalai Lama meetings of political leaders (endogeneity, 2002-2008)

\begin{tabular}{|c|c|c|c|c|c|c|c|c|c|}
\hline & $\begin{array}{l}\text { 2SLS } \\
\text { World } \\
\text { (1) }\end{array}$ & $\begin{array}{l}\text { Europe } \\
\text { (2) }\end{array}$ & $\begin{array}{l}\text { World } \\
\text { (3) }\end{array}$ & $\begin{array}{l}\text { World } \\
(4)\end{array}$ & $\begin{array}{l}\text { World } \\
\text { (5) }\end{array}$ & $\begin{array}{l}\text { GMM } \\
\text { World } \\
\text { (6) }\end{array}$ & $\begin{array}{l}\text { w/o FRA } \\
(7)\end{array}$ & $\begin{array}{l}\text { w/o IND } \\
(8)\end{array}$ & $\begin{array}{l}\text { W/o FRA\&IND } \\
\text { (9) }\end{array}$ \\
\hline DL meets political leader (t/t-1) & $\begin{array}{l}-0.229^{\star} \\
(0.052)\end{array}$ & $\begin{array}{l}-0.242^{\star \star} \\
(0.014)\end{array}$ & & & & & & & \\
\hline DL meets political leader (t) & & & $\begin{array}{l}-0.202^{*} \\
(0.063)\end{array}$ & $\begin{array}{l}-0.211^{*} \\
(0.057)\end{array}$ & $\begin{array}{l}-0.195^{\star} \\
(0.063)\end{array}$ & $\begin{array}{l}-0.203^{* *} \\
(0.020)\end{array}$ & $\begin{array}{l}-0.227^{\star \star} \\
(0.040)\end{array}$ & $\begin{array}{l}-0.153^{* *} \\
(0.031)\end{array}$ & $\begin{array}{l}-0.200^{* *} \\
(0.048)\end{array}$ \\
\hline DL meets political leader (t-1) & & & $\begin{array}{l}-0.221^{*} \\
(0.082)\end{array}$ & $\begin{array}{l}-0.171 \\
(0.134)\end{array}$ & & & & & \\
\hline (log) Exports (t-1) & & & & $\begin{array}{l}0.197^{\star *} \\
(0.024)\end{array}$ & $\begin{array}{l}0.198^{* *} \\
(0.023)\end{array}$ & $\begin{array}{l}0.373^{* * *} \\
(0.009)\end{array}$ & $\begin{array}{l}0.365^{\star *} \\
(0.018)\end{array}$ & $\begin{array}{l}0.335^{\star *} \\
(0.023)\end{array}$ & $\begin{array}{l}0.339^{* *} \\
(0.024)\end{array}$ \\
\hline (log) GDP & $\begin{array}{l}-0.041 \\
(0.896)\end{array}$ & $\begin{array}{l}0.255 \\
(0.697)\end{array}$ & $\begin{array}{l}-0.040 \\
(0.897)\end{array}$ & $\begin{array}{l}0.064 \\
(0.822)\end{array}$ & $\begin{array}{l}0.089 \\
(0.750)\end{array}$ & $\begin{array}{l}0.810^{* * *} \\
(0.000)\end{array}$ & $\begin{array}{l}0.836^{* * *} \\
(0.000)\end{array}$ & $\begin{array}{l}0.858^{* * *} \\
(0.000)\end{array}$ & $\begin{array}{l}0.872^{* * *} \\
(0.000)\end{array}$ \\
\hline (log) Population & $\begin{array}{l}3.458^{* *} \\
(0.031)\end{array}$ & $\begin{array}{l}2.360 \\
(0.477)\end{array}$ & $\begin{array}{l}3.447^{* *} \\
(0.032)\end{array}$ & $\begin{array}{l}3.505^{\star \star *} \\
(0.009)\end{array}$ & $\begin{array}{l}3.401^{* *} \\
(0.011)\end{array}$ & $\begin{array}{l}0.121^{*} \\
(0.093)\end{array}$ & $\begin{array}{l}0.120 \\
(0.124)\end{array}$ & $\begin{array}{l}0.138 \\
(0.115)\end{array}$ & $\begin{array}{l}0.144^{*} \\
(0.085)\end{array}$ \\
\hline (log) Exchange rate & $\begin{array}{l}0.147 \\
(0.391)\end{array}$ & $\begin{array}{l}-1.117 \\
(0.305)\end{array}$ & $\begin{array}{l}0.147 \\
(0.391)\end{array}$ & $\begin{array}{l}0.130 \\
(0.410)\end{array}$ & $\begin{array}{l}0.138 \\
(0.381)\end{array}$ & $\begin{array}{l}0.201 \\
(0.310)\end{array}$ & $\begin{array}{l}0.209 \\
(0.294)\end{array}$ & $\begin{array}{l}0.254 \\
(0.208)\end{array}$ & $\begin{array}{l}0.229 \\
(0.265)\end{array}$ \\
\hline $\begin{array}{l}\text { Angrist-Pischke } \mathrm{F} \text { test } \\
\text { (Test of excluded instruments) }\end{array}$ & $\begin{array}{l}12.69 \\
(0.000)\end{array}$ & $\begin{array}{l}6.99 \\
(0.000)\end{array}$ & $\begin{array}{l}23.90 / 15.40 \\
(0.000) /(0.000)\end{array}$ & $\begin{array}{l}23.55 / 15.32 \\
(0.000) /(0.000)\end{array}$ & $\begin{array}{l}29.12 \\
(0.000)\end{array}$ & & & & \\
\hline $\begin{array}{l}\text { Hansen } \mathrm{J} \\
\quad \text { (Overidentification test) }\end{array}$ & $\begin{array}{l}1.610 \\
(0.807)\end{array}$ & $\begin{array}{l}3.258 \\
(0.516)\end{array}$ & $\begin{array}{l}1.432 \\
(0.698)\end{array}$ & $\begin{array}{l}0.185 \\
(0.980)\end{array}$ & $\begin{array}{l}0.236 \\
(0.889)\end{array}$ & $\begin{array}{l}41.82 \\
(0.723)\end{array}$ & $\begin{array}{l}40.13 \\
(0.783)\end{array}$ & $\begin{array}{l}43.66 \\
(0.612)\end{array}$ & $\begin{array}{l}39.29 \\
(0.780)\end{array}$ \\
\hline $\begin{array}{l}\text { Kleinbergen Paap LM test } \\
\text { (Underidentification test) }\end{array}$ & $\begin{array}{l}22.40 \\
(0.000)\end{array}$ & $\begin{array}{l}15.28 \\
(0.009)\end{array}$ & $\begin{array}{l}21.13 \\
(0.000)\end{array}$ & $\begin{array}{l}21.17 \\
(0.000)\end{array}$ & $\begin{array}{l}19.61 \\
(0.000)\end{array}$ & & & & \\
\hline Endogeneity test & $\begin{array}{l}0.082 \\
(0.774)\end{array}$ & $\begin{array}{l}0.038 \\
(0.846)\end{array}$ & $\begin{array}{l}0.073 \\
(0.964)\end{array}$ & $\begin{array}{l}1.131 \\
(0.568)\end{array}$ & $\begin{array}{l}1.407 \\
(0.236)\end{array}$ & & & & \\
\hline Arellano-Bond test for AR1/AR2 & & & & & & $\begin{array}{l}-2.557 / 1.246 \\
(0.011) /(0.213) \\
\end{array}$ & $\begin{array}{l}-2.479 / 1.208 \\
(0.013) /(0.227) \\
\end{array}$ & $\begin{array}{l}-2.48 / 1.146 \\
(0.013) /(0.252)\end{array}$ & $\begin{array}{l}-2.465 / 1.149 \\
(0.014) /(0.250) \\
\end{array}$ \\
\hline R squared & 0.280 & 0.504 & 0.280 & 0.379 & 0.378 & & & & \\
\hline Observations & 912 & 247 & 912 & 863 & 863 & & & & \\
\hline Number of countries & 151 & 36 & 151 & 142 & 142 & 149 & 148 & 148 & 147 \\
\hline Number of instruments & 5 & 5 & 5 & 5 & 3 & 61 & 61 & 60 & 60 \\
\hline
\end{tabular}

Notes: - * significant at $10 \% ;{ }^{* *}$ significant at $5 \% ;{ }^{* * *}$ significant at $1 \%$

- 2SLS with clustered standard errors, country and time fixed effects. / System GMM with time dummies, Windmeijer finite sample correction and external instruments.

- Instruments (1)-(4): Number of Tibet Support Groups (lagged), Dalai Lama visit dummy (current and lagged) and Duration of Dalai Lama visit (in days, current and lagged).

- Instruments (5)-(9): Number of Tibet Support Groups (lagged), Dalai Lama visit dummy (current) and Duration of Dalai Lama visit (in days, current). 
The regressions in columns 1 to 5 of Table III.5 show the results for the second stage regressions of our 2SLS approach. ${ }^{117}$ Again, we present results for the relevant time period (2002-2008). Starting with the worldwide sample (column 1), the coefficient on the dummy variable indicating whether the Dalai Lama was received by a head of state or head of government in the current or previous year is negative and statistically significant, i.e., we still find that Dalai Lama meetings have a tradedeteriorating effect when controlling for potential endogeneity. The coefficient is somewhat larger than in the Fixed Effects regression (Table III.3, column 1). For the European subsample, displayed in column 2 of Table III.5, the Dalai Lama coefficient is significant at the five-percent level.

In order to shed light on the timing of the 'Dalai Lama Effect', we include two dummy variables, the first taking a value of 1 if a Dalai Lama meeting took place in the current period and the second taking a value of 1 if the Dalai Lama was received in the previous period. The results in column 3 of Table III.5 show that the coefficients for both dummy variables have the expected negative signs, are of similar size, and are significant at the ten-percent level. Tests for overidentification (Hansen $\mathrm{J}$ ) and underidentification (Kleinbergen Paap LM test) also confirm the validity of our instruments. Even though the 2SLS regression results support our previous findings, note that the $C$ test for endogeneity does not reject the null hypothesis of exogeneity of the Dalai Lama dummy. ${ }^{118}$ Consequently, the Fixed Effects estimates discussed in Section 4.2 are more efficient than the 2SLS estimates.

Next, we tackle a further endogeneity issue, which stems from the potential endogeneity of lagged export values. Since trade relationships are persistent over time, we include lagged exports as an additional explanatory variable in order to explain current exports to China as a function of past export values. Established commercial ties and signed contracts mean that exports evolve with inertia. It is possible that the lagged exports variable is endogenous in a short panel, which could lead to biased results (Nickell 1981). Unobserved panel level effects may be correlated with lagged exports, thereby making the 2SLS estimator inconsistent. In order to address this issue, we apply the two-step System GMM estimator, which

\footnotetext{
${ }^{117}$ All results are based on the user-written Stata command xtivreg2 (Schaffer 2005).

${ }^{118}$ Under conditional homoskedasticity, the C statistic is numerically equal to the Durbin-Wu-Hausman test. However, its main advantage is that it is robust to violations of conditional homoskedasticity (see Hayashi 2000: 232-234).
} 
incorporates equations in first differences and in levels (Arellano and Bover 1995; Blundell and Bond 1998). Since we have a small $T$ in our setting ( $T=7)$, we employ the Windmeijer correction to obtain standard errors which are larger and more reliable in finite samples (Windmeijer 2005). Meetings with the Dalai Lama and lagged exports are treated as endogenous and all additional covariates as strictly exogenous. Furthermore, we include time fixed effects and employ the same external instruments as in the 2SLS regression framework discussed above. To limit the number of instruments, the matrix of instruments is collapsed as proposed in Roodman (2009).

Before proceeding to the GMM estimation results, column 4 of Table III.5 reports for comparison the 2SLS results when lagged exports are included as an additional control variable. The coefficient on lagged exports to China is statistically significant at the five-percent level. Interestingly, the Dalai Lama dummy indicating a meeting with a political leader in the previous period becomes insignificant once we include the lagged exports variable. Arguably, the 'Dalai Lama Effect' of meetings in the previous period is already (partially) captured in the lagged export variable. However, the dummy variable indicating a reception of the Tibetan leader in the current period remains statistically significant at conventional levels as expected. In column 5 , we therefore exclude the dummy variable indicating a Dalai Lama meeting in the previous period. The coefficients on the remaining variables remain virtually unchanged.

Column 6 shows our GMM regression results for the worldwide sample. ${ }^{119}$ The estimated coefficient on Dalai Lama meetings is negative, statistically significant at the five-percent level, and of similar size as the corresponding value in the 2SLS setting. The coefficient on the lagged exports variable has the expected positive sign and is statistically significant at the five-percent level. The Hansen test on the validity of the instruments used does not reject the exogeneity of the covariates. The Arellano-Bond test does not reject the hypothesis of no second-order autocorrelation in the data, which needs to be absent in order for the estimator to be consistent. As a final robustness check, we exclude France in column 7 and India in column 8 from our sample, since both countries show extreme values in the distribution of our instrumental variables. France is the country with by far the most Tibet Support Groups (31 in our sample). India, in turn, is the country that experiences the longest

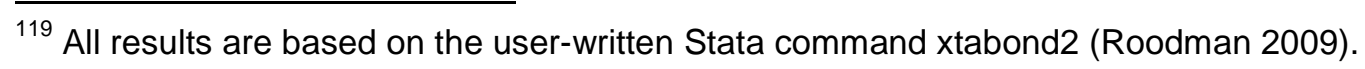


Dalai Lama visits (up to 124 days per year). Nevertheless, when separately or jointly excluding the two countries from the GMM regression, our variable of interest remains statistically significant at the five-percent level (columns 7-9). We therefore conclude that our results are not driven by these outliers.

\section{III.3.4 Results by Product Group}

Finally, we investigate which product groups drive the trade-deteriorating 'Dalai Lama Effect'. As indicated in the first column of Table III.6, the value of exports to China is especially concentrated among the following SITC product groups: 'Machinery and transport equipment' $(41.0 \%$ of total exports to China), 'Manufactured goods classified chiefly by material' (13.3\%), 'Chemicals and related products' (12.4\%) and 'Crude materials, inedible, except fuels' (12.1\%). Exports of goods of the most important product group, 'Machinery and transport equipment', are expected to be closely associated with the state of political relations between countries as negotiations over the purchase of such goods are commonly carried out during the course of high-rank trade talks between national representatives and trade delegations. Running separate regressions for each SITC product group, Table III.6 reports the full-sample results for the period 2002 to 2008. With the exception of 'Beverages and tobacco', the coefficients for all subgroups exhibit the expected negative sign in the Fixed Effects and FGLS regressions. However, only SITC group 7, which incorporates 'Machinery and transport equipment', the most important product group, turns out to be statistically significant in both regression frameworks. Furthermore, in the FGLS setting, we find a statistically significant and negative coefficient for 'Food, live animals', 'Crude materials' and 'Mineral fuels'.

Table III.7 reports our results when the regressions are repeated for European countries. Results are found to be more diverse in the European sample. In the Fixed Effects regressions, we find negative and statistically significant results for the group of 'Food, live animals' and, once again, 'Machinery and transport equipment'. The coefficients on Dalai Lama meetings for the remaining groups are not statistically significant at conventional levels. In the FGLS regressions, statistically significant effects at conventional levels are found for 'Crude materials', 'Mineral fuels', 'Chemicals', and 'Machinery and transport equipment'. 
Table III.6: Exports to China and Dalai Lama meetings of political leaders

(by product groups, all countries, 2002-2008)

\begin{tabular}{|c|c|c|c|c|c|c|c|}
\hline \multirow{3}{*}{$\begin{array}{l}\text { Product Group (SITC) } \\
\text { Food, live animals (0) }\end{array}$} & \multirow{3}{*}{\begin{tabular}{|l|}
$\%$ trade \\
$1.7 \%$
\end{tabular}} & \multicolumn{6}{|c|}{ World 2002-2008 } \\
\hline & & \multicolumn{2}{|c|}{ Fixed Effects } & \multicolumn{2}{|c|}{ FGLS AR(1) } & \multirow{2}{*}{\begin{tabular}{|l|} 
Obs. \\
710
\end{tabular}} & \multirow{2}{*}{$\begin{array}{l}\text { Countries } \\
124\end{array}$} \\
\hline & & -0.197 & $(0.283)$ & $-0.107^{\star}$ & $(0.075)$ & & \\
\hline Beverages and Tobacco (1) & $0.2 \%$ & 0.181 & $(0.545)$ & 0.115 & $(0.319)$ & 467 & 91 \\
\hline Crude materials, inedible, except fuels (2) & $12.1 \%$ & -0.140 & $(0.328)$ & $-0.116^{\star * \star}$ & $(0.003)$ & 840 & 140 \\
\hline Mineral fuels, lubricants and related materials (3) & $7.8 \%$ & -0.432 & $(0.275)$ & $-0.352^{\star * \star}$ & $(0.000)$ & 481 & 84 \\
\hline Animal and vegetable oils, fats and waxes (4) & $1.0 \%$ & -0.206 & $(0.661)$ & -0.046 & $(0.620)$ & 349 & 69 \\
\hline Chemicals and related products, n.e.s. (5) & $12.4 \%$ & -0.096 & $(0.593)$ & -0.049 & $(0.194)$ & 722 & 125 \\
\hline Manufactured goods classified chiefly by material (6) & $13.3 \%$ & -0.031 & $(0.874)$ & -0.032 & $(0.499)$ & 800 & 132 \\
\hline Machinery and transport equipment (7) & $41.0 \%$ & $-0.605^{\star * *}$ & $(0.000)$ & $-0.359^{* * *}$ & $(0.000)$ & 756 & 129 \\
\hline Miscellaneous manufactured articles (8) & $7.3 \%$ & -0.232 & $(0.291)$ & $-0.105^{\star}$ & $(0.054)$ & 754 & 128 \\
\hline Not classified elsewhere (9) & $2.2 \%$ & -0.294 & $(0.324)$ & -0.037 & $(0.675)$ & 504 & 100 \\
\hline
\end{tabular}

- All regressions with country and time fixed effects.

- Robust-p values in brackets; * significant at 10\%; ** significant at $5 \%$; ${ }^{* * *}$ significant at $1 \%$

- Standard errors in Fixed Effects regressions are adjusted for clustering across partner countries.

- FGLS regressions are corrected for cross-sectional heteroskedasticity across panels and first order autocorrelation.

- \% trade denotes the average share of each SITC product group in total exports to China.

Therefore, the only product group for which we find a statistically significant negative effect at conventional levels for both samples and both estimation techniques is 'Machinery and transport equipment'. This result suggests that the 'Dalai Lama Effect' exists predominantly for those goods that are commonly sold in the course of state visits and trade missions. Our results lend at least weak support in favor of a 'Dalai Lama Effect' operating through consumer opinions since negative coefficients on Dalai Lama meetings are found for consumption goods, namely 'Food, live animals' and 'Miscellaneous manufactured articles'. Finally, there is at least some evidence indicating that strategic goods such as 'Crude materials' and 'Mineral fuels' are not free from political influences. This contradicts Polachek (1980), who argues that oil exports show a low export elasticity to conflict between trading partners, as oil-dependent economies have little choice but to continue importing the product regardless of any bilateral conflicts with an oil-exporting country. 
Table III.7: Exports to China and Dalai Lama meetings of political leaders (by product groups, European countries, 2002-2008)

\begin{tabular}{|c|c|c|c|c|c|c|c|}
\hline \multirow{3}{*}{$\begin{array}{l}\text { Product Group (SITC) } \\
\text { Food, live animals (0) }\end{array}$} & \multirow{3}{*}{$\begin{array}{l}\% \text { trade } \\
1.3 \%\end{array}$} & \multicolumn{6}{|c|}{ Europe 2002-2008 } \\
\hline & & \multicolumn{2}{|c|}{ Fixed Effects } & \multicolumn{2}{|c|}{ FGLS AR(1) } & \multirow{2}{*}{\begin{tabular}{|l|} 
Obs. \\
213 \\
\end{tabular}} & \multirow{2}{*}{$\begin{array}{l}\text { Countries } \\
33\end{array}$} \\
\hline & & $-0.539^{\star *}$ & $(0.029)$ & -0.160 & $(0.110)$ & & \\
\hline Beverages and Tobacco (1) & $0.4 \%$ & 0.126 & $(0.784)$ & 0.279 & $(0.177)$ & 190 & 32 \\
\hline Crude materials, inedible, except fuels (2) & $5.7 \%$ & -0.052 & $(0.742)$ & $-0.114^{*}$ & $(0.084)$ & 242 & 36 \\
\hline Mineral fuels, lubricants and related materials (3) & $1.0 \%$ & -0.132 & $(0.695)$ & $-0.228^{*}$ & $(0.087)$ & 191 & 29 \\
\hline Animal and vegetable oils, fats and waxes (4) & $0.1 \%$ & -0.280 & $(0.715)$ & 0.100 & $(0.668)$ & 142 & 26 \\
\hline Chemicals and related products, n.e.s. (5) & $9.5 \%$ & -0.004 & $(0.985)$ & $-0.143^{* *}$ & $(0.011)$ & 237 & 36 \\
\hline Manufactured goods classified chiefly by material (6) & $12.5 \%$ & -0.306 & $(0.187)$ & -0.103 & $(0.171)$ & 241 & 36 \\
\hline Machinery and transport equipment (7) & $58.3 \%$ & $-0.396^{\star *}$ & $(0.025)$ & $-0.286^{\star \star \star}$ & $(0.000)$ & 246 & 36 \\
\hline Miscellaneous manufactured articles (8) & $7.0 \%$ & -0.191 & $(0.304)$ & -0.059 & $(0.262)$ & 245 & 36 \\
\hline Not classified elsewhere (9) & $3.6 \%$ & 0.060 & $(0.820)$ & 0.074 & $(0.610)$ & 177 & 30 \\
\hline \multicolumn{8}{|l|}{ Notes: } \\
\hline \multicolumn{8}{|l|}{ - All regressions with country and time fixed effects. } \\
\hline \multicolumn{8}{|c|}{ - Robust p-values in brackets; ${ }^{*}$ significant at $10 \% ;{ }^{* *}$ significant at $5 \% ;{ }^{* * *}$ significant at $1 \%$} \\
\hline \multicolumn{8}{|c|}{ - Standard errors in Fixed Effects regressions are adjusted for clustering across partner countries. } \\
\hline \multicolumn{8}{|c|}{ - FGLS regressions are corrected for cross-sectional heteroskedasticity across panels and first order autocorrelation. } \\
\hline \multicolumn{8}{|c|}{ - \% trade denotes the average share of each SITC product group in total exports to China. } \\
\hline
\end{tabular}

\section{III.4 Conclusion}

Our article contributes to the literature on the political determinants of trade through an assessment of the importance of the state of bilateral relations for trade with China. The Chinese administration frequently threatens, in a more-or-less open manner, that meetings between its trading partners' officials and the Dalai Lama will be met with animosity and lead to a subsequent deterioration in their trade relationships. Using data on the travel pattern of the Dalai Lama, we run a gravity model of exports to China from 159 partner countries in the 1991-2008 period to test for political influences on China's trading decisions. All models are estimated using Fixed Effects with clustered standard errors and Feasible Generalized Least Squares (FGLS) with a common AR(1) term. In order to account for the potential endogeneity of meetings with the Dalai Lama, the number of Tibet Support Groups and the travel pattern of the Buddhist leader are used as instruments in 2SLS and GMM regressions.

Empirical evidence confirms the existence of a trade-deteriorating effect of meetings with the Dalai Lama for the Hu Jintao era (2002-2008). However, we find at best weak evidence to support the existence of such an effect in earlier years. While 
our results suggest that systematic trade reductions are only caused by meetings with heads of state or government, we find no additional impact for meetings between the Dalai Lama and lower-ranking officials. As a consequence of a political leader's reception of the Dalai Lama in the current or previous period, exports to China decrease by $8.1 \%$ or $16.9 \%$ on average, depending on the estimation technique used. Furthermore, we find that this effect will have disappeared two years after a meeting took place. Analyzing disaggregated export data, 'Machinery and transport equipment' is found to be the only product group with a robust negative effect of Dalai Lama meetings on exports across samples and estimation techniques.

To sum up, this is strong evidence that bilateral political relations are of large importance for trade with China. Chinese trade relations are not free of political biases and the country seems to exploit trade ties as a foreign policy tool.

While political leaders should be aware of potential export losses as a consequence of receiving the Dalai Lama, not meeting with him is not necessarily the conclusion to be drawn from our findings. Despite the possible deterioration in trade, state leaders can see receiving the Dalai Lama as a means to project their stance on human rights and democracy. Therefore, the willingness to bear the costs of trade reductions in conjunction with bilateral disagreements lends credible resolve to the political position of such a country (see also Morrow 2003; Gartzke et al. 2001).

Beyond that, internationally coordinated receptions of the Dalai Lama by political leaders, or even joint meetings, are a possibility to reconcile commercial interests with domestic demands to receive the Tibetan leader. Such a strategy may reduce China's scope to play one trading partner off against another. As sanctions imposed on one country can generate rents to third countries through trade deviation, coordination among countries receiving the Dalai Lama can prevent the problem of one country avoiding the Dalai Lama to strengthen its commercial links with China at the expense of the others. Nonetheless, with the increasing economic power of China and other (autocratic) emerging countries, the (ab)use of trade ties as a foreign policy tool is likely to grow in importance. 


\section{References}

Aidt, Toke S. and Martin Gassebner, 2010, Do Autocratic States Trade Less? World Bank Economic Review 24, 1: 38-76.

Alesina, Alberto and David Dollar, 2000, Who Gives Foreign Aid to Whom and Why? Journal of Economic Growth 5, 1: 33-63.

Al-Yahya, Khalid and Nathalie Fustier, 2011, Saudi Arabia as a Humanitarian Donor: High Potential, Little Institutionalization, GPPi Research Paper No. 14, Global Public Policy Institute, Berlin, Germany.

Arellano, Manuel and Olympia Bover, 1995, Another Look at the Instrumental Variable Estimation of Error-Components Models, Journal of Econometrics 68, 1: 29-51.

Arellano, Manuel and Olympia Bover, 1995, Another Look at the Instrumental Variable Estimation of Error-Components Models, Journal of Econometrics 68, 1: 29-51.

Arellano, Manuel and Stephen Bond, 1991, Some Tests of Specification for Panel Data: Monte Carlo Evidence and an Application to Employment Equation, The Review of Economic Studies 58, 2: 277-297.

Asbridge, Mark and Swarna Weerasinghe, 2009, Homicide in Chicago from 1890 to 1930: Prohibition and its Impact on Alcohol and Non-Alcohol Related Homicides, Addiction 104, 3: 355-364.

Astorga, Luis and David A. Shirk, 2010, Drug Trafficking Organizations and CounterDrug Strategies in the US-Mexican Context, available at: http://usmex.ucsd.edu/assets/024/11632.pdf (accessed: July 2012).

Bahl, Roy W., Richard D. Gustely. and Michael J. Wasylenko, 1978, The Determinants of Local Government Police Expenditures: A Public Employment Approach, National Tax Journal 31, 1: 67-79.

Baltagi, Badi H., 2006, Estimating an Economic Model of Crime Using Panel Data from North Carolina, Journal of Applied Econometrics 21, 4: 543-547. 
Barro, Robert J. and Jong-Wha Lee, 2005, IMF Programs: Who Is Chosen and What Are the Effects? Journal of Monetary Economics 52, 7: 1245-1269.

Beck, Allen J. and Bernard E. Shipley, United States Bureau of Justice Statistics, 1989, Recidivism of prisoners released in 1983: US Dept. of Justice, Office of Justice Programs, Bureau of Justice Statistics.

Beck, Nathaniel and Jonathon N. Katz, 1995, What To Do (and Not To Do) with Time-Series Cross-Section Data, American Political Science Review 89, 3: 634-647.

Becker, Gary S., 1968, Crime and Punishment: An Economic Approach, The Journal of Political Economy 76, 2: 169-217.

Benini, Aldo, Charles Conley, Brody Dittemore and Zachary Waksman, 2009, Survivor Needs or Logistical Convenience? Factors Shaping Decisions to Deliver Relief to Earthquake-affected Communities, Pakistan 2005-06, Disasters 33, 1: 110-131.

Benson, Bruce L, David W. Rasmussen and Iljoong Kim, 1998, Deterrence and Public Policy: Trade-Offs in the Allocation of Police Resources, International Review of Law and Economics 18: 77-100.

Benson, Bruce L., Ian Sebastian Leburn and David W. Rasmussen, 2001, The Impact of Drug Enforcement on Crime: An Investigation of the Opportunity Cost of Police Resources, Journal of Drug Issues 31, 4: 989-1006.

Benson, Bruce L., lljoong Kim and David W. Rasmussen, 1994, Estimating Deterrence Effects: A Public Choice Perspective on the Economics of Crime Literature, Southern Economic Journal, 61, 1: 161-168.

Benson, Bruce L., lljoong Kim, David W. Rasmussen and Thomas W. Zhehlke, 1992, Is Property Crime Caused by Drug Use or by Drug Enforcement Policy? Applied Economics 24, 7: 679-692.

Bermeo, Sarah Blodgett, 2011, Foreign Aid and Regime Change: A Role for Donor Intent, World Development 39, 11: 2021-2031. 
Blundell, Richard and Stephen Bond, 1998, Initial Conditions and Moment Restrictions in Dynamic Panel Data Models, Journal of Econometrics 87, 1: 115-143.

Bräutigam, Deborah, 2010, The Dragon's Gift: The Real Story of China in Africa, Oxford, UK: Oxford University Press.

Bueno de Mesquita, Bruce Bueno and Alastair Smith, 2010, Leader Survival, Revolutions, and the Nature of Government Finance, American Journal of Political Science 54, 4: 936-950.

Bushway, Shawn D and Peter Reuter, 2011, Deterrence, Economics, and the Context of Drug Markets, Criminology \& Public Policy 10, 1: 183-194.

Bushway, Shawn, Brian D. Johnson and Lee Ann Slocum, 2007, Is the Magic Still There? The Use of the Heckman Two-Step Correction for Selection Bias in Criminology, Journal of Quantitative Criminology 23, 2:151-178.

Cairncross, Frances, 2001, The Death of Distance: How the Communications Revolution Is Changing our Lives, Harvard Business Press Books.

Cantor, David and Kenneth C. Land, 1985, Unemployment and Crime Rates in the Post-World War II United States: A Theoretical and Empirical Analysis, American Sociological Review 50, 3: 317-332.

Caulkins, Jonathan P. and Sara Chandler, 2006, Long-Run Trends in Incarceration of Drug Offenders in the United States, Crime \& Delinquency 52, 4: 619-641.

Cheibub, José A., Jennifer Gandhi and James R. Vreeland, 2010, Democracy and Dictatorship Revisited, Public Choice 143, 1-2: 67-101.

Cornwell, Christopher and William N. Trumbull, 1994, Estimating the Economic Model of Crime with Panel Data, The Review of Economics and Statistics 76, 2: 360-366.

Cyprusaid, 2009, The Development Cooperation Service of the Republic of Cyprus, Planning Bureau of the Republic of Cyprus, Nikosia, Cyprus, available at: http://www.planning.gov.cy/planning/planning.nsf/AttachmentArchive/1D6633B 
C4757FC74C2257599003BAF12/\$file/CyprusAid\%20Brochure\%20Eng.pdf?o penelement (accessed: July 2012).

Davis, Christina L. and Sophie Meunier, 2011, Business as Usual? Economic Responses to Political Tensions, American Journal of Political Science 55, 3: 628-646.

Dills, Angela K., Jefferey A. Miron and Garrett Summers, 2008, What do Economists Know About Crime? National Bureau of Economic Research.

Disdier, Anne-Celia and Thierry Mayer, 2007, Je t'aime, moi non plus: Bilateral Opinions and International Trade, European Journal of Political Economy 23, 4: $1140-1159$.

Donohue, John J. and Steven D. Levitt, 1998, Guns, Violence, and the Efficiency of Illegal Markets, The American Economic Review 88, 2: 463-467.

Dreher, Axel and Andreas Fuchs, 2011, Rogue Aid? The Determinants of China's Aid Allocation, Courant Research Centre 'Poverty, Equity and Growth Discussion Paper 93, University of Goettingen, Goettingen, Germany.

Dreher, Axel and Martin Gassebner, 2008, Does Political Proximity to the U.S. Cause Terror? Economics Letters 99, 1: 27-29.

Dreher, Axel and Nathan M. Jensen, 2007, Independent Actor or Agent? An Empirical Analysis of US Interests on IMF Conditions, Journal of Law \& Economics 50, 1: 105-124.

Dreher, Axel, Jan-Egbert Sturm and James Raymond Vreeland, 2009a, Development Aid and International Politics: Does Membership on the UN Security Council Influence World Bank Decisions? Journal of Development Economics 88, 7: 118.

Dreher, Axel, Jan-Egbert Sturm and James Raymond Vreeland, 2009b, Global Horse Trading: IMF Loans for Votes in the United Nations Security Council, European Economic Review 53, 1: 742-757. 
Dreher, Axel, Peter Nunnenkamp and Rainer Thiele, 2011, Are 'New' Donors Different? Comparing the Allocation of Bilateral Aid Between Non-DAC and DAC Donor Countries, World Development 39, 11: 1950-1968.

Drury, A. Cooper and Richard Stuart Olson, 1998, Disasters and Political Unrest: An Empirical Investigation, Journal of Contingencies and Crisis Management 6: 153-161.

Drury, A. Cooper, Richard S. Olson and Douglas A. Van Belle, 2005, The Politics of Humanitarian Aid: U.S. Foreign Disaster Assistance, 1964-1995, Journal of Politics 67, 2: 454-473.

Durlauf, Steve N. and Daniel S. Nagin, 2011, Overview of 'Imprisonment and Crime: Can Both Be Reduced?', Criminology \& Public Policy 10, 1: 9-12.

Eaton, Jonathon and Maxim Engers, 1992, Sanctions, Journal of Political Economy 100, 5: 899-928.

Eaton, Jonathon and Maxim Engers, 1999, Sanctions: Some Simple Analytics, The American Economic Review 89, 2: 409-414.

ECOSOC, 2008, Trends in South-South and Triangular Development Cooperation, Background Study for the Development Cooperation Forum, United Nations Economic and Social Council (ECOSOC), available at: http://www.un.org/en/ecosoc/docs/pdfs/south-south cooperation.pdf (last accessed: July 2012).

Ehrlich, Isaac, 1973, Participation in Illegitimate Activities: A Theoretical and Empirical Investigation, The Journal of Political Economy 81, 3: 521-565.

Eisensee, Thomas and David Strömberg, 2007, News Droughts, News Floods, and U.S. Disaster Relief, Quarterly Journal of Economics 122, 2: 693-728.

EM-DAT, 2012, The OFDA/CRED International Disaster Database, Université Catholique de Louvain, Brussels, Belgium, available at: http://www.emdat.be (last accessed: May 2012).

Fajnzylber, Pablo, Daniel Lederman and Norman Loayza, 2002, What Causes Violent Crime? European Economic Review 46, 7: 1323-1357. 
Fink, Günther and Silvia Redaelli, 2011, Determinants of International Emergency Aid - Humanitarian Need Only? World Development 39, 5: 741-757.

Fougère, Denis, Julien Pouget and Francis Kramarz, 2010, Youth Unemployment and Crime in France, Journal of the European Economic Association 7, 5: 909-938.

Francken, Nathalie, Bart Minten and Johan F.M. Swinnen, 2012, The Political Economy of Relief Aid Allocation: Evidence from Madagascar, World Development 40, 3: 486-500.

Fuchs, Andreas and Krishna Chaitanya Vadlamannati, 2012, The Needy Donor: An Empirical Analysis of India's Aid Motives, draft.

Gartzke, E., Quan Li and Charles Boehmer, 2001, Investing in the Peace: Economic Interdependence and International Conflict, International Organization 55, 2: 391-438.

Gassebner, Martin, Alexander Keck and Robert Teh, 2010, Shaken, Not Stirred: The Impact of Disasters on International Trade, Review of International Economics 18, 2: 351-368.

Gil-Pareja, Salvador, Rafael Llorca and Jose A. Martínez Serrano, 2008, Measuring the Impact of Regional Export Promotion: The Spanish Case, Papers in Regional Science 87, 1: 139-146.

Glick, Reuven and Alan Taylor, 2010, Collateral Damage: Trade Disruption and the Economic Impact of War, Review of Economics and Statistics 92, 1: 102-127.

Goldstein, Melvyn C., 1997, The Snow Lion and the Dragon: China, Tibet, and the Dalai Lama, Berkeley, CA: University of California Press.

Goldstein, Melvyn C., 1998, The Dalai Lama's Dilemma, Foreign Affairs 77, 1: 83-97.

Gould, Eric D., Bruce A. Weinberg and David B. Mustard, 2002, Crime Rates and Local Labor Market Opportunities in the United States: 1979-1997, Review of Economics and Statistics 84, 1: 45-61.

Gowa, Joanne and Edward Mansfield, 1993, Power Politics and International Trade, American Political Science Review 87, 2: 408-420. 
Griliches, Zvi and Jerry A. Hausman, 1986, Errors in Variables in Panel Data, Journal of Econometrics 31, 1: 93-118.

Guiso, Luigi, Paola Sapienza and Luigi Zingales, 2009, Cultural Biases in Economic Exchange? Quarterly Journal of Economics 124, 3: 1095-1131.

Gyatso, Tenzin, 1990, Freedom in Exile: The Autobiography of the Dalai Lama, New York, NY: Harper Perennial.

Hansen, Lars Peter, 1982, Large Sample Properties of Generalized Method of Moments Estimators, Econometrica 50, 4: 1029-1054.

Harmer, Adele and Ellen Martin, 2010, Diversity in Donorship: Field Lessons, Humanitarian Policy Group Research Report 30, Overseas Development Institute, London, UK.

Harmer, Adele and Lin Cotterrell, 2005, Diversity in Donorship: The Changing Landscape of Official Humanitarian Aid, Humanitarian Policy Group Research Report 20, Overseas Development Institute, London, UK.

Hayashi, Fumio, 2000, Econometrics, Princeton, NJ: Princeton University Press.

Head, Keith and John Ries, 2010, Do Trade Missions Increase Trade? Canadian Journal of Economics 43, 3: 754-775.

Heckman, James J., 1979, Sample Selection Bias as a Specification Error, Econometrica 47, 1: 153-161.

Heston, Alan, Robert Summers and Bettina Aten, 2011, Penn World Table, Version 7.0, Center for International Comparisons of Production, Income and Prices at the University of Pennsylvania, Philadelphia, PA.

Höffler, Anke and Verity Outram, 2011, Need, Merit, or Self-Interest-What Determines the Allocation of Aid? Review of Development Economics 15, 2: 237-250.

Howsen, Roy M. and Stephen Jarrell, 1987, Some Determinants of Property Crime: Economic Factors Influence Criminal Behavior But Cannot Completely Explain the Syndrome, American Journal of Economics and Sociology 46, 4: 445-457. 
Hufbauer, Gary, Jeffrey Schott, Kimberly Elliott and Barbara Oegg, 2007, Economic Sanctions Reconsidered (3rd edition), Washington, DC: Institute for International Economics.

Human Rights Watch, 2011, Neither Rights Nor Security Killings, Torture, and Disappearances in Mexico's War on Drug, available at: http://www.hrw.org/sites/default/files/reports/mexico1111webwcover_0.pdf (accessed: July 2012).

International Monetary Fund 2012, World Economic Outlook April 2012 - Growth Resuming, Dangers Remain, World Economic and Financial Surveys, Washington, USA.

Kahn, Matthew E., 2005, The Death Toll from Natural Disasters: The Role of Income, Geography, and Institutions, Review of Economics and Statistics 87, 2: 271284.

Kastner, Scott L., 2007, When Do Conflicting Political Relations Affect International Trade? Journal of Conflict Resolution 51, 4: 664-688.

Katz, Ethan, 2001, Bias in Conditional and Unconditional Fixed Effects Logit Estimation, Political Analysis 9, 4: 379-384.

Kaufmann, Daniel, Aart Kraay and Massimo Mastruzzi, 2009, Governance Matters VIII, Governance Indicators for 1996-2008, available at: http:/info.worldbank.org/governance/wgi/pdf/wgicharts.xls $\quad$ (accessed: February 13, 2010).

Keohane, Robert O. and Joseph S. Nye, 1977, Power and Interdependence: World Politics in Transition, Boston, MA: Little, Brown.

Kilby, Christopher, 2009, The Political Economy of Conditionality: An Empirical Analysis of World Bank Loan Disbursements, Journal of Development Economics 89, 1: 51-61.

Kilby, Christopher, 2011, Informal Influence in the Asian Development Bank, Review of International Organizations 6, 3-4: 223-257. 
King, Ryan S. and Marc Mauer, Sentencing Project, 2002, Distorted priorities: Drug offenders in state prisons: Sentencing Project, available at: http://www.soros.org/sites/default/files/9038.pdf (accessed: July 2012).

Kragelund, Peter, 2008, The Return of Non-DAC Donors to Africa: New Prospects for African Development? Development Policy Review 26, 5: 555-84.

Kragelund, Peter, 2010, The Potential Role of Non-Traditional Donors' Aid in Africa, ICTSD Issue Paper No. 11, International Centre for Trade and Sustainable Development, Geneva, Switzerland.

Kuziemko, llyana and Eric Werker, 2006, How Much is a Seat on the Security Council Worth? Foreign Aid and Bribery at the United Nations, Journal of Political Economy 114, 5: 905-930.

Kuziemko, llyana and Steven D. Levitt, 2004, An Empirical Analysis of Imprisoning Drug Offenders, Journal of Public Economics 88, 9-10: 2043-2066.

Levitt, Steven D. and Sudhir Alladi Venkatesh, 2000, An Economic Analysis of a Drug-Selling Gang's Finances, Quarterly Journal of Economics 115, 3: 755789.

Levitt, Steven D., 1997, Using Electoral Cycles in Police Hiring to Estimate the Effect of Police on Crime, The American Economic Review 92, 4: 270-290.

Levitt, Steven D., 1998, Why do Increased Arrest Rates Appear to Reduce Crime: Deterrence, Incapacitation, or Measurement Error? Economic Inquiry 36, 3: 353-372.

Levitt, Steven D., 2002, Using Electoral Cycles in Police Hiring to Estimate the Effects of Police on Crime: Reply, The American Economic Review 92, 4: 1244-1250.

Luechinger, Simon and Paul A. Raschky, 2009, Valuing Flood Disasters Using the Life Satisfaction Approach, Journal of Public Economics 93, 3-4: 620-633.

Manning, Richard, 2006, Will 'Emerging Donors' Change the Face of International Co-operation? Development Policy Review 24, 4: 371-385. 
Mansfield, Edward, Helen Milner and Peter Rosendorff, 2000, Free to Trade: Democracies, Autocracies, and International Trade, American Political Science Review 94, 2: 305-322.

Martin, Philippe, Thierry Mayer and Mathias Thoenig, 2008, Make Trade Not War? Review of Economic Studies 75, 3: 865-900.

Maurer, Marc and Ryan S. King, 2007, A 25-year Quagmire: The War on Drugs and Its Impact on American Society, The Sentencing Project, Washington, USA, http://www.sentencingproject.org/doc/publications/dp_25yearquagmire.pdf (accessed: July 2012).

Mayer, Thierry and Soledad Zignago, 2006, Notes on CEPII's Distances Measures, available at: http://www.cepii.fr/anglaisgraph/bdd/distances.htm (accessed: May 2009).

McCrary, Justin, 2002, Using Electoral Cycles in Police Hiring to Estimate the Effect of Police on Crime: Comment, The American Economic Review 92, 4: 12361243.

Meier, Claudia and C. S. R. Murphy, 2011, India's Growing Involvement in Humanitarian Assistance, GPPi Research Paper No. 13, Global Public Policy Institute, Berlin, Germany.

Méon, Pierre-Guillaume and Khalid Sekkat, 2008, Institutional Quality and Trade: Which Institutions? Which Trade? Economic Inquiry 46, 2: 227-240.

Minfin, 2007, Russia's Participation in International Development Assistance, Concept approved by the President of the Russian Federation, June 14th, available at: http://www1.minfin.ru/en/financial affairs/Dev Assis/concept rus/ (accessed: June 2012).

Miron, Jeffrey A., 1999, Violence and the US Prohibitions of Drugs and Alcohol, American Law and Economics Review 1, 1: 78-114.

Miron, Jeffrey A., 2001, Violence, Guns, and Drugs: A Cross-Country Analysis, Journal of Law \& Economics 44, 2: 615-633. 
Morrow, J. D., 2003, Assessing the Role of Trade as a Source of Costly Signals, in: Edward D. Mansfield and Brian M. Pollins (eds.), Economic Interdependence and International Conflict: New Perspectives on an Enduring Debate, Ann Arbor, MI: University of Michigan Press.

Morrow, James D., Randolph. M. Siverson and Tressa Tabares, 1998, The Political Determinants of International Trade: The Major Powers, 1907-1990, American Political Science Review 92, 4: 649-661.

Nadelmann, Ethan A., 1989, Drug Prohibition in the United States: Costs, Consequences, and Alternatives, Science 245, 4921: 939-947.

Nagin, Daniel S., 1998, Criminal Deterrence Research at the Outset of the TwentyFirst Century, Crime and Justice 23: 1-42.

Naím, Moisès, 2007, Rogue Aid, Foreign Policy 159, March/April: 95-96.

Nel, Philip and Marjolein Righarts, 2008, Natural Disasters and the Risk of Violent Civil Conflict, International Studies Quarterly 52, 1: 159-185.

Neumayer, Eric and Thomas Plümper, 2007, The Gendered Nature of Natural Disasters: The Impact of Catastrophic Events on the Gender Gap in Life Expectancy, 1981-2002, Annals of the Association of American Geographers 97, 3: 551-566.

Neumayer, Eric, 2003a, What Factors Determine the Allocation of Aid by Arab Countries and Multilateral Agencies? Journal of Development Studies 39, 4: 134-147.

Neumayer, Eric, 2003b, Do Human Rights Matter in Bilateral Aid Allocation? A Quantitative Analysis of 21 Donor Countries, Social Science Quarterly 84, 3: 650-666.

Neumayer, Eric, 2004, Arab-related Bilateral and Multilateral Sources of Development Finance: Issues, Trends, and the Way Forward, World Economy 27, 2: 281-300.

Neumayer, Eric, 2005, Is the Allocation of Food Aid Free from Donor Interest Bias? Journal of Development Studies 41, 3: 394-411. 
Nickell, Stephen J., 1981, Biases in Dynamic Models with Fixed Effects, Econometrica 49, 6: 1417-1426.

Nitsch, Volker and Dieter Schumacher, 2004, Terrorism and International Trade: An Empirical Investigation, European Journal of Political Economy 20, 2: 423-433.

Nitsch, Volker, 2007, State Visits and International Trade, World Economy 30, 12: 1797-1816.

Nowak-Lehmann D., Felicitas, Inmaculada Martínez-Zarzoso, Stephan Klasen and Dierk Herzer, 2009, Aid and Trade - A Donor's Perspective, Journal of Development Studies 45, 7: 1184-1202.

OCHA, 2011, Financial Tracking System, United Nations Office for the Coordination of Humanitarian Affairs, available at: http://fts.unocha.org/ (accessed: August 2011).

OECD, 2005, Assessment Framework for Coverage of Humanitarian Actions in DAC Peer Reviews, available at: http://www.oecd.org/dataoecd/59/59/35374051.pdf (accessed: July 2012).

Öhler, Hannes, Peter Nunnenkamp and Axel Dreher, 2012, Does Conditionality Work? A Test for an Innovative US Aid Scheme, European Economic Review 56, 1: 138-153.

Olson, Eric L., David A. Shirk and Andrew Selee, 2011, Shared responsibility: USMexico policy options for confronting organized crime, available at: http://alfinstitute.org/wp-content/uploads/2012/01/Shared_Responsibility.pdf (accessed: July 2012).

Parsons, Christopher R., Ronald Skeldon, Terrie L. Walmsley and L. Alan Winters, 2007, Quantifying International Migration: A Database of Bilateral Migrant Stocks, World Bank Policy Research Working Paper 4165, The World Bank, Washington, DC.

Pehnelt, Gernot, 2007, The Political Economy of China's Aid Policy in Africa, Jena Economic Research Paper 51, University of Jena, Germany. 
Plümper, Thomas and Eric Neumayer, 2009, Famine Mortality, Rational Political Inactivity, and International Food Aid, World Development 37, 1: 50-61.

Polachek, Solomon. W., 1980, Conflict and Trade, Journal of Conflict Resolution 24, 1: 55-78.

Pollins, Brian. M., 1989, Does Trade Still Follow the Flag? American Political Science Review 83, 2: 465-480.

Potter, David M. and Douglas A. Van Belle, 2008, News Coverage and Japanese Foreign Disaster Aid: A Comparative Example of Bureaucratic Responsiveness to the News Media, International Relations of the Asia-Pacific 9, 2: 295-315.

Raschky, Paul A. and Manijeh Schwindt, 2012, On the Channel and Type of Aid: The Case of International Disaster Assistance, European Journal of Political Economy 28, 1: 119-131.

Raschky, Paul A., 2008, Institutions and the Losses from Natural Disasters, Natural Hazards and Earth System Sciences 8, 4: 627-634.

Resignato, Andrew J., 2000, Violent Crime: A Function of Drug Use or Drug Enforcement? Applied Economics 32, 6: 681-688.

Richardson, Neil and Charles Kegley, 1980, Trade Dependence and Foreign Policy Compliance, International Studies Quarterly 24, 2: 191-222.

Roodman, David, 2009, How to Do xtabond2: An Introduction to "Difference" and "System" GMM in Stata, Stata Journal 9, 1: 86-136.

Rose, Andrew, 2007, The Foreign Service and Foreign Trade: Embassies as Export Promotion, World Economy 30, 1: 22-38.

Rosenfeld, Richard, 2009, Crime is the Problem: Homicides, Acquisitive Crime, and Economic Conditions, Journal of Quantitative Criminology 25: 287-306.

Round, Jeffery I. and Matthew Odedokun, 2004, Aid Effort and its Determinants, International Review of Economics \& Finance 13, 3: 293-309. 
Schaffer, Mark E., 2005, XTIVREG2: Stata Module to Perform Extended IV/2SLS, GMM and AC/HAC, LIML and k-Class Regression for Panel Data Models, Statistical Software Components S456501, Boston College Department of Economics, revised 28 Jun 2010.

Sen, Amartya, 1990, Public Action to Remedy Hunger, Arturo Tanco Memorial Lecture, August 2, London.

Shepard, Edward M. and Paul R. Blackley, 2005, Drug Enforcement and Crime: Recent Evidence from New York State, Social Science Quarterly 86, 2: 323342.

Sollars, David L., Bruce L. Benson and David W. Rasmussen, 1994, Drug Enforcement and the Deterrence of Property Crime Among Local Jurisdictions, Public Finance Review 22, 1: 22-45.

Staiger, Douglas and James. H. Stock, 1997, Instrumental Variables Regression with Weak Instruments, Econometrica 65, 3: 557-586.

State Council, 2011, White Paper on China's Foreign Aid, Xinhua/China's Information Office of the State Council, document available at: http://www.gov.cn/english/official/2011-04/21/content 1849913.htm (accessed: August 2011).

Strömberg, David, 2007, Natural Disasters, Economic Development, and Humanitarian Aid, Journal of Economic Perspectives 21, 3: 199-222.

Swimmer, Eugene, 1974a, Measurement of the Effectiveness of Urban Law Enforcement: A Simultaneous Approach, Southern Economic Journal 40, 4: 618-630.

Swimmer, Eugene, 1974b, The Relationship of Police and Crime, Criminology 12, 3: 293-314.

Thacker, Strom C., 1999, The High Politics of IMF Lending, World Politics 52: 38-75.

Tierney, Michael J., Daniel L. Nielson, Darren G. Hawkins, J. Timmons Roberts, Michael G. Findley, Ryan M. Powers, Bradley Parks, Sven E. Wilson and 
Robert L. Hicks, 2011, More Dollars than Sense: Refining Our Knowledge of Development Finance Using AidData, World Development 39, 11: 1891-1906.

Tubilewicz, Czeslaw, 2012, The Politics of Compassion: Examining a Divided China's Humanitarian Assistance to Haiti, International Relations of the Asia-Pacific, first published online May 2, 2012.

UNODC, 2010, World Drug Report 2010, United Nations Office on Drug and Crime, New York, USA, 2010, available at: http://www.unodc.org/unodc/en/data-andanalysis/WDR-2010.html (accessed: July 2012).

UNODC, 2012, World Drug Report 2012, United Nations Office on Drug and Crime, New York, USA, 2010, available at: http://www.unodc.org/unodc/en/data-andanalysis/WDR-2012.html (accessed July 2012).

Voeten, Erik and Adis Merdzanovic, 2009, United Nations General Assembly Voting Data, available at: http://hdl.handle.net/1902.1/12379 (accessed: June 2010).

Voeten, Erik and Adis Merdzanovic, 2009, United Nations General Assembly Voting Data, Georgetown University, Washington, DC, available at: http://hdl.handle.net/1902.1/12379 (last accessed: July 2012).

Wiesenfarth, Manuel and Thomas Kneib, 2010, Bayesian Geoadditive Sample Selection Models, Journal of the Royal Statistical Society: Series C (Applied Statistics) 59, 3: 381-404.

Windmeijer, Frank, 2005, A Finite Sample Correction for the Variance of Linear Efficient Two-step GMM Estimators, Journal of Econometrics 126, 1: 25-51.

Woods, Ngaire, 2008, Whose Aid? Whose Influence? China, Emerging Donors and the Silent Revolution in Development Assistance, International Affairs 84, 6: 1205-1221.

World Bank, 2009, World Development Indicators, CD-Rom, Washington, DC.

Worrall, John L. and Tomislav W. Kovandzic, 2010, Police Levels and Crime Rates: An Instrumental Variables Approach, Social Science Research 39, 3: 506516. 
Younas, Javed, 2008, Motivation for Bilateral Aid Allocation: Altruism or Trade Benefits, European Journal of Political Economy 24, 3: 661-674.

Zellner, Arnold, 1962, An Efficient Method of Estimating Seemingly Unrelated Regressions and Tests for Aggregation Bias, Journal of the American Statistical Association 57, 298: 348-368. 


\section{Appendix A}

Table A.1: Humanitarian aid and disaster relief of "new" donors

\begin{tabular}{|l|l|}
\hline Turkey & Ministry of Foreign Affairs \\
\hline Responsible agency & \\
\hline Objectives / Mission & $\begin{array}{l}\text { Channel humanitarian assistance rapidly to those countries in dire straits and support } \\
\text { international efforts to this end indiscriminate of race, religion, language and gender; } \\
\text { build a safer world, save human lives and protect the environment; build on own } \\
\text { experiences as a disaster-prone country }\end{array}$ \\
\hline Priorities & N/A \\
\hline Sources & www.mfa.gov.tr/humanitarian-assistance-by-turkey.en.mfa \\
\hline
\end{tabular}

\begin{tabular}{|c|c|}
\hline \multicolumn{2}{|l|}{ South Korea } \\
\hline Responsible agency & $\begin{array}{l}\text { Korean International Cooperation Agency (KOICA) } \\
\text { Ministry of Foreign Affairs and Trade } \\
\text { Other ministries and governmental agencies }\end{array}$ \\
\hline Objectives / Mission & $\begin{array}{l}\text { Provide immediate relief to refugees and the victims of natural disasters and war; } \\
\text { stabilize food supplies; repair and reconstruct health and education facilities; rebuild } \\
\text { economic and social infrastructure; facilitate industrial rehabilitation }\end{array}$ \\
\hline Priorities & Infrastructure support; aid in kind; emergency relief; training; focus on Asia \\
\hline Sources & $\begin{array}{l}\text { www.koica.go.kr/english/aid/disaster/index.html } \\
\text { http://en.rescue.go.kr/ }\end{array}$ \\
\hline
\end{tabular}

\begin{tabular}{|c|c|}
\hline Saudi Arabia & \\
\hline $\begin{array}{l}\text { Responsible } \\
\text { agency }\end{array}$ & No central agency \\
\hline $\begin{array}{l}\text { Objectives } \\
\text { Mission }\end{array}$ & Spread aid to who needs it; "Kingdom of Humanity" \\
\hline Priorities & Initiation of donation campaigns; focus on Arabic and Muslim countries \\
\hline Sources & $\begin{array}{l}\text { www.saudiembassy.pl/The,Kingdom,of,Saudi,Arabia, and,Humanitarian,aids,281 } \\
\text {.html }\end{array}$ \\
\hline
\end{tabular}


Table A.1: (continued): Humanitarian aid and disaster relief of "new" donors

\begin{tabular}{|l|l|}
\hline \multicolumn{2}{|l|}{ United Arab Emirates } \\
\hline $\begin{array}{l}\text { Responsible } \\
\text { agency }\end{array}$ & $\begin{array}{l}\text { UAE Office for the Coordination of Foreign Aid (OCFA) } \\
\text { Several government ministries, departments and agencies }\end{array}$ \\
\hline $\begin{array}{l}\text { Objectives } \\
\text { Mission }\end{array}$ & $\begin{array}{l}\text { Provide urgent relief to those suffering the effects of natural disasters and man- } \\
\text { made crises; dictated by an Islamic belief that helping those in need is a } \\
\text { primary duty and that part of the country's wealth from oil and gas should be } \\
\text { devoted to assisting less fortunate countries and individuals; lead the way in } \\
\text { responding to regional and international emergencies }\end{array}$ \\
\hline Priorities & $\begin{array}{l}\text { Middle East; Sub-Saharan Africa; Central and South Asia; difficult regions; high } \\
\text { risk areas }\end{array}$ \\
\hline Sources & $\begin{array}{l}\text { http://www.uaeinteract.com/government/development aid.asp } \\
\text { http://www.ocfa.gov.ae }\end{array}$ \\
\hline
\end{tabular}

\begin{tabular}{|l|l|}
\hline Czech Republic & $\begin{array}{l}\text { Ministry for Foreign Affairs } \\
\text { Mesponsible } \\
\text { agency }\end{array}$ \\
\hline $\begin{array}{l}\text { Objectives } \\
\text { Mission }\end{array}$ & $\begin{array}{l}\text { Save lives; alleviating human suffering; build resilience; prevent new disasters; } \\
\text { operate out of common human solidarity and independent of particular political } \\
\text { or other interests; regular annual humanitarian budget since 1995 }\end{array}$ \\
\hline Priorities & $\begin{array}{l}\text { Development priority partner countries (e.g., Afghanistan and Ethiopia); } \\
\text { countries that receive little aid (e.g., Zimbabwe, Myanmar, Sri Lanka and DR } \\
\text { Congo); floods response (high-capacity water pumps); decontamination; urban } \\
\text { search and rescue assistance; disaster risk reduction; early recovery in the local } \\
\text { communities }\end{array}$ \\
\hline Sources & \begin{tabular}{l} 
E-mail from Ministry of Foreign Affairs, www.mzv.cz/aid \\
\hline
\end{tabular} \\
\hline
\end{tabular}

\begin{tabular}{|c|c|}
\hline \multicolumn{2}{|l|}{ Singapore } \\
\hline $\begin{array}{l}\text { Responsible } \\
\text { agency }\end{array}$ & $\begin{array}{l}\text { Singaporean Civil Defence Force } \\
\text { Ministry of Foreign Affairs }\end{array}$ \\
\hline $\begin{array}{l}\text { Objectives } \\
\text { Mission }\end{array}$ & $\begin{array}{l}\text { Being a responsible member of the international community; does not aspire to } \\
\text { being a major donor; being part of an overall international contribution }\end{array}$ \\
\hline Priorities & $\begin{array}{l}\text { Decisions taken under consideration of the value added to the general relief } \\
\text { efforts and of the nature of Singapore's relations with the affected country; } \\
\text { emphasis on neighboring countries }\end{array}$ \\
\hline Sources & E-mail from Ministry of Foreign Affairs \\
\hline
\end{tabular}


Table A.1: (continued): Humanitarian aid and disaster relief of "new" donors

\begin{tabular}{|c|c|}
\hline \multicolumn{2}{|l|}{ Russian Federation } \\
\hline $\begin{array}{l}\text { Responsible } \\
\text { agency }\end{array}$ & $\begin{array}{l}\text { Ministry of Foreign Affairs } \\
\text { Ministry of Finance } \\
\text { Ministry for Emergencies }\end{array}$ \\
\hline $\begin{array}{l}\text { Objectives } \\
\text { Mission }\end{array}$ & $\begin{array}{l}\text { Eliminate the consequences of humanitarian, natural, environmental, and } \\
\text { industrial disasters and other emergencies }\end{array}$ \\
\hline Priorities & N/A \\
\hline Sources & $\begin{array}{l}\text { Minfin (2007) } \\
\text { www.mchs.gov.ru/eng }\end{array}$ \\
\hline
\end{tabular}

\begin{tabular}{|c|c|}
\hline \multicolumn{2}{|l|}{ China } \\
\hline $\begin{array}{l}\text { Responsible } \\
\text { agency }\end{array}$ & $\begin{array}{l}\text { Ministry of Foreign Affairs } \\
\text { Ministry of Commerce } \\
\text { Ministry of Health } \\
\text { Ministry of Civil Affairs } \\
\text { China Earthquake Administration }\end{array}$ \\
\hline $\begin{array}{l}\text { Objectives } \\
\text { Mission }\end{array}$ & $\begin{array}{l}\text { Reduce losses of life and property in disaster-stricken areas; help the victim } \\
\text { country tackle difficulties caused by the disaster; fulfill duty of a responsible } \\
\text { member of international society; humanitarian spirit of "People first" }\end{array}$ \\
\hline Priorities & $\mathrm{N} / \mathrm{A}$ \\
\hline Sources & $\begin{array}{l}\text { State Council (2011) } \\
\text { www.gov.cn/misc/2006-01/18/content 163087.htm }\end{array}$ \\
\hline
\end{tabular}

\begin{tabular}{|l|l|}
\hline Brazil & Ministry of Foreign Affairs \\
\hline $\begin{array}{l}\text { Responsible } \\
\text { agency }\end{array}$ & $/$ \\
\hline $\begin{array}{l}\text { Objectives } \\
\text { Mission }\end{array}$ & $\begin{array}{l}\text { Respond quickly to humanitarian emergencies caused by social and } \\
\text { environmental disasters; promote both food security and nutritional status of } \\
\text { vulnerable populations; implement measures to prevent and reduce disaster } \\
\text { risks; sustainable post-disaster early recovery; bring world nations and peoples } \\
\text { closer }\end{array}$ \\
\hline Priorities & $\begin{array}{l}\text { Priority to projects capable of igniting changes in the structural causes beneath } \\
\text { the situation of food insecurity; gifts of food, materials for temporary shelter and } \\
\text { health supplies; Latin American, Caribbean, African and Asian countries }\end{array}$ \\
\hline Sources & cooperacaohumanitaria.itamaraty.gov.br \\
\hline
\end{tabular}


Table A.1: (continued): Humanitarian aid and disaster relief of "new" donors

\begin{tabular}{|c|c|}
\hline Poland & \\
\hline $\begin{array}{l}\text { Responsible } \\
\text { agency }\end{array}$ & Ministry of Foreign Affairs \\
\hline $\begin{array}{l}\text { Objectives } \\
\text { Mission }\end{array}$ & Save lives and protect during disasters and crises \\
\hline Priorities & $\begin{array}{l}\text { Partner countries (e.g., Afghanistan, Georgia, Moldova, Palestinian Territory and } \\
\text { Ukraine); in difficult humanitarian situations (Sudan, Chad and Iraq) }\end{array}$ \\
\hline Sources & www.polishaid.gov.pl \\
\hline
\end{tabular}

\begin{tabular}{|l|l|}
\hline \multicolumn{2}{|l|}{ Hungary } \\
$\begin{array}{l}\text { Responsible } \\
\text { agency }\end{array}$ & $\begin{array}{l}\text { Ministry of Foreign Affairs } \\
\text { Other ministries } \\
\text { National Directorate for Disaster Management }\end{array}$ \\
\hline $\begin{array}{l}\text { Objectives } \\
\text { Mission }\end{array}$ & $\begin{array}{l}\text { Give the victims of conflicts and disasters speedy assistance; focus also on } \\
\text { rehabilitation and reconstruction }\end{array}$ \\
\hline Priorities & $\begin{array}{l}\text { Support in the sectors of health, water and sanitation; restoration of livelihoods; } \\
\text { focus on Central and South-East European region }\end{array}$ \\
\hline Sources & www.mfa.gov.hu/kum/en/bal/foreign policy/international development \\
\hline
\end{tabular}

\begin{tabular}{|l|l|}
\hline \multicolumn{2}{|l|}{ Cyprus } \\
\hline $\begin{array}{l}\text { Responsible } \\
\text { agency }\end{array}$ & $\begin{array}{l}\text { Minister of Foreign Affairs } \\
\text { CyprusAid (Planning Bureau) }\end{array}$ \\
\hline $\begin{array}{l}\text { Objectives } \\
\text { Mission }\end{array}$ & $/ \begin{array}{l}\text { Assist countries and people in dire situations; motivated by own experience after } \\
\text { the Turkish invasion of 1974; facilitator in emergency response situations; active } \\
\text { since 1994 }\end{array}$ \\
\hline Priorities & $\begin{array}{l}\text { Funds or in kind (pharmaceuticals, food and clothing); countries that are close } \\
\text { and enjoy good relations with Cyprus }\end{array}$ \\
\hline Sources & $\begin{array}{l}\text { E-mail from Ministry of Foreign Affairs } \\
\text { CyprusAid (2009) } \\
\text { http://www.planning.gov.cy/planning/planning.nsf/dmlcyactivities en/dmlcyactivit } \\
\text { ies en?OpenDocument }\end{array}$ \\
\hline
\end{tabular}


Table A.1: (continued): Humanitarian aid and disaster relief of "new" donors

\begin{tabular}{|c|c|}
\hline Slovakia & \\
\hline $\begin{array}{l}\text { Responsible } \\
\text { agency }\end{array}$ & $\begin{array}{l}\text { Ministry of Foreign Affairs } \\
\text { Ministry of Interior }\end{array}$ \\
\hline $\begin{array}{l}\text { Objectives } \\
\text { Mission }\end{array}$ & $\begin{array}{l}\text { Expression of solidarity with people in need; prevent the loss of lives; mitigate } \\
\text { the suffering of people affected by exceptional events like natural disasters, } \\
\text { armed conflicts or similar emergency situations; active since about } 2002\end{array}$ \\
\hline Priorities & Urgency; availability of resources; no pre-defined regional or sectoral priorities \\
\hline Sources & $\begin{array}{l}\text { E-Mail from Ministry of Foreign Affairs } \\
\text { www.foreign.gov.sk/en/foreign policy/slovak aid }\end{array}$ \\
\hline
\end{tabular}

\begin{tabular}{|c|c|}
\hline Israel & \\
\hline $\begin{array}{l}\text { Responsible } \\
\text { agency }\end{array}$ & $\begin{array}{l}\text { Ministry of Foreign Affairs } \\
\text { Agency for International Development Cooperation (MASHAV) }\end{array}$ \\
\hline $\begin{array}{l}\text { Objectives } \\
\text { Mission }\end{array}$ & $\begin{array}{l}\text { Respond in the wake of natural or man-made disasters; "by tragic circumstance, } \\
\text { Israel is a world leader in handling mass casualties;" active since } 1957 \text { (disaster } \\
\text { relief since the 1980s) }\end{array}$ \\
\hline Priorities & Emergency and disaster medicine; Gaza Strip; West Bank \\
\hline Sources & $\begin{array}{l}\text { www.mfa.gov.il/mfa/humanitarianaid/overview } \\
\text { mashav.mfa.gov.il } \\
\text { E-Mail from MASHAV }\end{array}$ \\
\hline
\end{tabular}

\begin{tabular}{|c|c|}
\hline Monaco & \\
\hline $\begin{array}{l}\text { Responsible } \\
\text { agency }\end{array}$ & Ministry of Foreign Affairs (Department of International Cooperation) \\
\hline $\begin{array}{l}\text { Objectives } \\
\text { Mission }\end{array}$ & $\begin{array}{l}\text { Support people affected by natural disasters or food shortage without any } \\
\text { political considerations; active since } 2007\end{array}$ \\
\hline Priorities & No geographic priorities \\
\hline Sources & $\begin{array}{l}\text { www.gouv.mc/Action-Gouvernementale/Monaco-dans-le-Monde/L-Aide- } \\
\text { Publique-au-Developpement-et-la-Cooperation-Internationale }\end{array}$ \\
\hline
\end{tabular}


Table A.1: (continued): Humanitarian aid and disaster relief of "new" donors

\begin{tabular}{|c|c|}
\hline Argentina & \\
\hline $\begin{array}{l}\text { Responsible } \\
\text { agency }\end{array}$ & Ministry of Foreign Affairs and Worship (Comisión Cascos Blancos) \\
\hline $\begin{array}{l}\text { Objectives } \\
\text { Mission }\end{array}$ & $\begin{array}{l}\text { Search for new proposals to reduce risks, prevent disasters, preparing } \\
\text { responses and minimize their impact; development of participatory and } \\
\text { preventive tools; incorporation of communities in risk reduction processes }\end{array}$ \\
\hline Priorities & Focus on the Americas \\
\hline Sources & www.cascosblancos.gov.ar \\
\hline
\end{tabular}

\section{Venezuela}

No information available

\begin{tabular}{|l|l|}
\hline \multicolumn{2}{|l|}{ Estonia } \\
$\begin{array}{l}\text { Responsible } \\
\text { agency }\end{array}$ & $\begin{array}{l}\text { Ministry of Foreign Affairs } \\
\text { Ministry of the Interior (Estonian Disaster Relief Team ) }\end{array}$ \\
\hline $\begin{array}{l}\text { Objectives } \\
\text { Mission }\end{array}$ & $\begin{array}{l}\text { Save human lives and render help to the victims; pay attention first and foremost } \\
\text { to most vulnerable groups of the population; most genuine form of solidarity } \\
\text { between people and countries; active since 1998 }\end{array}$ \\
\hline Priorities & Earthquakes; floods; war refugees \\
\hline Sources & $\begin{array}{l}\text { www.vm.ee } \\
\text { www.rescue.ee }\end{array}$ \\
\hline
\end{tabular}

\begin{tabular}{|l|l|}
\hline \multicolumn{2}{|l|}{ Malaysia } \\
$\begin{array}{l}\text { Responsible } \\
\text { agency }\end{array}$ & No unified procedure (case-by-case basis) \\
\hline $\begin{array}{l}\text { Objectives } \\
\text { Mission }\end{array}$ & Strive and support efforts in the area of international disaster relief \\
\hline Priorities & $\begin{array}{l}\text { Availability of technical expertise and technical equipment; language and } \\
\text { culture; focus on Malaysia's own natural disasters (flooding, sporadic peat soil } \\
\text { fire and forest fire/haze) }\end{array}$ \\
\hline Sources & E-mail from the Embassy of Malaysia in Berlin \\
\hline
\end{tabular}

\section{Thailand}

No information available 
Table A.1: (continued): Humanitarian aid and disaster relief of "new" donors

\begin{tabular}{|c|c|}
\hline \multicolumn{2}{|l|}{ Slovenia } \\
\hline $\begin{array}{l}\text { Responsible } \\
\text { agency }\end{array}$ & $\begin{array}{l}\text { Ministry of Foreign Affairs } \\
\text { Ministry of Defence } \\
\text { Administration for Civil Protection and Disaster Relief }\end{array}$ \\
\hline $\begin{array}{l}\text { Objectives } \\
\text { Mission }\end{array}$ & $\begin{array}{l}\text { Prevent or alleviate human suffering; non-discriminatory and not linked to } \\
\text { foreign policy objectives }\end{array}$ \\
\hline Priorities & $\begin{array}{l}\text { Reduction of poverty and hunger; mine action; assistance to children in post- } \\
\text { conflict situations; Western Balkans; Eastern Europe, the Caucasus and Central } \\
\text { Asia; Africa }\end{array}$ \\
\hline Sources & www.mzz.gov.si/en/foreign policy/foreign policy/ \\
\hline
\end{tabular}


Table A.2: List of donor countries by definition of "new" donors

\begin{tabular}{|c|c|c|c|c|c|c|c|}
\hline Donor country & \# aid & Aid & (mill. & Decision & Non-DAC & Poor & Autocracy \\
\hline United States of America & 269 & 832 & & 21 & & & \\
\hline Germany & 168 & 247 & & 26 & & & \\
\hline Norway & 134 & 187 & & 33 & & & \\
\hline Sweden & 132 & 192 & & 30 & & & \\
\hline Japan & 131 & 516 & & 13 & & & \\
\hline Italy & 102 & 124 & & 27 & & & \\
\hline France & 101 & 72 & & 20 & & & \\
\hline Switzerland & 95 & 78 & & 45 & & & \\
\hline Canada & 93 & 192 & & 24 & & & \\
\hline United Kingdom & 91 & 450 & & 29 & & & \\
\hline Spain & 83 & 113 & & 22 & & & \\
\hline Australia & 75 & 136 & & 21 & & & \\
\hline Ireland & 75 & 60 & & 30 & & & \\
\hline Denmark & 72 & 85 & & 25 & & & \\
\hline Luxembourg & 70 & 22 & & 37 & & & \\
\hline Netherlands & 69 & 153 & & 27 & & & \\
\hline Turkey & 54 & 84 & & 41 & $\mathrm{x}$ & $\mathrm{x}$ & \\
\hline Korea, Republic of & 54 & 25 & & 21 & $\mathrm{x}$ & & \\
\hline Belgium & 52 & 71 & & 35 & & & \\
\hline Saudi Arabia (Kingdom of) & 51 & 482 & & 42 & $\mathrm{x}$ & & $\mathrm{x}$ \\
\hline New Zealand & 50 & 36 & & 23 & & & \\
\hline United Arab Emirates & 47 & 46 & & 51 & $\mathrm{x}$ & & $\mathrm{x}$ \\
\hline Czech Republic & 44 & 9 & & 29 & $\mathrm{x}$ & & \\
\hline Austria & 41 & 18 & & 47 & & & \\
\hline Finland & 39 & 39 & & 30 & & & \\
\hline Singapore & 37 & 12 & & 34 & $\mathrm{x}$ & & $\mathrm{x}$ \\
\hline Greece & 35 & 35 & & 28 & & & \\
\hline Russian Federation & 30 & 35 & & 18 & $\mathrm{x}$ & $\mathrm{x}$ & $x$ \\
\hline China & 30 & 21 & & 15 & $x$ & $x$ & $\mathrm{x}$ \\
\hline Brazil & 26 & 5 & & 30 & $\mathrm{x}$ & $\mathrm{x}$ & \\
\hline Poland & 24 & 10 & & 17 & $\mathrm{x}$ & & \\
\hline Hungary & 23 & 2 & & 26 & $x$ & & \\
\hline Portugal & 19 & 11 & & 26 & & & \\
\hline Cyprus & 19 & 1 & & 61 & $\mathrm{x}$ & & \\
\hline Slovakia & 18 & 8 & & 20 & $x$ & & \\
\hline Israel & 18 & 4 & & 20 & $\mathrm{x}$ & & \\
\hline Monaco & 18 & 2 & & 44 & $\mathrm{x}$ & & $N / A$ \\
\hline Argentina & 18 & 0 & & 25 & $\mathrm{x}$ & $\mathrm{x}$ & \\
\hline Venezuela & 16 & 0 & & 18 & $\mathrm{x}$ & $\mathrm{x}$ & \\
\hline Estonia & 15 & 1 & & 20 & $\mathrm{x}$ & & \\
\hline Malaysia & 14 & 9 & & 9 & $\mathrm{x}$ & $\mathrm{x}$ & $x$ \\
\hline Thailand & 13 & 30 & & 19 & $\mathrm{x}$ & $\mathrm{x}$ & (X) \\
\hline Slovenia & 13 & 1 & & 15 & $x$ & & \\
\hline Qatar & 12 & 25 & & 16 & $\mathrm{x}$ & & $\mathrm{x}$ \\
\hline Iceland & 12 & 1 & & 29 & $x$ & & \\
\hline Liechtenstein & 12 & 1 & & 60 & $x$ & & \\
\hline Colombia & 12 & 0 & & 23 & $\mathrm{x}$ & $\mathrm{X}$ & \\
\hline South Africa & 11 & 2 & & 24 & $\mathrm{x}$ & $x$ & $\mathrm{x}$ \\
\hline Latvia & 11 & 1 & & 19 & $\mathrm{x}$ & $\mathrm{x}$ & \\
\hline Andorra & 11 & 0 & & 72 & $x$ & & \\
\hline Chile & 11 & 0 & & 12 & $\mathrm{x}$ & $\mathrm{x}$ & \\
\hline Morocco & 10 & 1 & & 24 & $\mathrm{x}$ & $\mathrm{x}$ & $\mathrm{X}$ \\
\hline Peru & 10 & 0 & & 35 & $x$ & $x$ & $(\mathrm{X})$ \\
\hline India & 9 & 31 & & 6 & $x$ & $x$ & \\
\hline Kuwait & 9 & 21 & & 11 & $x$ & & $x$ \\
\hline
\end{tabular}

Note: N/A - not available; $(X)$ - true in some years 
Table A.2: (continued): List of donor countries by definition of "new" donors

\begin{tabular}{|c|c|c|c|c|c|c|c|}
\hline Donor country & \# aid & Aid & (mill. & Decision & Non-DAC & Poor & Autocracy \\
\hline Kazakhstan & 9 & 7 & & 39 & $\mathrm{X}$ & $\mathrm{X}$ & $\mathrm{X}$ \\
\hline Mexico & 9 & 4 & & 33 & $x$ & $\mathrm{x}$ & $(\mathrm{X})$ \\
\hline Cuba & 9 & 0 & & 11 & $\mathrm{x}$ & $\mathrm{x}$ & $x^{\prime}$ \\
\hline Hong Kong & 7 & 7 & & 24 & $x$ & & $\mathrm{~N} / \mathrm{A}$ \\
\hline Trinidad and Tobago & 7 & 3 & & 14 & $\mathrm{x}$ & & \\
\hline Romania & 7 & 3 & & 27 & $x$ & $\mathrm{x}$ & \\
\hline Lithuania & 6 & 0 & & 24 & $x$ & $x$ & \\
\hline Laos & 6 & 0 & & 17 & $\mathrm{x}$ & $\mathrm{x}$ & $\mathrm{x}$ \\
\hline Pakistan & 6 & 0 & & 12 & $\mathrm{x}$ & $\mathrm{x}$ & $(\mathrm{X})$ \\
\hline Korea, Dem. Rep. & 6 & 0 & & 11 & $\mathrm{x}$ & $\mathrm{x}$ & $x$ \\
\hline Libya & 5 & 2 & & 21 & $\mathrm{x}$ & $\mathrm{x}$ & $\mathrm{x}$ \\
\hline Moldova & 5 & 0 & & 27 & $x$ & $x$ & \\
\hline Sri Lanka & 4 & 1 & & 8 & $\mathrm{x}$ & $\mathrm{x}$ & \\
\hline Nigeria & 4 & 1 & & 11 & $\mathrm{x}$ & $\mathrm{x}$ & \\
\hline Iran & 4 & 1 & & 15 & $\mathrm{x}$ & $x$ & $\mathrm{x}$ \\
\hline Mauritius & 4 & 0 & & 10 & $\mathrm{x}$ & $\mathrm{x}$ & \\
\hline Bulgaria & 4 & 0 & & 26 & $\mathrm{x}$ & $\mathrm{x}$ & \\
\hline Tunisia & 4 & 0 & & 18 & $\mathrm{x}$ & $\mathrm{x}$ & $\mathrm{x}$ \\
\hline Nicaragua & 4 & 0 & & 9 & $x$ & $x$ & \\
\hline Ecuador & 4 & 0 & & 8 & $x$ & $x$ & $(\mathrm{X})$ \\
\hline Jordan & 4 & 0 & & 12 & $\mathrm{x}$ & $\mathrm{x}$ & $x^{\prime}$ \\
\hline Malta & 3 & 11 & & 47 & $\mathrm{x}$ & & \\
\hline Indonesia & 3 & 1 & & 5 & $x$ & $x$ & \\
\hline Algeria & 3 & 1 & & 19 & $\mathrm{x}$ & $\mathrm{x}$ & $\mathrm{x}$ \\
\hline Azerbaijan & 3 & 1 & & 19 & $\mathrm{x}$ & $\mathrm{x}$ & $x$ \\
\hline Botswana & 3 & 1 & & 26 & $\mathrm{x}$ & $x$ & $\mathrm{x}$ \\
\hline Mauritania & 3 & 0 & & 17 & $\mathrm{x}$ & $\mathrm{x}$ & $(\mathrm{X})$ \\
\hline Belarus & 3 & 0 & & 29 & $x$ & $x$ & $x$ \\
\hline Oman & 3 & 0 & & 5 & $\mathrm{x}$ & & $\mathrm{x}$ \\
\hline Bangladesh & 3 & 0 & & 13 & $\mathrm{x}$ & $\mathrm{x}$ & $(\mathrm{X})$ \\
\hline Panama & 3 & 0 & & 8 & $x$ & $x$ & \\
\hline Kyrgyzstan & 2 & 27 & & 14 & $\mathrm{x}$ & $\mathrm{x}$ & $(\mathrm{X})$ \\
\hline Gabon & 2 & 1 & & 12 & $\mathrm{x}$ & $\mathrm{x}$ & $x$ \\
\hline Reunion & 2 & 0 & & 23 & $\mathrm{x}$ & $N / A$ & $\mathrm{~N} / \mathrm{A}$ \\
\hline Philippines & 2 & 0 & & 15 & $x$ & $\mathrm{x}$ & \\
\hline Vietnam & 2 & 0 & & 25 & $x$ & $x$ & $\mathrm{X}$ \\
\hline Faeroe Islands & 2 & 0 & & 44 & $\mathrm{x}$ & & $N / A$ \\
\hline Nepal & 2 & 0 & & 2 & $\mathrm{x}$ & $\mathrm{x}$ & $(\mathrm{X})$ \\
\hline Dominican Republic & 2 & 0 & & & $\mathrm{x}$ & $\mathrm{x}$ & \\
\hline Swaziland & 2 & 0 & & 14 & $\mathrm{x}$ & $\mathrm{x}$ & $\mathrm{x}$ \\
\hline San Marino & 2 & 0 & & & $\mathrm{x}$ & & \\
\hline Guatemala & 2 & 0 & & 3 & $\mathrm{x}$ & $\mathrm{x}$ & \\
\hline Fiji & 2 & 0 & & 48 & $\mathrm{x}$ & $\mathrm{x}$ & $(\mathrm{X})$ \\
\hline Cook Islands & 2 & 0 & & 55 & $x$ & $N / A$ & $\mathrm{~N} / \mathrm{A}$ \\
\hline Bahamas & 2 & 0 & & 31 & $\mathrm{x}$ & & \\
\hline Ukraine & 2 & 0 & & 10 & $\mathrm{x}$ & $\mathrm{x}$ & \\
\hline El Salvador & 2 & 0 & & 12 & $x$ & $x$ & \\
\hline Bolivia & 2 & 0 & & 4 & $\mathrm{x}$ & $\mathrm{x}$ & \\
\hline Syrian Arab Republic & 2 & 0 & & 4 & $x$ & $x$ & $x$ \\
\hline Tajikistan & 2 & 0 & & 12 & $\mathrm{x}$ & $\mathrm{x}$ & $\mathrm{x}$ \\
\hline Syrian Arab Republic & 2 & 0 & & 4 & $x$ & $x$ & $x$ \\
\hline Bolivia & 2 & 0 & & 4 & $\mathrm{x}$ & $\mathrm{x}$ & \\
\hline
\end{tabular}

Note: N/A - not available; $(X)$ - true in some years 
Table A.3: Sources and definitions

\begin{tabular}{|c|c|c|}
\hline Variable & Description & Source \\
\hline \multicolumn{3}{|l|}{ Dependent variables } \\
\hline $\begin{array}{l}\text { Aid dummy } \\
\text { (log) Decision time }\end{array}$ & $\begin{array}{l}1 \text { if donor provides emergency assistance to recipient after a natural disaster } \\
\text { (log) Number of days following a disaster before a donor commits herself to provide }\end{array}$ & $\begin{array}{l}\text { OCHA (2011) } \\
\text { OCHA (2011) }\end{array}$ \\
\hline \multicolumn{3}{|l|}{ Disaster characteristics } \\
\hline $\begin{array}{l}(\log ) \text { Total affected } \\
\text { (log) Killed }\end{array}$ & $\begin{array}{l}\text { (log) Number of people that have been injured, affected and left homeless after a } \\
\text { (log) Number of persons confirmed as dead and persons missing and presumed dead }\end{array}$ & $\begin{array}{l}\text { EM-DAT (2012) } \\
\text { EM-DAT (2012) }\end{array}$ \\
\hline \multicolumn{3}{|l|}{ Donor characteristics } \\
\hline $\begin{array}{l}\text { DAC } \\
\text { (log) GDP per capita } \\
\text { High income } \\
\text { Democracy } \\
\text { (log) Population }\end{array}$ & $\begin{array}{l}1 \text { if donor country is a member of the OECD Development Assistance Committee } \\
\text { (log) Real GDP per capita (Constant Prices: Laspeyres), derived from growth rate, lag } \\
1 \text { if donor country is classified as high-income country according to } 2010 \mathrm{GNI} \text { per } \\
1 \text { if the regime qualifies as democratic, lag } \\
\text { (log) Total population, lag }\end{array}$ & $\begin{array}{l}\text { Own construction } \\
\text { Penn World Tables (Heston et al. 2009) } \\
\text { World Bank (http://data.worldbank.org/about/country- } \\
\text { Cheibub et al. (2010) } \\
\text { World Bank (http://data.worldbank.org/indicator) }\end{array}$ \\
\hline \multicolumn{3}{|l|}{ Recipient characteristics } \\
\hline $\begin{array}{l}\text { (log) GDP per capita } \\
\text { (log) Population } \\
\text { Population density } \\
\text { Democracy } \\
\text { Control of corruption } \\
\text { UNSC member } \\
\text { (log) Mineral and energy }\end{array}$ & $\begin{array}{l}\text { (log) Real GDP per capita (constant } 2005 \text { Prices: Laspeyres), derived from growth } \\
\text { (log) Total population, lag } \\
\text { Total population divided by area in hectare, lag } \\
1 \text { if the regime qualifies as democratic, lag } \\
\text { Index ranging from }-2.5 \text { to } 2.5 \text { with higher values corresponding to better governance, } \\
1 \text { if a country is a temporary member of the United Nations Security Council, current } \\
\text { (log) Product of unit resource rents and physical quanitites of minerals and energy }\end{array}$ & $\begin{array}{l}\text { Penn World Tables (Heston et al. 2011) } \\
\text { World Bank (http://data.worldbank.org/indicator) } \\
\text { Own construction based on CEPII and World Bank data } \\
\text { Cheibub et al. (2010) } \\
\text { Kaufmann et al. (2009) } \\
\text { Dreher et al. (2009b) } \\
\text { World Bank (http://data.worldbank.org/indicator) }\end{array}$ \\
\hline \multicolumn{3}{|c|}{ S } \\
\hline $\begin{array}{l}\text { (log) Distance } \\
\text { Neighbor } \\
\text { Common colonial history } \\
\text { Common official language } \\
\text { Common major religion } \\
\text { (log) Migration in } \\
\text { (log) Migration out } \\
\text { UNGA voting } \\
\text { (log) Exports }\end{array}$ & $\begin{array}{l}\text { (log) Bilateral distance (weighted by populations of major cities) } \\
1 \text { if donor and recipient share a common border } \\
1 \text { if countries ever had a common colonizer or have ever been in a colonial } \\
1 \text { if countries share a common official language } \\
1 \text { if countries have the same major religion } \\
\text { (log) Stock of migrants from recipient country in donor country, 2000 round of } \\
\text { (log) Stock of migrants from donor country in recipient country, } 2000 \text { round of } \\
\text { UNGA voting alignment between donor and recipient, lag } \\
\text { (log) Exports to recipient country (\% of total exports of donor country), mirror data }\end{array}$ & $\begin{array}{l}\text { CEPII (Mayer and Zignago 2006) } \\
\text { CEPII (Mayer and Zignago 2006) } \\
\text { CEPII (Mayer and Zignago 2006) } \\
\text { CEPII (Mayer and Zignago 2006) } \\
\text { WCD (http://www.worldchristiandatabase.org/wcd/) } \\
\text { Global Migrant Origin Database (Parsons et al. 2007) } \\
\text { Global Migrant Origin Database (Parsons et al. 2007) } \\
\text { Voeten and Merdzanovic (2009) } \\
\text { UN Comtrade via WITS (http://wits.worldbank.org) }\end{array}$ \\
\hline
\end{tabular}

Notes:

- The value of 1 has been added to "total affected", "killed" and "mineral and energy depletion" before taking logarithms 
Table A.4: Descriptive statistics

\begin{tabular}{|c|c|c|c|c|c|}
\hline Variable & Obs & Mean & Std. Dev. & Min & Max \\
\hline \multicolumn{6}{|l|}{ Dependent variables } \\
\hline Aid dummy & 29412 & 0.09 & 0.28 & 0.00 & 1.00 \\
\hline (log) Decision time & 2194 & 2.62 & 1.20 & 0.00 & 5.18 \\
\hline \multicolumn{6}{|l|}{ Disaster severity } \\
\hline (log) Total affected & 29412 & 11.23 & 2.78 & 0.00 & 18.83 \\
\hline (log) Killed & 29412 & 3.56 & 2.30 & 0.00 & 12.02 \\
\hline \multicolumn{6}{|l|}{ Donor characteristics } \\
\hline DAC & 29412 & 0.27 & 0.44 & 0.00 & 1.00 \\
\hline (log) GDP per capita & 29412 & 9.35 & 1.04 & 6.80 & 11.92 \\
\hline High income & 29412 & 0.46 & 0.50 & 0.00 & 1.00 \\
\hline Democracy & 29412 & 0.70 & 0.46 & 0.00 & 1.00 \\
\hline (log) Population & 29412 & 16.47 & 1.73 & 12.53 & 21.00 \\
\hline \multicolumn{6}{|l|}{ Recipient characteristics } \\
\hline (log) GDP per capita & 29412 & 8.07 & 0.91 & 4.77 & 10.35 \\
\hline (log) Population & 29412 & 17.02 & 1.99 & 11.14 & 21.00 \\
\hline Population density & 29412 & 1.38 & 1.74 & 0.02 & 10.10 \\
\hline Democracy & 29412 & 0.65 & 0.48 & 0.00 & 1.00 \\
\hline Control of corruption & 29412 & -0.51 & 0.53 & -1.73 & 1.50 \\
\hline UNSC member & 29412 & 0.11 & 0.31 & 0.00 & 1.00 \\
\hline (log) Mineral and energy depletion & 29412 & 33.89 & 15.46 & 0.00 & 51.12 \\
\hline \multicolumn{6}{|l|}{ Bilateral variables } \\
\hline (log) Distance & 29412 & 8.84 & 0.71 & 5.25 & 9.89 \\
\hline Neighbor & 29412 & 0.02 & 0.15 & 0.00 & 1.00 \\
\hline Common colonial history & 29412 & 0.15 & 0.36 & 0.00 & 1.00 \\
\hline Common official language & 29412 & 0.11 & 0.31 & 0.00 & 1.00 \\
\hline Common major religion & 29412 & 0.43 & 0.50 & 0.00 & 1.00 \\
\hline (log) Migration in & 29412 & 5.31 & 3.14 & 0.00 & 16.05 \\
\hline (log) Migration out & 29412 & 4.63 & 2.74 & 0.00 & 15.40 \\
\hline UNGA voting & 29412 & 0.77 & 0.14 & 0.01 & 0.99 \\
\hline (log) Exports & 29412 & -4.24 & 3.13 & -17.66 & 4.05 \\
\hline
\end{tabular}

Note: Descriptive statistics for sample as in Table 2, column 1. 
Table A.5: Determinants of aid selection (Logit, marginal effects, 2000-09)

\begin{tabular}{|c|c|c|c|c|}
\hline & (1) & $(2)$ & (3) & $(4)$ \\
\hline \multicolumn{5}{|l|}{ Disaster severity } \\
\hline $\begin{array}{l}\text { (log) Total affected } \\
(\log ) \text { Killed }\end{array}$ & $\begin{array}{l}0.0079^{\star \star \star} \\
(0.000) \\
0.0266^{\star \star *} \\
(0.000)\end{array}$ & & $\begin{array}{l}0.0079^{\star \star *} \\
(0.000) \\
0.0269^{\star \star *} \\
(0.000)\end{array}$ & \\
\hline \multicolumn{5}{|l|}{ Donor characteristics } \\
\hline $\mathrm{DAC}$ & $\begin{array}{l}0.0384^{* * *} \\
(0.003)\end{array}$ & $\begin{array}{l}0.0381^{\star \star \star} \\
(0.006)\end{array}$ & & \\
\hline (log) GDP per capita & $\begin{array}{l}0.0759^{\star \star *} \\
(0.000)\end{array}$ & $\begin{array}{l}0.0730^{* * *} \\
(0.000)\end{array}$ & $\begin{array}{c}0.0589 \\
(0.201)\end{array}$ & $\begin{array}{c}0.0578 \\
(0.198)\end{array}$ \\
\hline Democracy & $\begin{array}{l}0.0188 \\
(0.140)\end{array}$ & $\begin{array}{l}0.0108 \\
(0.361)\end{array}$ & $\begin{array}{r}0.0057 \\
(0.869)\end{array}$ & $\begin{array}{c}0.0219 \\
(0.429)\end{array}$ \\
\hline (log) Population & $\begin{array}{l}0.0215^{\star * *} \\
(0.000)\end{array}$ & $\begin{array}{l}0.0183^{* * *} \\
(0.000)\end{array}$ & $\begin{array}{c}0.0935 \\
(0.163)\end{array}$ & $\begin{array}{c}0.0895 \\
(0.175)\end{array}$ \\
\hline \multicolumn{5}{|l|}{ Recipient characteristics } \\
\hline (log) GDP per capita & $\begin{array}{l}-0.0140^{\star \star \star} \\
(0.000)\end{array}$ & & $\begin{array}{l}-0.0142^{* \star \star} \\
(0.000)\end{array}$ & \\
\hline (log) Population & $\begin{array}{l}-0.0276^{* * *} \\
(0.000)\end{array}$ & & $\begin{array}{l}-0.0270^{* * *} \\
(0.000)\end{array}$ & \\
\hline Population density & $\begin{array}{l}-0.0025^{\star *} \\
(0.012)\end{array}$ & & $\begin{array}{l}-0.0025^{* * *} \\
(0.009)\end{array}$ & \\
\hline Democracy & $\begin{array}{r}0.0007 \\
(0.851)\end{array}$ & & $\begin{array}{l}-0.0007 \\
(0.846)\end{array}$ & \\
\hline Control of corruption & $\begin{array}{l}-0.0133^{* * *} \\
(0.000)\end{array}$ & & $\begin{array}{l}-0.0147^{* * *} \\
(0.000)\end{array}$ & \\
\hline $\begin{array}{l}\text { UNSC member } \\
\text { (log) Mineral and energy depletion }\end{array}$ & $\begin{array}{l}0.0147^{\star \star \star} \\
(0.002) \\
0.0005^{\star \star \star} \\
(0.001)\end{array}$ & & $\begin{array}{l}0.0139^{* \star *} \\
(0.003) \\
0.0004^{* \star *} \\
(0.003)\end{array}$ & \\
\hline \multicolumn{5}{|l|}{ Bilateral variables } \\
\hline (log) Distance & $\begin{array}{l}-0.0350^{\star * \star} \\
(0.000)\end{array}$ & $\begin{array}{l}-0.0243^{\star \star \star} \\
(0.000)\end{array}$ & $\begin{array}{l}-0.0360^{\star * \star} \\
(0.000)\end{array}$ & $\begin{array}{l}-0.0226^{\star * \star} \\
(0.000)\end{array}$ \\
\hline Neighbor & $\begin{array}{l}0.0331^{* \star *} \\
(0.005)\end{array}$ & $\begin{array}{l}0.0334^{\star * *} \\
(0.006)\end{array}$ & $\begin{array}{l}0.0239^{* *} \\
(0.039)\end{array}$ & $\begin{array}{l}0.0227^{* *} \\
(0.045)\end{array}$ \\
\hline Common colonial history & $\begin{array}{l}0.0114 \\
(0.113)\end{array}$ & $\begin{array}{r}0.0047 \\
(0.564)\end{array}$ & $\begin{array}{l}0.0195^{\star * *} \\
(0.005)\end{array}$ & $\begin{array}{l}0.0119^{*} \\
(0.098)\end{array}$ \\
\hline Common official language & $\begin{array}{c}0.0024 \\
(0.732)\end{array}$ & $\begin{array}{c}0.0113 \\
(0.115)\end{array}$ & $\begin{array}{l}0.0141^{* *} \\
(0.013)\end{array}$ & $\begin{array}{l}0.0233^{* * *} \\
(0.000)\end{array}$ \\
\hline Common major religion & $\begin{array}{l}0.0289^{* * *} \\
(0.000)\end{array}$ & $\begin{array}{l}0.0133 \\
(0.147)\end{array}$ & $\begin{array}{l}0.0275^{\star * *} \\
(0.000)\end{array}$ & $\begin{array}{l}0.0100 \\
(0.172)\end{array}$ \\
\hline (log) Migration in & $\begin{array}{l}0.0032^{\star *} \\
(0.043)\end{array}$ & $\begin{array}{l}0.0036^{\star *} \\
(0.030)\end{array}$ & $\begin{array}{l}0.0023^{* *} \\
(0.028)\end{array}$ & $\begin{array}{l}0.0029^{* * *} \\
(0.010)\end{array}$ \\
\hline (log) Migration out & $\begin{array}{r}0.0009 \\
(0.451)\end{array}$ & $\begin{array}{r}0.0027 \\
(0.141)\end{array}$ & $\begin{array}{l}0.0015^{*} \\
(0.096)\end{array}$ & $\begin{array}{l}0.0046^{* * *} \\
(0.000)\end{array}$ \\
\hline UNGA voting & $\begin{array}{l}-0.0516^{*} \\
(0.066)\end{array}$ & $\begin{array}{l}-0.0687^{\star *} \\
(0.017)\end{array}$ & $\begin{array}{c}0.0334 \\
(0.365)\end{array}$ & $\begin{array}{l}-0.0212 \\
(0.434)\end{array}$ \\
\hline (log) Exports & $\begin{array}{l}0.0053^{* * *} \\
(0.004)\end{array}$ & $\begin{array}{l}0.0070^{\star * *} \\
(0.000)\end{array}$ & $\begin{array}{l}0.0055^{\star \star \star} \\
(0.000)\end{array}$ & $\begin{array}{l}0.0079^{* * \star} \\
(0.000)\end{array}$ \\
\hline $\begin{array}{l}\text { Disaster-type dummies } \\
\text { Donor dummies } \\
\text { Emergency-recipient dummies }\end{array}$ & Yes & Yes & $\begin{array}{l}\text { Yes } \\
\text { Yes }\end{array}$ & $\begin{array}{l}\text { Yes } \\
\text { Yes }\end{array}$ \\
\hline Year dummies & Yes & & Yes & \\
\hline Number of observations & 29412 & 30622 & 29412 & 30622 \\
\hline
\end{tabular}

Notes:

- All models show marginal effects of Logit models with standard errors clustered at the donor level 


\section{Appendix B.1: Testing for ratio bias in the crime deterrence measure}

As explained in Section 3, a potential empirical issue stems from the setup of the deterrence measure as a ratio of the number of arrests per type of offence divided by its total prevalence. As observed in Gould et al. (2002) and Dills et al. (2008), the construction of such a deterrence measure can result in ratio bias (or division bias) since the crime statistics reflect the number of reported offences instead of the actual number of total offences. As a consequence, rising reporting rates, ceteris paribus, increase the number of reported crimes in the estimation, while depressing arrest rates. The resulting downward bias on the estimated deterrence coefficients may therefore lead to exaggerated predictions regarding the negative relationship between arrests, i.e., deterrence and offences.

Levitt (1998) provides a comprehensible approach to test for the prevalence of ratio bias in the measurement of offence deterrence. Since a significant proportion of crimes are never reported to the police, the data used in the estimation process only reflects a fraction of the unobserved total magnitude of crime. From the viewpoint of an econometric estimation, which seeks to fit a relationship of the nature $\ln \left(\right.$ crime $\left._{t}\right)=\lambda * \ln \left(a_{t} / c_{t}\right)+\epsilon_{t}$, this implies certain complications as the truly estimated relationship is actually given by $\ln \left(\right.$ crime $\left._{t} * r r_{t}\right)=\lambda * \ln \left(a_{t} / r r_{t} * c_{t}\right)+\epsilon_{t}$ with $\boldsymbol{r} \boldsymbol{r}_{\boldsymbol{t}}$ denoting the percentage of crimes reported. Due to the definition of the deterrence variable as an arrest rate, any stochastic error in the share of reported offences thus appears in the dependent variable as well as in the denominator of the deterrence variable. As a consequence, high reporting rates lead to an increase in the number of registered offences and a lower arrest rate, inducing a negative bias (i.e., overshooting) in $\lambda$ which is the estimated coefficient for the deterrence measure. Naturally, this problem can to a certain degree be tackled by including district-fixed effects which account for any district-specific and time-invariant bias towards underreporting.

Relying on a method suggested in Griliches and Hausman (1986), Levitt (1998) carries out a simple test to check for the prevalence of any asymptotic bias in his deterrence estimates. The test employed in his work consists of comparing the estimated values of the deterrence coefficients while switching from a first-difference estimator to second, third and fourth differences, i.e., 


$$
y_{i t}-y_{i t-1}=\beta\left(x_{i t}-x_{i t-1}\right)+\eta_{i t}-\eta_{i t-1}
$$

$$
y_{i t}-y_{i t-4}=\beta\left(x_{i t}-x_{i t-4}\right)+\eta_{i t}-\eta_{i t-4}
$$

When measuring the impact of crime deterrence on offences, the measure of reported crimes $\boldsymbol{x}_{\boldsymbol{i t}}$ merely serves as an imperfect proxy of the true number of offences $z_{i t}$ committed in a district which implies $x_{i t}=z_{i t}+v_{i t}$ with $v_{i t}$ denoting the i.i.d. measurement error with variance $\sigma_{v}^{2}$. As it can be assumed that the true numbers of offen $<$ ces in a district are serially correlated across time, i.e., $0<$ $\sigma_{z_{t}, z_{t-k}}<1$, the bias arising from this fact can be expected to decline as longer differences are used. In the case of non-stationarity in the data, the values of the coefficient would thus be monotonically declining in magnitude while moving away from the first-difference estimator. This behavior is driven by the fact that estimates based on first-differenced data intensify any bias arising from measurement error, while the influence of a potential error declines when repeating the same estimations with greater degrees of differentiation.

\begin{tabular}{|c|c|c|c|c|}
\hline & \begin{tabular}{|l} 
1st difference \\
(1)
\end{tabular} & $\begin{array}{l}\text { 2nd difference } \\
\text { (2) }\end{array}$ & $\begin{array}{l}\text { 3rd difference } \\
\text { (3) }\end{array}$ & $\begin{array}{l}\text { 4th difference } \\
\text { (4) }\end{array}$ \\
\hline Robbery & $\begin{array}{l}-1.439^{\star * *} \\
(-13.79)\end{array}$ & $\begin{array}{l}-1.591^{\star \star \star} \\
(-15.73)\end{array}$ & $\begin{array}{l}-1.739^{\star \star \star} \\
(-16.14)\end{array}$ & $\begin{array}{l}-1.817^{\star \star \star} \\
(-16.14)\end{array}$ \\
\hline Assault & $\begin{array}{l}-1.439^{* * *} \\
(-13.79)\end{array}$ & $\begin{array}{l}-1.591^{* * *} \\
(-15.73)\end{array}$ & $\begin{array}{l}-1.739^{* * *} \\
(-16.14)\end{array}$ & $\begin{array}{l}-1.817^{\star \star *} \\
(-16.14)\end{array}$ \\
\hline Murder & $\begin{array}{l}-1.088^{* * *} \\
(-13.81)\end{array}$ & $\begin{array}{l}-1.164^{* * *} \\
(-12.21)\end{array}$ & $\begin{array}{l}-1.260^{* * *} \\
(-13.24)\end{array}$ & $\begin{array}{l}-1.398^{* * *} \\
(-13.13)\end{array}$ \\
\hline Rape & $\begin{array}{l}-1.156^{\star * *} \\
(-10.61)\end{array}$ & $\begin{array}{l}-1.097^{\star \star *} \\
(-8.45)\end{array}$ & $\begin{array}{l}-1.226^{\star * *} \\
(-6.76)\end{array}$ & $\begin{array}{l}-1.210^{* \star *} \\
(-7.88)\end{array}$ \\
\hline
\end{tabular}

Table B. 1: Difference Estimators and Measurement Error in Arrest Rates

Employing the method suggested by Levitt (1998), the relationship between the prevalence of different types of offences and the deterrence measure specified above is estimated with increasing degrees of differentiation for each sub-group of 
NDCs, with the exception of gang killings where third-order differentiation is unfeasible due to the limited time period for which data is available (see Table A1 for detailed results). In line with Levitt (1998), the estimated coefficients show no sign of a monotone decline in magnitude when moving towards higher orders of differentiation. Instead, results similar to those in Levitt (1998) are found as the magnitude of the coefficients increases with the level of differentiation, indicating a lag in the response of crime rates to changes in arrest rates. 


\section{Appendix B.2: Review of Mexican anti-drug legislation}

Excerpt 1: Modification of Mexico's Ley General de Salud, Código Penal Federal and Código Federal de Procedimientos Penales (approved August 20 2009) $)^{120}$

Note: underscores added by the author

(...)

\section{CAPÍTULO VII}

Delitos Contra la Salud en su modalidad de Narcomenudeo

Artículo 479.- Para los efectos de este capítulo se entiende que el narcótico está destinado para su estricto e inmediato consumo personal, cuando la cantidad del mismo, en cualquiera de sus formas, derivados o preparaciones no exceda de las previstas en el listado siguiente:

\begin{tabular}{|l|l|l|}
\hline \multicolumn{3}{|c|}{ Tabla de Orientación de Dosis Máximas de Consumo Personal e Inmediato } \\
\hline Narcótico & Dosis máxima de consumo personal e inmediato \\
\hline Opio & $2 \mathrm{gr}$. \\
\hline Diacetilmorfina o Heroina & $50 \mathrm{mg}$. \\
\hline Cannabis Sativa, Indica o Mariguana & $5 \mathrm{gr}$. \\
\hline Cocaina & $500 \mathrm{mg}$. & Tabletas o cápsulas \\
\hline Lisergida (LSD) & $0.015 \mathrm{mg}$. & $\begin{array}{l}\text { Una unidad con peso no mayor a } \\
200 \mathrm{mg} .\end{array}$ \\
\hline MDA, & Polvo, granulado o cristal \\
\cline { 2 - 4 } Metilendioxianfetamina & $40 \mathrm{mg}$. & $\begin{array}{l}\text { Una unidad con peso no mayor a } \\
200 \mathrm{mg} .\end{array}$ \\
\hline $\begin{array}{l}\text { MDMA, dl-34-metilendioxi-n- } \\
\text { dimetilfeniletilamina }\end{array}$ & $40 \mathrm{mg}$. & $\begin{array}{l}\text { Una unidad con peso no mayor a } \\
200 \mathrm{mg} .\end{array}$ \\
\hline Metanfetamina & $40 \mathrm{mg}$. & \\
\hline
\end{tabular}

\section{CAPÍTULO VII}

Delitos Contra la Salud en su modalidad de Narcomenudeo

Artículo 473.- Para los efectos de este capítulo se entenderá por:

I. Comercio: la venta, compra, adquisición o enajenación de algún narcótico;

II. Farmacodependencia: Es el conjunto de fenómenos de comportamiento, cognoscitivos y fisiológicos, que se desarrollan luego del consumo repetido de

\footnotetext{
${ }^{120}$ The complete amendment to the legislation is available at http://dof.gob.mx/nota_detalle.php?codigo=5106093\&fecha=20/08/2009 (accessed: July 2012).
} 
estupefacientes o psicotrópicos de los previstos en los artículos 237 y 245 , fracciones I a III, de esta Ley;

III. Farmacodependiente: Toda persona que presenta algún signo o síntoma de dependencia a estupefacientes o psicotrópicos;

IV. Consumidor: Toda persona que consume o utilice estupefacientes 0 psicotrópicos y que no presente signos ni síntomas de dependencia;

V. Narcóticos: los estupefacientes, psicotrópicos y demás sustancias o vegetales que determinen esta Ley, los convenios y tratados internacionales de observancia obligatoria en México y los que señalen las demás disposiciones legales aplicables en la materia;

VI. Posesión: la tenencia material de narcóticos o cuando éstos están dentro del radio de acción y disponibilidad de la persona;

VII. Suministro: la transmisión material de forma directa o indirecta, por cualquier concepto, de la tenencia de narcóticos, y

VIII. Tabla: la relación de narcóticos y la orientación de dosis máximas de consumo personal e inmediato prevista en el artículo 479 de esta Ley.

Artículo 474.- Las autoridades de seguridad pública, procuración e impartición de justicia, así como de ejecución de sanciones de las entidades federativas, conocerán y resolverán de los delitos o ejecutarán las sanciones y medidas de seguridad a que se refiere este capítulo, cuando los narcóticos objeto de los mismos estén previstos en la tabla, siempre y cuando la cantidad de que se trate sea inferior a la que resulte de multiplicar por mil el monto de las previstas en dicha tabla y no existan elementos suficientes para presumir delincuencia organizada.

Las autoridades federales conocerán de los delitos en cualquiera de los casos siguientes:

I. En los casos de delincuencia organizada.

II. La cantidad del narcótico sea igual o mayor a la referida en el primer párrafo de este artículo.

III. El narcótico no esté contemplado en la tabla.

IV. Independientemente de la cantidad del narcótico el Ministerio Público de la Federación:
a)
Prevenga
en
el
conocimiento
del asunto 
Appendix B.3: Additional Regression Results

Table B.2: Effect of Drug Enforcement on non-drug offences at the state level

\begin{tabular}{|c|c|c|c|c|c|c|c|c|c|c|}
\hline Federal State & Robbery & Assault & Murder & Rape & $\begin{array}{l}\text { Drug enforcement } \\
(1998-2008)^{121}\end{array}$ & $\begin{array}{l}\text { \# of G } \\
2006\end{array}$ & $\begin{array}{r}\text { ang mu } \\
2007\end{array}$ & $\begin{array}{l}\text { rders } \\
2008\end{array}$ & 2009 & 2010 \\
\hline Aguascalientes & $\begin{array}{l}-0.63 \\
-0.98\end{array}$ & $\begin{array}{l}0.35 \\
0.52\end{array}$ & $\begin{array}{l}-0.32 \\
-0.44\end{array}$ & $\begin{array}{l}-0.48 \\
-0.62\end{array}$ & 0.164 & 0 & 37 & 38 & 31 & 46 \\
\hline Baja California & $\begin{array}{l}0.38 \\
0.49\end{array}$ & $\begin{array}{l}0.26 \\
0.40\end{array}$ & $\begin{array}{l}2.95 \\
1.54\end{array}$ & $\begin{array}{l}1.49 \\
1.74\end{array}$ & 0.133 & 8 & 209 & 779 & 484 & 540 \\
\hline Baja California & $\begin{array}{l}-1.27 \\
-1.62\end{array}$ & $\begin{array}{l}-2.87 \\
-10.70\end{array}$ & $\begin{array}{l}-2.22 \\
-1.68\end{array}$ & $\begin{array}{l}-1.74 \\
-1.25\end{array}$ & 0.131 & 0 & 6 & 2 & 1 & 10 \\
\hline Campeche & $\begin{array}{l}-2.46 \\
-2.59\end{array}$ & $\begin{array}{l}-3.67 \\
-2.47\end{array}$ & $\begin{array}{l}-1.26 \\
-0.78\end{array}$ & $\begin{array}{l}1.18 \\
0.52\end{array}$ & 0.120 & 0 & 8 & 7 & 6 & 10 \\
\hline Chiapas & $\begin{array}{l}-0.69 \\
-1.27\end{array}$ & $\begin{array}{l}-0.57 \\
-1.07\end{array}$ & $\begin{array}{l}0.30 \\
0.46\end{array}$ & $\begin{array}{l}-0.91 \\
-2.43\end{array}$ & 0.109 & 0 & 57 & 82 & 88 & 77 \\
\hline Chihuahua & $\begin{array}{l}-0.60 \\
-1.98\end{array}$ & $\begin{array}{l}-0.77 \\
-2.51\end{array}$ & $\begin{array}{l}-0.57 \\
-3.18\end{array}$ & $\begin{array}{l}-0.37 \\
-1.28\end{array}$ & 0.249 & 1 & 244 & 2118 & 3345 & 4427 \\
\hline Coahuila & $\begin{array}{l}-0.60 \\
-1.98\end{array}$ & $\begin{array}{l}-0.77 \\
-2.51\end{array}$ & $\begin{array}{l}-0.57 \\
-3.18\end{array}$ & $\begin{array}{l}-0.37 \\
-1.28\end{array}$ & 0.122 & 0 & 18 & 78 & 179 & 384 \\
\hline Colima & $\begin{array}{l}-1.10 \\
-3.16\end{array}$ & $\begin{array}{l}-0.08 \\
-0.17\end{array}$ & $\begin{array}{l}-0.63 \\
-2.04\end{array}$ & $\begin{array}{l}-0.23 \\
-0.43\end{array}$ & 0.317 & 5 & 27 & 48 & 87 & 179 \\
\hline Distrito Federal & $\begin{array}{l}-3.39 \\
-2.44\end{array}$ & $\begin{array}{l}-1.27 \\
-0.54\end{array}$ & $\begin{array}{l}-1.88 \\
-0.60\end{array}$ & $\begin{array}{l}-1.54 \\
-0.57\end{array}$ & 0.038 & 1 & 182 & 144 & 135 & 191 \\
\hline Durango & $\begin{array}{l}-0.67 \\
-2.31\end{array}$ & $\begin{array}{l}-0.32 \\
-0.68\end{array}$ & $\begin{array}{l}-0.21 \\
-0.26\end{array}$ & $\begin{array}{l}0.13 \\
0.21\end{array}$ & 0.313 & 0 & 108 & 276 & 674 & 834 \\
\hline Guanajuato & $\begin{array}{l}-0.96 \\
-3.50\end{array}$ & $\begin{array}{l}-0.90 \\
-2.80\end{array}$ & $\begin{array}{l}-0.47 \\
-2.16\end{array}$ & $\begin{array}{l}-0.80 \\
-2.08\end{array}$ & 0.132 & 0 & 51 & 79 & 234 & 152 \\
\hline Guerrero & $\begin{array}{l}-0.92 \\
-2.41\end{array}$ & $\begin{array}{l}-0.47 \\
-1.48\end{array}$ & $\begin{array}{l}-0.51 \\
-1.79\end{array}$ & $\begin{array}{l}-0.18 \\
-0.40\end{array}$ & 0.210 & 12 & 299 & 412 & 879 & 1137 \\
\hline Hidalgo & $\begin{array}{l}-0.48 \\
-0.35\end{array}$ & $\begin{array}{l}-2.52 \\
-2.96\end{array}$ & $\begin{array}{l}-2.25 \\
-0.95\end{array}$ & $\begin{array}{l}-6.44 \\
-1.98\end{array}$ & 0.083 & 0 & 43 & 38 & 34 & 52 \\
\hline Jalisco & $\begin{array}{l}\mathbf{0 . 0 1} \\
0.02\end{array}$ & $\begin{array}{l}\mathbf{0 . 0 6} \\
0.09\end{array}$ & $\begin{array}{l}-1.00 \\
-1.06\end{array}$ & $\begin{array}{l}-0.67 \\
-0.27\end{array}$ & 0.168 & 1 & 70 & 148 & 261 & 593 \\
\hline Estado de México & $\begin{array}{l}-0.34 \\
-1.24\end{array}$ & $\begin{array}{l}-0.24 \\
-1.37\end{array}$ & $\begin{array}{l}-1.06 \\
-2.59\end{array}$ & $\begin{array}{l}-0.05 \\
-0.15\end{array}$ & 0.072 & 0 & 111 & 364 & 440 & 623 \\
\hline Michoacán & $\begin{array}{l}-0.55 \\
-2.70\end{array}$ & $\begin{array}{l}-0.79 \\
-3.62\end{array}$ & $\begin{array}{l}-0.69 \\
-2.58\end{array}$ & $\begin{array}{l}-0.34 \\
-1.09\end{array}$ & 0.156 & 24 & 328 & 289 & 590 & 520 \\
\hline Morelos & $\begin{array}{l}-0.40 \\
-0.80\end{array}$ & $\begin{array}{l}-0.93 \\
-1.35\end{array}$ & $\begin{array}{l}-0.24 \\
-0.34\end{array}$ & $\begin{array}{l}-0.75 \\
-1.35\end{array}$ & 0.160 & 0 & 32 & 48 & 114 & 335 \\
\hline Nayarit & $\begin{array}{l}-0.95 \\
-3.01\end{array}$ & $\begin{array}{l}-0.67 \\
-2.08\end{array}$ & $\begin{array}{l}-0.73 \\
-1.98\end{array}$ & $\begin{array}{l}-0.89 \\
-1.26\end{array}$ & 0.131 & 0 & 11 & 28 & 37 & 377 \\
\hline Nuevo León & $\begin{array}{l}-1.18 \\
-2.97\end{array}$ & $\begin{array}{l}-0.75 \\
-2.97\end{array}$ & $\begin{array}{l}-1.24 \\
-3.00\end{array}$ & $\begin{array}{l}-0.13 \\
-0.35\end{array}$ & 0.198 & 4 & 130 & 105 & 112 & 620 \\
\hline Oaxaca & $\begin{array}{l}-1.40 \\
-2.81\end{array}$ & $\begin{array}{l}-1.49 \\
-3.51\end{array}$ & $\begin{array}{l}-1.25 \\
-4.12\end{array}$ & $\begin{array}{l}-1.20 \\
-3.89\end{array}$ & 0.172 & 0 & 62 & 121 & 87 & 167 \\
\hline Puebla & $\begin{array}{l}-1.08 \\
-3.16\end{array}$ & $\begin{array}{l}-0.92 \\
-2.67\end{array}$ & $\begin{array}{l}0.85 \\
1.61\end{array}$ & $\begin{array}{l}-1.32 \\
-2.00\end{array}$ & 0.142 & 0 & 6 & 22 & 28 & 51 \\
\hline Querétaro & $\begin{array}{l}-5.75 \\
-1.68\end{array}$ & $\begin{array}{l}-10.65 \\
-1.91\end{array}$ & $\begin{array}{l}1.55 \\
0.44\end{array}$ & $\begin{array}{l}-3.20 \\
-1.12\end{array}$ & 0.037 & 0 & 5 & 6 & 13 & 13 \\
\hline Quintana Roo & $\begin{array}{l}-0.57 \\
-1.36\end{array}$ & $\begin{array}{l}-1.62 \\
-3.41\end{array}$ & $\begin{array}{l}0.49 \\
0.17\end{array}$ & $\begin{array}{l}-3.20 \\
-1.12\end{array}$ & 0.130 & 0 & 26 & 29 & 32 & 64 \\
\hline San Luis Potosí & $\begin{array}{l}-0.34 \\
-0.68\end{array}$ & $\begin{array}{l}-1.13 \\
-1.72\end{array}$ & $\begin{array}{l}-0.98 \\
-0.81\end{array}$ & $\begin{array}{l}\mathbf{0 . 0 5} \\
0.04\end{array}$ & 0.081 & 0 & 10 & 34 & 8 & 135 \\
\hline Sinaloa & $\begin{array}{l}-0.91 \\
-4.73\end{array}$ & $\begin{array}{l}-0.03 \\
-0.12\end{array}$ & $\begin{array}{l}-0.63 \\
-3.19\end{array}$ & $\begin{array}{l}\mathbf{0 . 4 2} \\
1.25\end{array}$ & 0.235 & 3 & 426 & 1084 & 1059 & 1815 \\
\hline Sonora & $\begin{array}{l}-1.10 \\
-3.16\end{array}$ & $\begin{array}{l}-0.08 \\
-0.17\end{array}$ & $\begin{array}{l}-0.63 \\
-2.04\end{array}$ & $\begin{array}{l}-0.23 \\
-0.43\end{array}$ & 0.317 & 5 & 141 & 252 & 365 & 495 \\
\hline Tabasco & $\begin{array}{l}-0.91 \\
-1.71\end{array}$ & $\begin{array}{l}-0.12 \\
-0.24\end{array}$ & $\begin{array}{l}-0.46 \\
-0.42\end{array}$ & $\begin{array}{l}\mathbf{0 . 8 8} \\
1.55\end{array}$ & 0.068 & 1 & 27 & 35 & 65 & 73 \\
\hline Tamaulipas & $\begin{array}{l}-1.51 \\
-2.99\end{array}$ & $\begin{array}{l}-1.06 \\
-1.90\end{array}$ & $\begin{array}{l}0.74 \\
2.05\end{array}$ & $\begin{array}{l}2.71 \\
1.30\end{array}$ & 0.094 & 0 & 80 & 96 & 90 & 1209 \\
\hline Tlaxcala & $\begin{array}{l}-7.49 \\
-3.28\end{array}$ & $\begin{array}{l}-10.70 \\
-2.02\end{array}$ & $\begin{array}{l}-10.43 \\
-0.75\end{array}$ & n.a. & 0.109 & 0 & 0 & 3 & 6 & 4 \\
\hline Veracruz & $\begin{array}{l}-0.78 \\
-2.64\end{array}$ & $\begin{array}{l}-0.49 \\
-1.98\end{array}$ & $\begin{array}{l}\mathbf{0 . 0 3} \\
0.05\end{array}$ & $\begin{array}{l}-0.56 \\
-0.79\end{array}$ & 0.126 & 1 & 75 & 65 & 133 & 179 \\
\hline Yucatán & $\begin{array}{l}-1.72 \\
-4.10\end{array}$ & $\begin{array}{l}-1.96 \\
-3.38\end{array}$ & $\begin{array}{l}\mathbf{0 . 1 7} \\
0.03\end{array}$ & n.a. & 0.190 & 1 & 4 & 18 & 1 & 2 \\
\hline Zacatecas & $\begin{array}{l}-0.53 \\
-1.61\end{array}$ & $\begin{array}{l}-1.22 \\
-2.70\end{array}$ & $\begin{array}{l}-0.50 \\
-0.70\end{array}$ & $\begin{array}{l}-1.10 \\
-1.46 \\
\end{array}$ & 0.141 & 0 & 18 & 25 & 50 & 37 \\
\hline \multicolumn{11}{|c|}{$\begin{array}{l}\text { Notes: } \\
\text { - Estimated coefficient for drug enforcement is based on a Fixed Effects with country and time dummies } \\
\text { - Robust t-values provided below the coefficients } \\
\text { - Standard errors are clustered at the district level }\end{array}$} \\
\hline
\end{tabular}

${ }^{121}$ Note: The share of drug-related arrest among all arrests is calculated using the original dataset. 
Appendix B.4 Chronological split \& Additional robustness checks

Table B.3: Robbery, chronological break-down

\begin{tabular}{|c|c|c|c|c|c|c|}
\hline & FE pre 2006 & FE post 2006 & NB pre 2006 & NB post 2006 & GMM pre 2006 & GMM post 2006 \\
\hline Lagged dependent & & & & & $\begin{array}{c}0.393^{* * *} \\
(4.19)\end{array}$ & $\begin{array}{c}0.326^{* * *} \\
(4.50)\end{array}$ \\
\hline Drug enforcement & $\begin{array}{c}-0.747^{* * *} \\
(-7.42)\end{array}$ & $\begin{array}{c}-0.705^{* * *} \\
(-5.24)\end{array}$ & $\begin{array}{c}-0.868^{* * *} \\
(-9.48)\end{array}$ & $\begin{array}{c}-0.949 * * * \\
(-7.20)\end{array}$ & $\begin{array}{l}-0.909 \\
(-1.61)\end{array}$ & $\begin{array}{c}-1.074^{* *} \\
(-2.54)\end{array}$ \\
\hline Deterrence & $\begin{array}{c}-1.733^{* * *} \\
(-19.40)\end{array}$ & $\begin{array}{c}-1.657^{* * *} \\
(-11.43)\end{array}$ & $\begin{array}{c}-1.968^{* * *} \\
(-30.18)\end{array}$ & $\begin{array}{c}-1.898^{* * *} \\
(-16.32)\end{array}$ & $\begin{array}{c}-1.684^{* * *} \\
(-6.04)\end{array}$ & $\begin{array}{c}-1.653^{* * *} \\
(-6.09)\end{array}$ \\
\hline Drug Crime & $\begin{array}{c}0.125^{* * *} \\
(7.74)\end{array}$ & $\begin{array}{c}0.058^{* *} \\
(2.43)\end{array}$ & $\begin{array}{c}0.119^{* * *} \\
(9.27)\end{array}$ & $\begin{array}{c}0.087^{* * *} \\
(4.73)\end{array}$ & $\begin{array}{c}0.259^{* * *} \\
(3.33)\end{array}$ & $\begin{array}{c}0.120^{*} \\
(1.65)\end{array}$ \\
\hline Population & $\begin{array}{c}0.772^{* * *} \\
(4.65)\end{array}$ & $\begin{array}{l}-0.005 \\
(-0.15)\end{array}$ & $\begin{array}{c}0.188^{* * *} \\
(4.45)\end{array}$ & $\begin{array}{l}-0.015 \\
(-0.29)\end{array}$ & $\begin{array}{c}0.559 * * * \\
(3.85)\end{array}$ & $\begin{array}{c}0.683^{* * *} \\
(5.91)\end{array}$ \\
\hline Density & & & $\begin{array}{c}-0.057^{* *} \\
(-2.43)\end{array}$ & $\begin{array}{c}0.108^{* *} \\
(2.30)\end{array}$ & & \\
\hline Unemployment Rate & $\begin{array}{c}0.022^{* * *} \\
(3.07)\end{array}$ & $\begin{array}{l}-0.015 \\
(-1.56)\end{array}$ & $\begin{array}{l}0.010^{*} \\
(1.90)\end{array}$ & $\begin{array}{l}-0.008 \\
(-0.97)\end{array}$ & $\begin{array}{c}0.037^{* * *} \\
(3.46)\end{array}$ & $\begin{array}{c}0.040^{* * *} \\
(4.32)\end{array}$ \\
\hline R2 & 0.330 & 0.320 & & & & \\
\hline $\mathrm{N}$ & 3416 & 1660 & 3180 & 1353 & 2177 & 1187 \\
\hline Hansen J & & & & & 92.301 & 83.744 \\
\hline (p-value) & & & & & 0.113 & 0.280 \\
\hline Arellano-Bond test for AR1 in 1st differences & & & & & -5.167 & -3.807 \\
\hline (p-value) & & & & & 0.000 & 0.000 \\
\hline Arellano-Bond test for AR2 in 1st differences & & & & & 0.308 & -1.334 \\
\hline ( $p$-value) & & & & & 0.758 & 0.182 \\
\hline Number of districts & 872 & 817 & & & 552 & 529 \\
\hline Number of instruments & & & & & 90 & 87 \\
\hline \multicolumn{7}{|l|}{$* p<0.10, * * p<0.05, * * * p<0.01$} \\
\hline \multicolumn{7}{|c|}{ All regressions with time and district fixed effects; robust $t$-values in brackets } \\
\hline \multicolumn{7}{|c|}{ Standard errors are clustered at the district level } \\
\hline Two-step System GMM with time fixed effect & Windm & Ite san & tion & & & \\
\hline
\end{tabular}


Table B.4: Assault, chronological break-down

Lagged dependent

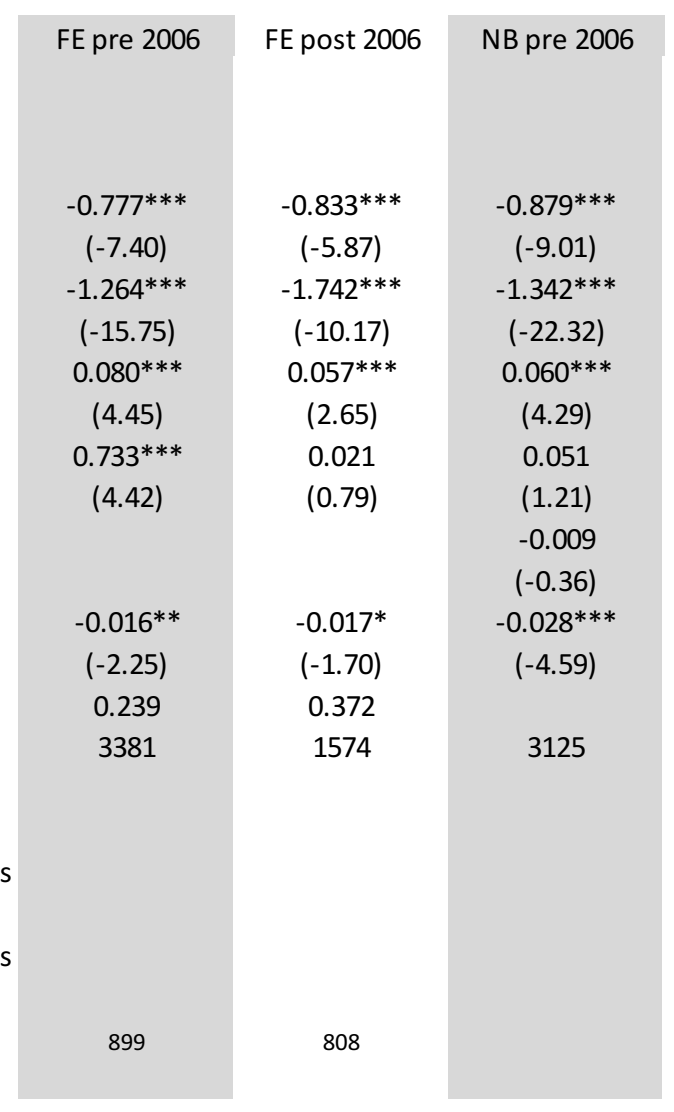

NB post 2006

GMM pre 2006 GMM post 2006

Drug enforcement

Deterrence

Drug Crime

Population

Density

Unemployment Rate

R2

$\mathrm{N}$

Hansen J

(p-value)

Arellano-Bond test for AR1 in 1st differences

( $p$-value)

Arellano-Bond test for AR2 in 1st differences

( $p$-value)

Number of districts

Number of instruments

$\begin{array}{ccc} & 0.356^{* * *} & 0.417^{* * *} \\ & (4.62) & (4.39) \\ -0.950^{* * *} & -1.205^{* *} & -1.212^{* * *} \\ (-7.29) & (-2.57) & (-3.19) \\ -1.928^{* * *} & -0.802^{* * *} & -1.455^{* * *} \\ (-21.00) & (-3.46) & (-4.59) \\ 0.085^{* * *} & 0.162^{* *} & 0.197^{* * *} \\ (4.45) & (2.43) & (2.86) \\ -0.003 & 0.615^{* * *} & 0.412^{* * *} \\ (-0.06) & (5.52) & (3.54) \\ 0.062 & & \\ (1.34) & & \\ -0.014^{*} & 0.007 & 0.017^{* *} \\ (-1.80) & (0.93) & (2.00) \\ & & \\ 1258 & 2096 & 1110 \\ & 75.196 & 85.801 \\ & 0.537 & 0.231 \\ & -4.891 & -3.313 \\ & 0.000 & 0.001 \\ & 0.107 & -0.735 \\ & 0.915 & 0.462 \\ & 566 & 524 \\ & 90 & 87\end{array}$

${ }^{*} \mathrm{p}<0.10, * * \mathrm{p}<0.05, * * * \mathrm{p}<0.01$

All regressions with time and district fixed effects; robust t-values in brackets

Standard errors are clustered at the district level

Two-step System GMM with time fixed effects and Windmeijer finite sample correction 
Table B.5: Murder, chronological break-down

\begin{tabular}{|c|c|c|c|c|c|c|}
\hline & FE pre 2006 & FE post 2006 & NB pre 2006 & NB post 2006 & GMM pre 2006 & GMM post 2006 \\
\hline Lagged dependent & & & & & $\begin{array}{c}0.248^{* * *} \\
(2.84)\end{array}$ & $\begin{array}{l}0.104 \\
(1.37)\end{array}$ \\
\hline Drug enforcement & $\begin{array}{c}-0.260^{* *} \\
(-2.35)\end{array}$ & $\begin{array}{c}-0.394^{* *} \\
(-2.51)\end{array}$ & $\begin{array}{c}-0.206^{* *} \\
(-2.08)\end{array}$ & $\begin{array}{c}-0.711^{* * *} \\
(-3.04)\end{array}$ & $\begin{array}{c}-0.950^{* *} \\
(-2.11)\end{array}$ & $\begin{array}{l}-0.420 \\
(-1.11)\end{array}$ \\
\hline Deterrence & $\begin{array}{c}-0.565^{* * *} \\
(-3.03)\end{array}$ & $\begin{array}{c}-0.648^{* * *} \\
(-4.48)\end{array}$ & $\begin{array}{c}-1.473^{* * *} \\
(-26.52)\end{array}$ & $\begin{array}{c}-0.359 * * * \\
(-3.49)\end{array}$ & $\begin{array}{c}-1.022^{* * *} \\
(-4.03)\end{array}$ & $\begin{array}{c}-1.606^{* * *} \\
(-4.38)\end{array}$ \\
\hline Drug Crime & & & $\begin{array}{l}0.026^{*} \\
(1.74)\end{array}$ & $\begin{array}{c}0.110^{* * *} \\
(3.31)\end{array}$ & $\begin{array}{c}0.170 * * \\
(2.55)\end{array}$ & $\begin{array}{l}0.084 \\
(1.01)\end{array}$ \\
\hline Population & $\begin{array}{c}0.549 * * \\
(2.38)\end{array}$ & $\begin{array}{l}-0.008 \\
(-0.25)\end{array}$ & $\begin{array}{l}-0.088 \\
(-1.52)\end{array}$ & $\begin{array}{c}-0.320^{* * *} \\
(-4.56)\end{array}$ & $\begin{array}{c}0.410^{* * *} \\
(4.53)\end{array}$ & $\begin{array}{c}0.543^{* * *} \\
(6.32)\end{array}$ \\
\hline Density & & & $\begin{array}{l}0.025 \\
(0.74)\end{array}$ & $\begin{array}{c}0.454^{* * *} \\
(7.91)\end{array}$ & & \\
\hline Unemployment Rate & $\begin{array}{l}-0.001 \\
(-0.10)\end{array}$ & $\begin{array}{c}-0.024^{* *} \\
(-2.23)\end{array}$ & $\begin{array}{l}-0.005 \\
(-0.62)\end{array}$ & $\begin{array}{l}-0.020 \\
(-1.31)\end{array}$ & $\begin{array}{l}-0.017^{*} \\
(-1.91)\end{array}$ & $\begin{array}{c}-0.036 * * * \\
(-3.32)\end{array}$ \\
\hline R2 & 0.045 & 0.072 & & & & \\
\hline $\mathrm{N}$ & 2580 & 1247 & 2472 & 1002 & 1751 & 949 \\
\hline Hansen J & & & & & 91.573 & 85.886 \\
\hline (p-value) & & & & & 0.123 & 0.229 \\
\hline Arellano-Bond test for AR1 in 1st differences & & & & & -4.995 & -4.289 \\
\hline ( $p$-value) & & & & & 0.000 & 0.000 \\
\hline Arellano-Bond test for AR2 in 1st differences & & & & & -0.840 & 0.656 \\
\hline ( $p$-value) & & & & & 0.401 & 0.512 \\
\hline Number of districts & 704 & 640 & & & 495 & 441 \\
\hline Number of instruments & & & & & 90 & 87 \\
\hline \multicolumn{7}{|c|}{$* p<0.10, * * p<0.05, * * * p<0.01$} \\
\hline \multicolumn{7}{|c|}{ All regressions with time and district fixed effects; robust $t$-values in brackets } \\
\hline \multicolumn{7}{|c|}{ Standard errors are clustered at the district level } \\
\hline Two-step System GMM with time fixed effects & & & & & & \\
\hline
\end{tabular}


Table B.6: Rape, chronological break-down

\begin{tabular}{|c|c|c|c|c|c|c|}
\hline & FE pre 2006 & FE post 2006 & NB pre 2006 & NB post 2006 & GMM pre 2006 & GMM post 2006 \\
\hline Lagged dependent & & & & & $\begin{array}{c}0.217^{* *} \\
(1.97)\end{array}$ & $\begin{array}{c}0.212^{* * *} \\
(3.07)\end{array}$ \\
\hline Drug enforcement & $\begin{array}{l}-0.416 \\
(-1.37)\end{array}$ & $\begin{array}{l}-0.173 \\
(-0.71)\end{array}$ & $\begin{array}{c}-0.909^{* * *} \\
(-3.04)\end{array}$ & $\begin{array}{l}-0.217 \\
(-0.86)\end{array}$ & $\begin{array}{l}-0.483 \\
(-0.73)\end{array}$ & $\begin{array}{c}-1.950^{* * *} \\
(-2.74)\end{array}$ \\
\hline Deterrence & $\begin{array}{c}-1.008^{* * *} \\
(-9.92)\end{array}$ & $\begin{array}{c}-1.568 * * * \\
(-11.88)\end{array}$ & $\begin{array}{c}-0.996 * * * \\
(-11.33)\end{array}$ & $\begin{array}{c}-1.796 * * * \\
(-12.16)\end{array}$ & $\begin{array}{c}-1.065^{* * *} \\
(-3.63)\end{array}$ & $\begin{array}{c}-2.320^{* * *} \\
(-8.24)\end{array}$ \\
\hline Drug Crime & $\begin{array}{l}0.051^{*} \\
(1.69)\end{array}$ & $\begin{array}{l}-0.027 \\
(-0.88)\end{array}$ & $\begin{array}{l}0.048 \\
(1.61)\end{array}$ & $\begin{array}{l}-0.027 \\
(-0.93)\end{array}$ & $\begin{array}{l}0.136 \\
(1.59)\end{array}$ & $\begin{array}{c}0.273^{* * *} \\
(3.19)\end{array}$ \\
\hline Population & $\begin{array}{l}-0.190 \\
(-0.56)\end{array}$ & $\begin{array}{l}0.028 \\
(0.95)\end{array}$ & $\begin{array}{c}-0.428^{* * *} \\
(-5.07)\end{array}$ & $\begin{array}{l}0.036 \\
(0.56)\end{array}$ & $\begin{array}{c}0.577^{* * *} \\
(4.52)\end{array}$ & $\begin{array}{c}0.329 * * * \\
(3.01)\end{array}$ \\
\hline Density & & & $\begin{array}{c}0.180^{* * *} \\
(4.63)\end{array}$ & $\begin{array}{l}-0.025 \\
(-0.41)\end{array}$ & & \\
\hline Unemployment Rate & $\begin{array}{l}-0.007 \\
(-0.48)\end{array}$ & $\begin{array}{l}-0.012 \\
(-1.01)\end{array}$ & $\begin{array}{l}0.003 \\
(0.29)\end{array}$ & $\begin{array}{l}-0.021^{*} \\
(-1.71)\end{array}$ & $\begin{array}{c}-0.031^{* * *} \\
(-3.13)\end{array}$ & $\begin{array}{l}0.001 \\
(0.07)\end{array}$ \\
\hline R2 & 0.230 & 0.385 & & & & \\
\hline $\mathrm{N}$ & 1383 & 931 & 1147 & 704 & 896 & 714 \\
\hline $\begin{array}{l}\text { Hansen J } \\
\text { (p-yalue) }\end{array}$ & & & & & $\begin{array}{c}99.335 \\
0.044\end{array}$ & $\begin{array}{c}80.708 \\
0.364\end{array}$ \\
\hline Arellano-Bond test for AR1 in 1st differences & & & & & -2.803 & -4.020 \\
\hline ( $p$-value) & & & & & 0.005 & 0.000 \\
\hline $\begin{array}{l}\text { Arellano-Bond test for AR2 in 1st differences } \\
\text { (p-value) }\end{array}$ & & & & & $\begin{array}{l}0.982 \\
0.326\end{array}$ & $\begin{array}{l}-0.928 \\
0.353\end{array}$ \\
\hline Number of districts & 536 & 496 & & & 360 & 375 \\
\hline Number of instruments & & & & & 90 & 87 \\
\hline \multicolumn{7}{|c|}{$* p<0.10, * * p<0.05, * * * p<0.01$} \\
\hline \multicolumn{7}{|c|}{ All regressions with time and district fixed effects; robust $t$-values in brackets } \\
\hline \multicolumn{7}{|c|}{ Standard errors are clustered at the district level } \\
\hline Two-step System GMM with time fixed effects & & & & & & \\
\hline
\end{tabular}


Table B.7: Robbery, additional robustness checks

\begin{tabular}{|c|c|c|c|c|}
\hline & $\begin{array}{l}\text { OLS } \\
(1)\end{array}$ & $\begin{array}{l}\mathrm{FE} \\
(2)\end{array}$ & $\begin{array}{l}\text { Neg. Binomial } \\
\text { (3) }\end{array}$ & $\begin{array}{c}\text { GMM } \\
(4)\end{array}$ \\
\hline Lagged dependent & $\begin{array}{c}0.656 * * * \\
(28.45)\end{array}$ & $\begin{array}{c}0.146 * * * \\
(6.94)\end{array}$ & $\begin{array}{c}0.175^{* * *} \\
(15.00)\end{array}$ & $\begin{array}{c}0.600 * * * \\
(12.23)\end{array}$ \\
\hline Drug enforcement & $\begin{array}{c}-0.715^{* * *} \\
(-9.47)\end{array}$ & $\begin{array}{c}-0.542 * * * \\
(-7.90)\end{array}$ & $\begin{array}{c}-0.519 * * * \\
(-8.91)\end{array}$ & $\begin{array}{c}-0.456 * * \\
(-2.53)\end{array}$ \\
\hline Deterrence & $\begin{array}{c}-1.294 * * * \\
(-17.92)\end{array}$ & $\begin{array}{c}-1.636 * * * \\
(-18.98)\end{array}$ & $\begin{array}{c}-1.778 * * * \\
(-24.75)\end{array}$ & $\begin{array}{c}-1.836 * * * \\
(-8.48)\end{array}$ \\
\hline (log) Drug Crime & $\begin{array}{c}0.198 * * * \\
(12.50)\end{array}$ & $\begin{array}{c}0.103 * * * \\
(7.53)\end{array}$ & $\begin{array}{c}0.074 * * * \\
(7.23)\end{array}$ & $\begin{array}{c}0.252 * * * \\
(6.14)\end{array}$ \\
\hline (log) Population & $\begin{array}{c}0.242 * * * \\
(10.47)\end{array}$ & $\begin{array}{l}0.034 \\
(0.99)\end{array}$ & $\begin{array}{c}0.045^{* *} \\
(2.13)\end{array}$ & $\begin{array}{c}0.283 * * * \\
(5.13)\end{array}$ \\
\hline Unemployment Rate & $\begin{array}{c}0.027 * * * \\
(8.20)\end{array}$ & $\begin{array}{l}-0.001 \\
(-0.22)\end{array}$ & $\begin{array}{l}-0.003 \\
(-0.61)\end{array}$ & $\begin{array}{c}0.021 * * * \\
(3.53)\end{array}$ \\
\hline $\mathrm{R} 2$ & 0.945 & 0.403 & & \\
\hline $\mathrm{N}$ & 3343 & 3343 & 3199 & 3311 \\
\hline Hansen J & & & & 317.774 \\
\hline (p-value) & & & & 0.218 \\
\hline Arellano-Bond test for AR1 in 1st differences & & & & -7.337 \\
\hline (p-value) & & & & 0.000 \\
\hline Arellano-Bond test for AR2 in 1st differences & & & & -0.545 \\
\hline (p-value) & & & & 0.586 \\
\hline Number of districts & 686 & 686 & 662 & 662.000 \\
\hline Number of instruments & & & & 316 \\
\hline \multicolumn{5}{|c|}{$\begin{array}{l}\text { Notes: } \\
\text { - Robust t-values in parenthesis; }{ }^{*} \text { significant at } 10 \% ;{ }^{* *} \text { significant at } 5 \% ; * * * \text { significant at } 1 \% \\
\text { - Fixed Effects regressions with time and district fixed effects } \\
\text { - Standard errors are clustered at the district level } \\
\text { - Two-step System GMM with time fixed effects and Windmeijer finite sample correction }\end{array}$} \\
\hline
\end{tabular}


Table B.8: Assault, additional robustness checks

\begin{tabular}{|c|c|c|c|c|}
\hline & $\begin{array}{l}\text { OLS } \\
(1)\end{array}$ & $\begin{array}{l}\mathrm{FE} \\
(2)\end{array}$ & $\begin{array}{l}\text { Neg. Binomial } \\
\text { (3) }\end{array}$ & $\begin{array}{c}\text { GMM } \\
(4)\end{array}$ \\
\hline Lagged dependent & $\begin{array}{c}0.659 * * * \\
(23.87)\end{array}$ & $\begin{array}{c}0.196 * * * \\
(7.26)\end{array}$ & $\begin{array}{c}0.186 * * * \\
(13.82)\end{array}$ & $\begin{array}{c}0.375^{* * *} \\
(6.05)\end{array}$ \\
\hline Drug enforcement & $\begin{array}{c}-0.737 * * * \\
(-7.83)\end{array}$ & $\begin{array}{c}-0.418 * * * \\
(-5.11)\end{array}$ & $\begin{array}{c}-0.429 * * * \\
(-5.73)\end{array}$ & $\begin{array}{c}-0.952 * * * \\
(-2.95)\end{array}$ \\
\hline Deterrence & $\begin{array}{c}-1.031 * * * \\
(-16.65)\end{array}$ & $\begin{array}{c}-1.256 * * * \\
(-13.76)\end{array}$ & $\begin{array}{c}-1.348 * * * \\
(-21.90)\end{array}$ & $\begin{array}{c}-1.392 * * * \\
(-6.07)\end{array}$ \\
\hline Drug Crime & $\begin{array}{c}0.088 * * * \\
(7.02)\end{array}$ & $\begin{array}{c}0.066 * * * \\
(4.56)\end{array}$ & $\begin{array}{c}0.025 * * \\
(2.20)\end{array}$ & $\begin{array}{c}0.170 * * * \\
(3.58)\end{array}$ \\
\hline Population & $\begin{array}{c}0.272 * * * \\
(9.27)\end{array}$ & $\begin{array}{c}0.102 * * * \\
(2.72)\end{array}$ & $\begin{array}{l}-0.006 \\
(-0.29)\end{array}$ & $\begin{array}{c}0.519 * * * \\
(6.56)\end{array}$ \\
\hline Unemployment Rate & $\begin{array}{l}-0.004 \\
(-1.62)\end{array}$ & $\begin{array}{c}-0.017 * * \\
(-2.57)\end{array}$ & $\begin{array}{c}-0.015^{* * *} \\
(-3.04)\end{array}$ & $\begin{array}{l}0.007 \\
(1.10)\end{array}$ \\
\hline R2 & 0.940 & 0.275 & & \\
\hline $\mathrm{N}$ & 3201.000 & 3201.000 & 3060.000 & 3201.000 \\
\hline Hansen J & & & & 186.753 \\
\hline ( $p$-value) & & & & 0.258 \\
\hline Arellano-Bond test for AR1 in 1st differences & & & & -6.003 \\
\hline (p-value) & & & & 0.000 \\
\hline Arellano-Bond test for AR2 in 1st differences & & & & -1.196 \\
\hline (p-value) & & & & 0.232 \\
\hline Number of districts & 678 & 678 & 678 & 678 \\
\hline Number of instruments & & & & 192 \\
\hline
\end{tabular}

Notes:

- Robust t-values in parenthesis; ${ }^{*}$ significant at $10 \% ;{ }^{* *}$ significant at $5 \%$; ${ }^{* * *}$ significant at $1 \%$

- Fixed Effects regressions with time and district fixed effects

- Standard errors are clustered at the district level

- Two-step System GMM with time fixed effects and Windmeijer finite sample correction 
Table B.9: Murder, additional robustness checks

\begin{tabular}{|c|c|c|c|c|}
\hline & $\begin{array}{l}\text { OLS } \\
(1)\end{array}$ & $\begin{array}{l}\mathbf{F E} \\
(2)\end{array}$ & $\begin{array}{l}\text { Neg. Binomial } \\
\text { (3) }\end{array}$ & $\begin{array}{c}\text { GMM } \\
\text { (4) }\end{array}$ \\
\hline Lagged dependent & $\begin{array}{c}0.526 * * * \\
(31.24)\end{array}$ & $\begin{array}{c}0.151^{* * * *} \\
(8.43)\end{array}$ & $\begin{array}{c}0.141 * * * \\
(8.84)\end{array}$ & $\begin{array}{c}0.333^{* * *} \\
(6.52)\end{array}$ \\
\hline Drug enforcement & $\begin{array}{c}-0.472 * * * \\
(-5.86)\end{array}$ & $\begin{array}{c}-0.436 * * * \\
(-4.55)\end{array}$ & $\begin{array}{c}-0.311^{* * *} \\
(-3.22)\end{array}$ & $\begin{array}{l}-0.348 \\
(-1.36)\end{array}$ \\
\hline Deterrence & $\begin{array}{c}-1.079 * * * \\
(-20.06)\end{array}$ & $\begin{array}{c}-1.257^{* * *} \\
(-16.27)\end{array}$ & $\begin{array}{c}-1.425 * * * \\
(-25.22)\end{array}$ & $\begin{array}{c}-0.983 * * * \\
(-4.34)\end{array}$ \\
\hline Drug Crime & $\begin{array}{c}0.157 * * * \\
(13.40)\end{array}$ & $\begin{array}{c}0.060 * * * \\
(3.12)\end{array}$ & $\begin{array}{c}0.035 * * \\
(2.37)\end{array}$ & $\begin{array}{c}0.171 * * * \\
(3.13)\end{array}$ \\
\hline Population & $\begin{array}{c}0.211 * * * \\
(12.30)\end{array}$ & $\begin{array}{l}0.012 \\
(0.33)\end{array}$ & $\begin{array}{c}-0.093 * * * \\
(-3.68)\end{array}$ & $\begin{array}{c}0.355^{* * *} \\
(6.04)\end{array}$ \\
\hline Unemployment Rate & $\begin{array}{c}-0.027^{* * *} \\
(-8.08)\end{array}$ & $\begin{array}{c}-0.022 * * * \\
(-2.96)\end{array}$ & $\begin{array}{c}-0.023^{* * *} \\
(-3.47)\end{array}$ & $\begin{array}{c}-0.030 * * * \\
(-4.59)\end{array}$ \\
\hline R2 & 0.848 & 0.319 & & \\
\hline $\mathrm{N}$ & 2653 & 2653 & 2526 & 2653 \\
\hline Hansen J & & & & 199.300 \\
\hline (p-value) & & & & 0.083 \\
\hline Arellano-Bond test for AR1 in 1st differences & & & & -7.243 \\
\hline (p-value) & & & & 0.000 \\
\hline Arellano-Bond test for AR2 in 1st differences & & & & -1.024 \\
\hline (p-value) & & & & 0.306 \\
\hline Number of districts & 571 & 571 & 571 & 571 \\
\hline Number of instruments & & & & 190 \\
\hline \multicolumn{5}{|c|}{$\begin{array}{l}\text { Notes: } \\
\text { - Robust t-values in parenthesis; }{ }^{*} \text { significant at } 10 \% ;{ }^{* *} \text { significant at } 5 \% ; * * * \text { significant at } 1 \% \\
\text { - Fixed Effects regressions with time and district fixed effects } \\
\text { - Standard errors are clustered at the district level } \\
\text { - Two-step System GMM with time fixed effects and Windmeijer finite sample correction }\end{array}$} \\
\hline
\end{tabular}


Table B.10: Rape, additional robustness checks

\begin{tabular}{|c|c|c|c|c|}
\hline & $\begin{array}{l}\text { OLS } \\
(1)\end{array}$ & $\begin{array}{l}\mathrm{FE} \\
(2)\end{array}$ & $\begin{array}{l}\text { Neg. Binomial } \\
\text { (3) }\end{array}$ & $\begin{array}{l}\text { GMM } \\
(4)\end{array}$ \\
\hline Lagged dependent & $\begin{array}{c}0.534 * * * \\
(20.58)\end{array}$ & $\begin{array}{c}0.162 * * * \\
(5.71)\end{array}$ & $\begin{array}{c}0.078 * * * \\
(3.49)\end{array}$ & $\begin{array}{c}0.313^{* * *} \\
(4.36)\end{array}$ \\
\hline Drug enforcement & $\begin{array}{c}-0.879 * * * \\
(-5.02)\end{array}$ & $\begin{array}{l}-0.334^{*} \\
(-1.68)\end{array}$ & $\begin{array}{c}-0.399 * \\
(-1.87)\end{array}$ & $\begin{array}{c}-1.442 * * * \\
(-3.75)\end{array}$ \\
\hline Deterrence & $\begin{array}{c}-1.137^{* * *} \\
(-16.63)\end{array}$ & $\begin{array}{c}-1.209 * * * \\
(-12.73)\end{array}$ & $\begin{array}{c}-1.444^{* * *} \\
(-15.80)\end{array}$ & $\begin{array}{c}-2.017^{* * *} \\
(-8.84)\end{array}$ \\
\hline Drug Crime & $\begin{array}{c}0.136^{* * *} \\
(8.31)\end{array}$ & $\begin{array}{l}0.041 \\
(1.65)\end{array}$ & $\begin{array}{l}-0.033 \\
(-1.47)\end{array}$ & $\begin{array}{c}0.285^{* * *} \\
(3.65)\end{array}$ \\
\hline Population & $\begin{array}{c}0.250 * * * \\
(8.39)\end{array}$ & $\begin{array}{c}0.079 * * \\
(2.20)\end{array}$ & $\begin{array}{l}-0.000 \\
(-0.01)\end{array}$ & $\begin{array}{c}0.293 * * * \\
(4.18)\end{array}$ \\
\hline Unemployment Rate & $\begin{array}{l}-0.004 \\
(-1.08)\end{array}$ & $\begin{array}{l}0.003 \\
(0.32)\end{array}$ & $\begin{array}{l}0.008 \\
(0.90)\end{array}$ & $\begin{array}{l}-0.009 \\
(-1.32)\end{array}$ \\
\hline $\mathrm{R} 2$ & 0.880 & 0.429 & & \\
\hline $\mathrm{N}$ & 1548 & 1548 & 1408 & 1548 \\
\hline Hansen J & & & & 180.296 \\
\hline ( $p$-value) & & & & 0.317 \\
\hline Arellano-Bond test for AR1 in 1st differences & & & & -4.454 \\
\hline (p-value) & & & & 0.000 \\
\hline Arellano-Bond test for AR2 in 1st differences & & & & 0.950 \\
\hline ( $p$-value) & & & & 0.342 \\
\hline Number of districts & 452 & 452 & 452 & 452 \\
\hline Number of instruments & & & & 189 \\
\hline
\end{tabular}

Notes:

- Robust t-values in parenthesis; ${ }^{*}$ significant at $10 \% ;{ }^{* *}$ significant at $5 \%$; ${ }^{* * *}$ significant at $1 \%$

- Fixed Effects regressions with time and district fixed effects

- Standard errors are clustered at the district level

- Two-step System GMM with time fixed effects and Windmeijer finite sample correction 


\section{Appendix C}

Table C.1: Data description

\begin{tabular}{|c|c|c|}
\hline Variable & Description & Data source \\
\hline (log) Exports & $\begin{array}{l}\text { Log of exports to China in given year from partner } \\
\text { country (SITC Rev. 3) (in current US\$) }\end{array}$ & $\begin{array}{l}\text { COMTRADE via WITS } \\
\text { (http://wits.worldbank.org) }\end{array}$ \\
\hline $\begin{array}{l}\text { Dalai Lama (DL) } \\
\text { meeting }\end{array}$ & $\begin{array}{l}\text { Binary dummy variable that is } 1 \text { if the Dalai Lama met } \\
\text { with } \\
\text { - a head of state or head of government } \\
\text { - a member of government (additionally } \\
\text { includes all ministers) } \\
\text { - a national official representative (additionally } \\
\text { includes speakers of parliament) } \\
\text { any dignitary listed by the Office of the Dalai } \\
\text { Lama (additionally includes former heads of } \\
\text { state or government, regional leaders, party } \\
\text { leaders, scientists, special envoys and } \\
\text { religious leaders, among others) } \\
\text { of the partner country }\end{array}$ & $\begin{array}{l}\text { Office of His Holiness the } 14^{\text {th }} \\
\text { Dalai Lama }\end{array}$ \\
\hline $\begin{array}{l}\text { Dalai Lama (DL) visits } \\
\text { country }\end{array}$ & $\begin{array}{l}\text { Binary dummy variable that is } 1 \text { if the Dalai Lama } \\
\text { travelled to partner country }\end{array}$ & $\begin{array}{l}\text { Office of His Holiness the } 14^{\text {th }} \\
\text { Dalai Lama }\end{array}$ \\
\hline $\begin{array}{l}\text { Duration of Dalai } \\
\text { Lama visit }\end{array}$ & $\begin{array}{l}\text { Number of days the Dalai Lama visited a partner } \\
\text { country }\end{array}$ & $\begin{array}{l}\text { Office of His Holiness the } 14^{\text {th }} \\
\text { Dalai Lama }\end{array}$ \\
\hline Tibet Support Groups & $\begin{array}{l}\text { Number of Tibet Support Groups (TSG) in partner } \\
\text { country and year (based on information on year of } \\
\text { foundation of TSG) }\end{array}$ & $\begin{array}{l}\text { Central Tibetan Administration, } \\
\text { own research }\end{array}$ \\
\hline (log) GDP & $\begin{array}{l}\text { Log of gross domestic product of partner country in } \\
\text { current US dollars }\end{array}$ & $\begin{array}{l}\text { World Development Indicators } \\
\text { (World Bank 2009) }\end{array}$ \\
\hline (log) Population & Log of population size of partner country & $\begin{array}{l}\text { World Development Indicators } \\
\text { (World Bank 2009) }\end{array}$ \\
\hline (log) Exchange rate & $\begin{array}{l}\text { Log of nominal exchange rate index (local currency } \\
\text { unit per Yuan) }(2000=1) \text {, which is calculated as the } \\
\text { ratio of the official exchange rate LCU per US } \$ \text { and } \\
\text { the official exchange rate US\$ per Chinese yuan }\end{array}$ & $\begin{array}{l}\text { World Development Indicators } \\
\text { (World Bank 2009) }\end{array}$ \\
\hline Other exports / GDP & $\begin{array}{l}\text { Total exports to all countries except China (as a } \\
\text { share of GDP) }\end{array}$ & $\begin{array}{l}\text { COMTRADE via WITS } \\
\text { (http://wits.worldbank.org) }\end{array}$ \\
\hline (log) Tariff rate & Log of trade-weighted bilateral tariff rate & $\begin{array}{l}\text { UNCTAD TRAINS via WITS } \\
\text { (http://wits.worldbank.org) }\end{array}$ \\
\hline $\begin{array}{l}\text { UNGA } \\
\text { alignment }\end{array}$ & $\begin{array}{l}\text { Number of times that a trading partner had the same } \\
\text { voting behavior as China in the United General } \\
\text { Assembly (as a share of all voting instances; } \\
\text { abstentions and absences are counted as } 0.5 \text { ) }\end{array}$ & $\begin{array}{l}\text { Voeten and Merdzanovic } \\
\text { (2009) }\end{array}$ \\
\hline
\end{tabular}

Note: All data are available for the 1991-2008 period. Information on Dalai Lama meetings and Dalai Lama visits were completed with information provided on www.buddhismtoday.com (accessed: April 2010). 
Table C.2: Descriptive Statistics

\begin{tabular}{|c|c|c|c|c|c|}
\hline Variable & Obs. & Mean & Std. Dev. & Min & Max \\
\hline \multicolumn{6}{|l|}{ Exports to China (in million US\$) } \\
\hline Total & 2066 & 1780 & 7560 & 0 & 125000 \\
\hline Food, life animals & 1564 & 53 & 156 & 0 & 2320 \\
\hline Beverages and Tobacco & 963 & 9 & 37 & 0 & 451 \\
\hline Crude materials, inedible, except fuels & 1770 & 267 & 1190 & 0 & 20500 \\
\hline Mineral fuels, lubricants and related materials & 1028 & 278 & 979 & 0 & 11800 \\
\hline Animal and vegetable oils, fats and waxes & 706 & 64 & 267 & 0 & 3900 \\
\hline Chemicals and related products, n.e.s. & 1524 & 282 & 1230 & 0 & 17200 \\
\hline Manufactured goods classified chiefly by material & 1768 & 286 & 1200 & 0 & 19700 \\
\hline Machinery and transport equipment & 1649 & 919 & 4200 & 0 & 62900 \\
\hline Miscellaneous manufactured articles & 1630 & 132 & 768 & 0 & 13900 \\
\hline Commodities and transactions not classified elsewhere & 1042 & 82 & 445 & 0 & 7490 \\
\hline \multicolumn{6}{|l|}{ Variable of interest } \\
\hline Dalai Lama meeting with political leader in t or $\mathrm{t}-1$ & 2066 & 0.07 & 0.26 & 0 & 1 \\
\hline Dalai Lama meeting with government member in $\mathrm{t}$ or $\mathrm{t}-1$ & 2066 & 0.11 & 0.31 & 0 & 1 \\
\hline Dalai Lama meeting with national official in t or $\mathrm{t}-1$ & 2066 & 0.11 & 0.31 & 0 & 1 \\
\hline Dalai Lama meeting with all dignitaries in $\mathrm{t}$ or $\mathrm{t}-1$ & 2066 & 0.12 & 0.33 & 0 & 1 \\
\hline Dalai Lama visits country in t or $\mathrm{t}-1$ & 2066 & 0.16 & 0.37 & 0 & 1 \\
\hline \multicolumn{6}{|l|}{ Instruments } \\
\hline Number of Tibet Support Groups & 2066 & 0.79 & 2.83 & 0 & 31 \\
\hline Dalai Lama visit dummy & 2066 & 0.10 & 0.30 & 0 & 1 \\
\hline Duration of Dalai Lama visit (in days) & 2066 & 1.36 & 7.68 & 0 & 124 \\
\hline \multicolumn{6}{|l|}{ Controls } \\
\hline GDP (in million US\$) & 2066 & 282000 & 1060000 & 106 & 14200000 \\
\hline Population (in million) & 2066 & 35 & 102 & 0 & 1140 \\
\hline Exchange rate $(2000=100)$ & 2066 & 1.28 & 11.45 & 0.0001 & 508.66 \\
\hline Other exports / GDP & 2053 & 27.15 & 20.74 & 0.31 & 176.26 \\
\hline Tariff rate & 1983 & 11.80 & 11.62 & 0.00 & 95.50 \\
\hline UNGA voting alignment with China & 2041 & 78.89 & 12.88 & 13.64 & 96.10 \\
\hline
\end{tabular}


Table C.3: List of countries

\begin{tabular}{|c|c|c|c|c|c|c|c|c|c|c|c|c|c|c|c|c|}
\hline $\begin{array}{l}\text { A } \\
\text { B } \\
\text { C } \\
\text { D } \\
\text { E } \\
\text { F } \\
\text { G } \\
\text { H } \\
\end{array}$ & & $\begin{array}{l}\text { f ve } \\
\text { f ye } \\
\text { f ye } \\
\text { f ye } \\
\text { f ye } \\
\text { o ye } \\
\text { of } \\
\text { of Til }\end{array}$ & $\begin{array}{l}\text { ars } \\
\text { ars } \\
\text { ars } \\
\text { ars } \\
\text { ars } \\
\text { ars } \\
\text { ays } \\
\text { et }\end{array}$ & $\begin{array}{l}\partial \mathrm{L} t \\
\partial \mathrm{L} n \\
\partial \mathrm{L} n \\
\partial \mathrm{L} \text { t } \\
\text { OL n } \\
\text { DL } n \\
\text { Dupp }\end{array}$ & $\begin{array}{l}\text { avel } \\
\text { iet } \\
\text { et y } \\
\text { avel } \\
\text { iet y } \\
\text { et y } \\
\text { sper } \\
\text { ort C }\end{array}$ & $\begin{array}{l}\text { led } \\
\text { ith } \\
\text { ith } \\
\text { led } \\
\text { ith } \\
\text { ith } \\
\text { t in } \\
\text { arou }\end{array}$ & $\begin{array}{l}\text { o cou } \\
\text { goverr } \\
\text { bolitic } \\
\text { o cou } \\
\text { gover } \\
\text { bolitic } \\
\text { count } \\
\text { ps (20 }\end{array}$ & $\begin{array}{l}1 \\
\text { ent } \\
\text { ead } \\
\text { (2 } \\
\text { ent } \\
\text { ead } \\
200 \\
20\end{array}$ & $\begin{array}{l}1-2008) \\
\text { ember (1991-2008) } \\
(1991-2008) \\
2-2008) \\
\text { ember (2002-2008) } \\
(2002-2008) \\
2008)\end{array}$ & & & & & & & \\
\hline Country & $\mathbf{A}$ & B & $\mathbf{C}$ & D & $E$ & $\mathbf{F}$ & G & $\mathrm{H}$ & Country & $\mathbf{A}$ & B & C & D & $E$ & $\mathbf{F}$ & $\mathbf{G}$ \\
\hline Albania* & 0 & 0 & 0 & 0 & 0 & 0 & 0 & 0 & Lithuania* & 2 & 2 & 2 & 0 & 0 & 0 & 0 \\
\hline Algeria & 0 & 0 & 0 & 0 & 0 & 0 & 0 & 0 & Luxembourg* & 1 & 0 & 0 & 1 & 0 & 0 & 2 \\
\hline Antigua and Barbuda & 0 & 0 & 0 & 0 & 0 & 0 & 0 & 0 & Macedonia, FYR* & 0 & 0 & 0 & 0 & 0 & 0 & 0 \\
\hline Argentina & 3 & 1 & 1 & 1 & 0 & 0 & 4 & 0 & Madagascar & 0 & 0 & 0 & 0 & 0 & 0 & 0 \\
\hline Armenia & 0 & 0 & 0 & 0 & 0 & 0 & 0 & 0 & Malawi & 0 & 0 & 0 & 0 & 0 & 0 & 0 \\
\hline Aruba & 0 & 0 & 0 & 0 & 0 & 0 & 0 & 0 & Malaysia & 0 & 0 & 0 & 0 & 0 & 0 & 0 \\
\hline Australia & 5 & 4 & 3 & 3 & 2 & 1 & 29 & 4 & Maldives & 0 & 0 & 0 & 0 & 0 & 0 & 0 \\
\hline Austria* & 8 & 7 & 5 & 3 & 3 & 2 & 21 & 2 & Mali & 0 & 0 & 0 & 0 & 0 & 0 & 0 \\
\hline Azerbaijan & 0 & 0 & 0 & 0 & 0 & 0 & 0 & 0 & Malta* & 0 & 0 & 0 & 0 & 0 & 0 & 0 \\
\hline Bahamas, The & 0 & 0 & 0 & 0 & 0 & 0 & 0 & 0 & Mauritania & 0 & 0 & 0 & 0 & 0 & 0 & 0 \\
\hline Bahrain & 0 & 0 & 0 & 0 & 0 & 0 & 0 & 0 & Mauritius & 0 & 0 & 0 & 0 & 0 & 0 & 0 \\
\hline Bangladesh & 0 & 0 & 0 & 0 & 0 & 0 & 0 & 0 & Mexico & 1 & 1 & 0 & 1 & 1 & 0 & 6 \\
\hline Barbados & 0 & 0 & 0 & 0 & 0 & 0 & 0 & 0 & Moldova & 0 & 0 & 0 & 0 & 0 & 0 & 0 \\
\hline Belarus & 0 & 0 & 0 & 0 & 0 & 0 & 0 & 0 & Mongolia & 5 & 2 & 1 & 2 & 1 & 1 & 13 \\
\hline Belgium* & 5 & 4 & 4 & 2 & 2 & 2 & 13 & 2 & Morocco & 0 & 0 & 0 & 0 & 0 & 0 & 0 \\
\hline Belize & 0 & 0 & 0 & 0 & 0 & 0 & 0 & 0 & Mozambique & 0 & 0 & 0 & 0 & 0 & 0 & 0 \\
\hline Benin & 0 & 0 & 0 & 0 & 0 & 0 & 0 & 0 & Namibia & 0 & 0 & 0 & 0 & 0 & 0 & 0 \\
\hline Bhutan & 0 & 0 & 0 & 0 & 0 & 0 & 0 & 0 & Nepal & 0 & 0 & 0 & 0 & 0 & 0 & 0 \\
\hline Bolivia & 0 & 0 & 0 & 0 & 0 & 0 & 0 & 0 & Netherlands* & 4 & 3 & 1 & 0 & 0 & 0 & 0 \\
\hline Bosnia and Herzegovina* & 0 & 0 & 0 & 0 & 0 & 0 & 0 & 0 & New Caledonia & 0 & 0 & 0 & 0 & 0 & 0 & 0 \\
\hline Botswana & 0 & 0 & 0 & 0 & 0 & 0 & 0 & 0 & New Zealand & 4 & 4 & 4 & 2 & 2 & 2 & 9 \\
\hline Brazil & 3 & 2 & 1 & 1 & 1 & 0 & 5 & 1 & Nicaragua & 1 & 2 & 2 & 0 & 0 & 0 & 0 \\
\hline Brunei & 0 & 0 & 0 & 0 & 0 & 0 & 0 & 0 & Niger & 0 & 0 & 0 & 0 & 0 & 0 & 0 \\
\hline Bulgaria* & 1 & 2 & 2 & 0 & 0 & 0 & 0 & 0 & Nigeria & 1 & 0 & 0 & 1 & 0 & 0 & 3 \\
\hline Burkina Faso & 0 & 0 & 0 & 0 & 0 & 0 & 0 & 0 & Norway* & 6 & 5 & 4 & 1 & 1 & 1 & 3 \\
\hline Burundi & 0 & 0 & 0 & 0 & 0 & 0 & 0 & 0 & Oman & 0 & 0 & 0 & 0 & 0 & 0 & 0 \\
\hline Cambodia & 0 & 1 & 1 & 0 & 0 & 0 & 0 & 0 & Pakistan & 0 & 0 & 0 & 0 & 0 & 0 & 0 \\
\hline Cameroon & 0 & 0 & 0 & 0 & 0 & 0 & 0 & 0 & Panama & 0 & 0 & 0 & 0 & 0 & 0 & 0 \\
\hline Canada & 4 & 3 & 2 & 3 & 3 & 2 & 30 & 3 & Papua New Guinea & 0 & 0 & 0 & 0 & 0 & 0 & 0 \\
\hline Central African Republic & 0 & 0 & 0 & 0 & 0 & 0 & 0 & 0 & Paraguay & 0 & 0 & 0 & 0 & 0 & 0 & 0 \\
\hline Chile & 3 & 3 & 2 & 1 & 1 & 0 & 5 & 0 & Peru & 1 & 1 & 1 & 1 & 1 & 1 & 4 \\
\hline Colombia & 1 & 0 & 0 & 1 & 0 & 0 & 3 & 0 & Philippines & 0 & 0 & 0 & 0 & 0 & 0 & 0 \\
\hline Congo, Rep. & 0 & 0 & 0 & 0 & 0 & 0 & 0 & 0 & Poland* & 3 & 4 & 4 & 1 & 1 & 1 & 8 \\
\hline Costa Rica & 1 & 1 & 1 & 1 & 1 & 1 & 4 & 1 & Portugal ${ }^{*}$ & 2 & 1 & 1 & 1 & 0 & 0 & 6 \\
\hline Cote d'Ivoire & 0 & 0 & 0 & 0 & 0 & 0 & 0 & 0 & Qatar & 0 & 0 & 0 & 0 & 0 & 0 & 0 \\
\hline Croatia* & 1 & 1 & 1 & 1 & 1 & 1 & 4 & 0 & Romania* & 0 & 0 & 0 & 0 & 0 & 0 & 0 \\
\hline Cyprus* & 0 & 0 & 0 & 0 & 0 & 0 & 0 & 0 & Russian Federation & 5 & 0 & 0 & 1 & 0 & 0 & 3 \\
\hline Czech Republic* & 6 & 5 & 4 & 4 & 3 & 2 & 17 & 4 & Rwanda & 0 & 0 & 0 & 0 & 0 & 0 & 0 \\
\hline Denmark* & 4 & 4 & 2 & 1 & 1 & 1 & 7 & 2 & Samoa & 0 & 0 & 0 & 0 & 0 & 0 & 0 \\
\hline Dominican Republic & 0 & 0 & $\overline{0}$ & 0 & 0 & 0 & 0 & 0 & Saudi Arabia & 0 & 0 & 0 & 0 & 0 & 0 & 0 \\
\hline Egypt, Arab Rep. & 0 & 0 & 0 & 0 & 0 & 0 & 0 & 0 & Senegal & 0 & 0 & 0 & 0 & 0 & 0 & 0 \\
\hline El Salvador & 1 & 1 & 1 & 1 & 1 & 1 & 3 & 0 & Serbia (Yugoslavia)* & 0 & 0 & 0 & 0 & 0 & 0 & 0 \\
\hline Eritrea & 0 & 0 & 0 & 0 & 0 & 0 & 0 & 0 & Seychelles & 0 & 0 & 0 & 0 & 0 & 0 & 0 \\
\hline Estonia* & 2 & 2 & 1 & 0 & 0 & 0 & 0 & 0 & Singapore & 0 & 0 & 0 & 0 & 0 & 0 & 0 \\
\hline Ethiopia & 0 & 0 & 0 & 0 & 0 & 0 & 0 & 0 & Slovak Republic* & 1 & 0 & 0 & 0 & 0 & 0 & 0 \\
\hline Fiji & 0 & 0 & 0 & 0 & 0 & 0 & 0 & 0 & Slovenia* & 1 & 1 & 1 & 1 & 1 & 1 & 3 \\
\hline Finland* & 2 & 1 & 0 & 1 & 0 & 0 & 4 & 0 & Solomon Islands & 0 & 0 & 0 & 0 & 0 & 0 & 0 \\
\hline France* $^{\star}$ & 12 & 5 & 3 & 3 & 1 & 1 & 24 & 3 & South Africa & 3 & 1 & 1 & 1 & 0 & 0 & 7 \\
\hline French Polynesia & 0 & 0 & 0 & 0 & 0 & 0 & 0 & 0 & Spain* & 4 & 0 & 0 & 2 & 0 & 0 & 8 \\
\hline Gabon & 1 & 0 & 0 & 0 & 0 & 0 & 0 & 0 & Sri Lanka & 0 & 0 & 0 & 0 & 0 & 0 & 0 \\
\hline Gambia, The & 0 & 0 & 0 & 0 & 0 & 0 & 0 & 0 & St. Kitts and Nevis & 0 & 0 & 0 & 0 & 0 & 0 & 0 \\
\hline Georgia & 0 & 0 & 0 & 0 & 0 & 0 & 0 & 0 & St. Lucia & 0 & 0 & 0 & 0 & 0 & 0 & 0 \\
\hline Germany* & 14 & 5 & 1 & 5 & 3 & 1 & 43 & 8 & St. Vincent and the G. & 0 & 0 & 0 & 0 & 0 & 0 & 0 \\
\hline Ghana & 0 & 0 & 0 & 0 & 0 & 0 & 0 & 0 & Sudan & 0 & 0 & 0 & 0 & 0 & 0 & 0 \\
\hline Greece* $^{*}$ & 0 & 0 & 0 & 0 & 0 & 0 & 0 & 1 & Suriname & 0 & 0 & 0 & 0 & 0 & 0 & 0 \\
\hline Grenada & 0 & 0 & 0 & 0 & 0 & 0 & 0 & 0 & Swaziland & 0 & 0 & 0 & 0 & 0 & 0 & 0 \\
\hline Guatemala & 1 & 1 & 1 & 1 & 1 & 1 & 3 & 0 & Sweden* & 6 & 3 & 2 & 2 & 0 & 0 & 7 \\
\hline Guinea & 0 & 0 & 0 & 0 & 0 & 0 & 0 & 0 & Switzerland ${ }^{\star}$ & 10 & 4 & 0 & 2 & 1 & 0 & 15 \\
\hline Guyana & 0 & 0 & 0 & 0 & 0 & 0 & 0 & 0 & Syrian Arab Republic & 0 & 0 & 0 & 0 & 0 & 0 & 0 \\
\hline Honduras & 0 & 0 & 0 & 0 & 0 & 0 & 0 & 0 & Tanzania & 0 & 0 & 0 & 0 & 0 & 0 & 0 \\
\hline Hungary* & 4 & 1 & 1 & 0 & 0 & 0 & 0 & 0 & Thailand & 1 & 0 & 0 & 0 & 0 & 0 & 0 \\
\hline Iceland* & 0 & 0 & 0 & 0 & 0 & 0 & 0 & 0 & Togo & 0 & 0 & 0 & 0 & 0 & 0 & 0 \\
\hline India & 18 & 9 & 7 & 7 & 4 & 2 & 616 & 2 & Tonga & 0 & 0 & 0 & 0 & 0 & 0 & 0 \\
\hline Indonesia & 1 & 0 & 0 & 0 & 0 & 0 & 0 & 1 & Trinidad and Tobago & 1 & 0 & 0 & 0 & 0 & 0 & 0 \\
\hline Iran, Islamic Rep. & 0 & 0 & 0 & 0 & 0 & 0 & 0 & 0 & Tunisia & 0 & 0 & 0 & 0 & 0 & 0 & 0 \\
\hline Ireland* & 1 & 2 & 2 & 0 & 0 & 0 & 0 & 1 & Turkey* & 0 & 0 & 0 & 0 & 0 & 0 & 0 \\
\hline Israel & 3 & 2 & 0 & 1 & 0 & 0 & 5 & 1 & Turkmenistan & 0 & 0 & 0 & 0 & 0 & 0 & 0 \\
\hline Italy* & 12 & 6 & 2 & 5 & 3 & 0 & 31 & 3 & Uganda & 0 & 0 & 0 & 0 & 0 & 0 & 0 \\
\hline Jamaica & 0 & 0 & 0 & 0 & 0 & 0 & 0 & 0 & Ukraine & 0 & 0 & 0 & 0 & 0 & 0 & 0 \\
\hline Japan & 12 & 0 & 0 & 7 & 0 & 0 & 69 & 3 & United Arab Emirates & 0 & 0 & 0 & 0 & 0 & 0 & 0 \\
\hline Jordan & 3 & 3 & 3 & 3 & 3 & 3 & 13 & 0 & United Kingdom* & 10 & 6 & 3 & 4 & 2 & 1 & 33 \\
\hline Kazakhstan & 0 & 0 & 0 & 0 & 0 & 0 & 0 & 0 & United States & 16 & 11 & 10 & 6 & 3 & 3 & 169 \\
\hline Kenya & 0 & 0 & 0 & 0 & 0 & 0 & 0 & 0 & Uruguay & 0 & 0 & 0 & 0 & 0 & 0 & 0 \\
\hline Korea, Rep. & 0 & 0 & 0 & 0 & 0 & 0 & 0 & 0 & Vanuatu & 0 & 0 & 0 & 0 & 0 & 0 & 0 \\
\hline Kuwait & 0 & 0 & 0 & 0 & 0 & 0 & 0 & 0 & Venezuela & 1 & 0 & 0 & 0 & 0 & 0 & 0 \\
\hline Kyrgyz Republic & 0 & 0 & 0 & 0 & 0 & 0 & 0 & 0 & Vietnam & 0 & 0 & 0 & 0 & 0 & 0 & 0 \\
\hline Latvia* & 2 & 2 & 2 & 0 & 0 & 0 & 0 & 1 & Yemen & 0 & 0 & 0 & 0 & 0 & 0 & 0 \\
\hline Lebanon & 0 & 0 & 0 & 0 & 0 & 0 & 0 & 0 & Zambia & 0 & 0 & 0 & 0 & 0 & 0 & 0 \\
\hline Lesotho & 0 & 0 & 0 & 0 & 0 & 0 & 0 & 0 & Zimbabwe & 0 & 0 & 0 & 0 & 0 & 0 & 0 \\
\hline Libya & 0 & 0 & 0 & 0 & 0 & 0 & 0 & 0 & & & & & & & & \\
\hline
\end{tabular}

Note: All countries included in the European subsample are marked with an asterix $\left({ }^{*}\right)$. 
Table C.4: Exports to China and Dalai Lama meetings of government members (Hypothesis 1, all countries, excluding SITC9)

\begin{tabular}{|c|c|c|c|c|c|c|}
\hline & Fixed Effec & & & FGLS AR(1 & & \\
\hline & $\begin{array}{l}1991-2008 \\
(1)\end{array}$ & $\begin{array}{l}\text { 1991-2001 } \\
\text { (2) }\end{array}$ & $\begin{array}{l}\text { 2002-2008 } \\
\text { (3) }\end{array}$ & $\begin{array}{l}1991-2008 \\
(4)\end{array}$ & $\begin{array}{l}\text { 1991-2001 } \\
\text { (5) }\end{array}$ & $\begin{array}{l}2002-2008 \\
(6)\end{array}$ \\
\hline DL meets government member & $\begin{array}{l}-0.048 \\
(0.583)\end{array}$ & $\begin{array}{l}-0.002 \\
(0.978)\end{array}$ & $\begin{array}{l}-0.128^{* *} \\
(0.032)\end{array}$ & $\begin{array}{l}-0.065^{*} \\
(0.051)\end{array}$ & $\begin{array}{l}-0.019 \\
(0.527)\end{array}$ & $\begin{array}{l}-0.056^{* *} \\
(0.014)\end{array}$ \\
\hline$(\log )$ GDP & $\begin{array}{l}0.537^{\star *} \\
(0.033)\end{array}$ & $\begin{array}{l}0.849^{* *} \\
(0.032)\end{array}$ & $\begin{array}{l}0.034 \\
(0.914)\end{array}$ & $\begin{array}{l}0.218^{\star \star \star} \\
(0.005)\end{array}$ & $\begin{array}{l}0.359^{\star \star \star} \\
(0.001)\end{array}$ & $\begin{array}{l}0.406^{\star \star \star} \\
(0.000)\end{array}$ \\
\hline (log) Population & $\begin{array}{l}3.551^{* * \star} \\
(0.001)\end{array}$ & $\begin{array}{l}3.077^{\star} \\
(0.050)\end{array}$ & $\begin{array}{l}3.409^{* *} \\
(0.041)\end{array}$ & $\begin{array}{l}0.468^{* \star \star} \\
(0.001)\end{array}$ & $\begin{array}{l}0.189 \\
(0.338)\end{array}$ & $\begin{array}{l}2.740^{\star \star *} \\
(0.000)\end{array}$ \\
\hline (log) Exchange rate & $\begin{array}{l}-0.089 \\
(0.365)\end{array}$ & $\begin{array}{l}-0.108 \\
(0.335)\end{array}$ & $\begin{array}{l}0.210 \\
(0.241)\end{array}$ & $\begin{array}{l}0.030 \\
(0.293)\end{array}$ & $\begin{array}{l}-0.058^{*} \\
(0.083)\end{array}$ & $\begin{array}{l}0.305^{\star \star \star} \\
(0.000)\end{array}$ \\
\hline R squared & 0.426 & 0.119 & 0.260 & & & \\
\hline Observations & 2,051 & 1,132 & 911 & 2,051 & 1,132 & 911 \\
\hline Number of countries & 159 & 147 & 151 & 159 & 147 & 151 \\
\hline
\end{tabular}

Notes:

- All regressions with country and time fixed effects.

- Robust p-values in brackets; * significant at 10\%; ** significant at $5 \%$; ${ }^{* \star *}$ significant at $1 \%$

- Standard errors in Fixed Effects regressions are adjusted for clustering across partner countries.

- FGLS regressions are corrected for cross-sectional heteroskedasticity across panels and first order autocorrelation. 
Table C.5: Exports to China and DL meetings at various political levels (Hypothesis 2, European countries, 2002-2008)

\begin{tabular}{|c|c|c|c|c|c|c|c|c|c|c|c|c|c|c|c|c|c|c|}
\hline & \multicolumn{9}{|c|}{ Fixed Effects } & \multicolumn{9}{|c|}{ FGLS AR(1) } \\
\hline & (1) & (2) & (3) & (4) & (5) & (6) & (7) & (8) & (9) & (10) & (11) & (12) & (13) & (14) & (15) & (16) & (17) & (18) \\
\hline political leader & $\begin{array}{l}-0.200^{* *} \\
(0.040)\end{array}$ & & & & & $\begin{array}{l}-0.250^{*} \\
(0.059)\end{array}$ & $\begin{array}{l}-0.193 \\
(0.154)\end{array}$ & $\begin{array}{l}-0.159 \\
(0.241)\end{array}$ & $\begin{array}{l}-0.223^{*} \\
(0.080)\end{array}$ & $\begin{array}{l}-0.244^{\star \star \star} \\
(0.000)\end{array}$ & & & & & $\begin{array}{l}-0.244^{\star \star \star} \\
(0.005)\end{array}$ & $\begin{array}{l}-0.203^{\star \star \star} \\
(0.007)\end{array}$ & $\begin{array}{l}-0.194^{* \star *} \\
(0.006)\end{array}$ & $\begin{array}{l}-0.233^{\star \star \star} \\
(0.000)\end{array}$ \\
\hline government member & & $-0.122^{*}$ & & & & 0.058 & & & & & $-0.140^{* \star *}$ & & & & 0.002 & & & \\
\hline 善 & & (0.098) & & & & $(0.452)$ & & & & & $(0.003)$ & & & & $(0.979)$ & & & \\
\hline national official & & & $-0.124^{\star}$ & & & & -0.009 & & & & & $-0.148^{\star \star \star}$ & & & & -0.048 & & \\
\hline 巴ه & & & $(0.067)$ & & & & $(0.920)$ & & & & & $(0.001)$ & & & & $(0.414)$ & & \\
\hline all dignitaries & & & & $-0.144^{\star \star}$ & & & & -0.051 & & & & & $-0.148^{\star \star \star}$ & & & & -0.062 & \\
\hline & & & & $(0.025)$ & & & & $(0.551)$ & & & & & $(0.001)$ & & & & $(0.249)$ & \\
\hline DL visits country & & & & & -0.072 & & & & 0.032 & & & & & $-0.091^{\star \star}$ & & & & -0.016 \\
\hline & & & & & $(0.190)$ & & & & $(0.670)$ & & & & & $(0.027)$ & & & & $(0.755)$ \\
\hline (log) GDP & 0.278 & 0.362 & 0.356 & 0.359 & 0.390 & 0.263 & 0.279 & 0.290 & 0.265 & $0.536^{\star \star \star}$ & $0.691^{\star \star *}$ & $0.701^{* \star *}$ & $0.683^{\star \star *}$ & $0.747^{\star * *}$ & $0.535^{\star \star *}$ & $0.548^{\star \star *}$ & $0.546^{\star \star *}$ & $0.542^{* * *}$ \\
\hline & $(0.681)$ & $(0.587)$ & $(0.592)$ & $(0.587)$ & $(0.557)$ & $(0.698)$ & $(0.680)$ & $(0.669)$ & $(0.699)$ & $(0.001)$ & $(0.000)$ & $(0.000)$ & $(0.000)$ & $(0.000)$ & $(0.002)$ & $(0.001)$ & $(0.001)$ & $(0.001)$ \\
\hline (log) Population & 2.278 & 2.208 & 2.160 & 2.450 & 2.087 & 2.225 & 2.284 & 2.397 & 2.233 & 0.108 & -0.123 & -0.139 & -0.111 & -0.206 & 0.109 & 0.090 & 0.093 & 0.099 \\
\hline & $(0.482)$ & $(0.495)$ & $(0.504)$ & $(0.450)$ & $(0.521)$ & $(0.491)$ & $(0.481)$ & $(0.463)$ & $(0.494)$ & $(0.670)$ & $(0.627)$ & $(0.583)$ & $(0.659)$ & $(0.423)$ & $(0.671)$ & $(0.724)$ & $(0.711)$ & $(0.700)$ \\
\hline (log) Exchange rate & -1.101 & -1.086 & -1.104 & -1.124 & -1.062 & -1.091 & -1.104 & -1.121 & -1.092 & -0.430 & -0.445 & -0.470 & -0.506 & -0.331 & -0.416 & -0.454 & -0.483 & -0.452 \\
\hline & $(0.306)$ & $(0.320)$ & $(0.315)$ & $(0.305)$ & $(0.336)$ & $(0.310)$ & $(0.307)$ & $(0.302)$ & $(0.309)$ & $(0.257)$ & $(0.249)$ & $(0.223)$ & $(0.190)$ & $(0.390)$ & $(0.274)$ & $(0.232)$ & $(0.205)$ & $(0.236)$ \\
\hline R squared & 0.504 & 0.502 & 0.502 & 0.503 & 0.501 & 0.504 & 0.504 & 0.504 & 0.504 & & & & & & & & & \\
\hline Observations & 247 & 247 & 247 & 247 & 247 & 247 & 247 & 247 & 247 & 247 & 247 & 247 & 247 & 247 & 247 & 247 & 247 & 247 \\
\hline Number of countries & 36 & 36 & 36 & 36 & 36 & 36 & 36 & 36 & 36 & 36 & 36 & 36 & 36 & 36 & 36 & 36 & 36 & 36 \\
\hline
\end{tabular}

All regressions with country and time fixed effects.

- Robust p-values in brackets; * significant at $10 \%$; ** significant at $5 \%$; ${ }^{* *}$ significant at $1 \%$

Standard errors in Fixed Effects regressions are adjusted for clustering across partner countries.

FGLS regressions are corrected for cross-sectional heteroskedasticity across panels and first order autocorrelation. 
Table C.6: Exports to China and Dalai Lama meetings of political leaders (first-stage results for 2SLS regressions, 2002-2008)

\begin{tabular}{|c|c|c|c|c|c|c|c|}
\hline & $\begin{array}{l}\text { 2SLS } \\
\text { World } \\
\text { (1) }\end{array}$ & $\begin{array}{l}\text { Europe } \\
\text { (2) }\end{array}$ & $\begin{array}{l}\text { World } \\
\text { (3) }\end{array}$ & & $\begin{array}{l}\text { World } \\
\text { (4) }\end{array}$ & & $\begin{array}{l}\text { World } \\
\text { (5) }\end{array}$ \\
\hline & $\mathrm{DL}(\mathrm{t}$ or $\mathrm{t}-1)$ & $\mathrm{DL}(\mathrm{t}$ or $\mathrm{t}-1)$ & $\mathrm{DL}(\mathrm{t})$ & $\mathrm{DL}(\mathrm{t}-1)$ & $\mathrm{DL}(\mathrm{t})$ & $\mathrm{DL}(\mathrm{t}-1)$ & $\mathrm{DL}(\mathrm{t})$ \\
\hline Number of TSGs (t-1) & $\begin{array}{l}0.157^{\star \star *} \\
(0.000)\end{array}$ & $\begin{array}{l}0.139^{\star * \star} \\
(0.001)\end{array}$ & $\begin{array}{l}0.100^{\star \star *} \\
(0.000)\end{array}$ & $\begin{array}{l}0.055^{\star *} \\
(0.017)\end{array}$ & $\begin{array}{l}0.100^{* \star *} \\
(0.000)\end{array}$ & $\begin{array}{l}0.055^{\star *} \\
(0.017)\end{array}$ & $\begin{array}{l}0.101^{* * *} \\
(0.000)\end{array}$ \\
\hline Dalai Lama visit dummy (t) & $\begin{array}{l}0.372^{\star \star \star} \\
(0.000)\end{array}$ & $\begin{array}{l}0.359^{* *} \\
(0.040)\end{array}$ & $\begin{array}{l}0.344^{\star \star \star} \\
(0.000)\end{array}$ & $\begin{array}{l}0.030 \\
(0.609)\end{array}$ & $\begin{array}{l}0.345^{\star \star *} \\
(0.000)\end{array}$ & $\begin{array}{l}0.031 \\
(0.604)\end{array}$ & $\begin{array}{l}0.353^{\star \star \star} \\
(0.000)\end{array}$ \\
\hline Dalai Lama visit dummy (t-1) & $\begin{array}{l}0.334^{\star \star *} \\
(0.000)\end{array}$ & $\begin{array}{l}0.329^{\star *} \\
(0.028)\end{array}$ & $\begin{array}{l}0.019 \\
(0.688)\end{array}$ & $\begin{array}{l}0.374^{\star \star *} \\
(0.000)\end{array}$ & $\begin{array}{l}0.019 \\
(0.693)\end{array}$ & $\begin{array}{l}0.374^{\star \star \star} \\
(0.000)\end{array}$ & \\
\hline Duration of Dalai Lama visit (t) & $\begin{array}{l}0.006 \\
(0.100)\end{array}$ & $\begin{array}{l}0.017 \\
(0.526)\end{array}$ & $\begin{array}{l}0.011^{\star *} \\
(0.025)\end{array}$ & $\begin{array}{l}0.001 \\
(0.934)\end{array}$ & $\begin{array}{l}0.011^{\star \star} \\
(0.025)\end{array}$ & $\begin{array}{l}0.001 \\
(0.938)\end{array}$ & $\begin{array}{l}0.010^{\star \star \star} \\
(0.004)\end{array}$ \\
\hline $\begin{array}{l}\text { Duration of Dalai Lama visit (t- } \\
\text { 1) }\end{array}$ & $\begin{array}{l}0.007 \\
(0.104)\end{array}$ & $\begin{array}{l}0.009 \\
(0.703)\end{array}$ & $\begin{array}{l}-0.004 \\
(0.645)\end{array}$ & $\begin{array}{l}0.007 \\
(0.242)\end{array}$ & $\begin{array}{l}-0.004 \\
(0.643)\end{array}$ & $\begin{array}{l}0.007 \\
(0.244)\end{array}$ & \\
\hline (log) Exports (t-1) & & & & & $\begin{array}{l}-0.003 \\
(0.365)\end{array}$ & $\begin{array}{l}-0.004 \\
(0.203)\end{array}$ & $\begin{array}{l}-0.002 \\
(0.429)\end{array}$ \\
\hline (log) GDP & $\begin{array}{l}-0.118 \\
(0.123)\end{array}$ & $\begin{array}{l}-0.299 \\
(0.364)\end{array}$ & $\begin{array}{l}-0.066^{*} \\
(0.088)\end{array}$ & $\begin{array}{l}-0.061 \\
(0.225)\end{array}$ & $\begin{array}{l}-0.073^{*} \\
(0.083)\end{array}$ & $\begin{array}{l}-0.065 \\
(0.230)\end{array}$ & $\begin{array}{l}-0.068 \\
(0.149)\end{array}$ \\
\hline (log) Population & $\begin{array}{l}0.512^{*} \\
(0.073)\end{array}$ & $\begin{array}{l}1.456 \\
(0.222)\end{array}$ & $\begin{array}{l}0.014 \\
(0.924)\end{array}$ & $\begin{array}{l}0.449^{\star \star} \\
(0.030)\end{array}$ & $\begin{array}{l}0.014 \\
(0.928)\end{array}$ & $\begin{array}{l}0.462^{\star \star} \\
(0.031)\end{array}$ & $\begin{array}{l}0.025 \\
(0.867)\end{array}$ \\
\hline (log) Exchange rate & $\begin{array}{l}-0.021 \\
(0.625)\end{array}$ & $\begin{array}{l}-0.653 \\
(0.832)\end{array}$ & $\begin{array}{l}-0.019 \\
(0.363)\end{array}$ & $\begin{array}{l}-0.006 \\
(0.835)\end{array}$ & $\begin{array}{l}-0.022 \\
(0.354)\end{array}$ & $\begin{array}{l}-0.006 \\
(0.832)\end{array}$ & $\begin{array}{l}-0.019 \\
(0.415)\end{array}$ \\
\hline $\begin{array}{l}\text { Angrist-Pischke } \mathrm{F} \text { test } \\
\text { (Test of excluded } \\
\text { instruments) }\end{array}$ & $\begin{array}{l}12.69 \\
(0.000)\end{array}$ & $\begin{array}{l}6.99 \\
(0.000)\end{array}$ & $\begin{array}{l}23.9 \\
(0.000)\end{array}$ & $\begin{array}{l}15.4 \\
(0.000)\end{array}$ & $\begin{array}{l}23.55 \\
(0.000)\end{array}$ & $\begin{array}{l}15.32 \\
(0.000)\end{array}$ & $\begin{array}{l}29.12 \\
(0.000)\end{array}$ \\
\hline R squared & 0.373 & 0.464 & 0.355 & 0.327 & 0.356 & 0.328 & 0.354 \\
\hline Observations & 912 & 247 & 912 & 912 & 863 & 863 & 863 \\
\hline Number of countries & 151 & 36 & 151 & 151 & 142 & 142 & 142 \\
\hline
\end{tabular}

Notes:

- First stage results for 2SLS regressions reported in Table 4. All regressions with clustered standard errors, country and time fixed effects.

- * significant at $10 \%$; ** significant at $5 \% ;{ }^{* * *}$ significant at $1 \%$ 


\section{Appendix C.7: Anecdotal Evidence}

Tibet's political status represents a long-run cause of conflict both in China and in international relations that revolves around the question of whether the incorporation of Tibet into China was in accordance with international law. In light of this, the Chinese administration has recognized that its position on Tibet's status not only needs to be enforced domestically, but also internationally. ${ }^{122}$ By opposing any notion from abroad that might challenge the status quo of the region, China not only aims to contain the spread of unrest inside Tibet, but also seeks to weaken the worldwide Tibetan independence movement. ${ }^{123}$ Within this context, the Dalai Lama, in his position as leader of the Tibetan community, is seen as a threat to the integrity of the Chinese nation. Consequently, meetings between foreign officials and the Dalai Lama are a constant source of bilateral diplomatic tensions with China.

Since going into exile in 1959 until the end of 2009, the Tibetan leader visited 62 countries on all continents. ${ }^{124}$ The Dalai Lama himself emphasizes the nonpolitical nature of his visits and uses his travels as an opportunity to meet foreign politicians in order to discuss - among other issues - the situation in Tibet. The Chinese administration emphasizes that Tibet forms an integral part of China and sees the Dalai Lama as a pretentious state leader with a separatist agenda regarding Tibet. Therefore, any meeting of foreign officials with the Buddhist monk is perceived by Beijing as interference with internal affairs. Despite Chinese opposition, many countries have, to an increasing extent, recognized the Dalai Lama as a notable religious leader, subsequently granting him considerable attention. At the same time, China has increased pressure on other countries to not receive the exiled Tibetan leader in any form.

In this appendix, we study anecdotal evidence on how the bilateral climate between China and its trading partners is influenced by meetings between foreign officials and the Dalai Lama and derive our hypotheses. Of course, the incidents involving diplomatic threats listed below are not exhaustive, but provide some

\footnotetext{
${ }^{122}$ According to an official government bulletin, China identifies the issue of Tibet as one of the "most important and sensitive" core issues to be respected by China's partners, available at: http://www.gov.cn/misc/2009-05/27/content 1326253.htm (accessed: July 12, 2012).

${ }_{123}$ As Goldstein (1998: 83) notes, international opinion plays an important role in conflicts over regional independence since "the ambiguity about when entities have the right to seek selfdetermination has made international opinion an important dimension of such disputes".

${ }^{124}$ In 1967, the Dalai Lama travelled outside India for the first time in order to visit Japan and Thailand. His first trip to Europe was in 1973 where he visited 12 countries in 75 days. In 1979, he travelled to the United States and Canada for the first time.
} 
illustrative examples. Moreover, many diplomatic threats occur outside of the public spotlight, as can be seen in the example of a letter written by China's ambassador Zhang Yun to the Dutch chairman of the Standing Committee on Foreign Affairs, Henk Jan Ormel. In the text, which to the surprise of the ambassador was made public, the Chinese embassy warned that Sino-Dutch relations might be negatively affected by a planned meeting between Dutch members of parliament and the Dalai Lama. ${ }^{125}$

\section{Hypothesis 1: Trade-deteriorating effect of Dalai Lama meetings}

In addition to purely diplomatic threats, China increasingly exerts economic pressure on foreign governments to discourage them from meeting with the Dalai Lama. The growing assertiveness of the Chinese administration towards meetings of foreign dignitaries with the Tibetan leader reflects China's rising economic power. As such, this growing economic power provides China with the leverage needed to advance its political interests.

The Dalai Lama was officially invited to the White House for the first time in 1991 by President George Bush senior. The reception marked a pronounced change from the policy of former US presidents and sparked immediate protest from the Chinese. ${ }^{126}$ During the subsequent two Clinton and Bush presidencies, the Dalai Lama has been a visitor to the White House a further nine times, provoking regular protest from Beijing. In 2007, the US Congress awarded the Congressional Gold Medal, the highest civil honor conferred in the United States, to the Dalai Lama. The act was compounded by the fact that the US president personally attended the award ceremony. In a statement issued one day later by the Chinese Ministry of Foreign Affairs, Spokesperson Liu Jianchao emphasized that the award "ha[d] severely hurt the feelings of the Chinese people and gravely undermined the relationship between China and the US," a wording that is characteristic of the Chinese reaction to countries officially receiving the Dalai Lama. Furthermore, he "urge[d] the US to take effective measures immediately to undo the severe adverse impact of its erroneous

\footnotetext{
125 "We are clear: no dalai lama visits," NRC Handelsblad, May 7, 2009, available at: http://www.nrc.nl/international/Features/article2234645.ece/We are clear no dalai lama visits (accessed: July 12, 2012).

126 "On my mind; Beijing Heart Attack", The New York Times, April 19, 1991, p. A27, available at: http://www.nytimes.com/1991/04/19/opinion/on-my-mind-beijing-heart-attack.html (accessed: July 12, 2012).
} 
act. ${ }^{127}$ In 2009, President Barack Obama decided not to receive the Dalai Lama. The media deemed the decision "unprecedented" and surmised that the president had strategically delayed the reception until after his state visit to Beijing. The meeting finally took place in February 2010 and caused considerable discontent in Beijing. Chinese authorities emphasized that the move damaged US-Chinese relations, which, in turn, would undermine the United States' recovery from the current economic crisis. ${ }^{128}$

Before Italian Prime Minister Silvio Berlusconi's reception of the Dalai Lama in 1995, the Chinese prime minister warned his Italian counterpart that "if this [the Italian] government will adopt a policy that could damage a matter of principle [for China], it may also damage trade relations." ${ }^{29}$ Facing potential trade retaliations by the Chinese, Berlusconi openly admitted to the Dalai Lama that the international community was facing a dilemma, "caught between the importance of maintaining trade relations and protecting human rights." ${ }^{130}$ The decision to meet the Tibetan leader, despite Chinese threats, was judged as "courageous" by both the Italian media and the Dalai Lama himself.

In contrast, Germany's political leaders refrained for a long time from meeting with the Dalai Lama. In this regard, a 1995 New York Times article critically assessed that German foreign policy was aimed at avoiding political conflict over human rights issues with China, so as not to endanger lucrative trade ties with the emerging economy. ${ }^{131}$ Bilateral discontent emerged between China and Germany when Chancellor Angela Merkel deviated from this general practice by receiving the Dalai Lama in the chancellery in 2007. Merkel's predecessor Gerhard Schröder, known for his keenness for good economic relations with China, criticized the decision as a mistake, bearing in mind the detrimental effect the meeting may have on bilateral relations with Beijing. In the lead up to the Dalai Lama's announced visit to Berlin, Chinese politicians warned that the meeting would severely damage economic ties.

\footnotetext{
127 "Foreign Ministry Spokesperson Liu Jianchao's Regular Press Conference", Ministry of Foreign Affairs of the People's Republic of China, October 18, 2007, available at: http://www.fmprc.gov.cn/eng/xwfw/s2510/2511/t373809.htm (accessed: July 12, 2012).

${ }_{128}$ "Destiny of Tibet 'in hands of people'", China Daily, February 3, 2010, available at: http://www.chinadaily.com.cn/china/2010-02/03/content 9417649 2.htm (accessed: July 12, 2012).

${ }_{129}$ "Li Peng "diffida" Berlusconi; II Cavaliere l'aveva promesso a Pannella. Ma Pechino avverte: "Sono in pericolo le relazioni commerciali"," La Stampa, June 15, 1994, p. 4, own translation.

130 ""Italia, grazie per il coraggio"; II leader tibetano a Palazzo Chigi, per la prima volta un governo italiano sfida il veto cinese", La Stampa, June 18, 1994, p. 7, own translation.

131 "Seeking China Deal, Bonn Shuns Rights Issue," The New York Times, July 13, 1995, available at: http://www.nytimes.com/1995/07/13/world/seeking-china-deal-bonn-shuns-rights-issue.html (accessed: July 12, 2012).
} 
In the aftermath of this meeting, several bilateral meetings at various political levels were cancelled. An article entitled "The Cost of Being Honest," published in the German weekly "Der Spiegel," concluded that the chancellor's foreign policy comes with a "Merkel cost" for business. ${ }^{132}$

Sino-French relations worsened as French government sources announced a meeting between Nicolas Sarkozy and the Dalai Lama. Chinese officials promptly insinuated that trade ties with France could suffer unless the meeting was cancelled. China sent a strong message to France, which held the EU presidency at the time, by cancelling the 11 th annual EU-China summit at rather short notice. ${ }^{133}$ In addition, the media reported that the finalization of a contract to purchase 150 passenger planes from Airbus was suddenly postponed without further explanation. ${ }^{134}$ After the actual meeting took place, Vice Foreign Minister He Yafei emphasized that it had "sabotage[d] the political basis of China-France and China-EU relations" and furthermore warned of "serious consequences" which France alone would have to bear. $^{135}$ In early 2009, France was crossed off the travel agenda of two Chinese trade delegations. The first delegation alone signed 15 billion US dollars' worth of trade deals in other European countries. Furthermore, Chinese Prime Minister Wen Jiabao did not pay any state visit to France during his trip to Europe in January 2009. When asked to comment on the itinerary of his European tour, he was cited saying: "I looked at a map of Europe on the plane. My trip goes around France. [...] We all know why." ${ }^{136}$

The case of Mongolia serves as a further illustration of China's antagonism towards countries receiving the Dalai Lama. The Dalai Lama has visited the country on several occasions since 1979 as the country has strong historical and cultural links with Tibet. As reported by media sources in 2002, China imposed a temporary ban on imports from Mongolia and blocked the only railway link between the two

\footnotetext{
132 "Merkel Foreign Policy Is Bad for Business," Spiegel Online, October 23, 2007, available at: http://www.spiegel.de/international/germany/0,1518,513067,00.html (accessed: July 12, 2012).

${ }^{133}$ The meeting had originally been scheduled to take place on December $1^{\text {st }}$ in France where over a hundred high-ranking Chinese politicians and business leaders would have met with their European counterparts.

${ }_{134}$ "China tells France Dalai Lama meeting could hurt trade," AFP, December 4, 2008, available at: http://www.google.com/hostednews/afp/article/ALeqM5ifBAQ8quVlihggVgOrfEUzkzrHWg (accessed: July 12, 2012).

135 "He Yafei Lodges a Strong Protest to France over Sarkozy's Meeting with the Dalai Lama," Ministry of Foreign Affairs of the People's Republic of China, December 12, 2010, available at: http://www.fmprc.gov.cn/eng/wib/zzjg/xos/gilb/3291/3293/t525570.htm (accessed: July 12, 2012).

136 "Premier: We all know why," China Daily, February 2, 2009, available at: http://www.chinadaily.com.cn/china/2009-02/03/content 7440286.htm (accessed: July 12, 2012).
} 
countries in response to the reception of the Tibetan leader by the Mongolian Prime Minister Nambaryn Enkhbayar. The import ban was lifted after only one day and no further official receptions of the Dalai Lama took place in Mongolia - despite him visiting the country again in 2006.

We thus hypothesize that a deterioration of the bilateral political climate and a decrease in bilateral diplomatic exchanges, as a result of foreign officials meeting the Dalai Lama, leads to a significant reduction in exports to China. Our first hypothesis reads as follows:

Hypothesis 1: There is a trade-deteriorating effect caused by foreign officials receiving the Dalai Lama.

\section{Hypothesis 2: Importance of the rank of the dignitary met}

Political leaders are aware that meetings with the Dalai Lama put considerable stress on countries' bilateral relations with China, and that it may also have negative implications for the economic ties between them. A first alternative to not receiving the Dalai Lama at all is to meet with him but not in official capacity as head of state. For example, when the Dalai Lama planned to visit Switzerland in 2008, Pascal Couchepin announced that he would be meeting with the religious leader not in his function as president of the Swiss Confederation, but as minister of culture. ${ }^{137}$ Similarly, the Clinton administration granted him the opportunity to visit the White House, even though he was formally received only by a minister and not the president himself. Despite official sources emphasizing that no formal encounter between the Dalai Lama and the US president was scheduled, Clinton nevertheless dropped in during the talks. In September 1995, a New York Times article concluded that a better treatment of the Dalai Lama "would [have] cost us [the US] trade with the Chinese."138

As a second alternative, leaders delegate the task to lower-ranked government representatives in the hope of reducing the negative effect that such meetings may have on bilateral relations with China. At the same time, the government still sedates pro-Tibet lobby groups, human rights organizations and

137 "Dalai Lama sagt Besuch in der Schweiz ab," NZZ Online, September 13, 2008, available at: http://www.nzz.ch/nachrichten/schweiz/dalai lama sagt besuch in der schweiz ab 1.831028.html (accessed: July 12, 2012).

138“On My Mind; If He Can, Can I?" The New York Times, September 15, 1995, available at: http://www.nytimes.com/1995/09/15/opinion/on-my-mind-if-he-can-can-i.html (accessed: July 12, 2012). 
other sympathizers of the Dalai Lama. For example, during his trip to the Netherlands in 2009, the Dalai Lama was received by some members of parliament and met with the country's foreign minister during a conference between Dutch religious leaders. Prime Minister Jan Peter Balkenende, however, reportedly feared that a personal encounter with the Tibetan leader would bring "unwarranted risk" to Sino-Dutch relations. ${ }^{139}$ A similar strategy seems to have been employed in Germany in 2008, one year after the first reception of the Dalai Lama by a German chancellor. In what could be interpreted as giving in to Chinese pressure, high-ranking members of the German government avoided a further encounter with the Dalai Lama, referring to their "tight schedules." Allowing all parties to save face, the Tibetan leader was received by the president of the German Bundestag, the minister of economic cooperation and other non-government politicians.

A shift to lower-ranking officials is also observable in Latin American countries. The Dalai Lama embarked on several trips throughout the region between 1989 and 2006. With respect to Dalai Lama receptions, a clear downward trend can be observed in terms of the rank of dignitaries met in the most important destination countries in the region, namely Argentina, Brazil, Chile and Mexico. While the Tibetan leader had been received by the respective presidents of these countries until 1999, he has had to content himself with being received by dignitaries of less political importance ever since. The case of Chile in 2006 provides a particularly interesting example, where the local media suspected Chilean President Michelle Bachelet of avoiding a meeting with the Dalai Lama so as not to jeopardize ongoing negotiations for the country's first trade agreement with China. ${ }^{140}$ By that time, China had also become Chile's second most important trading partner after the United States.

While receptions of the Dalai Lama by official state representatives such as government members may provoke trade reductions, the matter should be different in instances where the Dalai Lama meets with leaders of the political opposition. In an interview conducted in 2008, the Dalai Lama himself remarked that most

\footnotetext{
139 "Dalai lama meets foreign minister, but not prime minister," NRC Handelsblad, June 5, 2009, available http://www.nrc.nl/international/article2262841.ece/Dalai lama meets foreign minister, but not prime minister (accessed: July 12, 2012).

140 "DALAI LAMA: CAN I EVER TELL YOU HOW SORRY I AM?" The Santiago Times, May 16, 2006, see: $\quad$ http://www.santiagotimes.cl/index.php?option=com content\&view=article\&id=9130:DALAlLAMA:-CAN-I-EVER-TELL-YOU-HOW-SORRY-I-AM?\&catid=1:other\&ltemid=38 (accessed: July 12, 2012).
} 
politicians meet with him before they become minister or president. After taking office, however, the very same politicians tend to avoid meeting with him so as not to endanger trade ties with China. The Dalai Lama concluded that "economic relations with China gain the upper hand." behavior. Prime Minister John Key, who was still in opposition in 2007 and critical of the incumbent government's decision not to receive the Dalai Lama, also chose not to meet with the religious figure in 2009 after his party had come into power.

Therefore, the 'Dalai Lama Effect' should depend on the rank or the political importance of the dignitary met. Meetings with higher-ranking politicians pose a greater affront to the Chinese, who may then retaliate through a more pronounced reduction in bilateral trade:

Hypothesis 2: The detrimental effect of meetings with the Dalai Lama on exports increases with the rank of the dignitary met.

\section{Hypothesis 3: Evolvement over time}

Assuming that the reduction of commercial activity is intended to convey a warning to other trading partners, extensive prolongation of the measure might cause the implied welfare losses to outweigh the political benefits that China attains from the increased political compliance of its trading partners. In particular, it seems reasonable to believe that China cannot afford to substitute more differentiated goods from a Dalai Lama-receiving country in the long run. Therefore, China and its trading partners both have incentives to revive their bilateral relations.

Anecdotal evidence confirms that diplomatic ties are usually restored after some period of time has passed following a reception of the Dalai Lama. However, China expects countries to make diplomatic concessions to correct for what it coins as their "wrongdoings." For example, nine months after the meeting between French President Nicolas Sarkozy and the Dalai Lama, bilateral relations were mended with considerable diplomatic efforts towards reconciliation. Shortly after a declaration by France that it recognized Tibet as an integral part of the Chinese territory, France was due to receive a new Chinese trade delegation. In an article titled "France goes

\footnotetext{
141 „Ich will eine echte Autonomie,“ Cicero Magazin für Politische Kultur, January 1, 2008, own translation, available at: http://www.cicero.de/97.php?ress id=1\&item=2503 (accessed: July 12, 2012).
} 
back on China's shopping list," the China Daily emphasizes a causal link between France's compliance and the re-establishment of bilateral relations. ${ }^{142}$

Similar reconciliation had to be achieved between China and Austria in September 2007. After a meeting between the Dalai Lama and Austrian Chancellor Alfred Gusenbauer, diplomatic relations between Austria and China deteriorated significantly, leading to what the media described as a "minor ice-age" between the two countries. The media reported that Austrian diplomats were banned from contact with Chinese officials for about a year. In October 2008, a state visit of the Austrian chancellor in Beijing marked the end of the diplomatic tensions caused by the Dalai Lama reception. ${ }^{143}$

Therefore, we expect the trade-deteriorating effect of meetings with the Dalai Lama to be only of temporary nature:

Hypothesis 3: The trade-deteriorating 'Dalai Lama Effect' disappears as bilateral relations between China and partner countries recover.

142 "France goes back on China's shopping list," China Daily, October 29, 2009, available at: http://www.chinadaily.com.cn/china/2009-10/29/content 8865307.htm (accessed: July 12, 2012). ${ }_{143}$ "Gusenbauer: Irritationen mit China ausgeräumt," Die Presse.com, October 24, 2008, available at: http://diepresse.com/home/politik/aussenpolitik/425083/index.do?from=suche.intern.portal (accessed: July 12, 2012). 


\section{Eidesstattliche Versicherung}

Hiermit versichere ich an Eides Statt, dass die eingereichte Dissertation „Risk, Conflict and Challenges in the Context of Emerging Economies" selbständig verfasst habe. Anderer als der von mir angegebenen Hilfsmittel und Schriften habe ich mich nicht bedient. Alle wörtlich oder sinngemäß den Schriften anderer Autorinnen und/oder Autoren entnommenen Stellen habe ich kenntlich gemacht.

Göttingen, den 03.08.2012

Nils-Hendrik Klann 